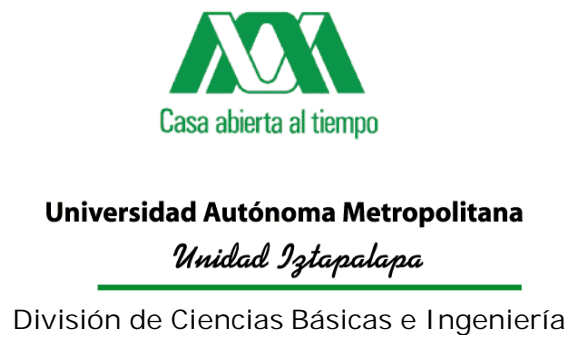

\title{
CUANTIFICACIÓN DEL GRADO DE CALCIFICACIÓN DE LA VÁLVULA AÓRTICA MEDIANTE PROCESAMIENTO DIGITAL EN IMÁGENES ECOCARDIOGRÁFICAS
}

TESIS QUE PRESENTA

RAYMUNDO BARRALES GUADARRAMA

PARA LA OBTENCIÓN DEL GRADO DE

MAESTRO EN INGENIERÍA BIOMÉDICA

ASESOR

DIPL. ING. ENRIQUE HERNÁNDEZ MATOS

ENERO DE 2003

\section{SINODALES:}

Dra. Sonia Charleston Villalobos

Dr. Ángel Romero Cárdenas

Dipl. Ing. Enrique Hernández Matos 


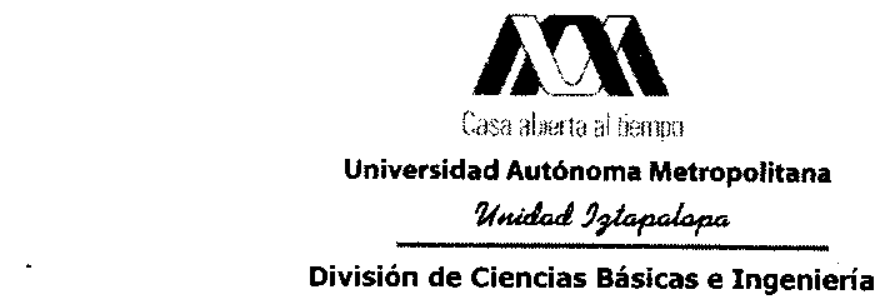

\title{
CUANTIFICACIÓN DEL GRADO DE CALCIFICACIÓN DE LA VÁLVULA AÓRTICA MEDIANTE PROCESAMIENTO DIGITAL EN IMÁGENES ECOCARDIOGRÁFICAS
}

\author{
TESIS QUE PRESENTA \\ RAYMUNDO BARRALES GUADARRAMA \\ PARA LA OBTENCIÓN DEL GRADO DE \\ MAESTRO EN INGENIERÍA BIOMÉDICA
}

ASESOR

DIPL. ING. ENRIQUE HERNÁNDEZ MATOS

ENERO DE 2003

\section{SINODALES:}

Dra. Sonia Charleston Villalobos

Dr. Ángel Romero Cárdenas

Dipl. Ing. Enrique Hernández Matos

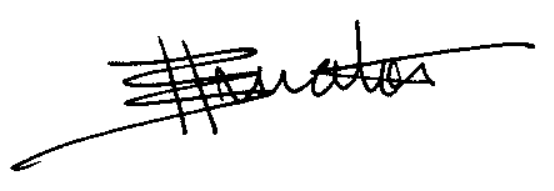




\section{AGRADECIMIENTOS.}

Agradezco profundamente la valiosa ayuda prestada para la realización de esta tesis a las siguientes personas:

A mi asesor, Dipl. Ing. Enrique Hernández Matos, por haber contribuido en mi formación profesional en el campo de la ecocardiografía y la ingeniería biomédica.

A la Dra. Sonia Charleston Villalobos, por sus valiosos consejos y asesorías que contribuyeron a avanzar en la realización de los trabajos técnicos de esta tesis.

Al Dr. Ángel Romero Cárdenas, Subjefe del Departamento de Ecocardiografía del Instituto Nacional de Cardiología "Ignacio Chávez", por todos los favores otorgados para trabajar dentro del Instituto, sus invaluables consejos en la determinación de los objetivos de la tesis y sus acertadas contribuciones a la formación del marco clínico de la misma.

Dentro del Instituto Nacional de Cardiología “Ignacio Chávez”, al Dr. Jesús Vargas Barrón, Jefe del Departamento de Ecocardiogafía de ese Instituto por las facilidades otorgadas para realizar los trabajos de campo, a la Dra. Nilda Espinola Zavaleta, por sus asesorías en el manejo del ecógrafo y la técnica de estudio, a la Dra. Nuria Zobeida Granados, al Dr. Roy Dueñas y al Dr. Federico Ibáñez, por la ayuda técnica prestada en la adquisición de las ecocardiografías transtorácicas, al Dr. Jesús Vázquez, Jefe del Departamento de Radiología, por facilitar el equipo y el material para las imágenes de rayos $\mathrm{X}$ de las piezas quirúrgicas y, finalmente, al Dr. Alberto Aranda y a la Dra. Norma Jiménez en el Departamento de Patología, que facilitaron el material fotográfico para las imágenes de las piezas quirúrgicas.

A mis amigos y condiscípulos en la Universidad por su apoyo moral.

A mis hermanos María del Carmen y Rogelio y a mi cuñada Isabel por todo el apoyo moral.

\section{A la memoria de mis queridos padres Carmen y Adán quienes me ayudaron siempre hasta sus últimas fuerzas.}


ÍNDICE

2.1 Normas de la ecocardiografía de dos dimensiones

utilizadas en la investigación

3

2.2 El fenómeno de la calcificación de la válvula aórtica

4

2.3 Importancia de la cuantificación del calcio depositado en la válvula aórtica

4.1 Criterios clínicos aplicados a las ecocardiografías para estimar la calcificación aórtica

4.2 Concepto de la cuantificación

\section{CAPÍTULO 5 LA TRANSFORMADA DIÁDICA WAVELET ORIENTADA} A LA BÚSQUEDA DE BORDES EN LA ECOCARDIOGRAFÍA DE LA VÁLVULA AÓRTICA

5.1 Introducción

5.2 Transformadas wavelet

5.2.1 La transformada wavelet continua (TWC)

5.2.2 La transformada diádica wavelet (TDW)

5.2.3 La wavelet diádica discreta

5.3 La función wavelet necesaria para la detección

poli-escalar de bordes

5.3.1 Diseño de los filtros $H(\omega), G(\omega)$ y $K(\omega) \quad 22$

$\begin{array}{lll}\text { 5.3.2 Implementación de los filtros wavelet } & 27\end{array}$

5.3.3 El algoritmo "à trous" 28

5.3.4 Transformada diádica wavelet discreta 2D 29

5.3.5 "Algorithme à trous" 2D 33

5.4 Resultados $\quad 34$

5.5 Discusión $\quad 36$ 
CAPÍTULO 6 LA BÚSQUEDA DE BORDES EN LA ECOCARDIOGRAFÍA DE LA VÁLVULA AÓRTICA

6.1 Introducción 39

6.2 "Modulus máxima" de la transformada wavelet

6.3 Detección poli-escalar de los bordes

6.4 Discusión

CAPÍTULO 7 REDUCCIÓN DEL RUIDO EN LAS ECOCARDIOGRAFÍAS DE LA VÁLVULA AÓRTICA

7.1 Introducción 56

7.2 Modelo para la supresión del ruido 56

7.3 Técnica de supresión del ruido 58

7.3.1 Umbralización suave

7.3.2 Criterio para la eliminación de los coeficientes DWT que representan al ruido

7.3.3 Estimación de la varianza del ruido $\sigma^{2}$.

7.4 La programación MATLAB para la técnica de "denoising” 68

7.5 Resultados

7.6 Discusión

8.1 Introducción 76

8.2 Segmentación de las regiones ecogénicas

8.3 Explicación del algoritmo de crecimiento de regiones

8.4 Resultados

8.5 Discusión

CAPÍTULO 9 MEDICIÓN DE LAS ÁREAS CALCIFICADAS DENTRO DEL ANILLO ANATÓMICO DE LA VÁLVULA AÓRTICA

84

9.1 El problema de la determinación del área del anillo anatómico de la válvula aórtica

9.2 Los intentos de reconstrucción del anillo anatómico de la válvula aórtica

9.3 Diseño de la técnica para la estimación aproximada del área del anillo anatómico de la válvula aórtica 9.3.1 Medición del anillo aórtico 
9.3.2 Estimación aproximada del área del anillo anatómico de la válvula aórtica

9.4 Resultados

99

9.5 Discusión

GLOSARIO

APÉNDICE A

APÉNDICE B

APÉNDICE C

APÉNDICE D

APÉNDICE E

APÉNDICE F

APÉNDICE G

APÉNDICE H 


\section{INTRODUCCIÓN}

En el campo de la medicina, la calidad diagnóstica de una imagen ultrasonográfica ha aumentado en la última década, debido a la incorporación de nuevas tecnologías que permiten generar imágenes ultrasonográficas de mayor resolución, con un poder de penetración mayor, sensibilidad incrementada y técnicas de procesamiento de la imagen integradas en el ecógrafo. Esto ha permitido a los médicos sonografistas apreciar detalles de la imagen que les proporcionan mayor información sobre la anatomía de las estructuras orgánicas estudiadas, precisar el diagnóstico de una patología, medir con exactitud las dimensiones de un órgano o un parámetro físico de importancia, predecir anomalías en el desarrollo del feto, acelerar un tratamiento médico, etc.

Las posibilidades tecnológicas para el diagnóstico de patologías cardiacas por medio del estudio de imágenes ultrasónicas del corazón, conocidas como ecocardiografías, han avanzado al proporcionar objetividad y exactitud, aunque una parte de la diagnosis clínica en esta área aún se fundamenta en la experiencia del médico sonografista. En los años 80, los diagnósticos que resultaban de la observación de las ecocardiografías en el Modo B de adquisición de imágenes (modo de la brillantez modulada en tiempo real), eran establecidos por el médico sonografista de acuerdo a sus propias estimaciones, su experiencia en el campo y el grado de entrenamiento con el equipo utilizado. Los ecógrafos avanzados permiten ahora mediciones en tiempo real sobre ecocardiografías inmóviles en el modo B, dando posibilidad a diagnósticos con elementos cuantitativos para juzgar el grado de una estenosis aórtica o mitral, de una insuficiencia aórtica o mitral, el grado de dilatación de una cavidad, el grado de aumento o disminución de un volumen, el grado de extensión de un derrame pericárdico o una lesión, etc.

Sin embargo, como ya se apuntó, otras patologías continúan diagnosticándose en base a experiencia. Es el caso de la cuantificación de las vegetaciones producidas por una endocarditis, la extensión de una enfermedad infiltrativa como el amiloide, la cuantificación del engrosamiento de las válvulas cardiacas debida a la fibrosis y, finalmente, la cuantificación del grado de calcificación de las válvulas cardiacas. La "escala" del médico para indicar la condición de estas patologías incluye los términos "ligero", "moderado", "grave" y "crítico". En particular, la calcificación de la válvula aórtica se califica bajo esta escala subjetiva.

El trabajo de investigación que se documenta en esta tesis, intenta cuantificar el grado de calcificación de la válvula aórtica en términos cuantitativos que indiquen al médico sonografista una estimación de la extensión del calcio en ésta. Parte del objetivo de esta investigación ha sido el de postular una escala objetiva del grado de calcificación de la válvula aórtica, en base a mediciones de la extensión del calcio en esta válvula cardiaca.

Primeramente, se enuncian los antecedentes correspondientes para justificar los objetivos perseguidos por esta tesis. A continuación, se describe la metodología aplicada 
para cuantificar el grado de calcificación en la válvula aórtica a partir del procesamiento digital de ecocardiografías. En resumen, esta metodología incluye el análisis wavelet poliescalar, la búsqueda de bordes poli-escalar y el crecimiento de regiones. La aplicación metódica de estas técnicas permiten estimar la región total del anillo anatómico de la válvula aórtica, el lugar en donde la cantidad de calcio es más importante, y las regiones calcificadas. La diferencia entre estas regiones corresponde a un grado en la escala de cuantificación propuesta. Finalmente, se realiza una discusión general sobre la confiabilidad del método y su utilidad como herramienta de diagnóstico. 


\begin{abstract}
ANTECEDENTES
A partir de la correspondiente lectura documental y de la entrevista con expertos, en este caso con las autoridades del Departamento de Ecocardiografía del Instituto Nacional de Cardiología "Ignacio Chávez", se eligió la detección de calcio en la válvula aórtica mediante el análisis de ecocardiografías como trabajo de tesis. La decisión se basó en los siguientes criterios:

$1^{\circ}$ Los casos de válvulas aórticas calcificadas no son escasos (de 3 a 4 casos por semana en la lista de quirófanos). Lo que permitiría obtener una cantidad aceptable de registros.

$2^{\circ}$ Otra de las válvulas del corazón humano que sufre calcificación es la válvula mitral. La documentación relacionada con las consecuencias de la calcificación de la válvula mitral es más abundante [1], [3], [4], [5], [6], [7] y sus referencias. Como se encontraron pocos trabajos relacionados con la calcificación de la válvula aórtica [9], [10], [12], se quiso reforzar la contribución de esta investigación al tema de la calcificación en la válvula aórtica.

$3^{\circ}$ Por otro lado, se presentan más casos de calcificación aórtica que de calcificación mitral (de 2 a 3 veces más, que es lo que ocurre en el INC).

$4^{\circ}$ La cantidad de calcio en la válvula aórtica está, en mucho casos, relacionada con el grado de estenosis entre el ventrículo izquierdo y la aorta $\left[3^{\mathrm{a}}, \mathrm{p} .1036\right]$. Una estimación del grado de la calcificación de la válvula aórtica arrojaría información sobre el grado de estenosis que sufre ésta y, por lo tanto, de la función cardiaca actual de un paciente [3a, p. 1038].

$5^{\circ}$ La calcificación en las otras válvulas (pulmonar y tricúspide), se presenta rara vez o no produce lesiones de cuidado [3a, pp. 1054-1061]. Lo que reforzó que la investigación se concentrara en el estudio de la calcificación de la válvula aórtica.
\end{abstract}

\title{
2.1 Normas de la ecocardiografía de dos dimensiones utilizadas en la investigación.
}

Las ecocardiografías para la investigación de la calcificación de la válvula aórtica del corazón humano y su cuantificación son, fundamentalmente, imágenes tomográficas de las estructuras cardiacas que tienen como principal ventaja el ofrecer información anatómica detallada en un solo plano de imagen, aunque la integración de datos necesita de otros planos [1]. Existen tres planos tomográficos normalizados por el Comité en Nomenclatura y Normas de la Sociedad Americana de Ecocardiografía [2] que permiten visualizar la válvula aórtica y realizar mediciones y/o caracterizaciones. El haz ultrasónico que forma la 
imagen de las estructuras orgánicas es coplanar a estos planos normalizados. La figura 2.1 muestra los planos de imagen definidos por este Comité.

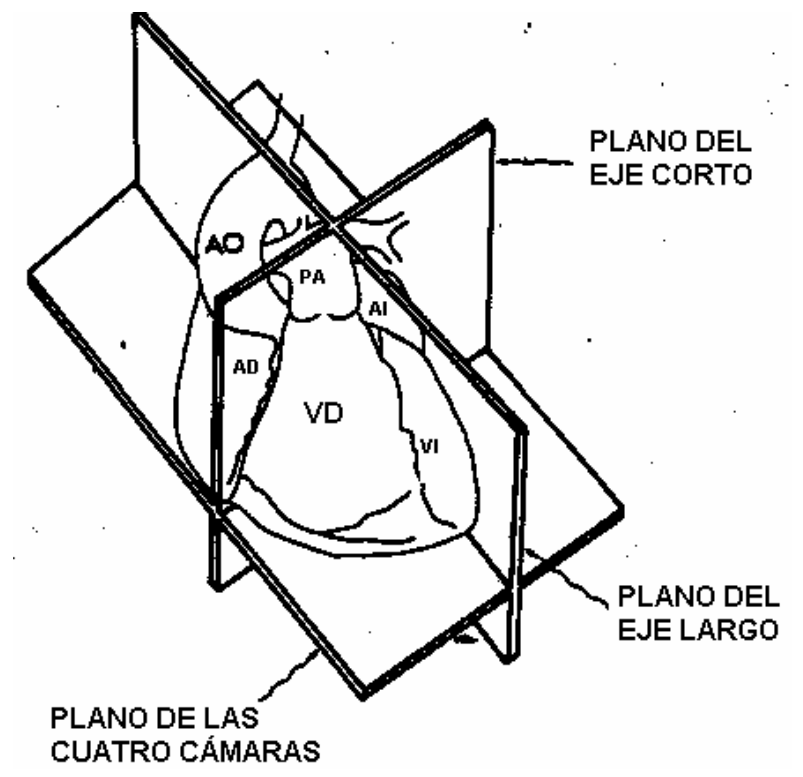

Fig. 2.1 Diagrama de los tres planos ortogonales de imagen utilizados para visualizar el corazón con ecocardiografías de dos dimensiones. $\mathrm{AO}=$ aorta, $\mathrm{AD}=$ aurícula derecha, $\mathrm{AI}=$ aurícula izquierda, $\mathrm{AP}=$ arteria pulmonar, $\mathrm{VD}$ = ventrículo derecho, $\mathrm{VI}$ = ventrículo izquierdo. Tomado y adaptado de [2]

Los planos de imagen utilizados en este proyecto son:

ß El plano de imagen en el eje largo formado por el plano que corta al corazón perpendicularmente a las superficies dorsal y ventral del cuerpo y paralelo al eje largo del corazón (ver Fig. 2.1). Este plano se necesita, como se hace evidente en el capítulo 9, para la medición del anillo aórtico.

ß El plano de imagen en el eje corto formado por el plano que corta al corazón perpendicularmente a las superficies dorsal y ventral del cuerpo, pero perpendicular al eje largo del corazón (ver Fig. 2.1). Este es el plano que permite ver las regiones calcificadas de los velos aórticos.

El lector deberá consultar el apéndice B para una descripción más detallada de los planos tomográficos utilizados en este trabajo, así como una descripción anatómica de la estructura de la aorta en cada uno de ellos.

\subsection{El fenómeno de la calcificación de la válvula aórtica.}

Al inicio de este capítulo, se estableció que un objetivo principal es la detección del calcio en la válvula aórtica. La calcificación degenerativa de la válvula aórtica consiste en la deposición del elemento calcio $\left(\mathrm{Ca}^{++}\right)$sobre las valvas de ésta. La calcificación es gradual, a lo largo de muchos años, y gradualmente también se inmovilizan las valvas a lo largo de sus líneas de flexión y en sus bases [3]. La calcificación puede extenderse en 
dirección de las comisuras, aunque es rara la fusión de éstas. La calcificación es causa principal de estenosis en el adulto, en general mayor de los 65 años [3a, p. 1036], y está considerada como un proceso degenerativo o senil. Esta patología se ha documentado desde 1904. La figura 2.2 muestra un esquema del aspecto de una válvula aórtica calcificada. La válvula mitral también presenta calcificación y, curiosamente, aunque la experiencia de campo adquirida durante la investigación comprobó que los casos de reemplazo valvular debidos a la calcificación severa de la válvula mitral eran 2 a 3 veces menores a los casos de reemplazo valvular aórtico por la misma razón, su caracterización está numerosamente documentada ([1], [3], [4], [5], [6], [7] y sus referencias).

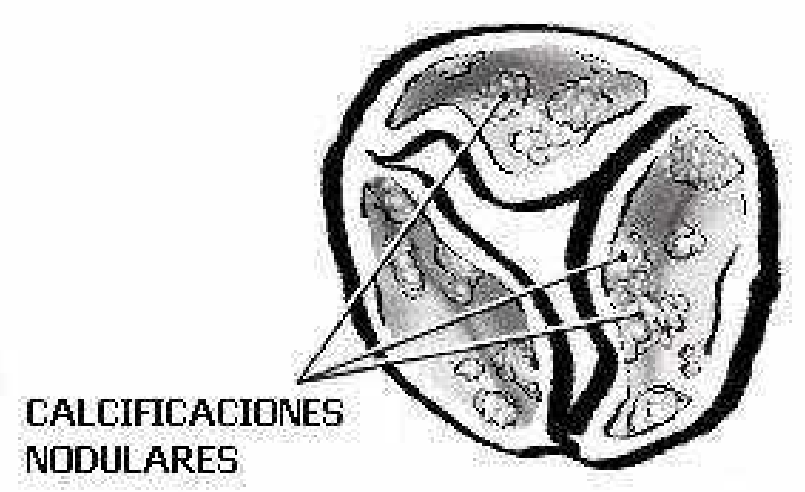

Fig. 2.2 Válvula degenerada por calcificación.

Al presente, existen dos causas para explicar la deposición del calcio en la válvula aórtica:

1. La calcificación se debe a años de esfuerzos mecánicos normales durante el ciclo diástole-sístole [3]. Esta hipótesis no viene documentada en la referencia. No explica exactamente cuál es el mecanismo que produce la acumulación del calcio.

2. Actualmente, no se piensa que, en el proceso que implica la calcificación de la válvula aórtica, el calcio sea el único agente que se deposite sobre los tejidos de esta válvula. La hipótesis más aceptada recientemente es que la calcificación va aparejada a un proceso arteriosclerótico común en las personas de edad avanzada [8].

Primero, comienza con un daño a la íntima, la capa más interna de células de los vasos sanguíneos. Muchos factores la pueden dañar, pero el que nos interesa es el daño producido por los radicales libres, los cuales la oxidan a pesar de los antioxidantes naturales del cuerpo. La cantidad de radicales libres aumenta con la edad y se puede agravar por el tabaquismo y el consumo de dietas ricas en colesterol que aumentan los niveles de lipoproteinas, las cuales favorecen la oxidación.

Segundo, el sistema inmunológico actúa de manera natural a este daño, produciendo monocitos que acuden al lugar del daño y se vuelven macrófagos que 
fagocitan partículas de grasa las cuales devienen en una espuma esponjosa. Más tarde, las plaquetas se adhieren al área dañada, iniciando una coagulación intrínseca. Es aquí donde interviene el calcio, pues este es un elemento esencial en el mecanismo de coagulación. Este proceso se repetirá mientras se mantenga gran cantidad de radicales libres en el organismo.

En la figura 2.3 se muestra la fotografía de una pieza quirúrgica correspondiente a los velos de la válvula aórtica que presenta zonas pastosas y amarillentas en los lugares donde se ha depositado el calcio.

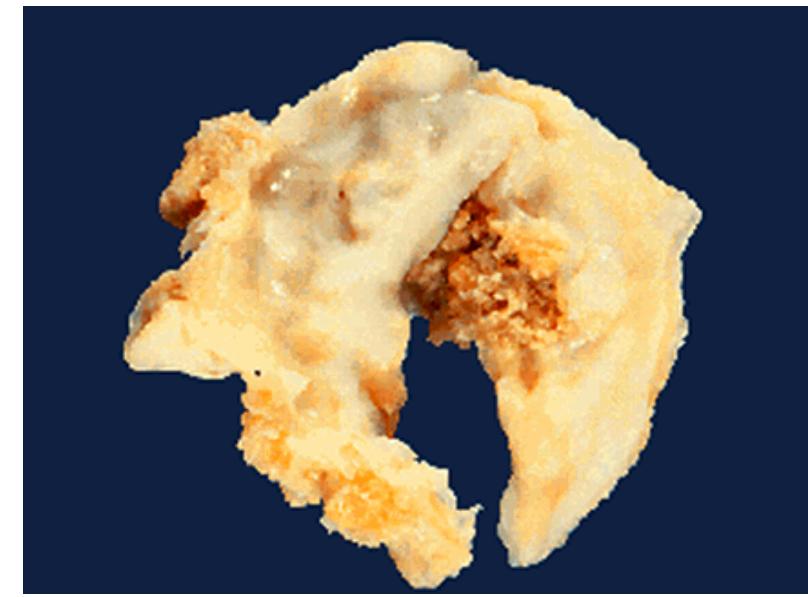

Fig. 2.3 Fotografía de unos velos aórticos calcificados.

\subsection{Importancia de la cuantificación del calcio depositado en la válvula aórtica.}

Comúnmente, la deposición de calcio en las primeras etapas del proceso degenerativo, comienza alrededor de las valvas aórticas y, en el transcurso de los años, avanza aleatoriamente sobre las valvas hasta llegar a las comisuras y los bordes de los velos donde puede, en ocasiones, presentarse fusión de todos ellos.

La calcificación es común entre los adultos mayores de 65 años y se presenta preferentemente entre los varones, quienes superan a las mujeres en una proporción de 5:1 [9].

A finales de los años 90, se encontraron evidencias de que el proceso degenerativo que produce la calcificación de las valvas no es simplemente una consecuencia de la edad, pues investigadores como Lindroos, del Colegio Americano de Cardiología [10], no han encontrado evidencias de válvulas calcificadas en un $25 \%$ a un $45 \%$ de pacientes octogenarios. Se han encontrado deposiciones de lípidos y producción de proteínas como la osteopontina, lo que ha hecho pensar que el proceso puede guardar similitudes con la arterioesclerosis, como ya se había mencionado. Esta posibilidad se ve reforzada por el hecho de que se han identificado factores de riesgo como el tabaquismo, la hipertensión, la hiperlipidemia, niveles de lipoproteína (a) y la diabetes [9]. 
La consecuencia natural del proceso de calcificación de la válvula aórtica es el padecimiento progresivo de la estenosis aórtica. Las gráficas de la figura 2.4 muestran la alta relación entre la estenosis aórtica y la calcificación de la válvula aórtica [3a, p. 1036].
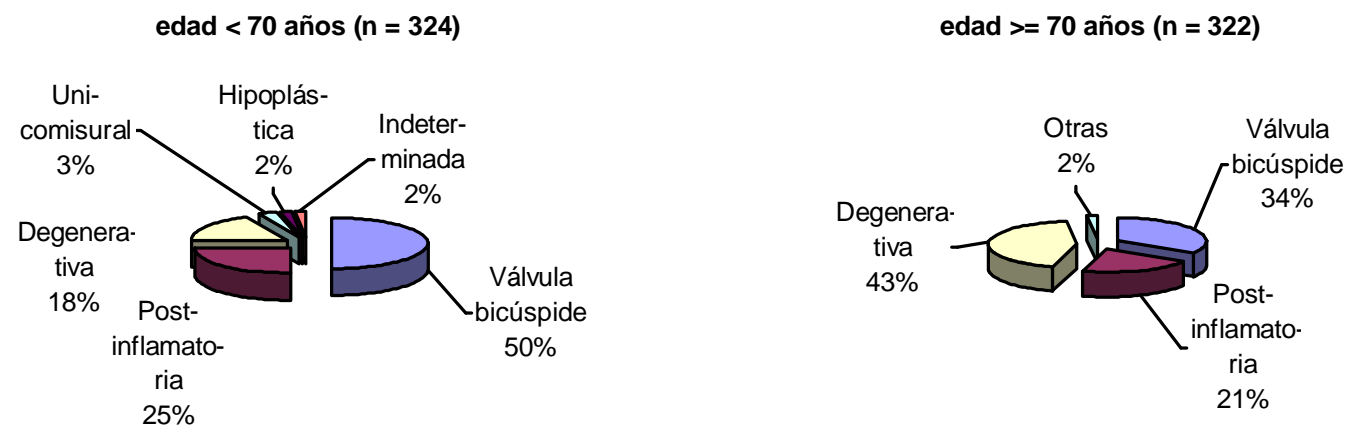

Fig. 2.4 Causas de la estenosis aórtica para dos grupos de edad. Tomado y adaptado de [3a].

La figura 2.5 muestra un ejemplo de estenosis aórtica crítica en la cual se notan engrosadas las valvas de la aorta.

Como la estenosis aórtica se desarrolla gradualmente al igual que la calcificación (incluso en el transcurso de décadas), el ventrículo izquierdo se adapta a la presión sistólica aumentada, desarrollando a su vez un proceso hipertrófico que resulta en el engrosamiento de las paredes del ventrículo izquierdo, mientras se mantiene un volumen normal en la cámara. La hipertrofia concéntrica pareciera una adaptación apropiada para compensar las altas presiones intracavitarias. Desgraciadamente, esta adaptación provoca consecuencias adversas. El corazón hipertrofiado [3a, pp.1038-1039]:

ß Reduce el flujo de sangre coronario por gramo de músculo.

B Exhibe una limitada reserva vasodilatoria coronaria.

B El esfuerzo hemodinámico (taquicardia) produce una mala distribución del flujo sanguíneo coronario.

ß Se produce una isquemia subendocárdica provocando disfunción sistólica o diastólica del ventrículo izquierdo.

ß Se incrementa la sensibilidad al daño isquémico con infartos mayores.

Después de que se establecen los síntomas evidentes (angina, síncope, falla coronaria), el tiempo de supervivencia es de 2 a 3 años. Sin embargo, existen pacientes asintomáticos. Muchos médicos tratan a los pacientes asintomáticos conservadoramente. En los pacientes con síntomas se recomienda la cirugía correctiva [3a, p. 1042]. 


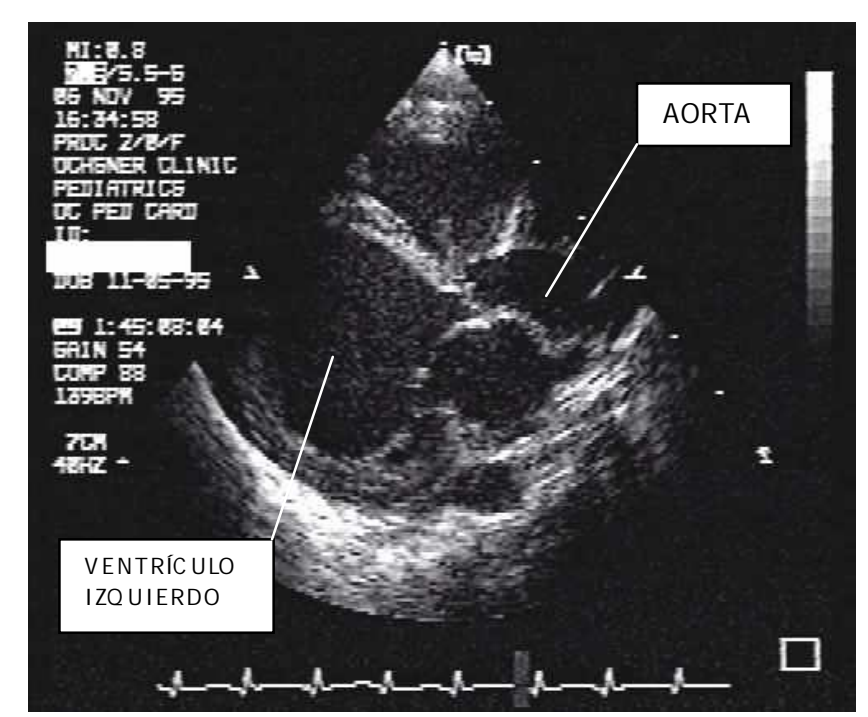

Fig. 2.5 Ventrículo izquierdo muy dilatado debido a una estenosis aórtica crítica.

Como el grado de calcificación es directamente proporcional al grado de estenosis [3], se observó que era importante cuantificar de alguna manera la presencia de calcio en la válvula aórtica. Cuantificar el grado de calcificación no debe aceptarse como una medición pronóstica para indicar un determinado tratamiento. La cuantificación del calcio en la válvula aórtica que se propone en este trabajo, únicamente tiene un carácter diagnóstico, es decir, la técnica de cuantificación solamente deberá pertenecer al conjunto de herramientas que el cardiólogo utiliza para concluir un diagnóstico. No puede tratarse de un método médico preventivo porque:

$1^{\circ}$ No se ha afirmado contundentemente que la calcificación sea la única causa de estenosis aórtica (ver fig. 2.4).

$2^{\circ}$ La edad no es un factor decisivo en la aparición de calcio en la válvula aórtica [10].

$3^{\circ}$ De acuerdo a la experiencia de campo en el INC "Ignacio Chávez", es posible detectar calcio en las valvas en una cantidad moderada donde el paciente apenas presenta una estenosis aórtica ligera (excepciones a lo señalado en [3]).

Por otro lado, y como se mencionó anteriormente, otro punto de importancia para justificar este trabajo, es la falta de una escala objetiva del grado de calcificación de la válvula aórtica en la literatura consultada [1], [3], [3a], [9], [10], [11], [12], [13]. En [10] es vaga la referencia a la estimación del engrosamiento de las valvas aórticas, mientras que en [9] se hace referencia a una escala del 0 (normal) al 3+ (severa) propuesta para el protocolo ecocardiográfico particular que sirvió para el estudio de los factores dominantes en la calcificación aórtica y, de nuevo, la estimación es subjetiva. Además, no se informa de la calificación correspondiente a los puntos intermedios. La documentación ofrece la escala subjetiva de Reid C.L. et al. reproducida en [1] p. 237, y que se incluye aquí como recurso de ilustración en la Tabla 2.1. Esta escala subjetiva de la calcificación de la válvula mitral no tiene correspondencia para el caso de la válvula aórtica. 


\begin{tabular}{|c|c|}
\hline CALCIFICACION & PUNTUACIÓN \\
\hline $\begin{array}{c}\text { Un área de brillantez aumentada } \\
\text { sobre la ecocardiografía }\end{array}$ & 1 \\
\hline $\begin{array}{c}\text { Areas esparcidas de brillantez } \\
\text { confinadas a los márgenes de las } \\
\text { valvas }\end{array}$ & 2 \\
\hline $\begin{array}{c}\text { Brillantez extendida hacia la } \\
\text { porción media de las valvas }\end{array}$ & 3 \\
\hline $\begin{array}{c}\text { Brillantez extendida en la mayor } \\
\text { parte del tejido de la valva }\end{array}$ & 4 \\
\hline $\begin{array}{c}\text { La puntuación total se obtiene } \\
\text { sumando las puntuaciones de } \\
\text { cada una de las cuatro } \\
\text { características }\end{array}$ & \\
\hline
\end{tabular}

Tabla 2.1 Calcificación de la válvula mitral en ecocardiografías por Reid C.L. et al.: Influence of mitral valve morphology on mitral balloon commissurotomy: Immediate and 6-month results from the NHLBI Ballon Valvuloplasty registry, Am. Heart J., 124:657, 1992. 


\section{OBJETIVOS DEL PROYECTO DE TESIS}

De acuerdo a los antecedentes expuestos en el Capítulo 2 de este trabajo, los objetivos particulares del proyecto de tesis presente son:

1. Cuantificar, mediante un método de medición semi-automático basado en el procesamiento digital de ecocardiografías, el grado de calcificación de la válvula aórtica.

2. Definir una escala objetiva del grado de calcificación de la válvula aórtica. 


\section{METODOLOGÍA}

\subsection{Criterios clínicos aplicados a las ecocardiografías para estimar la calcificación aórtica.}

La metodología para cuantificar el calcio en la válvula aórtica, objeto de esta tesis, está basada en los criterios utilizados por los médicos sonografistas del INC "Ignacio Chávez" para evaluar el grado de calcificación, aunque actualmente este grado se califica subjetivamente. Estos criterios son:

$1^{\circ}$ La extensión de las áreas que presentan gran ecogenicidad ${ }^{1}$ o hiper-reflectancia a la inspección visual. Normalmente, el médico sonografista ajusta los controles del ecógrafo para observar una imagen suavizada (penetración moderada, ganancia media de la señal de retorno, modificación de la escala de grises, ajustes automáticos de la imagen) y lograr así la diferenciación entre las áreas calcificadas y los tejidos normales. Cuando el calcio se deposita en los tejidos de la válvula aórtica, forma regiones de tejido de alta impedancia acústica los cuales no son atravesados completamente por el haz ultrasónico. La energía del haz ultrasónico se refleja casi completamente cuando llega a estas regiones y el transductor ultrasónico del ecógrafo detecta esta energía reflejada como una región ecogénica (de gran brillantez) en el modo B. Los tejidos libres de calcio presentan una impedancia acústica muy baja y la energía del haz es completamente absorbida en estas regiones. La Fig. 4.1 muestra un ejemplo de una imagen ajustada en el ecógrafo SONOS 5500 de Agilent Technologies para diferenciar las áreas calcificadas en un corte paraesternal de eje corto. Por lo tanto, una región calcificada se observa en el ecógrafo como una región ecogénica. Los tejidos normales no presentan ecogenicidad.

Para lograr resultados estándares, durante la estancia se trató de encontrar un ajuste único de los controles del ecógrafo para todos los pacientes que permitiese distinguir las áreas calcificadas (ecogénicas) de las áreas sin calcio, tal como lo hacen los médicos sonografistas. Sin embargo, la experiencia de campo generó las siguientes observaciones:

Los ajustes elegidos inicialmente no permitían lograr en todos los casos el mejor plano de imagen posible del paciente. En el Apéndice C, se incluyen las páginas de la guía "Alphabetical Control Summary, HP SONOS 5500 Imaging System" [14] que explican cómo se fijan los ajustes necesarios para visualizar las ecocardiografías de interés.

\footnotetext{
${ }^{1}$ Es un término muy utilizado por los médicos sonografistas como sinónimo de brillantez.
} 


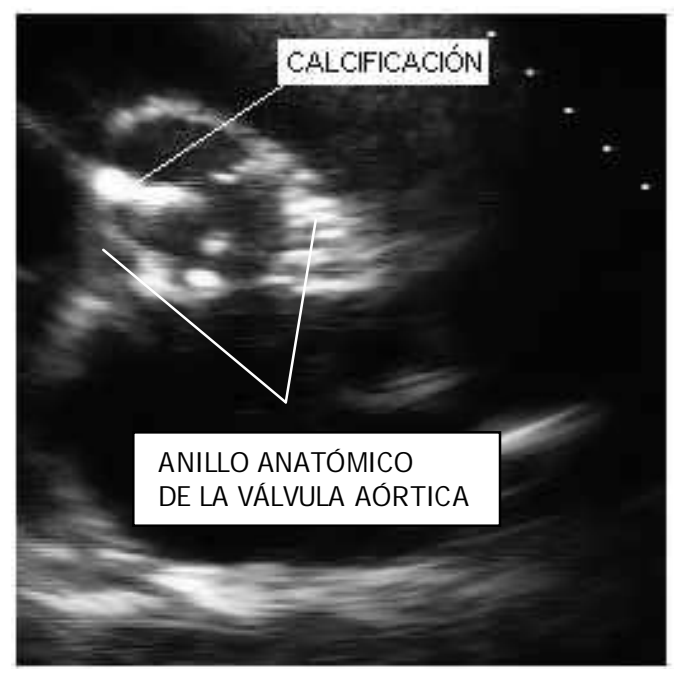

Fig. 4.1 Válvula aórtica calcificada en el corte paraesternal de eje corto. La calcificación se extiende evidentemente sobre los bordes de las valvas derecha coronaria y no coronaria como un área ecogénica.

ß En todos los estudios se utilizó el transductor s3 que es un transductor ultrabanda lineal sectorial con fusión de armónicas mejorada, lo que permite mejorar la definición del endocardio en pacientes con "mala ventana"2. Los detalles técnicos de la sonda son escasos [15].

B Con el objeto de resaltar la diferencia entre los tejidos con alta impedancia acústica (calcificados o fibrosos) y los de baja impedancia acústica en los pacientes con "malas ventanas", se debió de modificar los valores de algunos de los ajustes del ecógrafo. Al inicio de las adquisiciones, se comenzaba con el ajuste protocolario (Apéndice A) y, de acuerdo a la "ventana" presentada por el paciente, se realizaban las modificaciones. Las "malas ventanas" provienen de pacientes que, en general, poseen una complexión muy robusta, han abusado del tabaco o han desarrollado una capa de aire entre la piel y el miocardio y no permite que el haz ultrasónico penetre bien. Los controles que se modifican son (ver Apéndice C):

\section{La ganancia en Modo B, \\ La compresión y \\ El postprocesamiento}

$2^{\circ}$ La sombra acústica proyectada por las regiones de mayor impedancia acústica. La extensión de la sombra acústica es un indicativo del grado de extensión de la calcificación. Sin embargo, esta característica es más bien evidente cuando se practican exámenes transesofágicos. Esta característica finalmente no se tuvo en cuenta en este proyecto porque los estudios se restringieron a la modalidad transtorácica. La Fig. 4.2 muestra una imagen transesofágica donde se aprecia la sombra acústica proyectada desde las valvas calcificadas en diástole.

\footnotetext{
${ }^{2}$ Ver el glosario para la definición del término.
} 


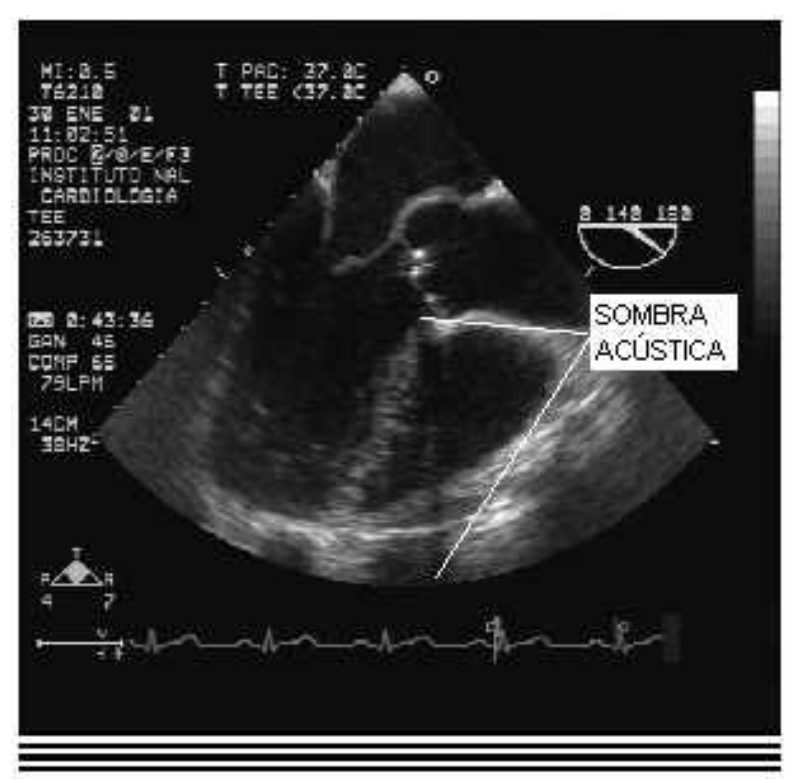

Fig. 4.2 Ejemplo de sombra acústica.

$3^{\circ}$ La localización de las áreas calcificadas. La experiencia de los médicos sonografistas del INC señala que, en general, la calcificación aparece inicialmente a lo largo de la línea de base de las valvas y de ahí comienza a extenderse hacia el cuerpo de las mismas, sus bordes, las comisuras y las paredes del anillo aórtico, en ese orden. De manera que el médico sonografista se concentra en estas áreas en particular cuando trata de evaluar el grado de calcificación. La localización de los nódulos calcificados (Fig. 2.2) será responsabilidad del médico ultrasonografista, pues la metodología no es completamente automática en el sentido de localizar estos nódulos sobre las valvas.

Por otra parte, antes de dar el diagnóstico "Calcificación de la Válvula Aórtica”, el médico sonografista recolecta datos personales del paciente y realiza mediciones hemodinámicas que, en conjunto, forman un contexto que respalda al diagnóstico inicial. Los datos de este contexto están ilustrados en el Apéndice A.

Tanto los criterios aplicados sobre la imagen como el contexto, contribuyen a declarar una válvula aórtica calcificada y a estimar el grado de calcificación. Como se ha expuesto, la cuantificación objetiva, vía el procesamiento digital de la imagen, se basará en los criterios aplicados a ésta y se conservará el contexto para reforzar el resultado del procesamiento.

\subsection{Concepto de la cuantificación.}

a) La cuantificación objetiva tiene su fundamento en la determinación del área del anillo anatómico de la válvula aórtica, que es el área que contiene a las valvas y donde se encuentra la mayor parte de la calcificación en la válvula aórtica, y en la determinación 
de las áreas calcificadas-áreas ecogénicas-que aparecen sobre la ecocardiografía de la aorta.

b) Se propone aquí diferenciar el porcentaje del área calcificada del porcentaje total del área del anillo anatómico y hacer corresponder este porcentaje con una escala postulada por los médicos ecografistas. Por ejemplo, el área del anillo anatómico correspondería a un $100 \%$ o un cierto número de pixeles. Suponiendo que se encuentra un área calcificada del $30 \%$ del área total del anillo aórtico, entonces el paciente tendría un grado " 3 " de calcificación en una escala del 1 al 10, con " 1 " como grado mínimo y "10” como grado máximo.

c) Inicialmente, se concibió que para lograr esta medición, se requería la delimitación del área del anillo anatómico de la válvula aórtica del paciente, lo que llevaba a buscar los bordes de este anillo anatómico, los cuales, como su nombre lo indica, constituyen un perímetro con la forma aproximada de un "anillo" o circunferencia. Al pensar en implementar un algoritmo buscador de bordes, se ha tenido en cuenta que el ruido granular típico de las ultrasonografías debía reducirse para evitar obtener bordes ajenos al anillo anatómico de la válvula aórtica.

d) Las áreas ecogénicas (calcificadas) se aíslan y determinan gracias a un algoritmo de crecimiento de regiones. Las áreas de interés son crecidas mediante el criterio de la diferencia de medias y el crecimiento se inicia con semillas plantadas por el médico sonografista.

e) La medición de las áreas ecogénicas (en número de pixeles) correspondería a un porcentaje inferior al $100 \%$ del área del anillo anatómico. El área del anillo anatómico de la válvula aórtica podría estimarse con técnicas morfológicas de la imagen (área de una imagen binaria). 


\section{LA TRANSFORMADA DIÁDICA WAVELET ORIENTADA A LA BÚSQUEDA DE BORDES EN LA ECOCARDIOGRAFÍA DE LA VÁLVULA AÓRTICA}

\subsection{Introducción.}

Entre las características más importantes en el análisis de imágenes, se encuentran los bordes de estructuras importantes [18, p.189]. Si un pixel ${ }^{1}$ en una imagen se encuentra dentro del borde de un objeto, entonces los pixeles vecinos forman una zona de transición en el nivel de gris. Las características principales de tal transición son su pendiente y su dirección [16].

Tal como se explicó en la sección 4.2, inciso a), la determinación del área del anillo anatómico de la válvula aórtica puede llevarse a cabo conociendo los límites o bordes que la forman. En un primer intento por determinar esta área, se ha recurrido a la aplicación del concepto de la detección poli-escalar de bordes. Este concepto surgió a inicios de los años 70 para su aplicación en el campo de la visión por computadora. Bajo este concepto, es posible detectar los bordes de pequeñas estructuras y grandes objetos de una misma escena. La escala define el tamaño de la vecindad de pixeles donde se calculan las variaciones pronunciadas de la imagen. Con esta técnica, se espera obtener los bordes del anillo anatómico, aunque incompletos debido a que las paredes de la aorta al nivel del anillo aórtico se funden con otras estructuras tisulares cardiacas. Se espera también que, al tener suficientes porciones de los bordes, en este caso un número suficiente de arcos de círculo, la forma completa del anillo anatómico de la válvula aórtica pudiese ser reconstruida a partir de técnicas de enlace de bordes (búsqueda heurística, ajuste de curvas, transformada Hough, etc.). Con la delimitación completa del anillo anatómico, la medición del área se puede realizar aplicando nuevamente el algoritmo SGR (Seeded Growing Region) del capítulo 5, posiblemente sobre una imagen binaria o la instrucción bwarea de MATLAB.

\subsection{Transformadas wavelet.}

A continuación se repasan los conceptos matemáticos más importantes de la teoría wavelet que se aplicó en esta investigación.

\footnotetext{
${ }^{1}$ Ver el Glosario para la definición del término.
} 


\subsubsection{La transformada wavelet continua (TWC).}

Una transformada wavelet puede utilizarse para descomponer señales que dependen de funciones wavelet dilatadas en magnitud y transladadas (recorridas) en el tiempo. Una wavelet es una función $\psi \in L^{2}(\Re)$ de promedio cero:

$$
\int_{-\infty}^{+\infty} \psi(t) d t=0
$$

que en general se normaliza $\|\psi\|=1$ y se centra alrededor de $t=0$. Una transformada wavelet continua real de $f \in L^{2}(\Re)$ se puede definir como:

$$
W f(u, s)=\left\langle f, \psi_{u, s}\right\rangle
$$

donde $\psi$ es una wavelet real y

$$
\psi_{u, s}(t)=\frac{1}{\sqrt{s}} \psi\left(\frac{t-u}{s}\right)
$$

El término $u$ translada o recorre en el tiempo a la wavelet $\psi$ y el término $s$ la escala o pondera. Si se impone que $\|\psi\|=1$, esto implica que $\left\|\psi_{u, s}\right\|=1$. La transformada wavelet de $f \in L^{2}(\mathfrak{R})$ se puede escribir entonces como:

$$
W f(u, s)=\left\langle f, \psi_{u, s}\right\rangle=\int_{-\infty}^{+\infty} f(t) \frac{1}{\sqrt{s}} \psi^{*}\left(\frac{t-u}{s}\right) d t
$$

Es interesante hacer notar que esta última expresión se puede rescribir como una convolución:

con

$$
W f(u, s)=\int_{-\infty}^{+\infty} f(t) \frac{1}{\sqrt{s}} \psi *\left(\frac{t-u}{s}\right) d t=f * \psi(u)
$$

$$
\Psi(t)=\frac{1}{\sqrt{s}} \psi *\left(\frac{-t}{s}\right)
$$

\subsubsection{La transformada diádica wavelet (TDW).}

Para construir una representación wavelet invariante a la translación, la escala $s$ se discretiza pero no el parámetro de translación $u$. La escala se muestrea a lo largo de una secuencia diádica $\left\{2^{j}\right\}_{j \in Z}$, para simplificar los cálculos numéricos en computadora. Cálculos rápidos se pueden realizar con bancos de filtros.

La transformada wavelet diádica de $f \in \mathbf{L}^{2}(\Re)$ se define como: 


$$
W f\left(u, 2^{j}\right)=\int_{-\infty}^{+\infty} f(t) \frac{1}{\sqrt{2^{j}}} \psi\left(\frac{t-u}{2^{j}}\right) d t=f * \overline{\psi_{2^{j}}}(u),
$$

con

$$
\overline{\psi_{2^{j}}}(t)=\psi_{2^{j}}(-t)=\frac{1}{\sqrt{2^{j}}} \psi\left(\frac{-t}{2^{j}}\right) .
$$

Es posible demostrar que, si el eje de las frecuencias está completamente cubierto por wavelets diádicas dilatadas, como se ilustra en la figura 5.1, entonces se trata de una representación completa y estable.

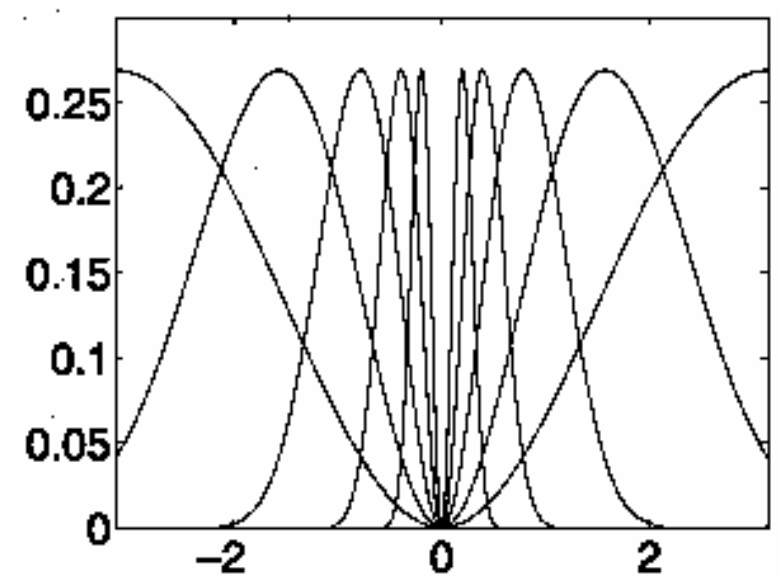

Fig. 5.1 Transformadas de Fourier escaladas de $\left|\psi\left(2^{j} \omega\right)\right|^{2}$ para $1 \leq j \leq 5$ y $\omega \in[-\pi, \pi]$. (Tomado y adaptado de [18]).

\subsubsection{La wavelet diádica discreta.}

Una wavelet discreta escalada por $a^{j}$ se define como [18, p. 89]:

$$
\psi_{j}[n]=\frac{1}{a^{j}} \psi\left(\frac{n}{a^{j}}\right)
$$

Entonces, si $a^{j}=2^{j}$ se puede definir una Wavelet Diádica Discreta como:

$$
\psi_{j}[x]=\frac{1}{2^{j}} \psi\left(\frac{x}{2^{j}}\right)
$$

Esta es la definición que se utilizará en este trabajo para el dominio discreto de la wavelet.

En general, para evitar problemas donde ya no existe una imagen $f[n]$ de $n$, una función discreta $f[n]$ y las wavelets $\psi_{j}[n]$ se tratan como señales periódicas de periodo $\mathrm{N}$. 
Entonces, la transformada wavelet discreta se puede escribir como una convolución circular $\Psi_{j}[n]=\psi_{j}^{*}[-n]$ :

$$
W f\left[n, 2^{j}\right]=\sum_{m=0}^{N-1} f[m] \psi_{j}^{*}[m-n]=f \otimes \Psi_{j}[n]
$$

Esta consideración se toma en cuenta, como se puede ver en el apéndice D, para las imágenes de descomposición.

\subsection{La función wavelet necesaria para la detección poli-escalar de bordes.}

En esta sección, se proponen las wavelets y los filtros que generan los coeficientes wavelet en el sentido de la búsqueda de bordes poli-escalar. A continuación se ofrece la relación entre la TDW y la búsqueda de bordes poli-escalar, en particular la que tiene que ver con el algoritmo de Canny porque éste y la detección poli-escalar de bordes son equivalentes, como se demuestra en el capítulo 6. Se recomienda referirse a [18] si se quiere profundizar en la breve explicación que se ofrece a continuación.

De la Fig. 5.1, es necesario entonces que la transformada de Fourier de $\psi_{j}(x)$ cumpla con que:

$$
A \leq \sum_{j=-\infty}^{+\infty}\left|\psi\left(2^{j} \omega\right)\right|^{2} \leq B
$$

La restricción sobre la transformada de Fourier de la función de reconstrucción $\chi(x)$ (no única) es:

$$
\sum_{j=-\infty}^{+\infty} \psi\left(2^{j} \omega\right) \chi\left(2^{j} \omega\right)=1
$$

Una función $f(x)$ se puede reconstruir completamente a partir de su TDW utilizando la identidad:

$$
f(x)=\sum_{j=-\infty}^{+\infty} W_{j} f * \chi_{j}(x)
$$

donde:

$$
\chi_{j}(x)=2^{-j} \chi\left(2^{-j} x\right)
$$

Señalemos que, en la práctica, cuando se utilizan sistemas digitales para las aplicaciones numéricas, el procesamiento se realiza sobre funciones discretas en lugar de funciones continuas. Cuando la función a ser transformada se encuentra bajo la forma discreta, la escala $2^{j}$ no puede variar sobre todo el dominio $Z$. La proporción de muestreo 
finita de los sistemas digitales, impide a la escala de ser arbitrariamente pequeña, así como las características del hardware restringen el uso de una escala arbitrariamente grande. Considérese que la escala más fina se normaliza a 1 y la escala más gruesa corresponde a $2^{J}$, donde $J \in \mathbf{N}$ denota el número de niveles de análisis.

El suavizamiento de una función $f(x) \in \mathbf{L}^{2}(\Re)$ se define como:

$$
S_{m} f(x)=f * \phi_{m}(x)
$$

donde $\phi_{m}(x)=2^{-m} \phi\left(2^{-m} x\right)$ con $m \in \boldsymbol{Z}$ y $\phi(x)$ es una función de suavizamiento (i.e. su integral es igual a 1 y $\phi(x) \rightarrow 0$ cuando $|x| \rightarrow \infty)$.

Mallat y Zhong [21] han elegido una función de suavizamiento real $\phi(x)$ cuya transformada de Fourier satisface:

$$
|\hat{\phi}(\omega)|^{2}=\sum_{j=1}^{\infty} \psi\left(2^{j} \omega\right) \chi\left(2^{j} \omega\right)
$$

Además, en [21] también se demuestra que existe una función discreta de energía finita $f(n) \in l^{2}(\boldsymbol{Z})$ tal que:

$$
\forall n \in Z \quad D=S_{1} f(n)
$$

la cual permite calcular un muestreo uniforme de la TDW de $f(x)$ a cualquier escala mayor a 1. Por lo tanto, se puede escribir:

$$
\left\{\begin{array}{l}
W_{j}^{d} f=\left(W_{j} f(n+s)\right)_{n \in Z} \\
S_{j}^{d} f=\left(S_{j} f(n+s)\right)_{n \in Z}
\end{array}\right.
$$

donde $s$ es un corrimiento en el muestreo que depende únicamente de $\psi(x)$. Para cualquier escala gruesa $2^{J}$, la secuencia de señales discretas:

$$
\left\{S_{J}^{d} f,\left(W_{J}^{d} f\right)_{1 \leq j \leq J}\right\}
$$

se conoce como la Transformada Diádica Wavelet Discreta (TDWD) de $D=S_{1} f(n)$.

Para una cierta elección de wavelets, la TDWD puede implementarse gracias a un esquema jerárquico de filtros digitales.

La transformada de Fourier de $\phi(x)$ debe satisfacer [18]: 


$$
\hat{\phi}(\omega)=\prod_{k=1}^{\infty} \frac{H\left(2^{-k} \omega\right)}{\sqrt{2}}=\frac{1}{\sqrt{2}} H\left(\frac{\omega}{2}\right) \phi\left(\frac{\omega}{2}\right)
$$

la respuesta en frecuencia del filtro pasa-bajas $H(\omega)$ es derivable y

$$
|H(\omega)|^{2}+|H(\omega+\pi)|^{2} \leq 1 \quad \text { con } \quad|H(0)|=\sqrt{2}
$$

Calculando para las dos primeras escalas de la ecuación (5.2), se llega a:

$$
\psi(2 \omega) \chi(2 \omega)=|\hat{\phi}(\omega)|^{2}-|\hat{\phi}(2 \omega)|^{2}
$$

Para $\hat{\phi}(2 \omega)$ en la ecuación (5.3) tenemos:

$$
\hat{\phi}(2 \omega)=\frac{1}{\sqrt{2}} H(\omega) \hat{\phi}(\omega)
$$

Si se elige:

$$
\psi(2 \omega)=\frac{1}{\sqrt{2}} G(\omega) \hat{\phi}(\omega)
$$

$\mathrm{y}$

$$
\chi(2 \omega)=\frac{1}{\sqrt{2}} K(\omega) \hat{\phi}^{*}(\omega)
$$

donde $G(\omega)$ y $H(\omega)$ son respuestas en frecuencia de filtros digitales, “*” indica la conjugación compleja e insertando las ecuaciones (5.5), (5.6) y (5.7) en la ecuación (5.4), se observa una relación entre las respuestas en frecuencia de los filtros [21]:

$$
\forall \omega \in[-\pi, \pi] \quad|H(\omega)|^{2}+G(\omega) K(\omega)=2
$$

Por otro lado, del concepto de función de suavizamiento (smoothing function), sabemos que si $\theta(x)$ es una de estas funciones, entonces su integral es $1 \mathrm{y}$ converge a 0 en el infinito. Además, si suponemos que $\theta(x)$ es derivable de segundo orden, podemos definir:

$$
\begin{aligned}
\psi^{a}(x) & =\frac{d \theta(x)}{d x} \\
\psi^{b}(x) & =\frac{d^{2} \theta(x)}{d x^{2}}
\end{aligned}
$$

\footnotetext{
${ }^{2}$ La literatura no distingue entre $H(\omega)$ y $h(\omega)$.
} 
por definición, las funciones $\psi^{a}(x)$ y $\psi^{b}(x)$ pueden considerarse como wavelets, porque su integral es igual a cero:

$$
\begin{aligned}
& \int_{-\infty}^{+\infty} \psi^{a}(x) d x=0 \\
& \int_{-\infty}^{+\infty} \psi^{b}(x) d x=0
\end{aligned}
$$

De la ecuación (5.1) e introduciendo (5.9):

$$
\begin{aligned}
& W_{m}^{a} f(x)=f * \psi_{m}^{a}(x)=f *\left(m \frac{d \theta_{m}}{d x}\right)(x)=m \frac{d}{d x}\left(f * \theta_{m}\right)(x) \\
& W_{m}^{b} f(x)=f * \psi_{m}^{b}(x)=f *\left(m^{2} \frac{d^{2} \theta_{m}}{d x^{2}}\right)(x)=m^{2} \frac{d^{2}}{d x^{2}}\left(f * \theta_{m}\right)(x)
\end{aligned}
$$

Las transformadas wavelet $W_{m}^{a} f(x)$ y $W_{m}^{b} f(x)$ son, respectivamente, la primera y segunda derivada de la señal suavizada a la escala $m$. El máximo local de $W_{m}^{a} f(x)$ corresponde entonces a los cruces por cero de $W_{m}^{b} f(x)$ y a los puntos de inflexión de $f * \theta_{m}(x)$. La detección del máximo local correspondería a una detección de bordes según Canny [23]. Cuando la escala $m$ es grande, la convolución con $\theta_{m}(x)$ elimina fluctuaciones pequeñas de la señal; por lo tanto, únicamente se detectan las variaciones pronunciadas de grandes estructuras.

La búsqueda de bordes mediante la detección de cruces por cero o la detección de máximos locales son procedimientos similares. Sin embargo, el método de los máximos locales tiene algunas ventajas. Un punto de inflexión de $f * \theta_{m}(x)$ puede ser un mínimo o un máximo o un mínimo del valor absoluto de su primera derivada. Los máximos del valor absoluto de la primera derivada son puntos de variación pronunciados de $f * \theta_{m}(x)$, mientras que los mínimos corresponden a variaciones lentas. Con un operador de la segunda derivada, es difícil distinguir estos dos tipos de cruce por cero. Por el contrario, con una derivada de primer orden, se pueden seleccionar fácilmente los puntos de variación pronunciada detectando únicamente los máximos locales de $\left|W_{m}^{a} f(x)\right|$. Además, los cruces por cero dan información de la posición, pero no diferencian entre fluctuaciones pequeñas de la amplitud y discontinuidades importantes [21].

Es fácil extender el concepto de Canny al dominio 2-D. La función de suavizamiento en 2-D $\theta(x, y)$ cuya integral sobre $x$ y $y$ es igual a 1 y converge a 0 en el infinito puede servir para suavizar una imagen $f(x, y)$ a diferentes escalas $m$ (convolución de $f$ con $\left.\theta_{m}(x, y)\right)$. Se puede entonces calcular el vector gradiente $\dot{\nabla}\left(f * \theta_{m}\right)(x, y)$. La dirección del vector gradiente en un punto $\left(x_{0}, y_{0}\right)$ indica la dirección en el plano de la imagen $(x, y)$ a 
lo largo de la cual la derivada direccional de $f(x, y)$ tiene el valor absoluto más grande. Los bordes se definen como los puntos $\left(x_{0}, y_{0}\right)$ donde el módulo del vector gradiente es máximo en la dirección hacia la cual el vector gradiente apunta en el plano de la imagen. Los puntos borde son puntos de inflexión de la superficie $f * \theta_{m}(x, y)$. A continuación, se relaciona esta forma de detección de bordes con una transformada wavelet 2-D:

Se definen dos funciones wavelet $\psi^{1}(x, y)$ y $\psi^{2}(x, y)$ de manera que:

$$
\begin{aligned}
& \left\{\begin{array}{l}
\psi^{1}(x, y)=\frac{\partial \theta(x, y)}{\partial x} \\
\psi^{2}(x, y)=\frac{\partial \theta(x, y)}{\partial y}
\end{array}\right. \\
& \left\{\begin{array}{l}
\psi_{m}^{1}(x, y)=\frac{1}{m^{2}} \psi^{1}\left(\frac{x}{m}, \frac{y}{m}\right) \\
\psi_{m}^{2}(x, y)=\frac{1}{m^{2}} \psi^{2}\left(\frac{x}{m}, \frac{y}{m}\right)
\end{array}\right.
\end{aligned}
$$

Para $f(x, y) \in \mathbf{L}^{2}\left(\Re^{2}\right)$, la transformada wavelet de $f(x, y)$ a la escala $m$ tiene dos componentes definidos por:

$$
\left\{\begin{array}{l}
W_{m}^{1} f(x, y)=f * \psi_{m}^{1}(x, y) \\
W_{m}^{2} f(x, y)=f * \psi_{m}^{2}(x, y)
\end{array}\right.
$$

pudiéndose probar además que:

$$
\left(\begin{array}{l}
W_{m}^{1} f(x, y) \\
W_{m}^{2} f(x, y)
\end{array}\right)=m\left(\begin{array}{l}
\frac{\partial}{\partial x}\left(f * \theta_{m}\right)(x, y) \\
\frac{\partial}{\partial y}\left(f * \theta_{m}\right)(x, y)
\end{array}\right)=m \stackrel{r}{\nabla}\left(f * \theta_{m}\right)(x, y)
$$

Por lo tanto, los puntos borde se pueden localizar a partir de las dos componentes $W_{m}^{1} f(x, y)$ y $W_{m}^{2} f(x, y)$ de la transformada wavelet [21].

\subsubsection{Diseño de los filtros $H(\omega), G(\omega)$ y $K(\omega)$.}

A partir de aquí, se puede realizar la síntesis de los filtros que producen los coeficientes de la TDWD. Primero, se expresarán las respuestas en frecuencia 1-D de cada filtro. 
Supóngase que se busca una wavelet de soporte compacto, anti-simétrica o simétrica, que muestra una buena capacidad para la detección de bordes (i.e. equivalente a una primera o segunda derivada de alguna función de suavizamiento) y es regular. Estas restricciones descartan completamente el uso de wavelets ortonormales.

Cuando una wavelet $\psi(x)$ es anti-simétrica alrededor de cero (i.e. una función impar), $G(\omega)$ es una función imaginaria impar y cuando una wavelet $\psi(x)$ es simétrica alrededor de cero (i.e. una función par), $G(\omega)$ es una función real par. La función $H(\omega)$ es par y real en ambos casos.

Para que una wavelet $\psi(x)$ sea la primera derivada de alguna función de suavizamiento $\theta(x), \psi(\omega)$ debe tener un cero de primer orden en $\omega=0 \mathrm{y}$, por lo tanto, $G(\omega)$ debe tener un cero de primer orden en $\omega=0$.

Sin embargo, aún después de satisfacer todas las restricciones anteriores, queda un gran número de posibilidades para $H(\omega)$.

La ecuación (5.8) implica menos restricciones que en un espacio ortogonal donde, forzosamente, $|H(\omega)|^{2}+|G(\omega)|^{2}=1$. Entonces es posible elegir wavelets diferentes con características diferentes entre sí (simetría, anti-simetría, decaimiento rápido, etc.). En particular, para fines de localización, se requieren wavelets madre con dos características principales:

a) Soporte compacto y

b) Rápido decaimiento.

Para este trabajo, se investigó que una familia de funciones de escalamiento que puede proporcionar wavelets madre de las características deseadas es:

$$
\hat{\phi}(\omega)=\left[\frac{\operatorname{sen}(\omega / 2)}{\omega / 2}\right]^{m+1} e^{i \varepsilon \omega / 2}
$$

con $\varepsilon=1$ si $m$ es par o $\varepsilon=0$ si $m$ es non.

Esta es una clase de funciones de Battle-Lemarié llamadas B-spline que generan análisis poli-resolución [33] y posee las siguientes características:

i) $\quad \phi_{m}(x)$ tiene soporte compacto en $\left[-\frac{m}{2}-1, \frac{m}{2}\right]$ si $m$ es par $\mathrm{y}$ en $\left[-\frac{m-1}{2}, \frac{m+1}{2}\right]$ si $m$ es impar y

ii) $\phi_{m}(x)$ tiene un decaimiento exponencial. 
$\operatorname{De}(5.3)$ :

$$
H(\omega)=\sqrt{2} \frac{\hat{\phi}(2 \omega)}{\hat{\phi}(\omega)}
$$

e insertando (5.10):

$$
\begin{gathered}
H(\omega)=\sqrt{2} \frac{\left[\frac{\operatorname{sen} \omega}{\omega}\right]^{m+1} e^{i \varepsilon \omega}}{\left[\frac{\operatorname{sen}(\omega / 2)}{\omega / 2}\right]^{m+1} e^{i \varepsilon \omega / 2}} \\
\Leftrightarrow \quad H(\omega)=\sqrt{2}[\cos \omega / 2]^{m+1} e^{i \varepsilon \omega / 2}
\end{gathered}
$$

Una vez que $H(\omega)$ se ha elegido, el producto $G(\omega) \hat{\phi}(\omega)$ está restringido por la ecuación (5.8). La wavelet diádica $\psi(x)$ se construye igual que las wavelets ortogonales o biortogonales [18]. Se necesita una wavelet $\psi(x)$ igual a la derivada de primer orden de una función de suavizamiento $\theta(x)$ :

$$
\psi(x)=\theta^{\prime}(x)=\frac{d \theta(x)}{d x} \Rightarrow i \omega \theta^{\prime}(\omega)=\psi(\omega)
$$

Esto implica que $\psi(\omega)$ debe tener un cero de orden 1 en $\omega=0 .|\hat{\phi}(0)|=1$ siempre en un análisis poli-resolución [18] y además, según Mallat y Meyer [18]:

$$
\hat{\psi}(\omega)=\frac{1}{\sqrt{2}} G\left(\frac{\omega}{2}\right) \phi\left(\frac{\omega}{2}\right)
$$

Por lo tanto, $G\left(\frac{0}{2}\right)=\sqrt{2} \psi(0)$ debe tener un cero de orden 1 también. ; $G(\omega)$ es también la derivada de orden 1 de una función de suavizamiento! En la literatura [18], [20], [21] [24] se acostumbra de elegir:

$$
G(\omega)=\sqrt{2} c i e^{i \omega / 2} \operatorname{sen}(\omega / 2)
$$

Nótese que $G(\omega)=O(\omega)^{3}$ en la vecindad de $\omega=0$.

De (5.10):

${ }^{3} f(n)=O(g(n))$ "del orden de:" $\exists K \mid f(n) \leq K g(n)$. 


$$
\begin{aligned}
K(\omega) & =\frac{2-\mid H(\omega)^{2}}{G(\omega)} \\
& =\frac{2-2[\cos (\omega / 2)]^{2 m+2}}{\sqrt{2} c i e^{i \omega / 2} \operatorname{sen}(\omega / 2)} \\
& =-\frac{\sqrt{2}}{c} i e^{-i \omega / 2}\left\{\frac{1-[\cos (\omega / 2)]^{2 m+2}}{\operatorname{sen}(\omega / 2)}\right\} \\
K(\omega) & =-\frac{\sqrt{2}}{c} i e^{-i \omega / 2} \operatorname{sen}(\omega / 2) \sum_{n=0}^{m} \cos ^{2 n}(\omega / 2)
\end{aligned}
$$

La fig. 5.2 muestra las respuestas a impulso de los filtros $H, G$ y $K$ y la tabla 5.1 los valores de $h[n], g[n]$ y $k[n]$. (Nota: no se tiene en cuenta en esta tabla el valor $\sqrt{2}$ ). En el apéndice $\mathrm{D}$ se muestra el programa MATLAB para calcular las respuestas a impulso.
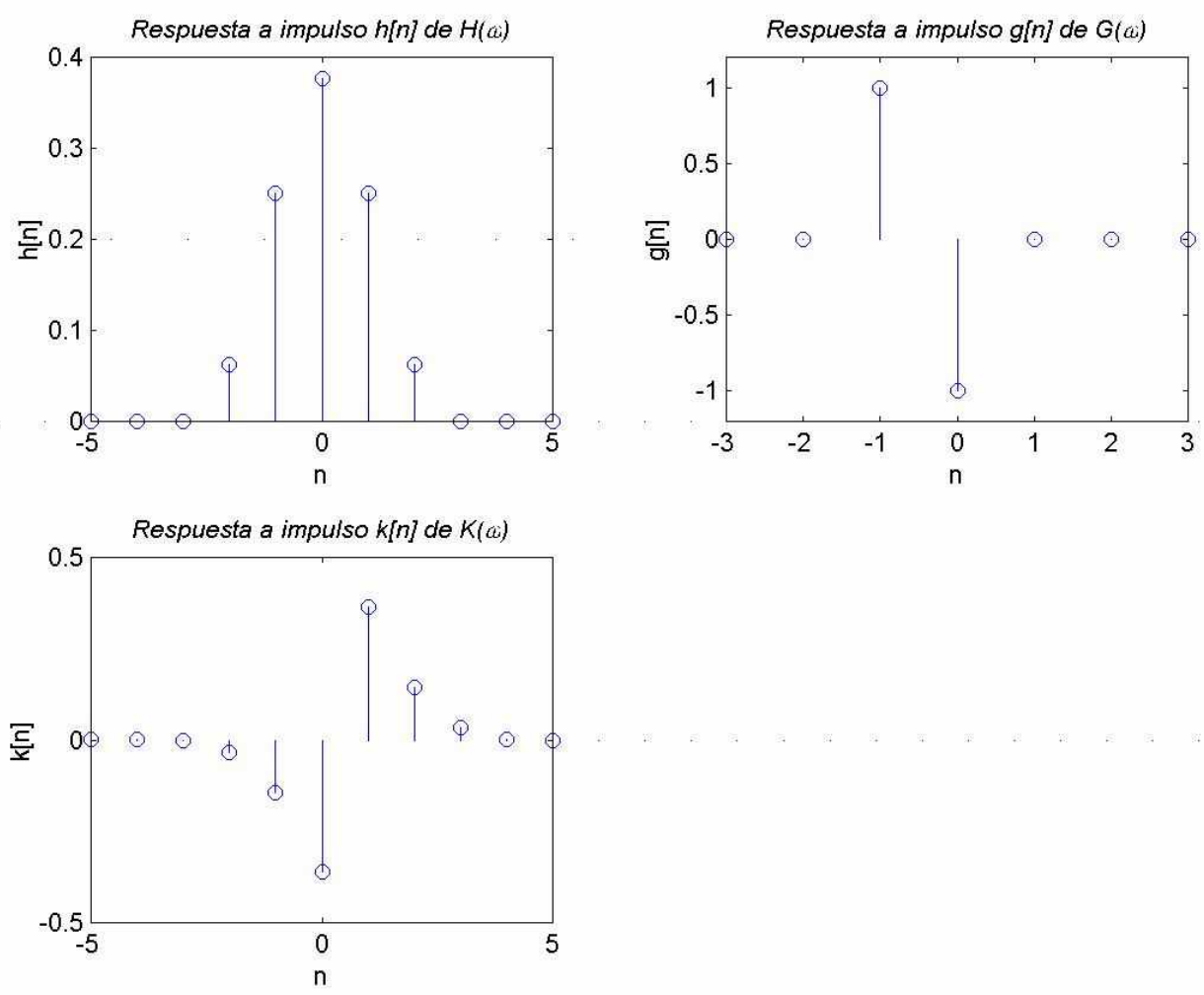

Fig. 5.2 Respuestas a impulso de los filtros $\mathrm{H}, \mathrm{G}$ y K. 


\begin{tabular}{||c|c|c|c||}
\hline \hline$n$ & $h[n]$ & $g[n]$ & $k[n]$ \\
\hline-4 & & & \\
\hline-3 & & & -0.00307355 \\
\hline-2 & 0.06212262 & & -0.03419838 \\
\hline-1 & 0.25076513 & 0.99995399 & -0.14388848 \\
\hline 0 & 0.3766669 & -0.99733223 & -0.36231190 \\
\hline 1 & 0.25076513 & & 0.36387748 \\
\hline 2 & 0.06212262 & & 0.14357485 \\
\hline 3 & & & 0.03374386 \\
\hline 4 & & & 0.00279506 \\
\hline \hline
\end{tabular}

Tabla 5.1 Respuestas a impulso de los filtros FIR correspondientes a $H(\omega), G(\omega)$ y $K(\omega)$.

Entonces: $\quad \hat{\phi}(\omega)=\left(\frac{\operatorname{sen}\left(\frac{\omega}{2}\right)}{\frac{\omega}{2}}\right)^{m+1} e^{i \varepsilon /(\omega / 2)} \quad$ función de escalamiento

mientras que aplicando la ecuación (5.12) a la ecuación (5.6), se obtiene:

$$
\psi(\omega)=\frac{c}{4} i \omega\left(\frac{\operatorname{sen}\left(\frac{\omega}{4}\right)}{\frac{\omega}{4}}\right)^{m+1} \quad \text { wavelet de análisis }
$$

$\psi(x)$ es la primera derivada de una función de suavizamiento $\theta(x)$ cuya transformada de Fourier es:

$$
\hat{\theta}(\omega)=\frac{c}{4}\left(\frac{\operatorname{sen}\left(\frac{\omega}{4}\right)}{\frac{\omega}{4}}\right)^{m+1}
$$

función de suavizamiento

Nótese que $\hat{\theta}(\omega)$ es una función spline de grado $m+1$. Aumentando el grado de $\hat{\theta}(\omega)$ ésta deviene más localizada en el dominio de la frecuencia y tiene un soporte mayor en el dominio espacial. Para el uso que se le solicita a $\psi(x)$, se ha elegido en este trabajo $m=3$ y $c=2$ de manera que $\psi(\omega)$ sea una spline cúbica y haya conformidad con las ecuaciones (104) y (106) en [21]. 


\subsubsection{Implementación de los filtros wavelet.}

De manera similar a las transformadas wavelet ortogonales y biortogonales discretas [19], la TDWD puede implementarse gracias a un esquema jerárquico de filtros. Utilizando la definición de la TDWD junto con las ecuaciones (5.5) y (5.6), se puede formular la sección de análisis del banco jerárquico de filtros. En un primer nivel de análisis (descomposición diádica con $k=1$ y $2^{1}$ normalizado a 1 ), tenemos:

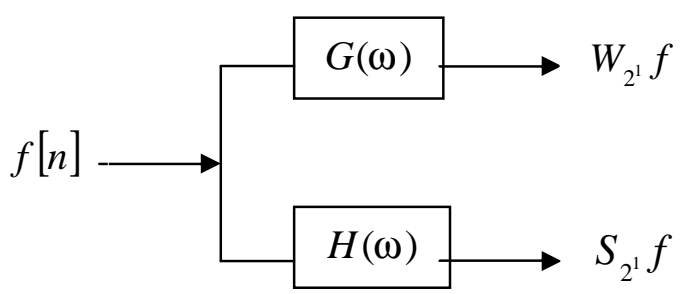

Fig.5.3 Primer nivel de descomposición del banco de filtros de análisis de una TDWD.

Para los siguientes niveles de descomposición $(k>1$ en la ecuación (5.3)), se aplican los filtros de las ecuaciones (5.11), (5.12) y (5.13) con alguna escala $2^{j}$. Cada uno de estos nuevos filtros deviene $H\left(2^{j} \omega\right), G\left(2^{j} \omega\right)$ y $K\left(2^{j} \omega\right)$. La figura 5.4 muestra el esquema del banco de filtros jerárquico de análisis hasta el nivel $J=3$ :

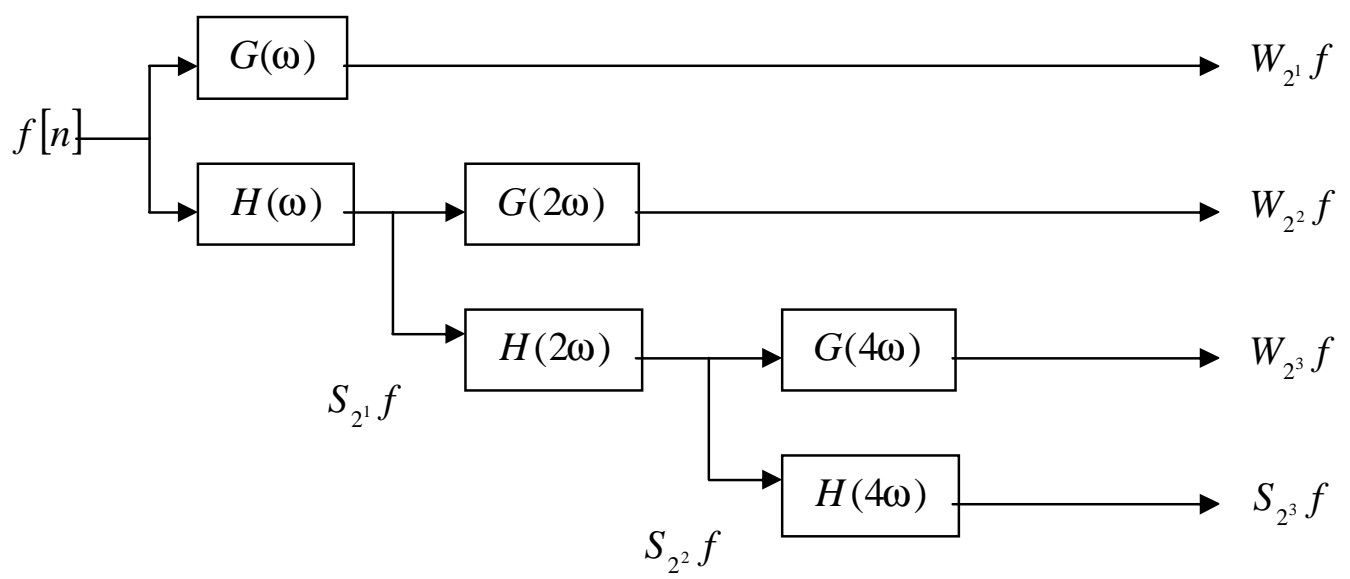

Fig. 5.4 Banco de filtros jerárquico de análisis de una TDWD representado hasta el nivel $m=3$.

Recuérdese que las siguientes relaciones:

$$
\sum_{j=-\infty}^{+\infty} \psi\left(2^{j} \omega\right) \chi\left(2^{j} \omega\right)=1
$$




$$
|H(\omega)|^{2}+G(\omega) K(\omega)=2 \quad \text { con } \quad|H(\omega)|^{2}=H(\omega) H^{*}(\omega)
$$

indican reconstrucción perfecta de la señal $f(x)$ original y la ecuación (5.7) relaciona a la wavelet de reconstrucción $\chi(\omega)$ con el filtro $K(\omega)$. El banco de filtros jerárquico que incluye la reconstrucción de $f(x)$ para $J=3$ se muestra en la figura 5.5.

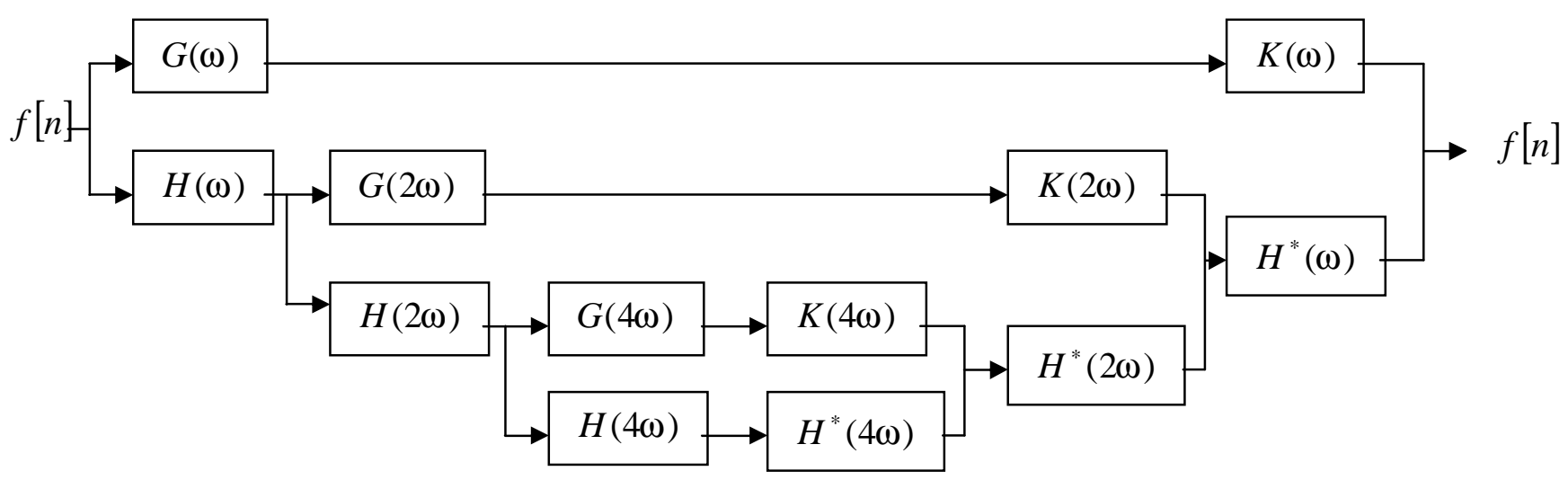

Fig. 5.5 Banco de filtros jerárquico completo (análisis y síntesis) representado hasta el nivel $m=3$. Existe reconstrucción perfecta como en el caso de las wavelets ortogonales y biortogonales [19].

\subsubsection{El algoritmo "à trous".}

Remárquese que, en el dominio espacial, cada uno de los filtros $H\left(2^{j} \omega\right), G\left(2^{j} \omega\right)$ y $K\left(2^{j} \omega\right)$ representan el sobre-muestreo de la respuesta a impulso a escalas $2^{j}$, esto es, se insertan $2^{j}-1$ ceros entre los coeficientes de cada uno de los filtros. La Transformada Diádica Wavelet Rápida (TDWR) calculada con el banco de filtros de la figura 5.4, se conoce con el nombre francés de "algorithme à trous" introducido por Holschneider, Kronland-Martinet, Morlet y Tchamitchian (1989). La complejidad de este banco de filtros aumenta linealmente con el número de niveles.

El algoritmo propuesto [21] para el cálculo 1D de la TDWR es el siguiente:

\footnotetext{
${ }^{4}$ Algoritmo con hoyos, debido a la inserción de ceros entre cada coeficiente del filtro.
} 


$$
\begin{aligned}
& j=0 \\
& \text { while }(j<J) \\
& \qquad \begin{array}{l}
W_{2^{j+1}} f=S_{2^{j}} f * G_{p} \\
\quad S_{2^{j+1}} f=S_{2^{j}} f * H_{p}
\end{array} \\
& \quad j=j+1 \\
& \text { end of while }
\end{aligned}
$$

y el algoritmo de la reconstrucción es el siguiente:

$$
\begin{aligned}
& \quad \begin{array}{l}
j=J \\
\text { while }(j>0)
\end{array} \\
& \qquad S_{2^{j-1}} f=W_{2^{j}} f * K_{p-1}+S_{2^{j}} f * H_{p-1}^{*} \\
& \quad j=j-1 \\
& \text { end of while }
\end{aligned}
$$

donde $H_{p}, G_{p}$ y $K_{p}$ son los filtros discretos después de haber insertado $2^{p}-1$ ceros entre cada uno de los coeficientes de los filtros $H, G$ y $K$. La función de transferencia de cada filtro es respectivamente $H\left(2^{p} \omega\right), \quad G\left(2^{p} \omega\right)$ y $K\left(2^{p} \omega\right) . H^{*}\left(2^{p} \omega\right)$ es el complejo conjugado de $H\left(2^{p} \omega\right)$.

\subsubsection{Transformada diádica wavelet discreta 2D.}

Los postulados de las secciones 5.2 y 5.3 son válidos para el caso 2D. Es posible pues aplicar un muestreo uniforme de la transformada wavelet de $f(x, y)$ a escalas mayores a 1. Para cualquier escala $2^{j}$ :

$$
\left\{\begin{array}{l}
W_{2^{j}}^{1} f=\left(W_{2^{j}}^{1} f(n+s, m+s)\right)_{(n, m) \in Z^{2}} \\
W_{2^{j}}^{2} f=\left(W_{2^{j}}^{2} f(n+s, m+s)\right)_{(n, m) \in Z^{2}} \\
S_{2^{j}} f=\left(S_{2^{j}} f(n+s, m+s)\right)_{(n, m) \in Z^{2}}
\end{array}\right.
$$

de acuerdo a la definición de la transformada wavelet 2D. El siguiente conjunto forma la Transformada Diádica Wavelet Discreta 2D (TDWD2D):

$$
\left\{S_{2^{j}} f,\left(W_{2^{j}}^{1} f\right)_{1 \leq j \leq J},\left(W_{2^{j}}^{2} f\right)_{1 \leq j \leq J}\right\}
$$

La reconstrucción perfecta se cumple cuando: 


$$
\left\{\begin{array}{l}
\sum_{j=-\infty}^{+\infty}\left(\hat{\psi}^{1}\left(2^{j} \omega_{x}, 2^{j} \omega_{y}\right) \chi^{1}\left(2^{j} \omega_{x}, 2^{j} \omega_{y}\right)+\psi^{2}\left(2^{j} \omega_{x}, 2^{j} \omega_{y}\right) \chi^{2}\left(2^{j} \omega_{x}, 2^{j} \omega_{y}\right)\right)=1 \\
f(x, y)=\sum_{j=-\infty}^{+\infty}\left(W_{2^{j}}^{1} f * \chi_{2^{j}}^{1}(x, y)+W_{2^{j}}^{2} f * \chi_{2^{j}}^{2}(x, y)\right)
\end{array}\right.
$$

en el dominio continuo. Se pueden escoger, como antes, las wavelets $\psi^{1}(x, y)$ y $\psi^{2}(x, y)$ con la conveniente característica de que estas funciones se pueden expresar en sendos productos separables de las variables $x$ y $y$ [24]. Sean las siguientes definiciones:

$$
\left\{\begin{array}{l}
\psi(2 \omega)=\frac{1}{\sqrt{2}} G(\omega) \hat{\phi_{0}}(\omega) \text { con } \hat{\phi_{0}}(\omega)=\prod_{p=1}^{+\infty} H\left(2^{-p} \omega\right) \\
\psi^{1}(x, y)=\psi(x) 2 \phi_{0}(2 y) \\
\psi^{2}(x, y)=2 \phi_{0}(2 x) \psi(y)
\end{array}\right.
$$

definiciones que implican que:

$$
\begin{gathered}
\psi^{1}\left(2 \omega_{x}, 2 \omega_{y}\right)=\mathrm{F}\left\{\psi^{1}(x, y)\right\} \\
\psi^{2}\left(2 \omega_{x}, 2 \omega_{y}\right)=\mathrm{F}\left\{\psi^{2}(x, y)\right\} \\
\Leftrightarrow\left\{\begin{array}{l}
\psi^{1}\left(2 \omega_{x}, 2 \omega_{y}\right)=\frac{1}{\sqrt{2}} G\left(\omega_{x}\right) \hat{\phi_{0}}\left(\omega_{x}\right) \hat{\phi_{0}}\left(\omega_{y}\right) \\
\psi^{2}\left(2 \omega_{x}, 2 \omega_{y}\right)=\hat{\phi_{0}}\left(\omega_{x}\right) \frac{1}{\sqrt{2}} G\left(\omega_{y}\right) \hat{\phi_{0}}\left(\omega_{y}\right)
\end{array}\right.
\end{gathered}
$$

puesto que la función de suavizamiento $\phi(x, y)$ también es separable:

$$
\phi(x, y)=\phi_{0}(x) \phi_{0}(y)
$$

Las wavelets de reconstrucción se definen como [21]:

$$
\left\{\begin{array}{l}
\chi^{1}\left(2 \omega_{x}, 2 \omega_{y}\right)=\frac{1}{\sqrt{2}} K\left(\omega_{x}\right) L\left(\omega_{y}\right) \hat{\phi}\left(\omega_{x}\right) \hat{\phi}\left(\omega_{y}\right) \\
\chi^{2}\left(2 \omega_{x}, 2 \omega_{y}\right)=\frac{1}{\sqrt{2}} K\left(\omega_{y}\right) L\left(\omega_{x}\right) \hat{\phi}\left(\omega_{x}\right) \hat{\phi}\left(\omega_{y}\right)
\end{array}\right.
$$

donde $K(\omega)$ y $L(\omega)$ satisfacen [21]: 


$$
\left\{\begin{array}{l}
G(\omega) K(\omega)+|H(\omega)|^{2}=2 \\
L(\omega)=\frac{1+|H(\omega)|^{2}}{2}
\end{array}\right.
$$

Las wavelets $2 \mathrm{D}$ se derivan de las wavelets $1 \mathrm{D}$ de las secciones 5.2 y 5.3 . La descomposición de la TDWD2D se puede formular en términos de las siguientes relaciones recursivas entre los niveles $j$ y $j+1$ en el dominio de Fourier:

$$
\left\{\begin{array}{l}
W_{j+1}^{1}\left[f\left(\omega_{x}, \omega_{y}\right)\right]=G\left(2^{j} \omega_{x}\right) S_{j}\left[f\left(\omega_{x}, \omega_{y}\right)\right] \\
W_{j+1}^{2}\left[f\left(\omega_{x}, \omega_{y}\right)\right]=G\left(2^{j} \omega_{y}\right) S_{j}\left[f\left(\omega_{x}, \omega_{y}\right)\right] \\
S_{j+1}\left[f\left(\omega_{x}, \omega_{y}\right)\right]=H\left(2^{j} \omega_{x}\right) H\left(2^{j} \omega_{y}\right) S_{j}\left[f\left(\omega_{x}, \omega_{y}\right)\right]
\end{array}\right.
$$

donde $j \geq 0$ y $S_{0}\left[f\left(\omega_{x} \omega_{y}\right)\right] \equiv \hat{f}\left(\omega_{x}, \omega_{y}\right)$. La reconstrucción de $S_{0}\left\lfloor f\left(\omega_{x} \omega_{y}\right)\right\rfloor$ se representa mediante la siguiente relación de recursividad:

$$
\begin{array}{r}
S_{j}\left[f\left(\omega_{x}, \omega_{y}\right)\right]=W_{j+1}^{1}\left[f\left(\omega_{x}, \omega_{y}\right)\right] K\left(2^{j} \omega_{x}\right) L\left(2^{j} \omega_{y}\right)+W_{j+1}^{2}\left[f\left(\omega_{x}, \omega_{y}\right)\right] L\left(2^{j} \omega_{x}\right) K\left(2^{j} \omega_{y}\right) \\
+S_{j+1}\left[f\left(\omega_{x}, \omega_{y}\right)\right] \bar{H}\left(2^{j} \omega_{x}\right) \bar{H}\left(2^{j} \omega_{y}\right)
\end{array}
$$

donde $\bar{H}$ es el complejo conjugado de $H$. La figura 5.6 muestra el esquema jerárquico de los filtros para implementar la TDWR2D hasta el nivel $J=3$. Los supra-índices 1 y 2 corresponden a las TDWD en las direcciones Horizontal y Vertical, respectivamente. Si no aplica algún tipo de procesamiento entre la etapa de descomposición y la etapa de reconstrucción, entonces habrá reconstrucción perfecta de la señal de entrada. 


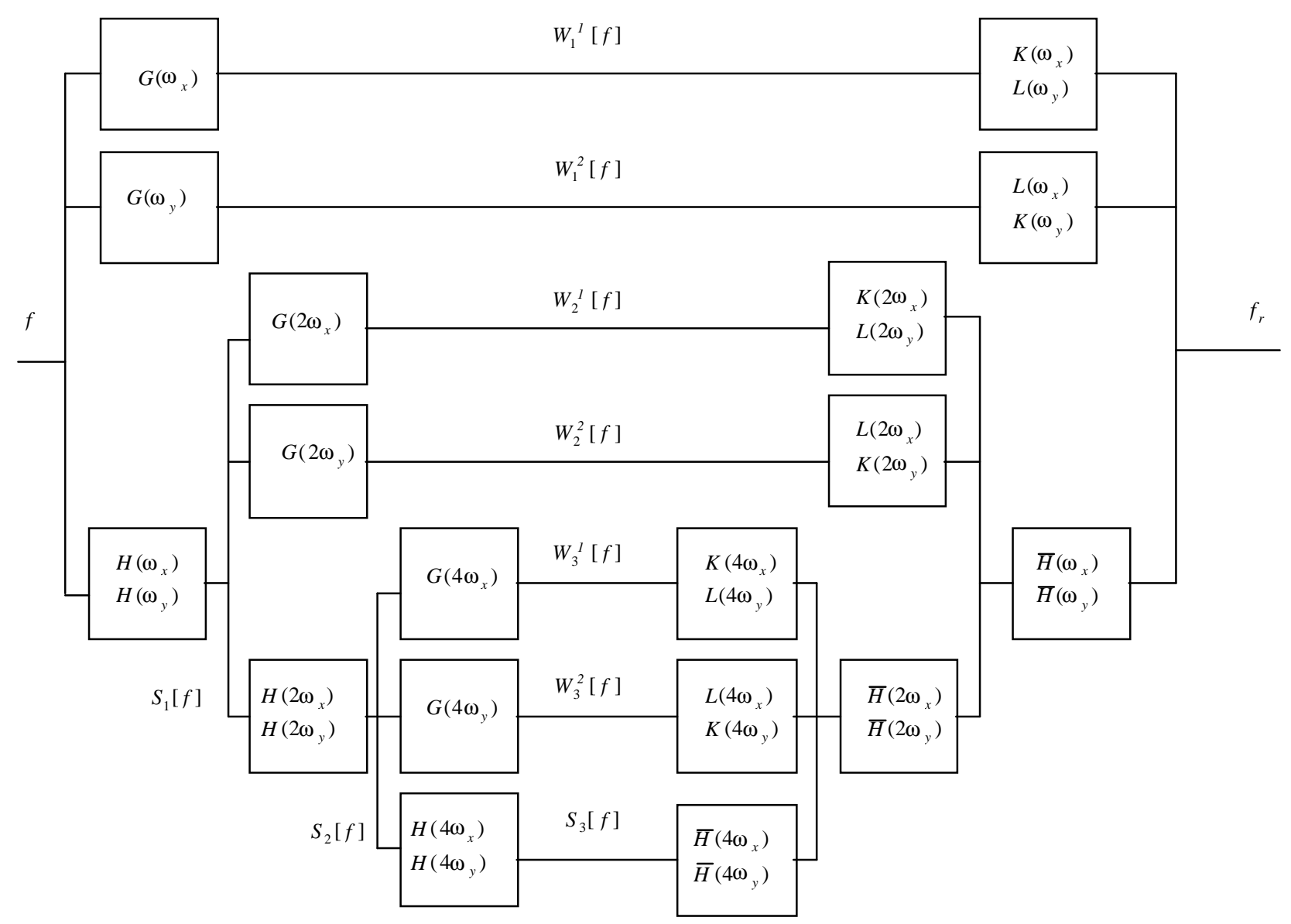

Fig. 5.6 Descomposición y reconstrucción de una función 2D mediante la TDWR a 3 niveles.

Los coeficientes del filtro $L$ se calculan a partir de:

$$
\begin{gathered}
L(\omega)=\frac{1+|H(\omega)|^{2}}{2}=\frac{1+2 \cos ^{2 m+2}(\omega / 2)}{2} \\
L(\omega)=\frac{1+2[\cos (\omega / 2)]^{2 m+2}}{2}
\end{gathered}
$$

con el programa MATLAB del apéndice D. La figura 5.7 muestra la respuesta a impulso encontrada y la tabla 5.2 muestra los valores de $l[n]$. 


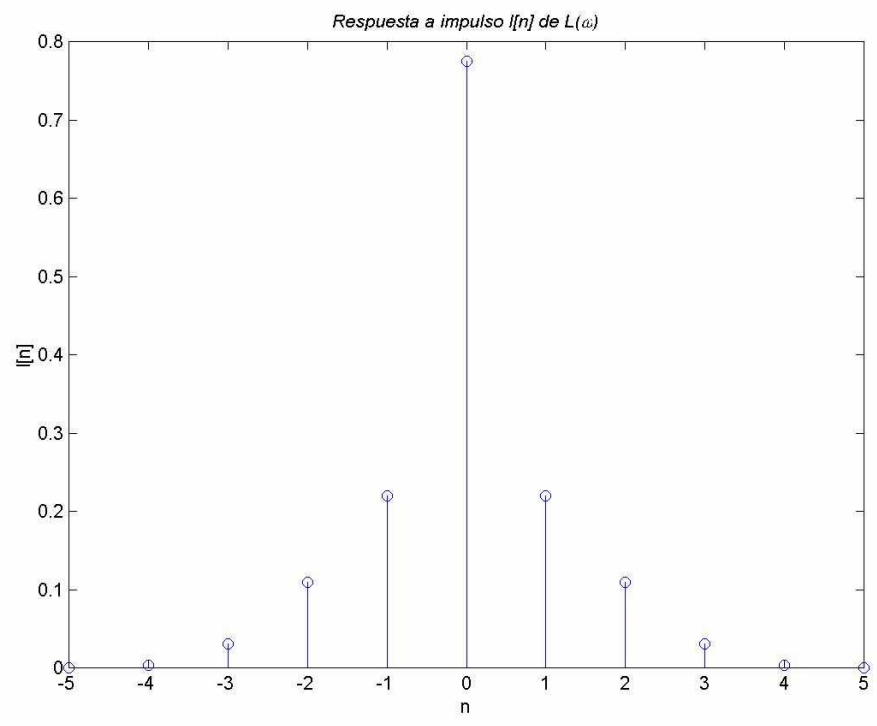

Fig. 5.7 Respuesta a impulso del filtro $L(\omega)$.

\begin{tabular}{|c|c|}
\hline$n$ & $l[n]$ \\
\hline-4 & 0.00341499 \\
\hline-3 & 0.03070522 \\
\hline-2 & 0.10943289 \\
\hline-1 & 0.22001639 \\
\hline 0 & 0.77537424 \\
\hline 1 & 0.22001639 \\
\hline 2 & 0.10943289 \\
\hline 3 & 0.03070522 \\
\hline 4 & 0.00341499 \\
\hline
\end{tabular}

Tabla 5.2 Coeficientes del filtro discreto 1[n] de reconstrucción en el esquema de la TDWR2D.

\subsection{5 "Algorithme à trous" $2 \mathrm{D}$.}

A continuación se relaciona el pseudocódigo correspondiente a la implementación mediante el algoritmo "à trous" 2D de la TDWR2D [21]. Como en el caso 1D, $L_{p}$ es el filtro sobre-muestreado con $2^{p}-1$ ceros insertados entre sus coeficientes. $D$ es el filtro de Dirac y se entiende que las convoluciones $2 \mathrm{D}$ se realizan separadamente para $\omega_{x}$ y $\omega_{y}$. 
Descomposición:

$$
\begin{aligned}
& j=0 \\
& \text { while }(j<J) \\
& \quad W_{2^{j+1}}^{1} f=S_{2^{j}} f *\left(G_{p}, D\right) \\
& \quad W_{2^{j+1}}^{2} f=S_{2^{j}} f *\left(D, G_{p}\right) \\
& \quad S_{2^{j+1}} f=S_{2^{j}} f *\left(H_{p}, H_{p}\right) \\
& \quad j=j+1
\end{aligned}
$$

end of while

Reconstrucción:

$$
\begin{aligned}
& \begin{array}{l}
j=J \\
\text { while }(j>0)
\end{array} \\
& \qquad \begin{array}{r}
S_{2^{j-1}} f=W_{2^{j}}^{1} f *\left(K_{p-1}, L_{p-1}\right)+W_{2^{j}}^{2} f *\left(L_{p-1}, K_{p-1}\right) \\
\quad+S_{2^{j}} f *\left(\bar{H}_{p-1}, \bar{H}_{p-1}\right)
\end{array} \\
& \quad j=j+1 \\
& \text { end of while }
\end{aligned}
$$

\subsection{Resultados.}

En el apéndice D se relaciona el programa MATLAB que permite la descomposición y reconstrucción de una ecocardiografía según el algoritmo de la TDWR2D y su inverso. Se incluye en este apéndice las explicaciones complementarias para el entendimiento del programa.

En la figura 5.8 se muestra un ejemplo de la descomposición diádica wavelet de la ecocardiografía de una válvula aórtica. La ecocardiografía original es una imagen fija NTSC de $720 \times 480$ pixeles que se adquiere conectando una tarjeta de adquisición de video DV500 (Pinnacle Systems) a la salida de video compuesto del ecógrafo SONOS 5500 (Agilent Technologies). El software asociado (Premiere 5.1 de ADOBE) permite grabar las imágenes fijas seleccionadas como archivos de imagen *.bmp tipo "truecolor" pero que MATLAB convierte a una imagen de 256 niveles de gris. La válvula aórtica se localiza mejor dentro de una imagen reducida a $128 \times 128$ pixeles $\left(2^{7} \times 2^{7}\right.$ pixeles, $J=7$ niveles $)$. Los procesamientos de imagen subsecuentes se harán con imágenes a esta resolución. Se presentan las componentes en la dirección $x$ (horizontal) $\left(W_{2^{j}}^{1} f\right)_{1 \leq j \leq 7}$ y en la dirección $y$ (vertical) $\left(W_{2^{j}}^{2} f\right)_{1 \leq j \leq 7}$, así como la última componente de aproximación $S_{2^{7}} f$. 

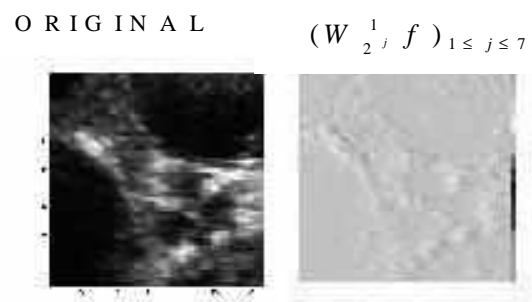

$\left(W_{22^{j}}^{2} f\right)_{1 \leq j \leq 7}$
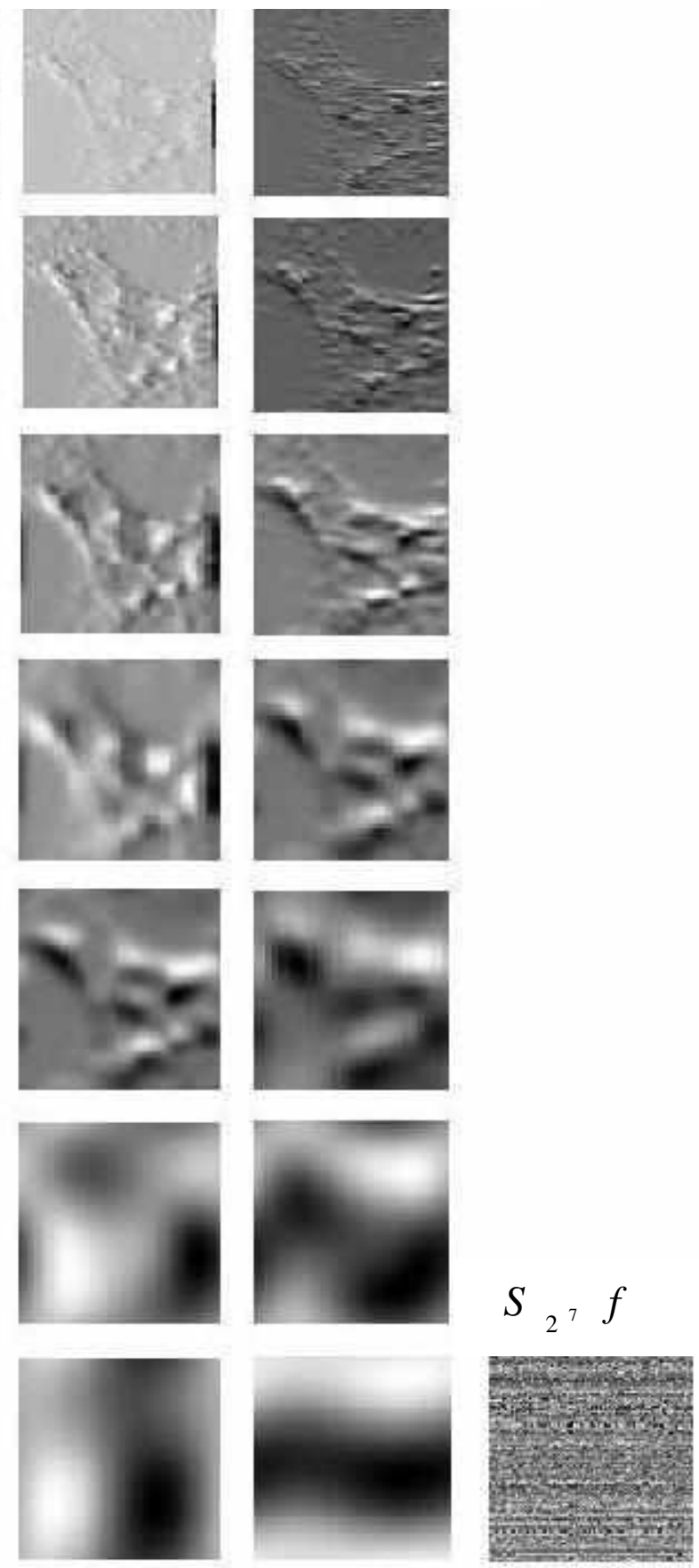

Fig. 5.8 Descomposición TDWR2D de la ecocardiografía de una válvula aórtica en el corte paraesternal de eje corto a 7 niveles en la dirección $x$ y $y$. Se muestra al final la última aproximación. 
La figura 5.9 muestra la reconstrucción obtenida mediante el procedimiento de reconstrucción.

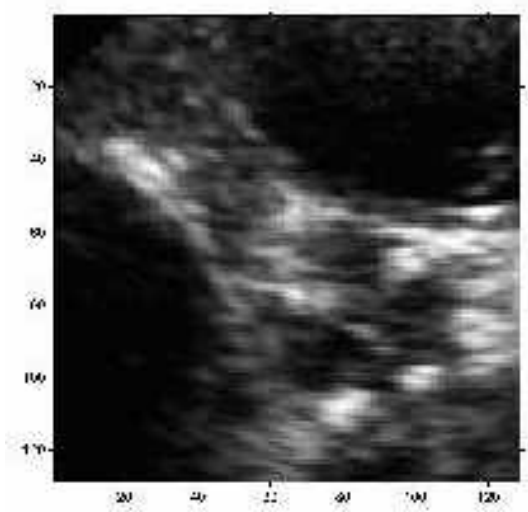

a)

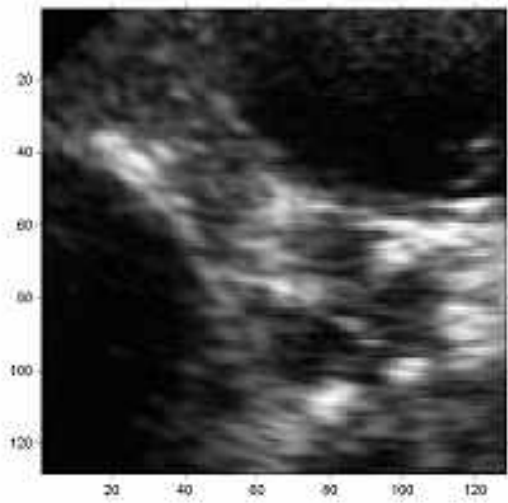

b)

Fig. 5.9 a) Ecocardiografía original. Resolución: $128 \times 128$ pixeles. b) Ecocardiografía reconstruída a partir de la TDWR2D, constante $=0.227, \mathrm{PSNR}=+33.18 \mathrm{~dB}$.

\subsection{Discusión.}

Visualmente, la figura $5.9 \mathrm{~b}$ ) ilustra los buenos resultados de periodizar las columnas y renglones de la matriz imagen que representa a la ecocardiografía actual (cf. Apéndice D).

¿Es posible hablar de una reconstrucción perfecta de la ecocardiografía? Si los filtros están cuidadosamente diseñados, la reconstrucción será solamente muy aproximada, pero no perfecta. Para conocer el grado de aproximación a la reconstrucción perfecta, se utiliza la figura de la relación pico señal a ruido definida por:

$$
P S N R=20 \log _{10}(b / r m s)
$$

donde:

$b$ es el máximo valor de la señal (típicamente 255 ó 1) y

$r m s$ es la raíz cuadrada media de la diferencia entre dos imágenes.

La PSNR tiene unidades de decibel $(\mathrm{dB})$ y mide el cociente entre la señal pico y la diferencia entre dos imágenes. Un incremento de $20 \mathrm{~dB}$ corresponde a un decremento de una década en la diferencia rms entre dos imágenes. Por lo tanto, la PSNR mide la diferencia entre dos imágenes. El apéndice D lista el programa MATLAB que realiza el cálculo de la PSNR.

La condición de reconstrucción (5.8) se puede utilizar para probar que [18, p. 155], en el caso de las convoluciones separadas:

$$
\hat{a}_{j+1}(\omega) H\left(2^{j} \omega\right)+\hat{d}_{j+1}(\omega) K\left(2^{j} \omega\right)=2 \hat{a}_{j}(\omega)
$$


donde $\hat{d}_{J}$ son los coeficientes wavelet a la salida de los filtros de descomposición en cada nivel $J$ y $\hat{a}_{k}$ los coeficientes de aproximación que completan la información, es la transformada de Fourier de:

$$
a_{j}[n]=\frac{1}{2}\left(a_{j+1} * \bar{h}_{j}[n]+d_{j+1} * k_{j}[n]\right)
$$

Por lo tanto, teóricamente se debe multiplicar por 0.5 en cada nivel de reconstrucción. Si esto se hace en la línea del programa MATLAB correspondiente a la reconstrucción:

$$
x=0.5 *(i y r+i y c+i y h) ;
$$

la PSNR en una reconstrucción a 4 niveles es:

$$
P S N R=+20.23 d B
$$

Mallat [18, p. 185] informa de errores en la reconstrucción del orden de $10^{-2}$ el cual es un error que la visión humana no discierne en una imagen. En general, para las wavelets diádicas, Meyer y Berman han probado que la reconstrucción exacta no es posible. Los coeficientes de la transformada wavelet diádica que representan los máximos locales no tienen las mismas amplitudes que en el dominio continuo. Para lograr una reconstrucción muy aproximada visualmente a la ecocardiografía original o bien hacer máxima la PSNR, se tuvo que encontrar mediante prueba y error una constante de reconstrucción diferente a 0.5. La tabla 5.3 muestra algunas constantes de prueba y las PSNRs de reconstrucción correspondientes. La figura $5.9 \mathrm{~b}$ ) muestra un ejemplo de una de las reconstrucciones más aproximadas a la original que se pudo lograr (constante $=0.227$, PSNR $=+33.18 \mathrm{~dB}$ ). La figura 5.10 muestra ejemplos de reconstrucciones menos aproximadas.

\begin{tabular}{|c|c|}
\hline CONSTANTE & PSNR (dB) \\
\hline 0.5 & +20.23 \\
\hline 0.3 & +23.82 \\
\hline 0.227 & +33.18 \\
\hline 0.25 & +28.56 \\
\hline 0.2 & +24.85 \\
\hline 0.1 & +14.99 \\
\hline
\end{tabular}

Tabla 5.3 Constantes de reconstrucción y PSNRs correspondientes. 


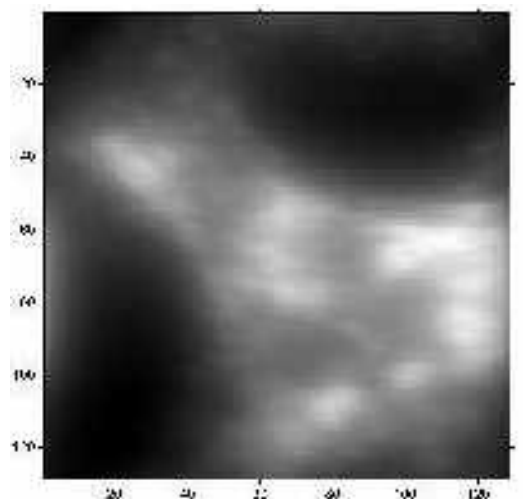

a)

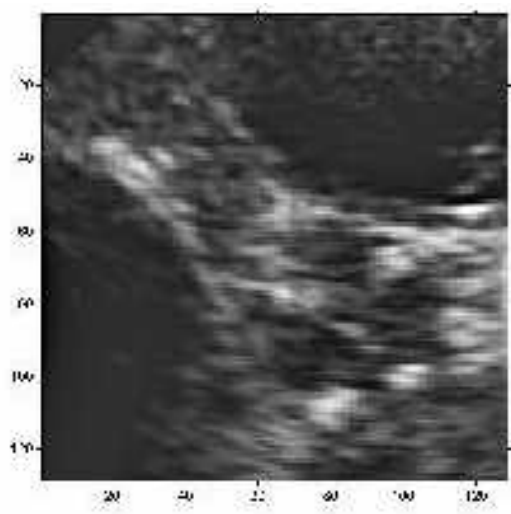

b)

Fig. 5.10 Reconstrucciones de ecocardiografías a partir de la TDWR2D. a) Constante $=0.5$, PSNR $=+20.23$ $\mathrm{dB}$ b) Constante $=0.3$, PSNR $=+23.82 \mathrm{~dB}$.

Con el error de reconstrucción reducido a un mínimo, el resultado visual es aceptable y se ha decidido continuar con estos resultados parciales el trabajo de investigación. La búsqueda de bordes es independiente de la reconstrucción diádica, pero su importancia se explica en el capítulo 8. 


\section{LA BÚSQUEDA DE BORDES EN LA ECOCARDIOGRAFÍA DE LA VÁLVULA AÓRTICA}

\subsection{Introducción.}

Los bordes de una imagen pueden considerarse como conjuntos de puntos donde la intensidad de la imagen tiene transiciones pronunciadas. Los bordes que definen las formas de una escena, podrán ser detectadas sólo para determinadas escalas de análisis en la descomposición wavelet. En el campo de la visión por computadora, las escalas más finas de un análisis poli-escalar permiten reconocer texturas, mientras que las escalas más gruesas permiten la detección de bordes (formas) [18, p.189]. Sin embargo, las ecocardiografías muestran variaciones pronunciadas de la imagen que no pertenecen a bordes de grandes estructuras. Esto ocurre así debido principalmente a:

- las variaciones en la impedancia acústica de los diferentes tejidos pueden producir sobre la ecocardiografía áreas muy ecogénicas o patrones ecogénicos irregulares, los cuales pueden provocar grandes variaciones que impiden hacer la discriminación entre textura y bordes,

- el ruido de granulado, inherente a las ecocardiografías, puede hacer variar la orientación de los bordes verdaderos de una estructura tanto a escalas finas como a escalas gruesas, produciendo errores en el reconocimiento de una textura o la dirección correcta de un borde.

En este trabajo, interesa separar la superficie irregular de los tejidos que aparecen sobre la imagen del corte ultrasónico de los contornos de las grandes estructuras. El anillo anatómico de la válvula aórtica es una de estas grandes estructuras. Esta forma puede presentar discontinuidades que podrían ser corregidas mediante técnicas de enlace de bordes para finalmente estimar el área del anillo anatómico.

\section{2 "Modulus maxima” de la transformada wavelet.}

Como bien apuntan Mallat y Zhong [21], "La detección poli-escalar de bordes según Canny es equivalente a encontrar los máximos locales de una transformada wavelet”. Se observa que:

- La convolución de $f$ con una función de suavizamiento $\theta_{m}$ (cf. sección 5.3) promedia a $f$ sobre un dominio proporcional a la escala $m$. 
- El término modulus maxima [18, p. 76] describe cualquier punto $\left(u_{0}, m_{0}\right)$ del plano tiempo-escala (o del plano espacio-escala 1D) $(u, m)$ tal que $|W f(u, m)|$ es localmente máximo en $u=u_{0}$. Esto implica que:

$$
\frac{\partial W f\left(u_{0}, m_{0}\right)}{\partial u}=0
$$

Este máximo local debe ser un máximo local estricto a la izquierda o la derecha de $u_{0}$ para evitar tener cualquier máximo local cuando $\left|W f\left(u, m_{0}\right)\right|$ sea constante.

- $\operatorname{Si} \psi^{a}(x)=\frac{d \theta(x)}{d x}$ entonces $W^{a} f(u, m)=m \frac{d}{d u}\left(f * \bar{\theta}_{m}\right)(u)$ tiene modulus maxima en puntos de variación pronunciada de $f * \bar{\theta}_{m}(s)$. Este modulus maxima poliescalar se utiliza para localizar discontinuidades y bordes en las imágenes.

Estas observaciones se ilustran en la figura 6.1.

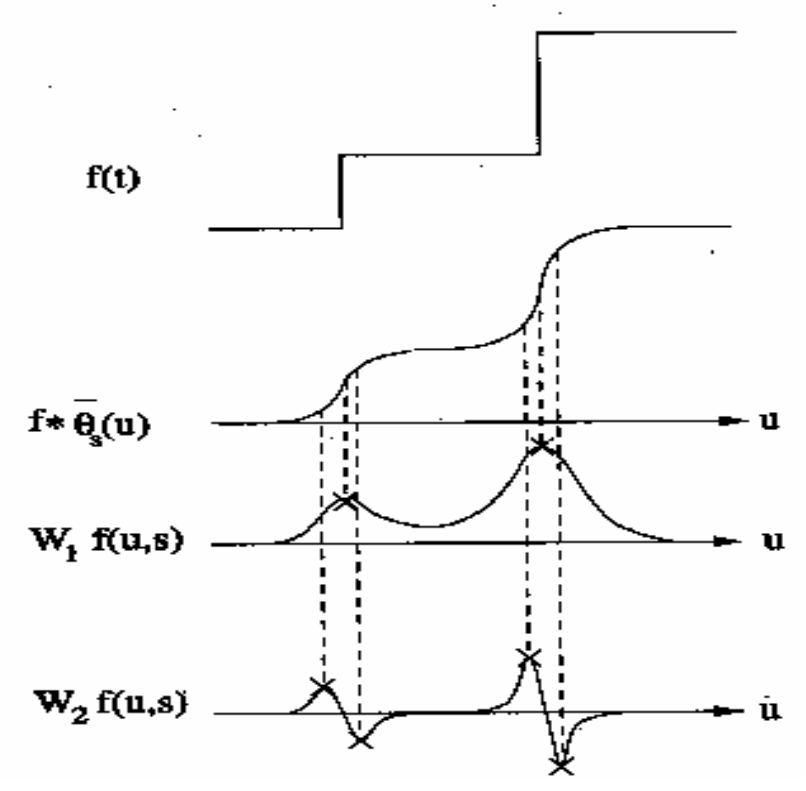

Fig. 6.1 La convolución $f * \overline{\theta_{s}}(u)$ promedia a $f$ sobre un dominio proporcional a $s$. Si $\psi=-\theta^{\prime}$ entonces $W_{1} f(u, s)=s \frac{d}{d u}\left(f * \bar{\theta}_{s}\right)(u)$ tiene modulus maxima en puntos pronunciados de variación de $f * \bar{\theta}_{s}(u)$. Si $\psi=\theta^{\prime \prime}$ entonces el modulus maxima de $W_{2} f(u, s)=s^{2} \frac{d^{2}}{d u^{2}}\left(f * \theta_{s}\right)(u)$ corresponde a curvaturas localmente máximas. (Tomado y adaptado de [18]).

De la siguiente relación (cf. sección 5.3): 


$$
\left(\begin{array}{l}
W_{m}^{1} f(x, y) \\
W_{m}^{2} f(x, y)
\end{array}\right)=m\left(\begin{array}{l}
\frac{\partial}{\partial x}\left(f * \overline{\theta_{m}}\right)(x, y) \\
\frac{\partial}{\partial y}\left(f * \overline{\theta_{m}}\right)(x, y)
\end{array}\right)=m \stackrel{r}{\nabla}\left(f * \bar{\theta}_{m}\right)(x, y)
$$

$m=2^{j}$ para el caso diádico $2 \mathrm{D}$, entonces:

$$
\left.\left(\begin{array}{l}
W_{2^{j}}^{1} f(x, y) \\
W_{2^{j}}^{2} f(x, y)
\end{array}\right)=2^{j}\left(\begin{array}{l}
\frac{\partial}{\partial x}\left(f * \bar{\theta}_{2^{j}}\right)(x, y) \\
\frac{\partial}{\partial y}\left(f * \bar{\theta}_{2^{j}}\right)(x, y)
\end{array}\right)=2^{j} \nabla_{\left(f * \theta_{2^{j}}\right.}\right)(x, y)
$$

Las dos componentes de la transformada wavelet son proporcionales a las dos componentes del vector gradiente $\dot{\nabla}\left(f * \bar{\theta}_{2^{j}}\right)(x, y)$. Para cada escala $2^{j}$, el módulo del vector gradiente es proporcional a:

$$
M_{2^{j}} f(x, y)=\sqrt{\left|W_{2^{j}}^{1} f(x, y)\right|^{2}+\left|W_{2^{j}}^{2} f(x, y)\right|^{2}}
$$

El ángulo del vector gradiente está dado por:

$$
\begin{gathered}
A_{2^{j}} f(x, y)=\left\{\begin{array}{lrr}
\alpha & \text { si } & W_{2^{j}}^{1} f(x, y) \geq 0 \\
\pi-\alpha & \text { si } & W_{2^{j}}^{1} f(x, y)<0
\end{array}\right. \\
\text { con } \quad \alpha=\operatorname{tg}^{-1}\left(\frac{W_{2^{j}}^{2} f(x, y)}{W_{2^{j}}^{1} f(x, y)}\right)
\end{gathered}
$$

Igual que en el algoritmo de Canny [23], los puntos de variación pronunciada de $f * \bar{\theta}_{2^{j}}(x, y)$ son los puntos $(x, y)$ donde el módulo $M_{2^{j}} f(x, y)$ tiene un máximo local en la dirección del gradiente dado por $A_{2^{j}} f(x, y)$. Estos puntos se llaman modulus maxima de la transformada wavelet.

Entonces, en cada nivel de descomposición se calcula el módulo del vector gradiente $M_{2^{j}} f(x, y)$ con ayuda de:

$$
\left\{\begin{array}{l}
W_{J}^{1} f(x, y) \\
W_{J}^{2} f(x, y)
\end{array}\right.
$$


En la figura 6.2 se muestran las imágenes que representan al módulo del gradiente en cada nivel de descomposición. La instrucción MATLAB correspondiente a este cálculo es:

$$
\mathrm{ng}=\operatorname{sqrt}\left(i \mathrm{~m}(:,:, \mathrm{m}) .{ }^{\mathrm{im}}(:,:, \mathrm{m})+i \mathrm{~m}(:,:, \mathrm{m}+1) \cdot{ }^{\mathrm{im}}(:,:, \mathrm{m}+1)\right) \text {; }
$$

donde $\operatorname{im}(:,:, \mathrm{m})$ representa a cada una de las matrices-imagen $W_{2^{j}}^{1,2} f(x, y)$. 

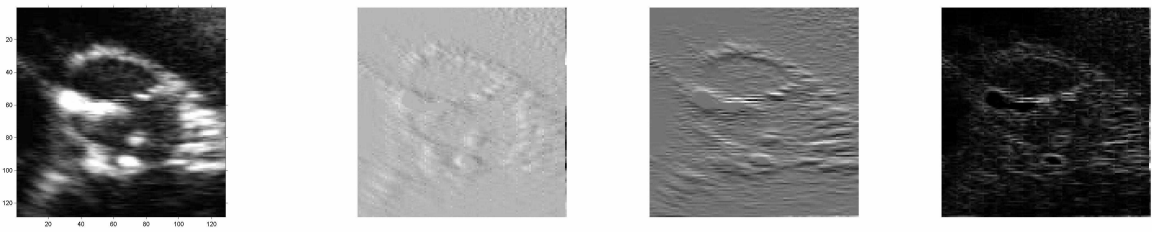

$$
i=1
$$
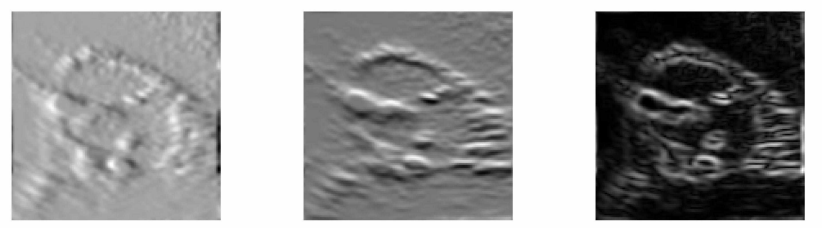

$$
\mathrm{i}=2
$$
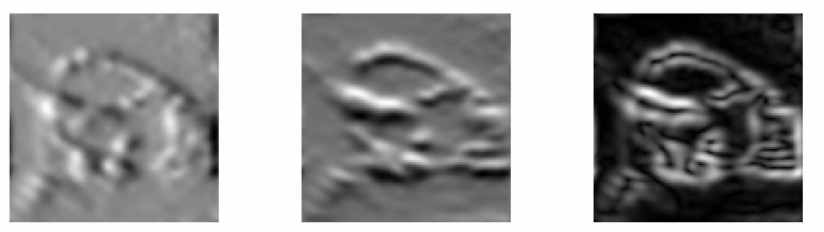

$$
i=3
$$
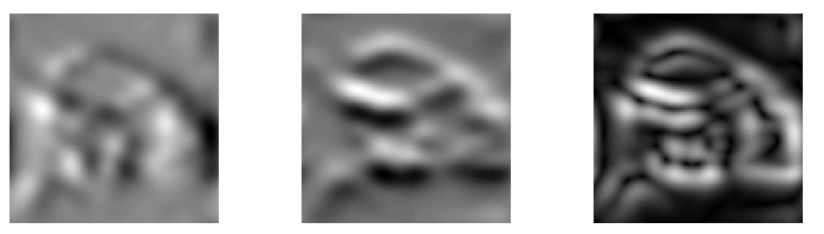

$$
\mathrm{i}=4
$$
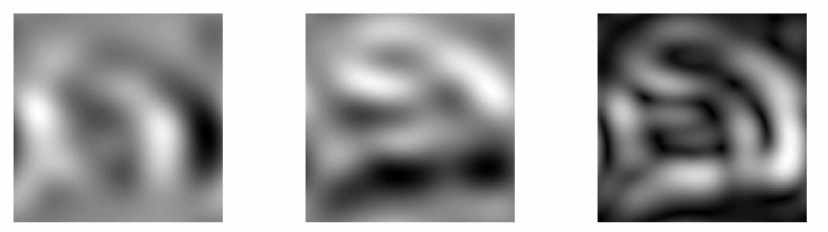

$$
i=5
$$
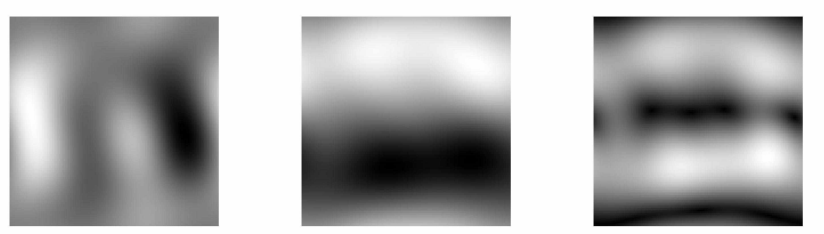

$$
i=6
$$

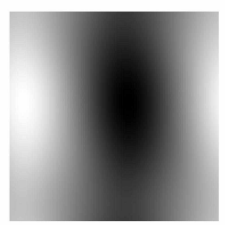

a)

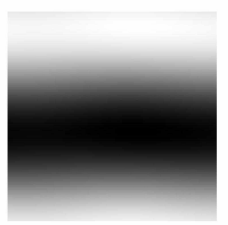

b)

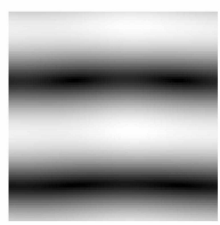

c)

Fig. 6.2 En el ángulo superior izquierdo aparece la imagen original $f(x, y)$, resolución $128 \times 128$ pixeles, $1 \leq j \leq 7$. a) $W_{2^{j}}^{1} f(x, y)$; b) $W_{2^{j}}^{2} f(x, y) ;$ c) $M_{2^{j}} f(x, y)$. 


\subsection{Detección poli-escalar de los bordes.}

Una vez calculado el módulo del gradiente en cada nivel de la descomposición diádica wavelet, se puede proceder a la búsqueda de los bordes. Con Canny [23], este procedimiento inicia con la supresión de no máximos y continúa con la umbralización por histéresis. En nuestro caso, por razones que quedarán claras más adelante, la etapa de umbralización se ha antepuesto a la etapa de supresión de no máximos.

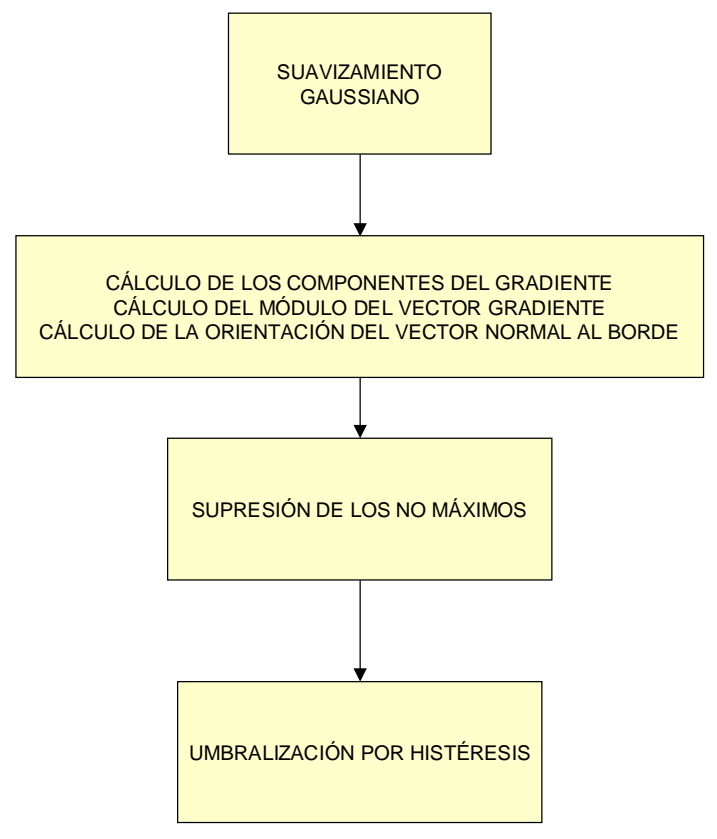

Fig. 6.3 Diagrama de flujo de las etapas principales del algoritmo de Canny.

Las etapas del algoritmo de Canny son las siguientes:

1. Aplicar un filtro Gaussiano de suavizamiento a una imagen de entrada $f(x, y)$ ayuda a reducir el ruido y, por lo tanto, la detección de falsos bordes provenientes del ruido de la imagen se eliminan. Cabe señalar en este punto que, en este trabajo, esta etapa se describe en el siguiente capítulo.

2. Para cada uno de los puntos de la imagen suavizada $J(x, y)$ :

a) Se calculan las componentes del gradiente $J_{x}$ y $J_{y}$. Esta parte ha sido realizada con el algoritmo de descomposición diádica wavelet. Estas componentes corresponden a $\left\{W_{J}^{1} f(x, y), W_{J}^{2} f(x, y)\right\}$ respectivamente. 
b) Se forma la imagen del módulo del vector gradiente $E_{s}(x, y)$ con cada uno de los puntos $e_{s}(x, y)=\sqrt{J_{x}^{2}(x, y)+J_{y}^{2}(x, y)}$. Esta imagen se ha formado con el cálculo de $M_{2^{j}} f(x, y)$ (ver Fig. 6.2).

c) Se forma la imagen de la orientación del vector normal al punto de borde $E_{o}(x, y)$ con cada uno de los puntos $e_{o}(x, y)=\operatorname{arctg} \frac{J_{y}}{J_{x}}$.

3. Etapa de supresión de los no máximos. El algoritmo discreto clásico de Canny considera 4 direcciones $d_{1}, d_{2}, d_{3}$ y $d_{4}$ identificadas con las orientaciones a $0^{\circ}, 45^{\circ}$, $90^{\circ}$ y $135^{\circ}$ (con respecto al eje horizontal). Entonces, para cada píxel $(x, y)$ :

a) Se encuentra la dirección $d_{k}$ que mejor se aproxima a la dirección $E_{o}(x, y)$ (la normal al eje)

b) Se declara una matriz de ceros $I(x, y)$ del tamaño de $f(x, y)$. Si $E_{s}(x, y)$ es más pequeña que al menos uno de sus dos vecinos a lo largo de $d_{k}$, entonces se deja $I(x, y)=0$ (supresión); en caso contrario, se asigna $I(x, y)=E_{s}(x, y)$.

En este trabajo, esta etapa no se lleva a cabo exactamente igual que Canny [23] o Mallat [18]. Se ha preferido utilizar la idea de David Young de la Universidad de Sussex [25] porque evita formar la imagen $E_{o}(x, y)$. En esta técnica, cada píxel de la imagen gradiente se hace igual a 0 (o al mínimo valor en la imagen) a menos que se trate de un máximo local a lo largo de la línea orientada en la dirección del gradiente. Los pixeles que quedan (iguales a 1 o al máximo valor en la imagen) son los pixeles de los picos sobre las "cordilleras" vistas en la imagen del gradiente. En este caso no se calculan explícitamente los puntos $e_{o}(x, y)$, sino que se estima la localización de dos puntos $M_{2^{j}} f\left(x_{1}, y_{1}\right)$ y $M_{2^{j}} f\left(x_{2}, y_{2}\right)$ muy cercanos a un punto candidato a ser parte de un borde $M_{2^{j}} f\left(x_{0}, y_{0}\right)$, todos ellos sobre la dirección de búsqueda del gradiente. $M_{2^{j}} f\left(x_{0}, y_{0}\right)$ se elige como punto de borde verdadero si su valor es mayor a $M_{2^{j}} f\left(x_{1}, y_{1}\right)$ y a $M_{2^{j}} f\left(x_{2}, y_{2}\right)$. He aquí cómo se implementa en este trabajo la idea de D. Young: 


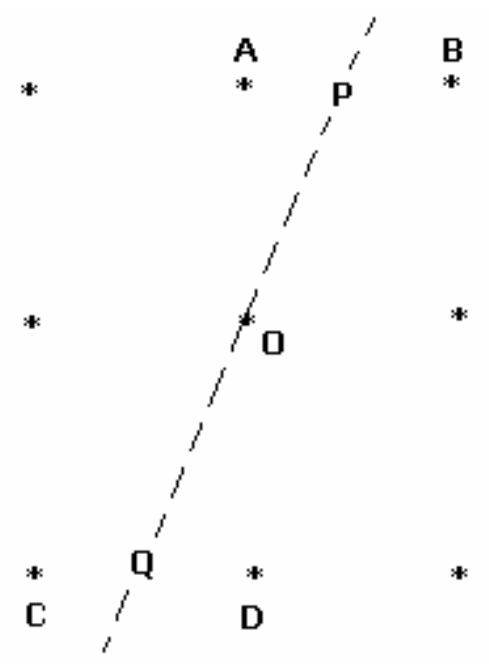

Fig. 6.4 La figura ilustra la manera de elegir el punto $\mathrm{O}$ como un punto de un borde verdadero.

Obsérvese la figura 6.4. O marca al píxel de interés $M_{2^{j}} f\left(x_{0}, y_{0}\right)$ y cada uno de los asteriscos * marca el centro de cada uno de sus 8 vecinos. Se localizan entonces los pixeles $\mathbf{A}, \mathbf{B}, \mathbf{C}$ y $\mathbf{D}$ que se encuentran cerca de la línea de dirección del gradiente. El gradiente en el punto $\mathbf{P}$ se estima mediante interpolación lineal entre $\mathbf{A}$ y $\mathbf{B}$ y el gradiente en el punto $\mathbf{Q}$ se interpola linealmente entre $\mathbf{C}$ y $\mathbf{D}$. $\mathbf{O}$ es un máximo local si su gradiente es mayor que los gradientes en $\mathbf{P}$ y $\mathbf{Q}$. La línea de dirección de búsqueda del gradiente se encuentra de la siguiente manera:

Recuérdese que la derivada direccional de $f$ en la dirección de un vector unitario $\stackrel{\dot{u}}{\text { es: }}$

$$
D_{u}(f)=\dot{\nabla} f \cdot \stackrel{r}{u}
$$

Esta es la razón de cambio de $f$ en la dirección de $\dot{u}$.

Recuérdese también que:

$$
\stackrel{r}{a} \cdot \vec{b}=\|\stackrel{r}{a}\| \dot{b} \| \cos \theta
$$

donde $\theta$ es el ángulo entre los vectores $\stackrel{a}{a}$ y $\dot{b}$.

Combinando (6.1) y (6.2), se tiene que:

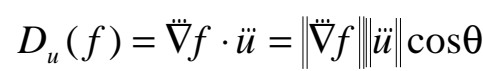

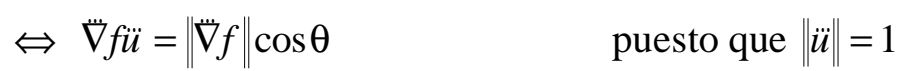




$$
\Rightarrow-1 \leq \frac{\dot{\nabla} f_{r} \cdot{ }^{r}}{\|\nabla f\|} \leq 1 \quad \text { puesto que }-1 \leq \cos \theta \leq 1
$$

Por lo tanto, la dirección del gradiente normalmente dada por $\theta$ medida a partir del eje horizontal, puede encontrarse calculando la cantidad $\frac{\grave{\nabla} f \cdot r}{\|\nabla f\|}$ para $\dot{u}$ como dirección horizontal o vertical.

Cada punto perteneciente a un borde (verdadero o no) se busca localmente. En esta parte del trabajo, se utiliza una matriz $\mathbf{Z}$ de $3 \times 3$ con $\operatorname{los} 8$ vecinos del punto $M_{2^{j}} f\left(x_{0}, y_{0}\right)$ que se visita para saber si es un punto de borde o no y se recorre esta matriz a lo largo de cada uno de los renglones de la imagen formada por $M_{2^{j}} f(x, y)$. Para la matriz $\mathbf{Z}$, las matrices con las orientaciones del gradiente en la dirección horizontal y la dirección vertical son:

Dirección horizontal: $\quad X=\left[\begin{array}{lll}-1 & 0 & 1 \\ -1 & 0 & 1 \\ -1 & 0 & 1\end{array}\right]$

Dirección vertical: $\quad Y=\left[\begin{array}{ccc}-1 & -1 & -1 \\ 0 & 0 & 0 \\ 1 & 1 & 1\end{array}\right]$

$M_{2^{j}} f\left(x_{1}, y_{1}\right)$ y $M_{2^{j}} f\left(x_{2}, y_{2}\right)$ son equidistantes con respecto a $M_{2^{j}} f\left(x_{0}, y_{0}\right)$ sobre la línea de la dirección del gradiente (como en el ejemplo de la figura 6.4). Esta línea (imaginaria) se traza localizando en $\mathbf{X}$ y $\mathbf{Y}$ los siguientes puntos de dirección:

$$
\left\{\begin{array}{l}
\frac{W_{J}^{1}\left[f\left(x_{1}, y_{1}\right)\right]}{M_{2^{j}} f\left(x_{1}, y_{1}\right)},-\frac{W_{J}^{1}\left[f\left(x_{1}, y_{1}\right)\right]}{M_{2^{j}} f\left(x_{1}, y_{1}\right)} \text { para } X \\
\frac{W_{J}^{2}\left[f\left(x_{1}, y_{1}\right)\right]}{M_{2^{j}} f\left(x_{1}, y_{1}\right)},-\frac{W_{J}^{2}\left[f\left(x_{1}, y_{1}\right)\right]}{M_{2^{j}} f\left(x_{1}, y_{1}\right)} \text { para } Y
\end{array}\right.
$$

Los dos puntos sobre la línea de dirección del gradiente local deben corresponder a dos valores de gradiente en la matriz $\mathbf{Z}$, los cuales se encuentran mediante interpolación. En este caso, la función MATLAB interp2 es de gran ayuda para realizar todo el procedimiento de búsqueda de la dirección del gradiente local y de los gradientes más próximos a $M_{2^{j}} f\left(x_{0}, y_{0}\right)$ sobre esta dirección. Se considera importante dejar claramente explicada la fase del algoritmo que resuelve la búsqueda de bordes mediante 
la supresión de no máximos modificada en la manera que se ha explicado. En este sentido se analiza enseguida las líneas del programa MATLAB correspondiente:

Se calcula el módulo del gradiente en cada nivel de descomposición como se explica en el $\S 6.2$.

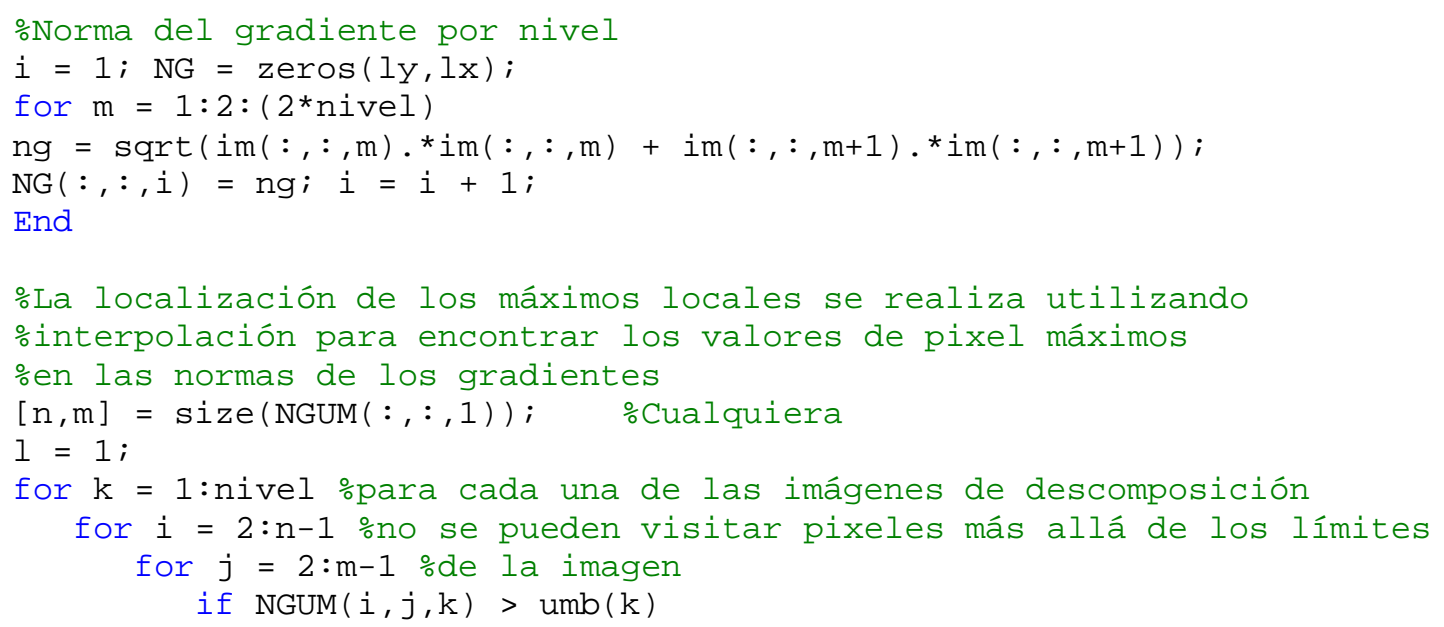

Las matrices de dirección

$$
\begin{aligned}
& X=[-1,0,+1 ;-1,0,+1 ;-1,0,+1] ; \\
& Y=[-1,-1,-1 ; 0,0,0 ;+1,+1,+1] ;
\end{aligned}
$$

La matriz local con los valores de los módulos del gradiente

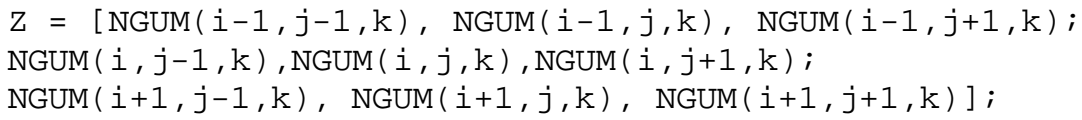

Cálculo de la dirección del gradiente en la dirección horizontal

$$
X I=[i m(i, j, l) / N G(i, j, k),-i m(i, j, l) / N G(i, j, k)] \text {; }
$$

Cálculo de la dirección del gradiente en la dirección vertical

$$
Y I=[i m(i, j, l+1) / N G(i, j, k),-i m(i, j, l+1) / N G(i, j, k)] ;
$$

Se ordena la interpolación de los valores de los gradientes más cercanos a NGUM $(i, j)$ según su misma dirección. interp2 busca los valores de XI y YI en X y y y calcula por interpolación lineal los valores correspondientes en z y los retorna en $\mathrm{zI}$.

$$
\mathrm{ZI}=\text { interp2 }(\mathrm{X}, \mathrm{Y}, \mathrm{Z}, \mathrm{XI}, \mathrm{YI}) \text {; }
$$


Si el valor del gradiente visitado $\operatorname{NGUM}(i, j, k)$, en la imagen de descomposición $k$, es mayor a sus gradientes vecinos interpolados y localizados sobre su línea de dirección, entonces se trata de un máximo local. Se forma una nueva imagen $B(i, j, k)$ con el valor máximo del nivel de gris $L \max (\mathrm{k})$ correspondiente al máximo local encontrado y que sin duda pertenece a un borde.

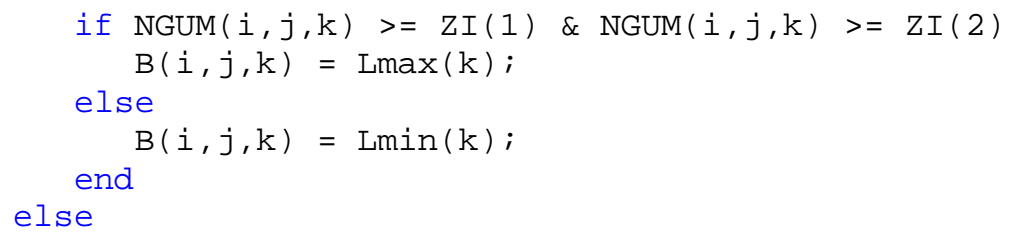

Los puntos que no pertenecen a un borde se hacen iguales al valor mínimo de la imagen $\mathrm{k}$ del gradiente

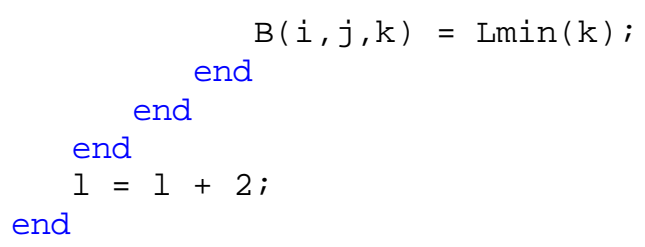

4. Umbralización por histéresis. Según Canny, se definen dos umbrales $\tau_{1}$ y $\tau_{2}$ tales que $\tau_{1}<\tau_{2}$ y para cada uno de los pixeles de la imagen $I$, formada después de la supresión de no máximos, visitados en un orden determinado:

a) Se localiza el siguiente píxel de borde no visitado tal que $I(x, y)>\tau_{2}$

b) Comenzando con $I(x, y)$ se siguen las cadenas de máximos locales conectados, en las dos direcciones perpendiculares a la normal del borde hasta que $I(x, y)>\tau_{1}$. Se marcan todos los puntos visitados y se guarda una lista de las ubicaciones de todos los puntos en el contorno conectado que se ha encontrado.

Esta etapa reduce a un contorno del ancho de un píxel el contorno de máximos locales encontrados en la etapa anterior. Sin embargo, es claro que la umbralización puede preceder a la supresión de no máximos y la posterior supresión puede formar contornos del ancho de un píxel. En este trabajo, se modifica la imagen $M_{2^{j}} f(x, y)$ de manera que los niveles de gris de ella se muestren a partir de un umbral que se elige sumando al valor del gradiente mínimo, en esa imagen, un porcentaje de la distancia entre el umbral mínimo y el máximo, es decir, se "recortan las faldas de las cordilleras" de los modulo máxima. Este porcentaje se fija según los criterios de la sección 6.3. Durante la supresión de no máximos "las cordilleras se adelgazan" hasta el ancho de un píxel. El código MATLAB correspondiente a la umbralización es el siguiente: 
oLímite a la localización de los máximos locales

alfa es el parámetro de control del umbral.

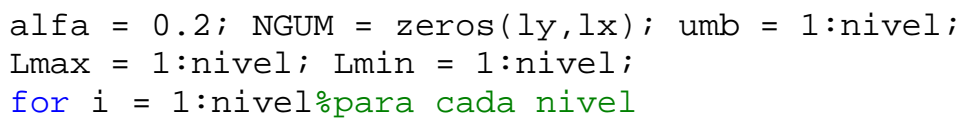

Extracción del valor máximo y el valor mínimo de las normas del gradiente en cada imagen de descomposición

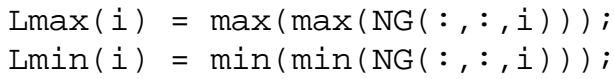

Control del umbral

$\operatorname{umb}(i)=\operatorname{alfa}(\operatorname{Lmax}(i)-\operatorname{Lmin}(i))+\operatorname{Lmin}(i)$;

Se guardan únicamente los gradientes máximos antes y después de la umbralización

$\operatorname{NGUM}(:,:, i)=\max (\operatorname{NG}(:,:, i), \operatorname{umb}(i) . * \operatorname{ones}(\operatorname{size}(\operatorname{NG}(:,:, i))))$; end

La supresión de no máximos se lleva posteriormente a cabo siempre y cuando:

if $\operatorname{NGUM}(i, j, k)>\operatorname{umb}(k)$

Es claro que la función MATLAB:

$$
\text { edge(I,'canny') }
$$

no fue utilizada para la búsqueda de bordes porque no ofrecía la flexibilidad de elegir el umbral a partir del cual se podía considerar un valor del módulo del gradiente como parte de un borde y además se debían incluir ciclos "for" para el manejo de las diferentes imágenes de descomposición. Por otro lado, la codificación diseñada para la parte de supresión de los no máximos es más simple que la que ofrece esta instrucción. Además, la instrucción sigue bien el procedimiento de la figura 6.3 que inicia con el preprocesamiento de la imagen con el filtro Gaussiano, pre-procesamiento cambiado en este trabajo por la descomposición wavelet diádica.

La figura 6.5 ilustra los resultados de la búsqueda de bordes en la ecocardiografía de una válvula aórtica de $128 \times 128$ pixeles ( 7 niveles de descomposición) con el algoritmo de Canny modificado según la descripción precedente. 

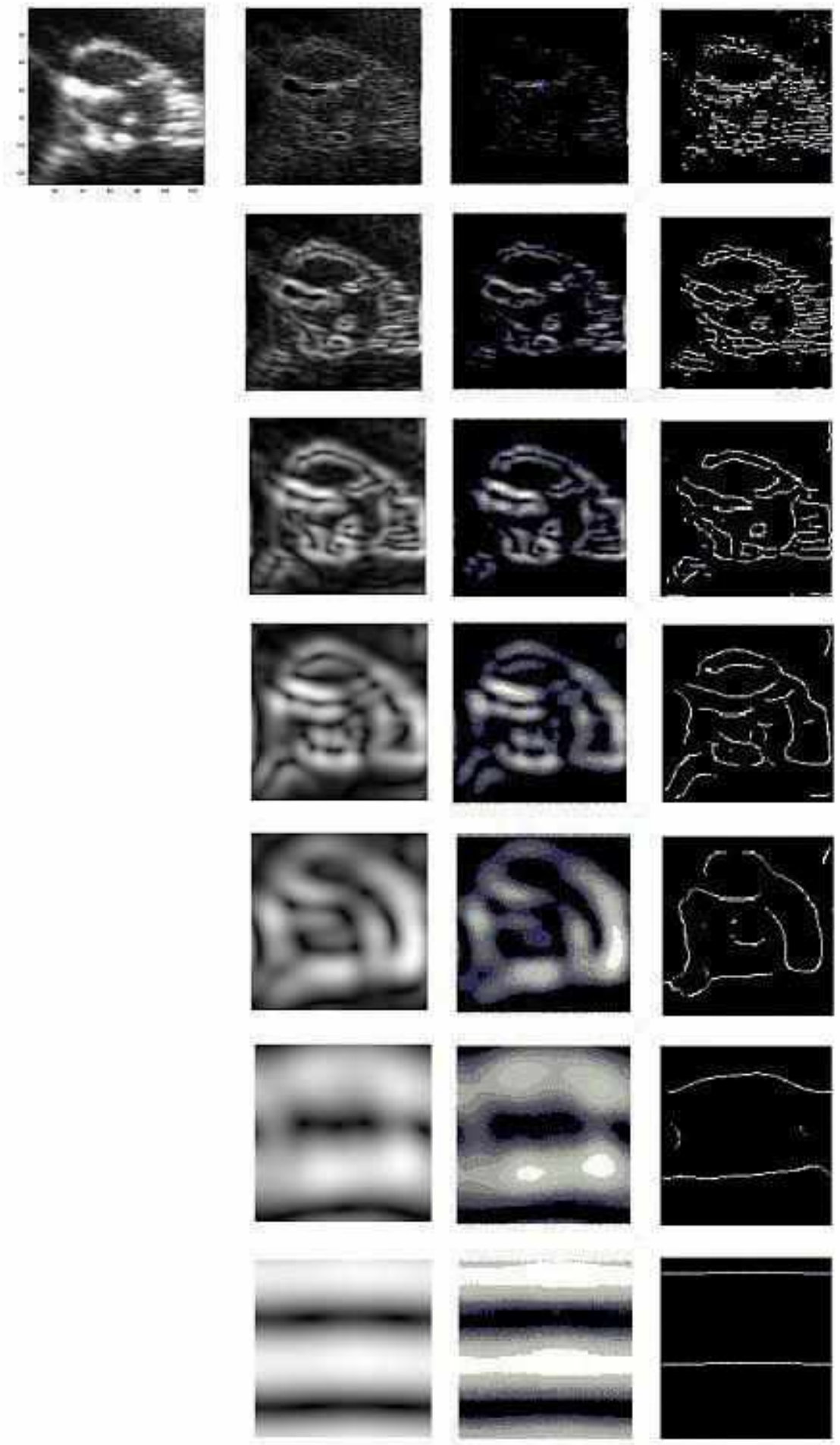

a)

b)

c)

Fig. 6.5 En el ángulo superior izquierdo, la imagen original $\mathrm{N}=128 \times 128$, a) $M_{2^{j}} f(x, y)_{1 \leq j \leq 7}$, b) supresión de los no máximos $I(x, y)$, c) Modulus maxima para alfa $=0.2$. 


\subsection{Discusión.}

Las imágenes de los modulus maxima, es decir, del mapa de bordes en cada nivel de descomposición wavelet, son el resultado de aplicar la supresión de no máximos según Canny y el cálculo, por interpolación lineal, de la ubicación de la norma del gradiente perteneciente a un borde "verdadero" en la dirección del gradiente, hasta lograr "cadenas" de valores modulus maxima del ancho de un píxel.

Ahora bien, como se anticipaba, la forma de las grandes estructuras en la ecocardiografía depende del nivel de descomposición y, tal como se revela en este caso, la forma del anillo anatómico de la válvula aórtica aparece definida para el nivel $j=3$. Recuérdese de la sección 6.1 que interesa buscar bordes a la manera de Mallat para poder tener un mapa de bordes de grandes estructuras, como es el caso del anillo anatómico de la válvula aórtica. Estos bordes se distinguen en un nivel de descomposición wavelet específico. Esta es la diferencia más importante entre la búsqueda de bordes según Mallat y el algoritmo de Canny. A propósito se ha elegido la ecocardiografía transtorácica de un corte paraesternal de eje corto que muestra un anillo anatómico bien definido y las cadenas de modulus maxima correspondientes forman arcos de elipse que podrían ser tratados con algún algoritmo de reconstrucción de formas (por ejemplo, mediante el empleo de la transformada Hough). La figura 6.6 combina la imagen modulus maxima en el nivel 3 con la imagen original para comprobar la definición de los bordes.

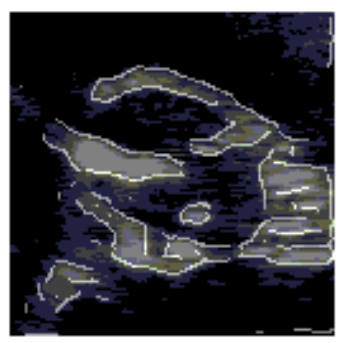

Fig 6.6 Imagen modulus maxima en el tercer nivel de descomposición wavelet sobrepuesta a la ecocardiografía original.

Este resultado en particular hizo pensar en la posibilidad de estimar automáticamente el área del anillo anatómico una vez reconstruido su contorno interno. Como se discutirá en el Capítulo 9, en la mayoría de las ecocardiografías del eje corto, no se lograron contornos tan bien definidos una vez sintetizada la imagen modulus maxima de tercer nivel.

El tiempo para sintetizar las imágenes modulus maxima en los 7 niveles de descomposición diádica wavelet correspondiente a una ecocardiografía de $128 \times 128$ pixeles depende, lógicamente, del valor alfa del parámetro de control de la umbralización en la etapa de supresión de no máximos. La tabla 6.1 muestra el tiempo de procesamiento de 7 niveles para algunos valores de alfa. Las imágenes se han procesado en una máquina PENTIUM III a $550 \mathrm{MHz}$. 


\begin{tabular}{|c|c|}
\hline alfa & T(s) \\
\hline 0.1 & 351 \\
\hline 0.2 & 267 \\
\hline 0.3 & 218 \\
\hline 0.4 & 184 \\
\hline 0.5 & 150 \\
\hline
\end{tabular}

Tabla 6.1 T es el tiempo en segundos que el programa MATLAB tarda en sintetizar las imágenes de borde hasta el nivel 7 para los valores de alfa mostrados.

Para completar la discusión, se presenta a continuación algunos ejemplos de la búsqueda de bordes para distintos valores del umbral alfa. Los experimentos que se llevaron a cabo variando este parámetro, demostraron que con valores pequeños de alfa, se obtenían bordes que no contribuyen a la forma del anillo anatómico y se aumenta el tiempo de procesamiento, mientras que con valores grandes de alfa, el tiempo de procesamiento se reduce pero los bordes de las formas interesantes se pierden.

Como únicamente se requeriría la imagen de tercer nivel, se ha hecho una evaluación para fijar un nivel de alfa óptimo donde la cantidad de pixeles en el mapa de bordes defina suficientemente al anillo anatómico de la válvula aórtica y no comprometan el tiempo de ejecución. Los resultados se muestran en la Tabla 6.2.

\begin{tabular}{|c|c|c|}
\hline alfa & $\mathbf{T}(\mathbf{s})$ & \# pixeles imagen bordes con $\mathbf{j}=\mathbf{3}$ \\
\hline 0.02 & 174 & 1637 \\
\hline 0.04 & 135 & 1529 \\
\hline 0.06 & 119 & 1398 \\
\hline 0.08 & 100 & 1286 \\
\hline 0.1 & 87 & 1199 \\
\hline 0.2 & 54 & 928 \\
\hline 0.3 & 35 & 759 \\
\hline 0.4 & 24 & 596 \\
\hline 0.5 & 18 & 393 \\
\hline
\end{tabular}

Tabla 6.2 Tiempo de procesamiento y cantidad de pixeles correspondientes a la imagen de bordes de tercer nivel.

La figura 6.7 muestra la función $T=f($ alfa $)$, pero es más importante la figura 6.8 , pues muestra que la cantidad de pixeles en la imagen de bordes de tercer nivel se degrada aproximadamente a una razón constante a partir de alfa $=0.2$. Abajo de este nivel, la cantidad de bordes es redundante para definir el contorno del anillo anatómico, pero esto sólo se aprecia en las imágenes correspondientes. La figura 6.9 muestra ejemplos de estas observaciones. 


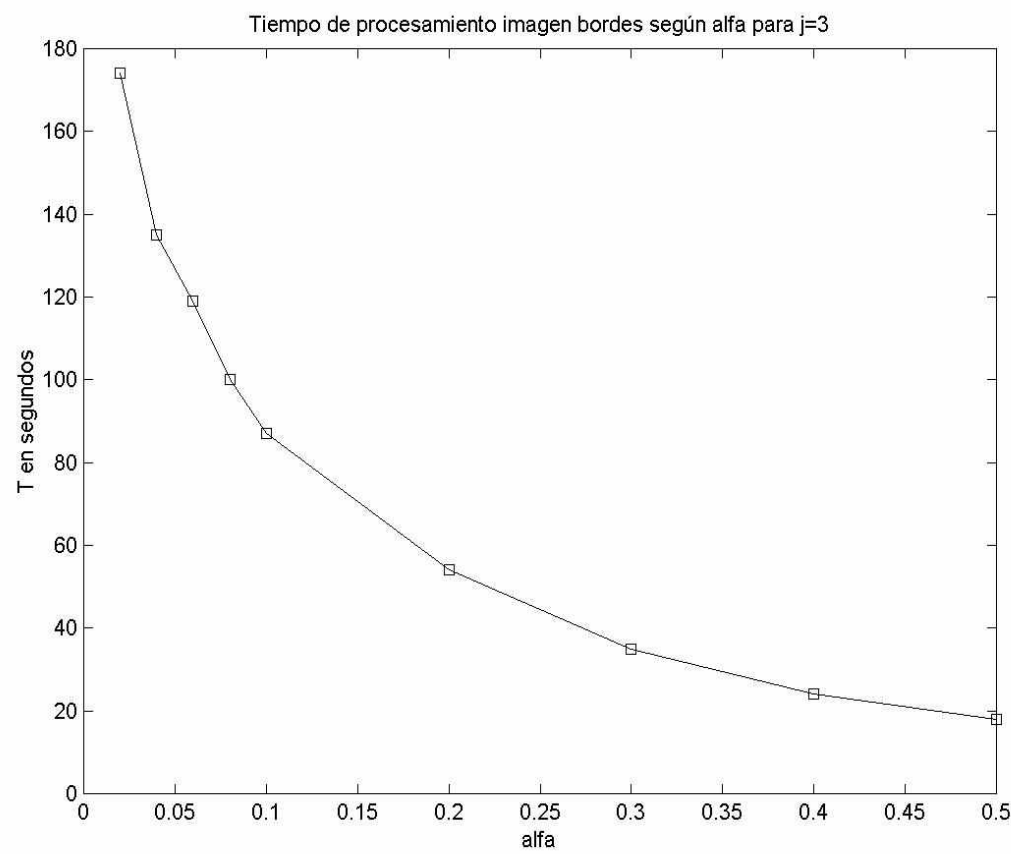

Fig. 6.7 Tiempo de procesamiento para el nivel 3 de la imagen de bordes según el parámetro alfa.

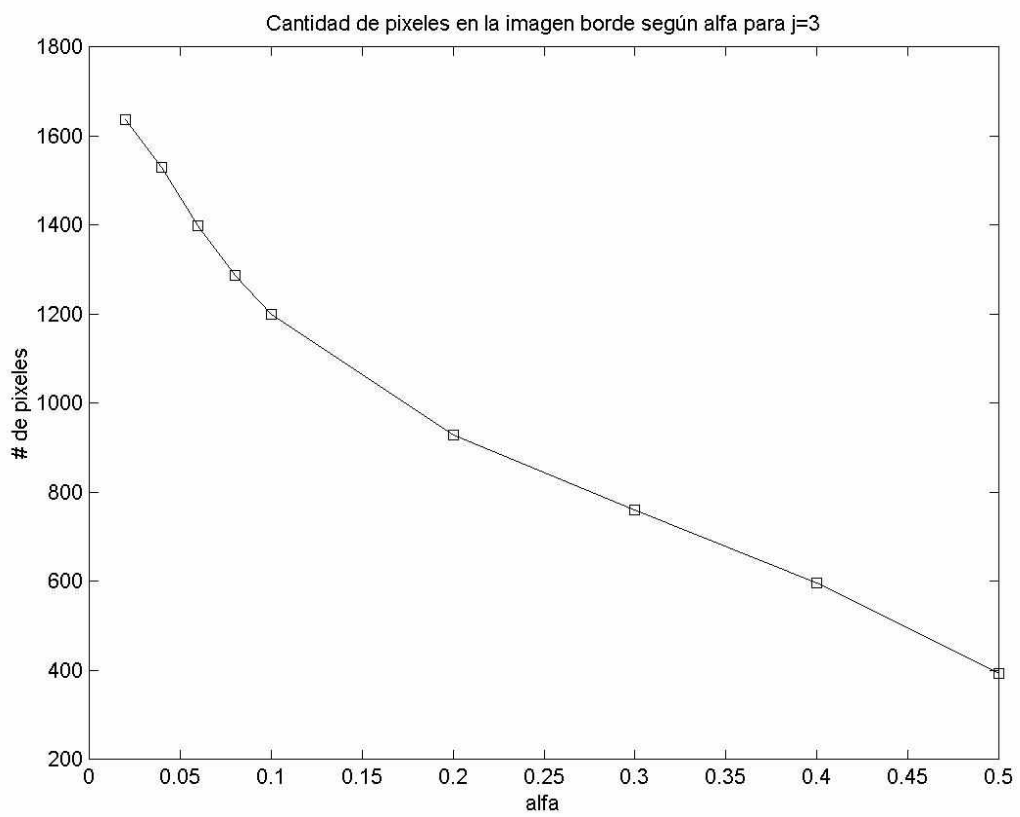

Fig. 6.8 Cantidad de pixeles en la imagen de bordes de tercer nivel según el parámetro alfa. 


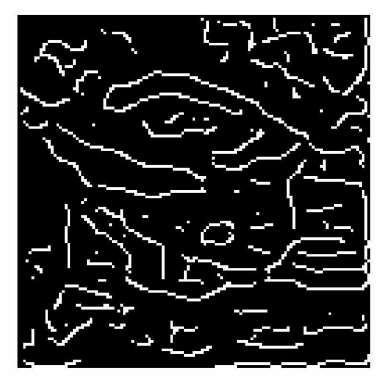

a)

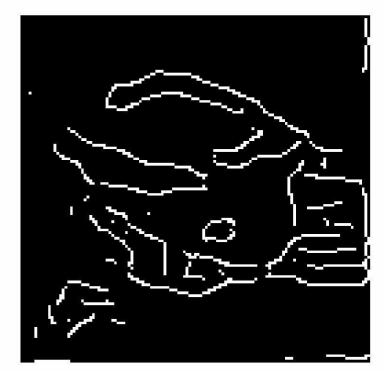

b)

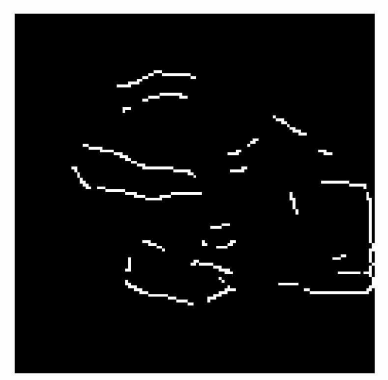

c)

Fig. 6.5 Mapa de bordes en el nivel 3 para: a) alfa $=0.02$, b) alfa $=0.2$ y c) alfa $=0.5$.

Por lo tanto, se fijó el valor de alfa en 0.2. El tiempo de procesamiento es razonable: menos de 1 minuto considerando que el procesamiento se realizaría en computadora en el gabinete del médico sonografista.

Como se explicó en la sección 6.3, la etapa inicial de reducción de ruido necesaria para evitar de generar bordes falsos, no se llevó a cabo con el filtro Gaussiano como lo hace Canny. Se verá en el Capítulo 7 que este pre-procesamiento de la imagen es naturalmente realizado con el proceso de eliminación de ruido de D. Donoho. 


\section{REDUCCIÓN DEL RUIDO EN LAS ECOCARDIOGRAFÍAS DE LA VÁLVULA AÓRTICA}

\subsection{Introducción.}

En el Capítulo 6 se justificó la necesidad de reducir el ruido en una ecocardiografía dispuesta para la búsqueda de bordes, a la manera del preprocesamiento propuesto por el algoritmo de Canny. En este trabajo, se encontró que la reducción del ruido se podía llevar a cabo de manera natural con la técnica de reducción de ruido mediante umbralización suave propuesta por David L. Donoho [26].

\subsection{Modelo para la supresión del ruido.}

En vista de que el patrón de ruido granular en ultrasonido es producido por interferencia coherente relacionada con la superficie rugosa del objeto [20], que es el caso de la textura tisular del corazón, es difícil establecer un modelo para el ruido granular ${ }^{1}$. Por otro lado, recuérdese que este modelo será utilizado al interior de un análisis diádico poli-escalar que busca una cierta característica de las imágenes ecocardiográficas. El análisis diádico junto con la técnica de supresión del ruido no deben entrar en conflicto, esto es, se debe de poder reducir el ruido sin afectar características importantes de la imagen. Los intentos en el dominio del espacio o en el dominio de Fourier de llevar a cabo simultáneamente la supresión de ruido y la conservación de características se resuelven ineficazmente para un solo conjunto de datos:

a) En el dominio de Fourier, el ruido se suprime normalmente con alguna clase de filtro pasa-bajas, pero a costa de esfumarr características importantes.

b) Conservar o mejorar características de una imagen tales como los bordes o la textura, se llevan a cabo en este mismo dominio con alguna clase de filtro pasaaltas con el riesgo consecuente de amplificar el ruido.

c) Se podría pensar en una solución intermedia donde se utilice un filtro pasa-banda, pero entonces la capacidad de suprimir ruido y conservar características se verían limitadas, sobre todo en el tipo de imágenes con las que se trabaja aquí.

Es por estas razones que se ha adoptado la representación poli-escalar de Mallat y Zhong [21] pues ha probado ser un buen método para separar ruido y características de manera eficaz, simultánea y localmente [20].

\footnotetext{
${ }^{1}$ El término en inglés es "speckle noise". En español también se acepta el término "ruido de moteado".
} 
En este trabajo se utiliza el modelo general de A. K. Jain, utilizado también en [20], para el ruido granular y formulado como:

$$
f(x, y)=g(x, y) \eta_{u}(x, y)+\eta_{a}(x, y)
$$

donde:

$g(x, y) \quad$ es una función 2D desconocida (por ejemplo, la imagen original libre de ruido que se quiere recuperar),

$f(x, y) \quad$ es una observación con ruido de $g(x, y)$,

$\eta_{u}(x, y)$ es el ruido multiplicativo producido por la interferencia coherente,

$\eta_{a}(x, y)$ es el ruido aditivo producido por el transductor ultrasónico [20 bis] y

$(x, y) \in \mathfrak{R}$ son las coordenadas espaciales.

Para el caso de las ecocardiografías, el efecto del ruido aditivo es mucho menor al efecto del ruido multiplicativo, de manera que [20 bis]:

$$
\left\|\eta_{a}(x, y)\right\|^{2}<<\left\|g(x, y) \eta_{u}(x, y)\right\|^{2}
$$

Por lo tanto, podemos expresar a $f(x, y)$ como:

$$
f(x, y)=g(x, y) \eta_{u}(x, y)
$$

El homomorfismo que transforma la multiplicación en suma es la función logaritmo:

$$
\ln \{f(x, y)\}=\ln \{g(x, y)\}+\ln \left\{\eta_{u}(x, y)\right\}
$$

Este es el resultado importante a partir del cual se puede hacer la reducción del ruido, pues ahora la componente multiplicativa de éste aparece como una componente aditiva que puede aproximarse como ruido blanco. Zong et al. [20] aplican propiedades de las transformaciones lineales a la versión discreta de la ecuación (7.1) para llegar a las siguientes expresiones:

$$
\begin{aligned}
& \mathrm{W}\{\ln f[m, n]\}=\left\{\left(W_{j}^{d}\{\ln f[m, n]\}\right)_{d=1,2,1 \leq j \leq J}, S_{J}\{\ln f[m, n]\}\right\} \\
& W\{\ln g[m, n]\}=\left\{\left(W_{j}^{d}\{\ln g[m, n]\}\right)_{d=1,2,1 \leq j \leq J}, S_{J}\{\ln g[m, n]\}\right\} \\
& W\left\{\ln \eta_{u}[m, n]\right\}=\left\{\left(W_{j}^{d}\left\{\ln \eta_{u}[m, n]\right\}\right)_{d=1,2,1 \leq j \leq J}, S_{J}\left\{\ln \eta_{u}[m, n]\right\}\right\}
\end{aligned}
$$

donde $W\{\quad$ es el operador de la TDWD [21]. 
Se aprovecha aquí el hecho de que el ruido en las ecocardiografías se encuentra en la banda de altas frecuencias, por lo tanto el ruido se verá muy reducido después de un número finito de suavizamientos $\left\{S_{J}\left\{\ln \eta_{u}[m, n]\right\}\right\} \rightarrow 0$. Zong [20] reporta que después de 5 descomposiciones wavelet es posible lograr una reducción de ruido aceptable en el procesamiento de ecocardiografías. Para sintetizar un mapa de bordes confiable, como se explica en el capítulo 6, será necesario recuperar $W\{\ln g[m, n]\}$ a partir de $W\{\ln f[m, n]\}$ y reducir $W\left\{\ln \eta_{u}[m, n]\right\}$ en el dominio wavelet. $g[m, n]$ o su aproximación podrá ser recuperada aplicando finalmente la DWT inversa e invirtiendo el logaritmo neperiano.

\subsection{Técnica de supresión del ruido.}

Johnstone y Donoho desarrollaron una técnica para reducir el número de coeficientes wavelet (wavelet shrinkage) necesarios para una reconstrucción perfecta de una señal de entrada. De esta manera, sólo se necesitan unos cuantos coeficientes wavelet para recuperar una señal. La técnica de reducción se le conoce con el nombre de umbralización (thresholding) y existe bajo dos modalidades: umbralización fuerte (hard thresholding) y umbralización suave (soft thresholding). La definición de las técnicas se puede consultar en [19], p.387. Resulta claro que el proceso de umbralización puede utilizarse para reducir el ruido de una señal al suprimir los coeficientes wavelet que lo representan. En general, cuando las características interesantes de una señal en el dominio wavelet se pueden distinguir claramente del ruido, se prefiere utilizar la reducción de coeficientes wavelet mediante la umbralización fuerte. Cuando ocurre el caso contrario, es preferible utilizar la umbralización suave. Justamente, en este trabajo nos interesa "suavizar" la imagen ecocardiográfica para evitar encontrar bordes "falsos" producidos por variaciones pronunciadas de los coeficientes wavelets debidas al ruido de alta frecuencia y reducir el tiempo de búsqueda de bordes que no pertenezcan a grandes estructuras como en el caso del anillo anatómico de la válvula aórtica o el anillo aórtico.

\subsubsection{Umbralización suave.}

Se incluye la definición de la umbralización suave que se utiliza en este trabajo para cumplir con la integridad del mismo.

La umbralización suave es un operador no lineal [26] que puede describirse de la siguiente manera:

$$
u(\stackrel{r}{x})=\mathrm{T}_{s}(v(\stackrel{r}{x}), t)=\operatorname{sign}(v(\stackrel{r}{x}))(|v(\stackrel{r}{x})|-t)_{+}
$$

donde el parámetro de umbralización $t$ es proporcional al nivel de ruido $\sigma$ y $\dot{x}$ tiene el mismo dominio que $u(x) \cdot u\left(\begin{array}{l}x \\ x\end{array}\right)$ es el resultado de la umbralización suave y tiene el mismo signo que $v(\dot{x})$ si no es cero. La expresión $(|v(x)|-t)_{+}$, se define como: 


$$
(|v(\stackrel{r}{x})|-t)_{+}= \begin{cases}|v(\stackrel{r}{x})|-t & \text { si }|v(\stackrel{r}{x})|>t \\ 0 & \text { de otra manera }\end{cases}
$$

La función $\operatorname{sign}(v)$ se define como:

$$
\operatorname{sign}(v)=\left\{\begin{array}{lll}
1 & \text { si } & v>0 \\
-1 & \text { si } & v<0 \\
0 & \text { de } & \text { otra manera }
\end{array}\right.
$$

\subsubsection{Criterio para la eliminación de los coeficientes DWT que representan al ruido.}

Los coeficientes wavelet, modificados por la umbralización suave que reduce el ruido granular, quedarían expresados como:

$$
W_{j, b a j o_{-} \text {ruido }}^{d}=\mathrm{T}_{s}\left(W_{j}^{d} f(m, n), t_{j}^{d}\right)
$$

con: $\quad d=1,2$ (dirección horizontal o vertical), $1 \leq j \leq J . t_{j}^{d}$ es un umbral relacionado con el nivel de ruido, la orientación y la escala. Zong [20] notó que los coeficientes wavelet que con más probabilidad representan al ruido, se localizan en los niveles de descomposición 1, 2, 3 y 4 y forman una distribución densa que decae conforme aumenta el valor del coeficiente wavelet en estos niveles y en las direcciones vertical y horizontal. (ver figura 7.1). El conocer la distribución de la energía de estos coeficientes de acuerdo a su magnitud permite estimar un valor para $t_{j}^{d}$. Zong [20] regula la umbralización suave aplicando un coeficiente que depende de los umbrales donde la concentración de energía se hace mínima. El umbral es máximo para $\mathrm{j}=1$ y mínimo para $\mathrm{j}=\mathrm{J}=7$ y él propone una relación lineal entre J y el umbral. Se ha querido comprobar la observación de Zong con la ayuda de la figura 7.1, la cual muestra los niveles de energía encontrados en una ecocardigrafía típica perteneciente a esta investigación y adquirida en el Departamento de Ecocardiografía del Instituto Nacional de Cardiología "Ignacio Chávez" con la técnica descrita en el capítulo 2. 

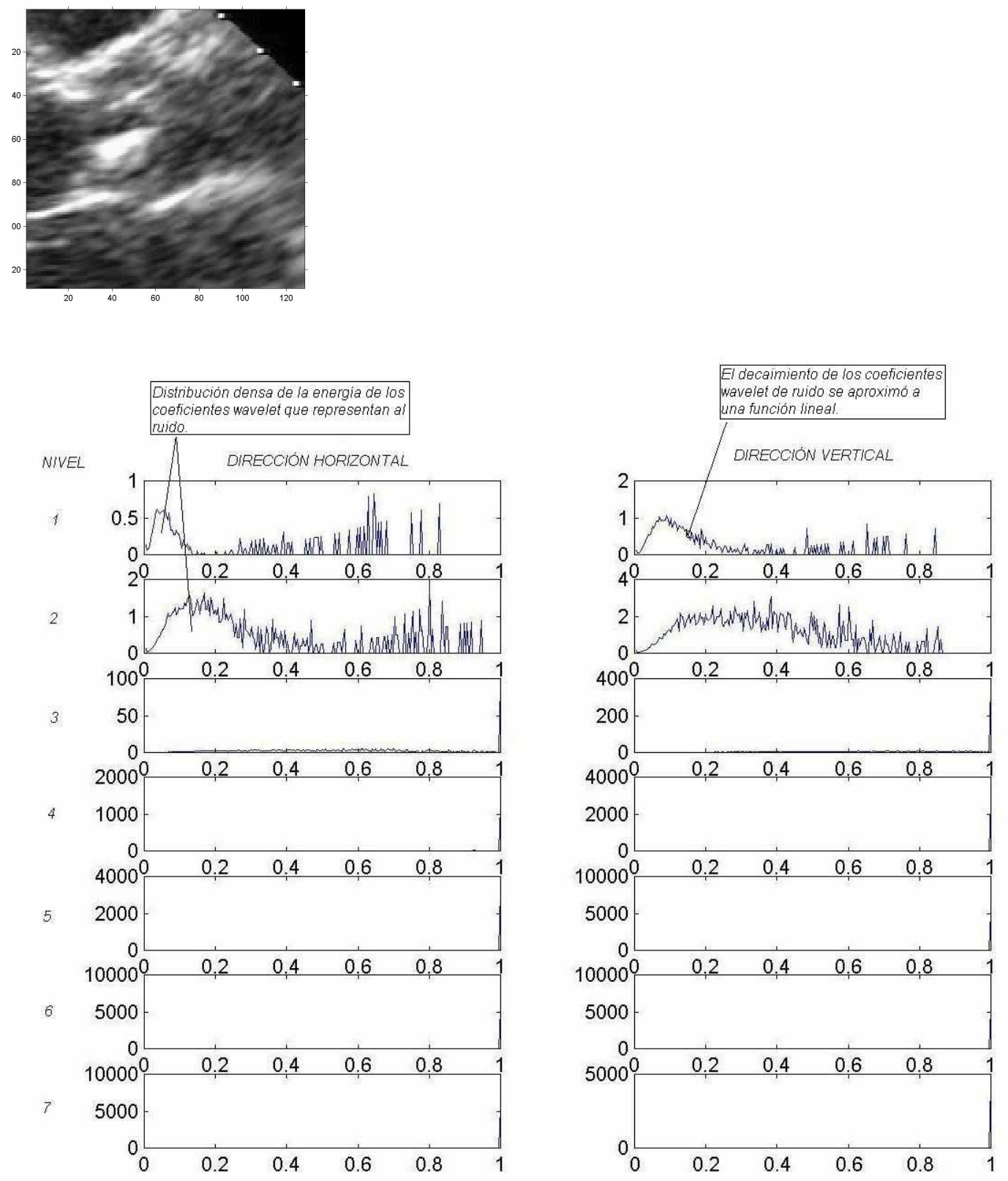

Fig. 7.1 Niveles de energía de los coeficientes wavelet de una ecocardiografía del corte paraesternal de eje largo de 128x128 pixeles en cada uno de sus 7 niveles de descomposición y en cada orientación.

La fig. 7.1 muestra las gráficas de los niveles de energía contra la magnitud de los coeficientes wavelet normalizados en el intervalo [0,1] en todos los niveles de descomposición $(J=7)$ de una ecocardiografía transtorácica de eje largo paraesternal, tanto en la dirección horizontal como en la dirección vertical. 
Las gráficas de la energía se formaron a partir del conteo del número de coeficientes wavelet de la misma magnitud, gracias a la generación de sendos histogramas, y calculando la energía del conjunto de coeficientes para esa magnitud con la siguiente fórmula:

$$
\mathrm{E}_{W}=\sum_{i=1}^{k}\left[W_{j}^{d} f(m, n)\right]^{2}
$$

donde $k$ representa el número de coeficientes wavelet de la misma magnitud. La energía así calculada se ha dejado indicada como una magnitud. En esta figura, se puede notar que las regiones de densidad de energía que representan al ruido, se presentan en los niveles 1 y 2 mientras que en los niveles superiores esta concentración desaparece. A diferencia de Zong, el valor del umbral donde decae la densidad de energía es mayor en el nivel 2 que en el nivel 1 y las regiones de densidad de energía sólo aparecen en estos 2 niveles. Por lo tanto, el coeficiente que regula la umbralización suave se calcula únicamente en función de los niveles 1 y 2 y con los umbrales observados en las ecocardiografías de este trabajo. El ruido puede minimizarse si se reducen o eliminan los coeficientes wavelet que dan origen a las regiones de densidad de energía, pero se necesita obtener el valor de umbral $t_{j}^{d}$.

Recuérdese que $t_{j}^{d}=f\left(\sigma_{j}^{d}\right)$ pero en este trabajo se ve la necesidad de hacerlo depender también del umbral donde la concentración de energía decae completamente porque este umbral no es el mismo en cada nivel de descomposición y sólo se quiere eliminar los coeficientes wavelet que representan al ruido con el procedimiento de la umbralización suave. Sea $U$ la designación para estos umbrales. Se propone entonces la siguiente función para estimar el valor de $t_{j}^{d}$ :

$$
t_{j}^{d}=U \sigma_{j}^{d}
$$

donde:

$$
\begin{aligned}
& U=\alpha(j-1)+U_{\text {min }} \\
& \alpha=\frac{U_{\text {MAX }}-U_{\text {min }}}{(j=2)-(j=1)}
\end{aligned}
$$

cantidades que surgen de las observaciones en el párrafo anterior y la figura 7.2 de abajo.

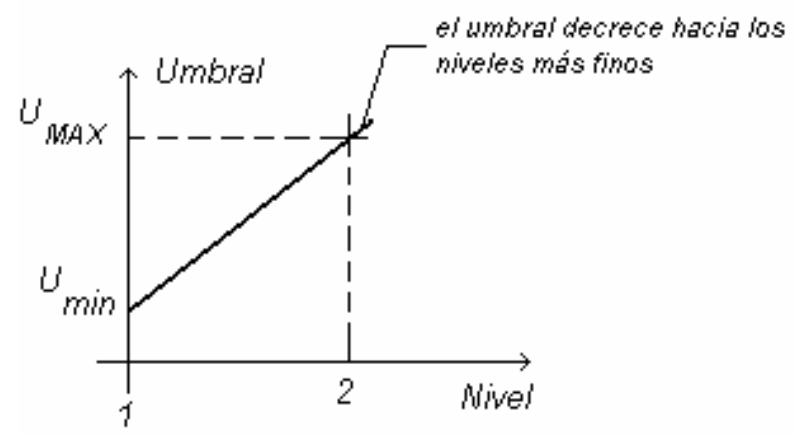

Fig. 7.2 Función de escalamiento para el cálculo de los umbrales $t_{j}^{d}$. 
La elección de $U_{M A X}$, umbral por debajo del cual se debe reducir o eliminar la energía del ruido o los coeficientes wavelet que lo representan, se hizo empíricamente, observando las energías en los niveles 1 y 2 de varias ecocardiografías del estudio. El mismo criterio se aplicó para la elección de $U_{\min }$. En la figura 7.3 se muestran cinco ejemplos de las ecocardiografías utilizadas en este estudio y los niveles de energía correspondientes a los dos primeros niveles de descomposición DWT.
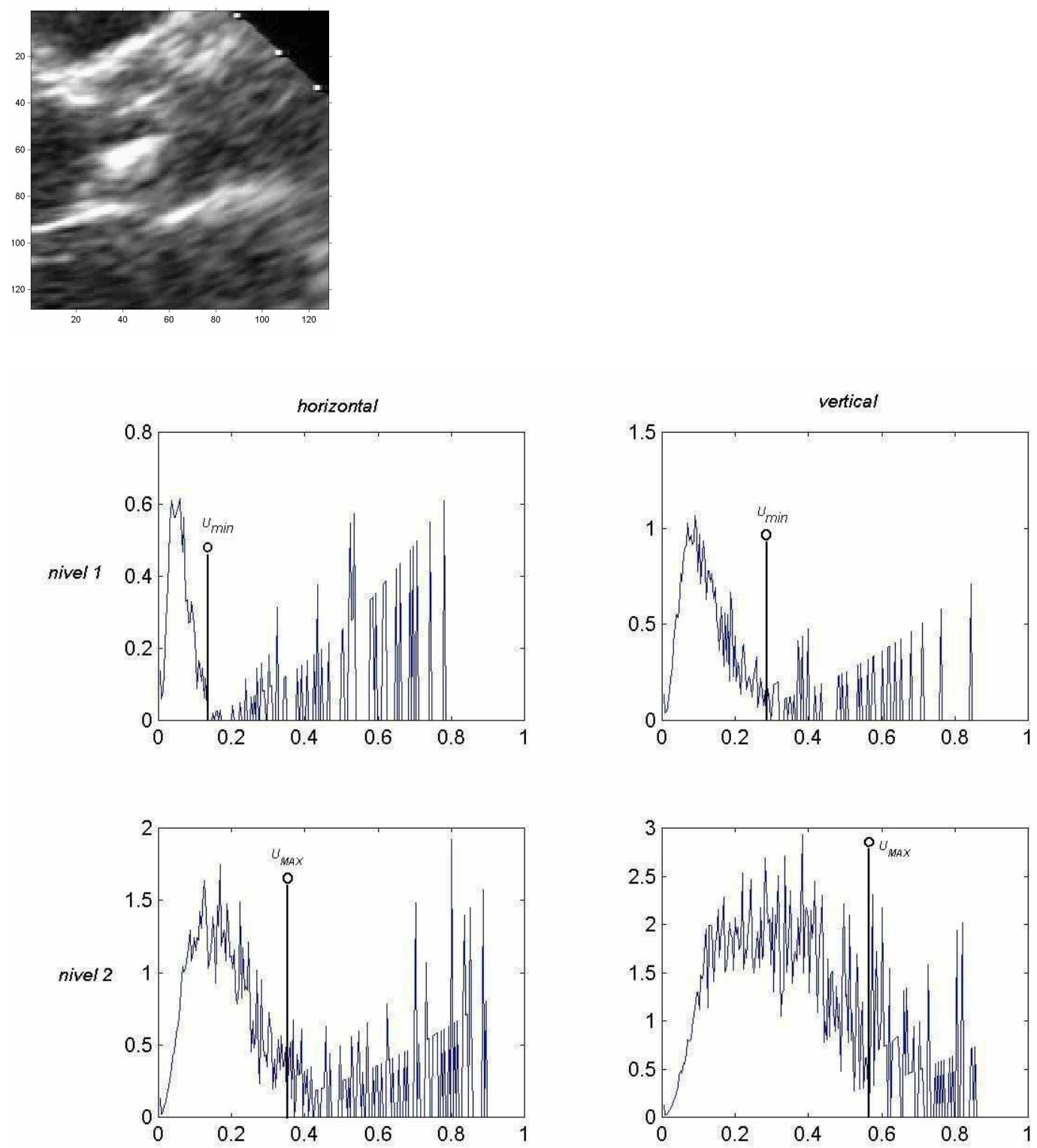

Fig. 7.3 (a) Energía de $W_{j}^{d}\{f[m, n]\}_{j=d=1,2}$ de algunas ecocardiografías. 

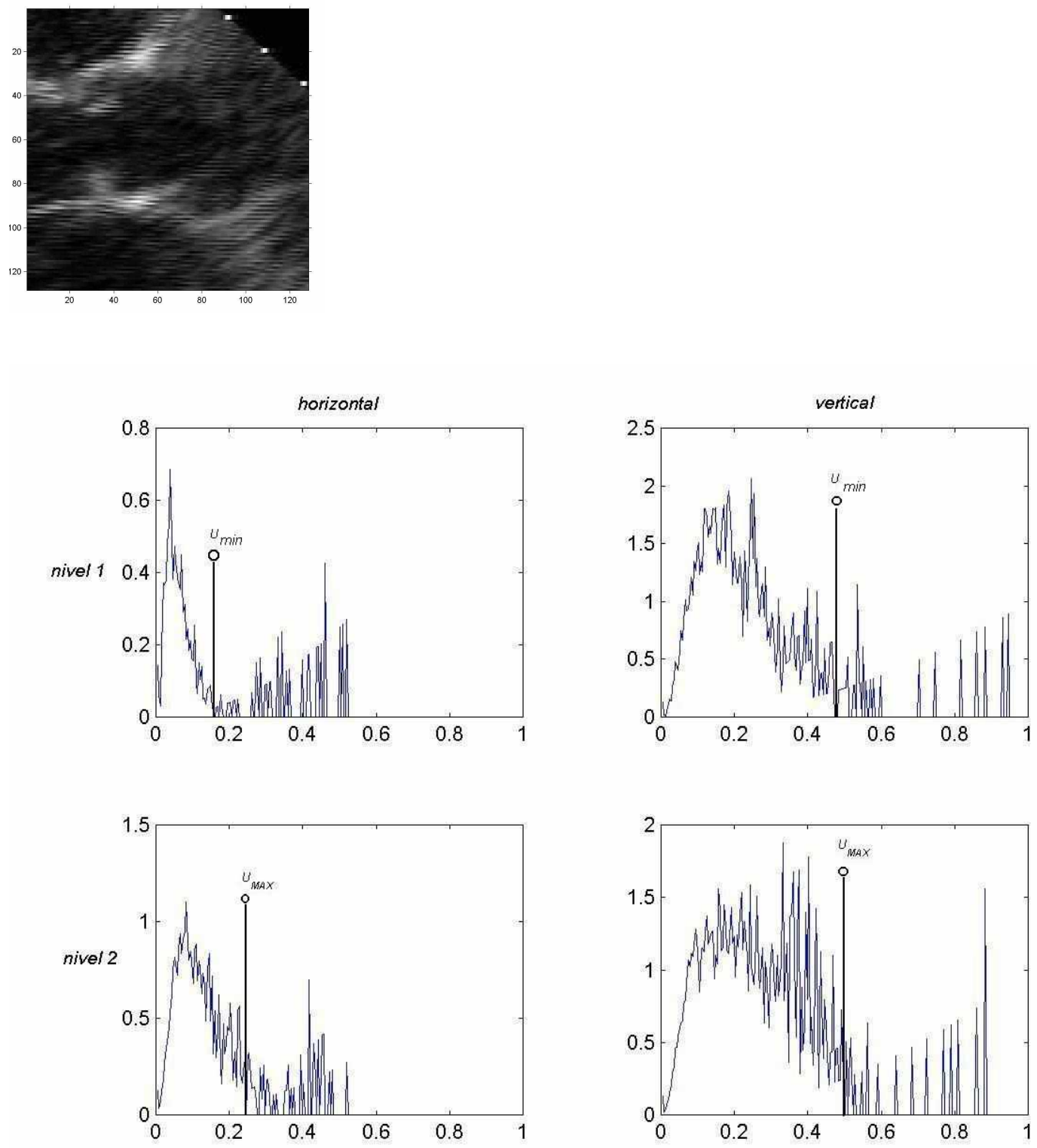

Fig. 7.3 (b) Continuación 

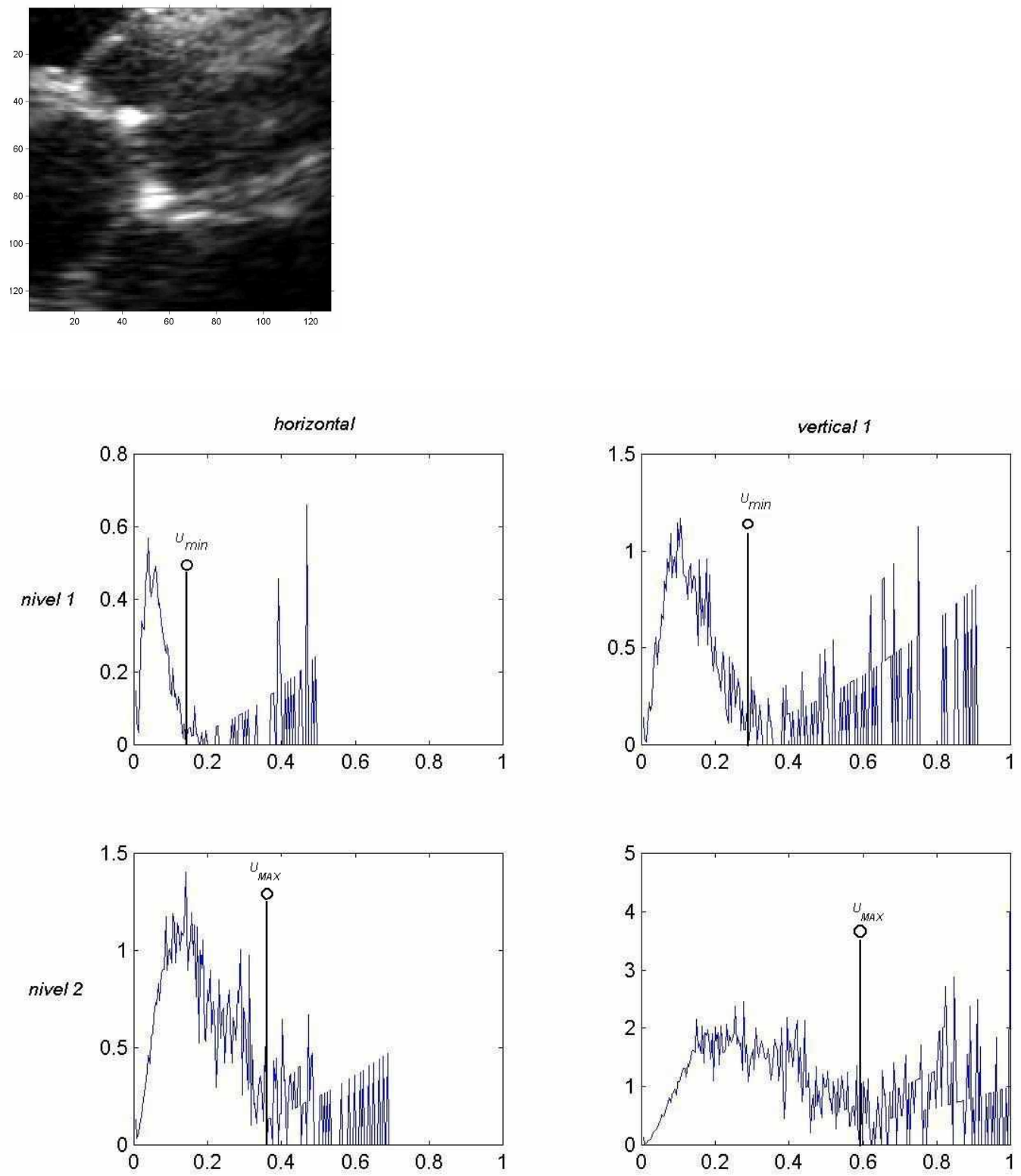

Fig. 7.3 (c) Continuación 

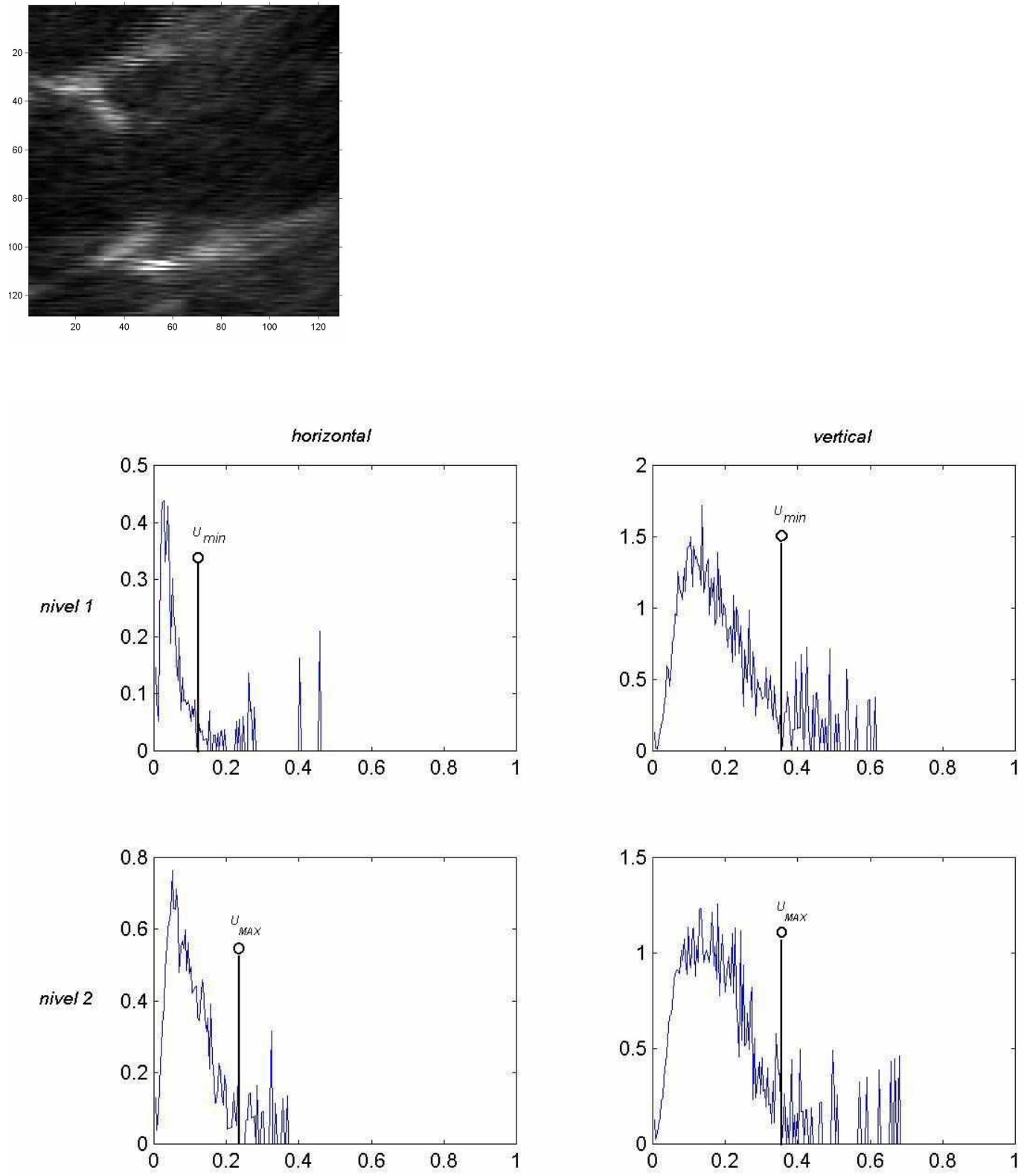

Fig. 7.3 (d) Continuación 

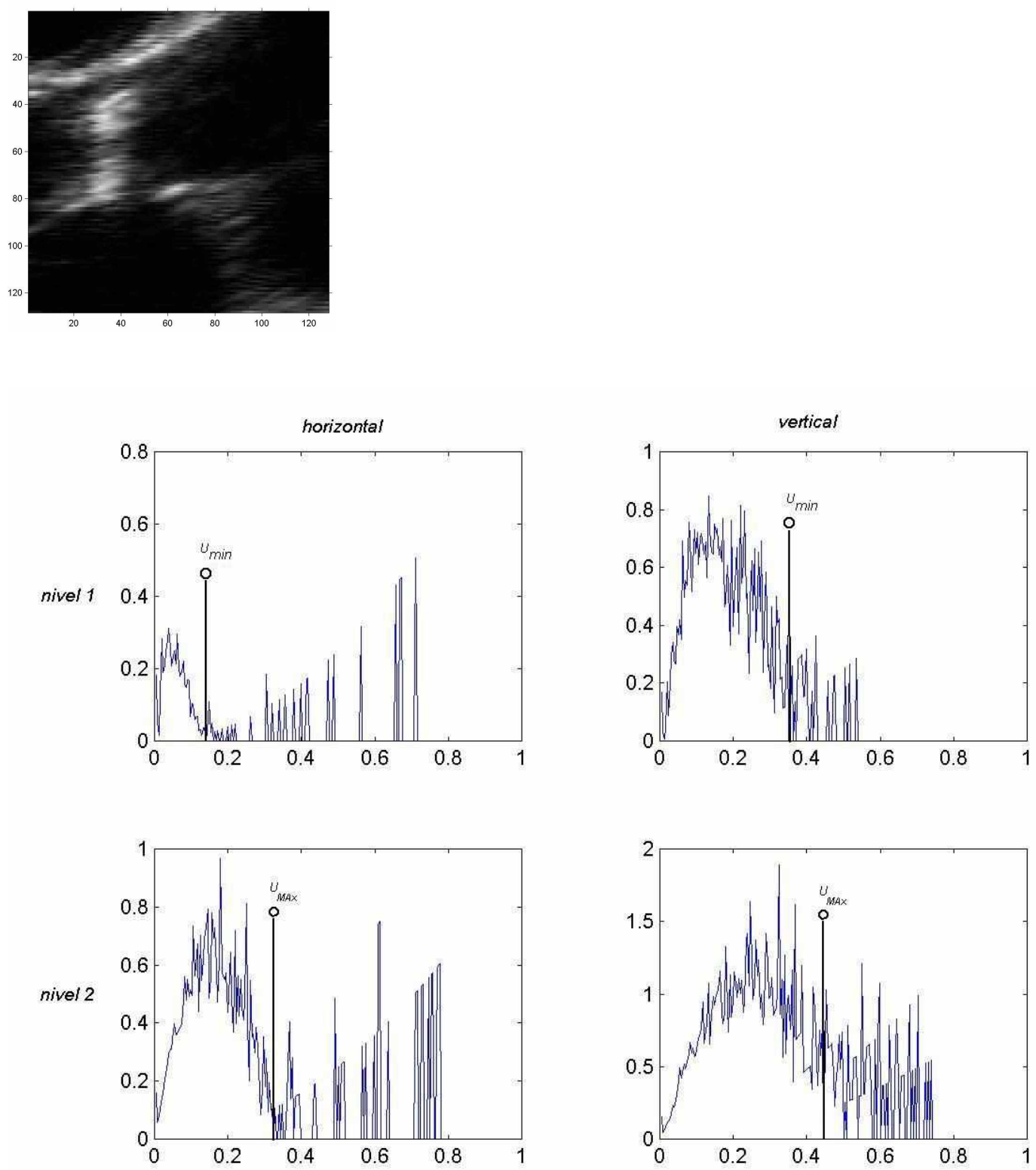

Fig. 7.3 (e) Continuación

Como se esperaba, las concentraciones de energía se encuentran en los 2 niveles de escala más gruesa y es ahí donde se intenta la umbralización suave. La tabla 7.1 muestra los valores de $U_{M A X}$ correspondientes a las imágenes de la figura 7.3, en ese orden: 


\begin{tabular}{||c|c|c|c|c||}
\hline NIVEL & $\mathbf{1}$ & $\mathbf{1}$ & $\mathbf{2}$ & $\mathbf{2}$ \\
\hline ORIENTACIONES & horizontal & vertical & horizontal & vertical \\
\hline $\mathbf{U}_{\max }$ figura 7.3 (a) & 0.14 & 0.3 & 0.38 & 0.56 \\
\hline $\mathbf{U}_{\max }$ figura 7.3 (b) & 0.155 & 0.5 & 0.245 & 0.52 \\
\hline $\mathbf{U}_{\max }$ figura 7.3 (c) & 0.14 & 0.32 & 0.39 & 0.6 \\
\hline $\mathbf{U}_{\max }$ figura 7.3 (d) & 0.12 & 0.35 & 0.235 & 0.355 \\
\hline $\mathbf{U}_{\max }$ figura 7.3 (e) & 0.14 & 0.345 & 0.332 & 0.45 \\
\hline
\end{tabular}

Tabla 7.1 Valores para $U_{\max }\left(\right.$ Los valores de $U_{\max }$ en la tabla 7.1 están normalizados).

Los valores en la tabla 7.1 ayudan a fijar el valor de $U_{\text {MAX }}$ alrededor del valor 0.5 (valor normalizado).El valor normalizado de $U_{\min }$ se elige aquí con valor $U_{\min }=0.1$, según las observaciones. Por lo tanto, $\alpha=+0.4$.

\subsubsection{Estimación de la varianza del ruido $\sigma^{2}$.}

El umbral $t_{j}^{d}$ depende principalmente del nivel de descomposición y del nivel del ruido (desviación standard) $\sigma_{j}^{d}$ en la imagen [20]. En los casos prácticos, el nivel de ruido se desconoce.

Para la explicación que sigue, se conviene en simplificar la ecuación (7.1) de la siguiente manera:

$$
\begin{array}{ll} 
& \ln \{f(x, y)\}=\ln \{g(x, y)\}+\ln \left\{\eta_{u}(x, y)\right\} \\
\Leftrightarrow \quad & X[n]=f[n]+W[n]
\end{array}
$$

Para estimar la varianza $\sigma^{2}$ del ruido $W[n]$ en la expresión $X[n]=f[n]+W[n]$ donde $f[n]$ es la señal libre de ruido, se necesita suprimir la influencia de $f[n]$. Cuando $f$ es razonablemente suave, es decir, sin cambios abruptos, es posible calcular un estimador robusto a partir de la mediana (median) de los coeficientes wavelet más finos [18, p. 459].

La señal $X$ de tamaño $N$ posee $N / 2$ coeficientes wavelet de la forma $\left\{\left\langle X, \Psi_{l, m}\right\rangle\right\}_{0 \leq m<N / 2}$ a la escala más fina $2^{l}=2 N^{-1}$. El coeficiente $\left|\left\langle f, \psi_{l, m}\right\rangle\right|$ es pequeño si $f$ es suave a lo largo del soporte de $\psi_{l, m}$, en cuyo caso: $\left\langle X, \psi_{l, m}\right\rangle \approx\left\langle W, \psi_{l, m}\right\rangle$. Por el contrario, $\left|\left\langle f, \psi_{l, m}\right\rangle\right|$ es grande si $f$ tiene una transición pronunciada en el soporte de $\psi_{l, m}$. Una señal razonablemente suave tiene pocas transiciones pronunciadas $\mathrm{y}$, por lo tanto, produce un número de coeficientes wavelet, de amplitud notable, que es pequeño 
comparado con $N / 2$ [18, p. 459]. En la escala más fina, la señal $f$ tiene influencia sobre el valor de una pequeña porción de los coeficientes $\left\langle X, \psi_{l, m}\right\rangle$ de amplitud grande que se consideran "aislados", es decir, no interesan para el cálculo de $\sigma^{2}$. Todos los demás coeficientes son aproximadamente iguales a $\left\langle W, \psi_{l, m}\right\rangle$, los cuales se consideran variables aleatorias Gaussianas independientes de varianza $\sigma^{2}$.

Un estimador robusto de $\sigma^{2}$ se puede calcular a partir de la mediana de $\left\{\left\langle X, \psi_{l, m}\right\rangle\right\}_{0 \leq m<N / 2}$. La mediana de $P$ coeficientes está definida como $\operatorname{Med}\left(\beta_{p}\right)_{0 \leq p<P}$ donde $\beta$ representa a los $\mathrm{P}$ coeficientes. $\operatorname{Med}\left(\beta_{p}\right)_{0 \leq p<P}$ es el valor del coeficiente medio $\beta_{n_{o}}$ de rango $P / 2$. Contrario a un promedio, la mediana no depende de los valores específicos de $\beta_{p}>\beta_{n_{o}}$. Si $M$ es la mediana del valor absoluto de $P$ variables aleatorias Gaussianas independientes de media cero y de varianza $\sigma^{2}$, entonces se puede demostrar que [26]:

$$
E\{M\} \approx 0.6745 \sigma
$$

La varianza $\sigma^{2}$ del ruido $W$ se estima a partir de la mediana $M_{X}$ de $\left.\left\{\left|X, \Psi_{l, m}\right|\right\rangle\right\}_{0 \leq m<N / 2}$ despreciando la influencia de $f$ :

$$
\sigma=\frac{M_{X}}{0.6745}
$$

De hecho, $f$ es responsable de algunos coeficientes "aislados" de amplitud grande, pero esto tiene poco impacto sobre $M_{X}$.

Con esta forma de estimar el nivel de ruido (la desviación standard $\sigma$ ), es posible finalmente conocer el valor de $t_{j}^{d}$. Para cualquier ecocardiografía:

\begin{tabular}{|c|c|c||}
\hline NIVEL $\mathbf{j}$ & $t_{j}^{h}=U \sigma_{j}^{h}$ & $t_{j}^{v}=U \sigma_{j}^{v}$ \\
\hline 1 & $0.1 \sigma_{1}^{h}$ & $0.1 \sigma_{1}^{v}$ \\
\hline 2 & $0.5 \sigma_{2}^{h}$ & $0.5 \sigma_{2}^{v}$ \\
\hline
\end{tabular}

Tabla 7.2 $t_{j}^{d}$ en $\mathrm{j}=1,2$ para la umbralización suave.

\subsection{La programación MATLAB para la técnica de “denoising”.}

El programa MATLAB correspondiente a la técnica de "denoising" descrita en el apartado 7.3, se desarrolló siguiendo el siguiente diagrama de flujo: 


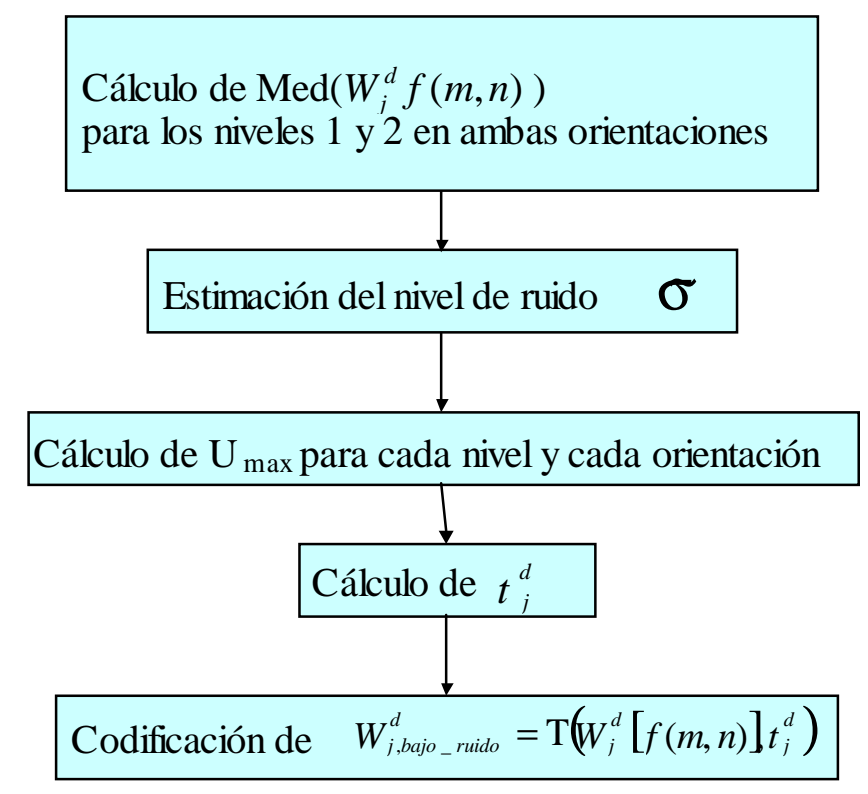

Fig. 7.4 Diagrama de flujo para el procedimiento de "denoising".

El apéndice E muestra el programa completo del procedimiento de "denoising”. Pero aquí incluimos la explicación del procedimiento ilustrándolo sólo para un nivel y una orientación:

Distribución de la energía

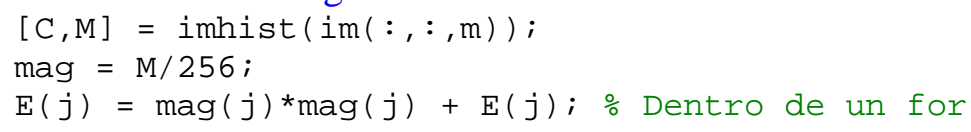

Parámetros para el cálculo de $t_{j}^{d}$

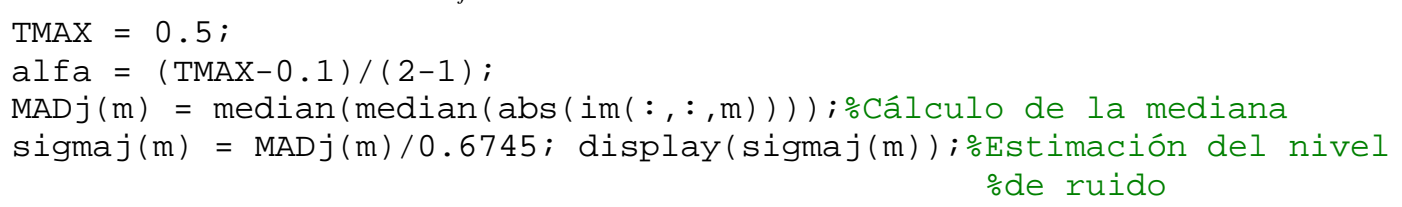

Cálculo del umbral para la umbralización suave:

th $(1)=(0.1-\operatorname{alfa}(1)) * \operatorname{sigmaj}(1) ;$

Umbralización suave (supresión del ruido):

$$
\operatorname{im}(:,:, 1)=\text { wthresh }\left(i m(:,:, 1), \mathrm{s}^{\prime}, \text { th }(1)\right) \text {; }
$$

Como se puede notar en la última línea, la umbralización suave se lleva a cabo fácilmente utilizando la función MATLAB wthresh perteneciente al "toolbox wavelet" de 
la versión 5. Esta instrucción codifica exactamente el algoritmo de D. Donoho. En esta parte del trabajo, la determinación del umbral $t_{j}^{d}$ fue la tarea más delicada.

\subsection{Resultados.}

Obsérvese que se utiliza todo el tiempo imágenes (matrices) de clase "double" (valores de doble precisión) y se prescinde, por lo tanto, de los valores normalizados de los coeficientes wavelet.

En la figura 7.5, se muestran los resultados del proceso de supresión del ruido (“denoising”) para algunas ecocardiografías del estudio.

La figura 7.6 muestra el resultado de la umbralización suave sobre la ecocardiografía de la figura 7.3 a) y los niveles de energía correspondientes. 

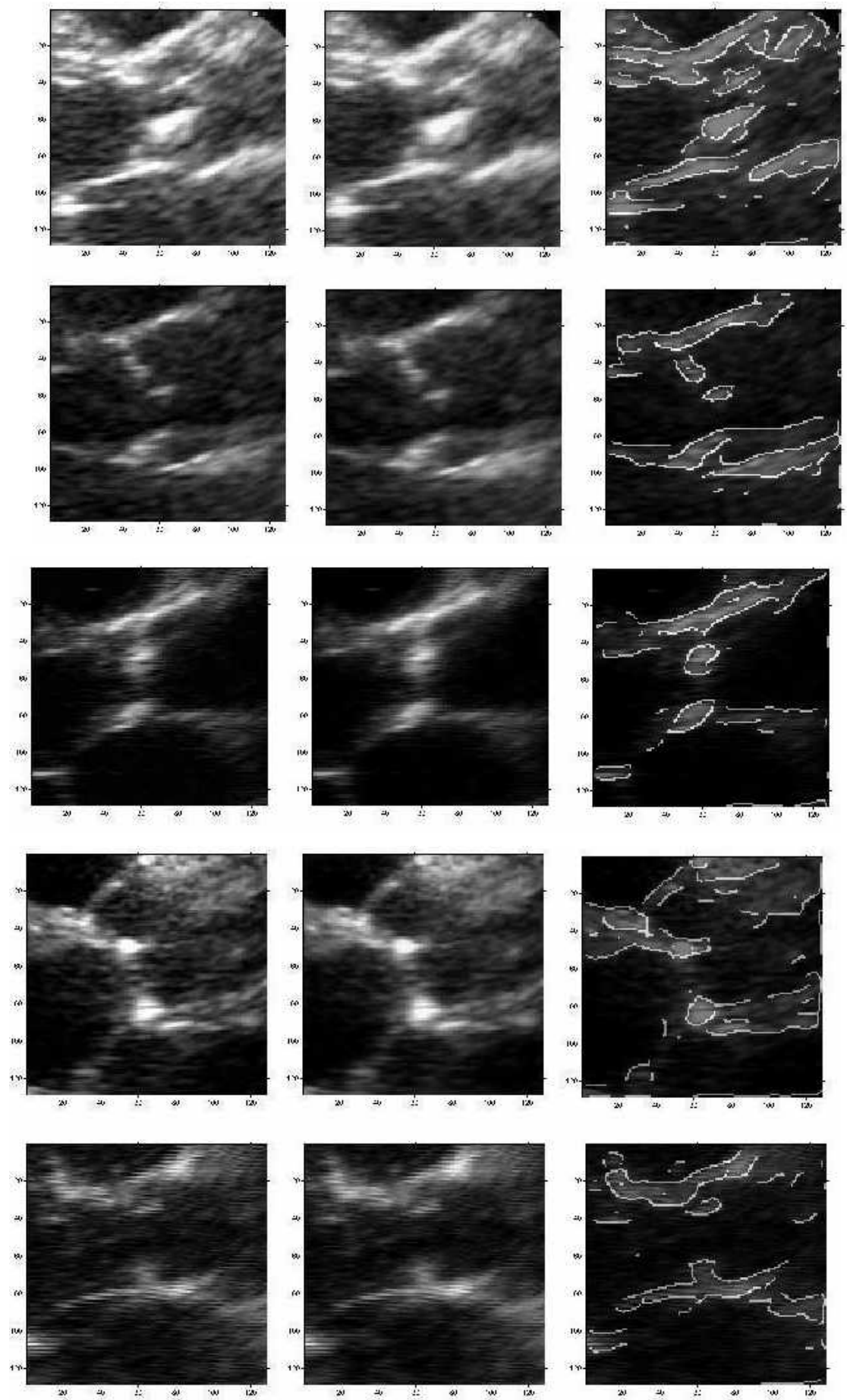

a)

b)

c)

Fig. 7.5 Resultados del proceso de supresión de ruido (“denoising”): a) Ecocardiografías originales, b) Ecocardiografías con ruido reducido; c) Mapas de bordes después de la supresión del ruido. 

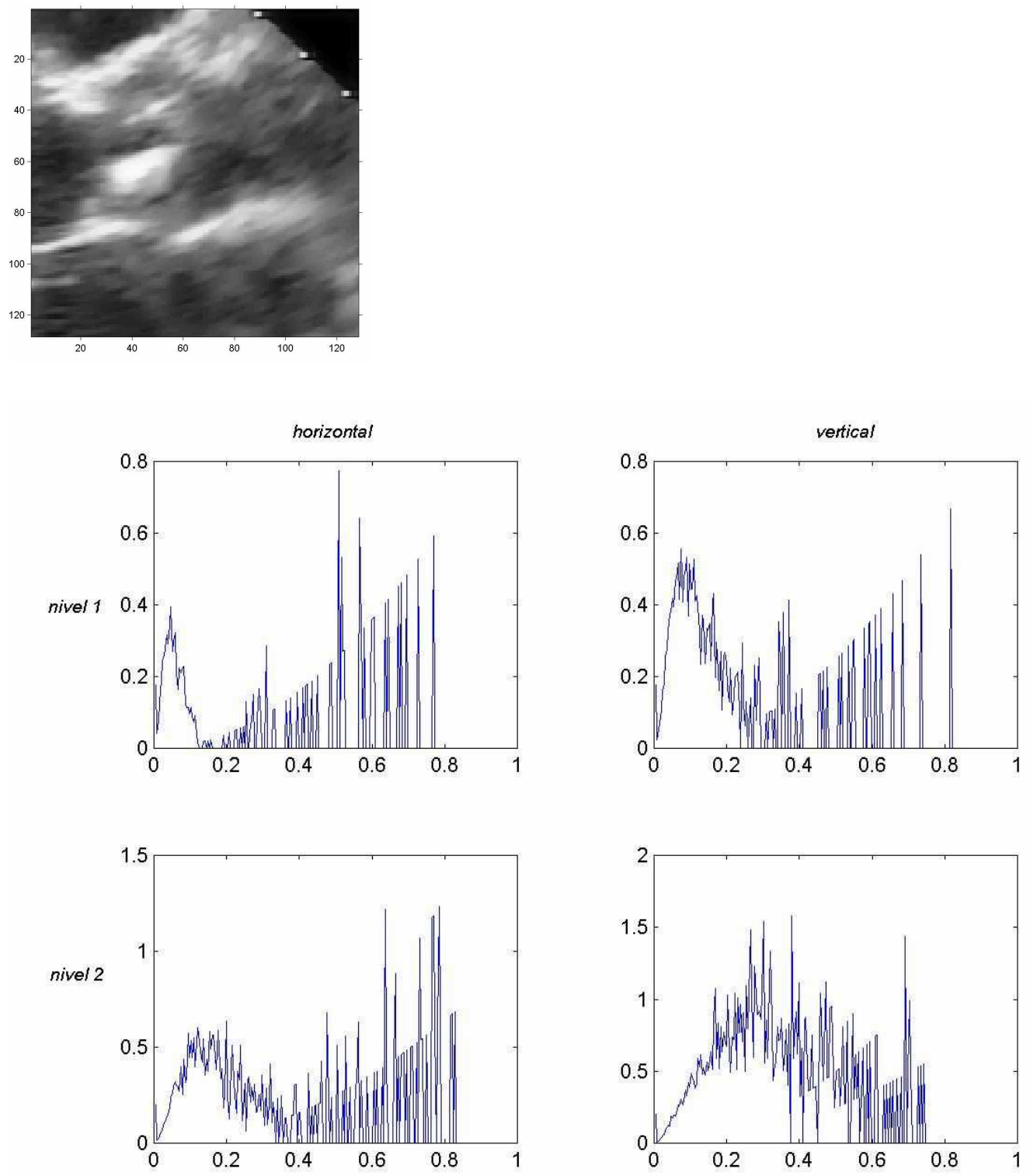

Fig. 7.6 Ecocardiografía y gráficas de los niveles de energía contra magnitud de los coeficientes DWT después de la supresión del ruido.

\subsection{Discusión.}

Claramente se puede observar, al comparar la figura 7.3 a) con la figura 7.6 , que después de la operación de umbralización suave los niveles de energía correspondientes al ruido (coeficientes wavelet pequeños) se han reducido aproximadamente a la mitad sin menoscabo de las formas estructurales, como se puede constatar en la figura 7.5. 
Es menester decir que se tuvo que ajustar la constante multiplicativa en la reconstrucción al valor 0.191 para mantener una PSNR alta (+35.07 dB). La introducción del tratamiento homomórfico degrada la aproximación a la reconstrucción perfecta.

¿Es justificado el método propuesto para la estimación de $t_{j}^{d}$ ?. Donoho [26] y otros autores [18] proponen la cantidad $\sqrt{2 \ln N}$ con $N=2^{J}$ con lo cual obtienen un umbral constante $U=\sigma \sqrt{2 \ln N}$. En este trabajo se desarrolló un umbral que depende también de la escala y donde el nivel de ruido se calcula dinámicamente (para cada escala y cada orientación). Para contar con una comparación más objetiva, se hicieron pruebas sobre la imagen "Lenna" contaminándola con ruido multiplicativo ("speckle noise") con una varianza de 0.04 y probando la umbralización suave independiente de la energía del ruido y la propuesta en esta sección. La figura 7.7 muestra los resultados visuales obtenidos. Con el algoritmo propuesto se obtiene una restauración de la imagen más aproximada a la original a diferencia del algoritmo independiente de la energía. La PSNR también es superior: +24.02 dB contra $20.32 \mathrm{~dB}$. Se piensa que esta prueba es suficiente para validar el procedimiento de reducción de ruido en las ecocardiografías.

Recuérdese que se anticipaba en el capítulo 6 que el procedimiento de reducción del ruido granular era necesario para reducir variaciones pronunciadas de los coeficientes wavelet no pertenecientes a la estructura de la aorta, los cuales provocarían la síntesis de un mapa de bordes redundante. El tiempo de procesamiento se alargaría inútilmente. En este sentido, la umbralización suave es un procedimiento auxiliar a la búsqueda de bordes. 


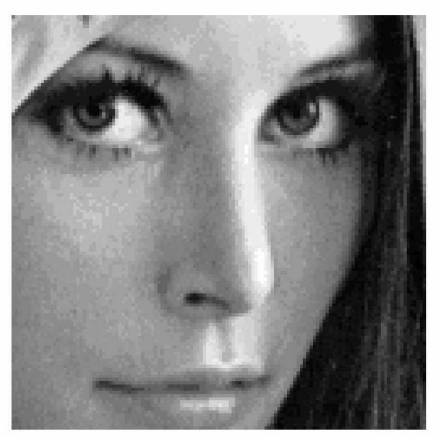

Fig. 7.7 a) Imagen "Lenna" original de $128 \times 128$ pixeles. $\mathrm{N}=128$.
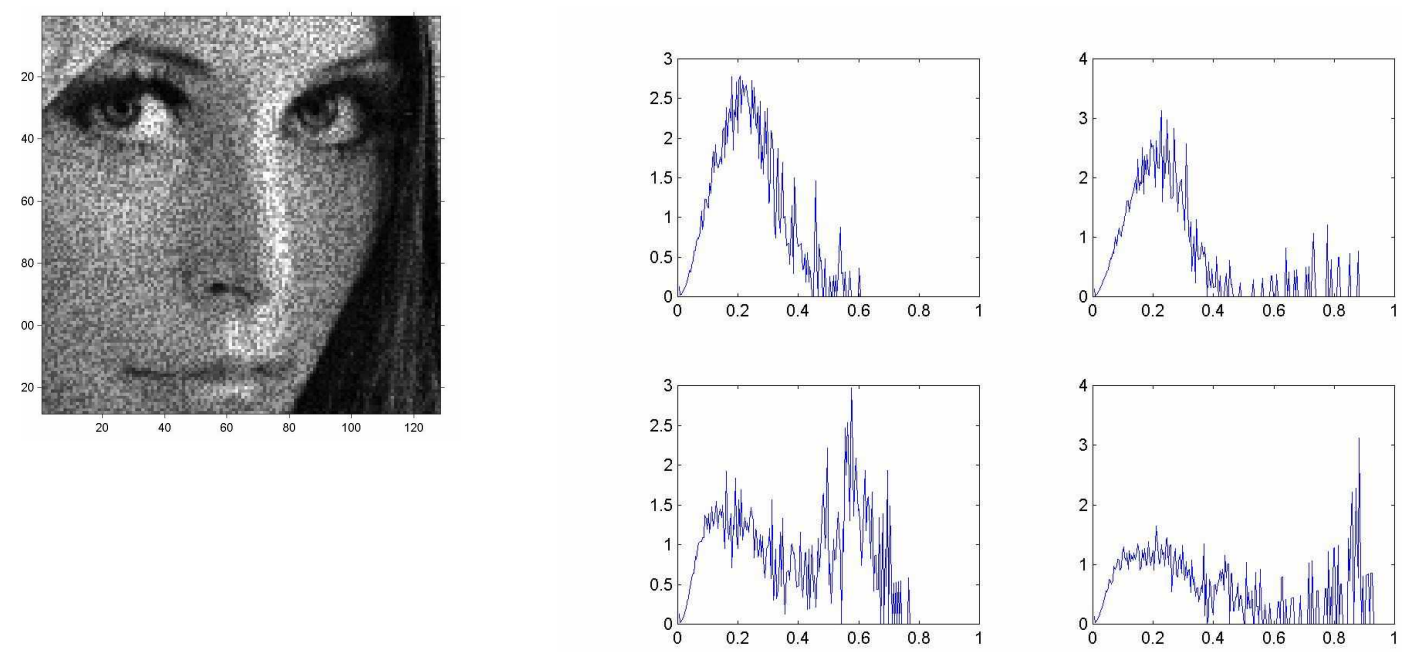

Fig. 7.7 b) "Lenna" contaminada con ruido multiplicativo (varianza $=0.04$ ) y niveles de energía de los coefientes wavelet en el nivel 1 y 2 del orden acostumbrado.
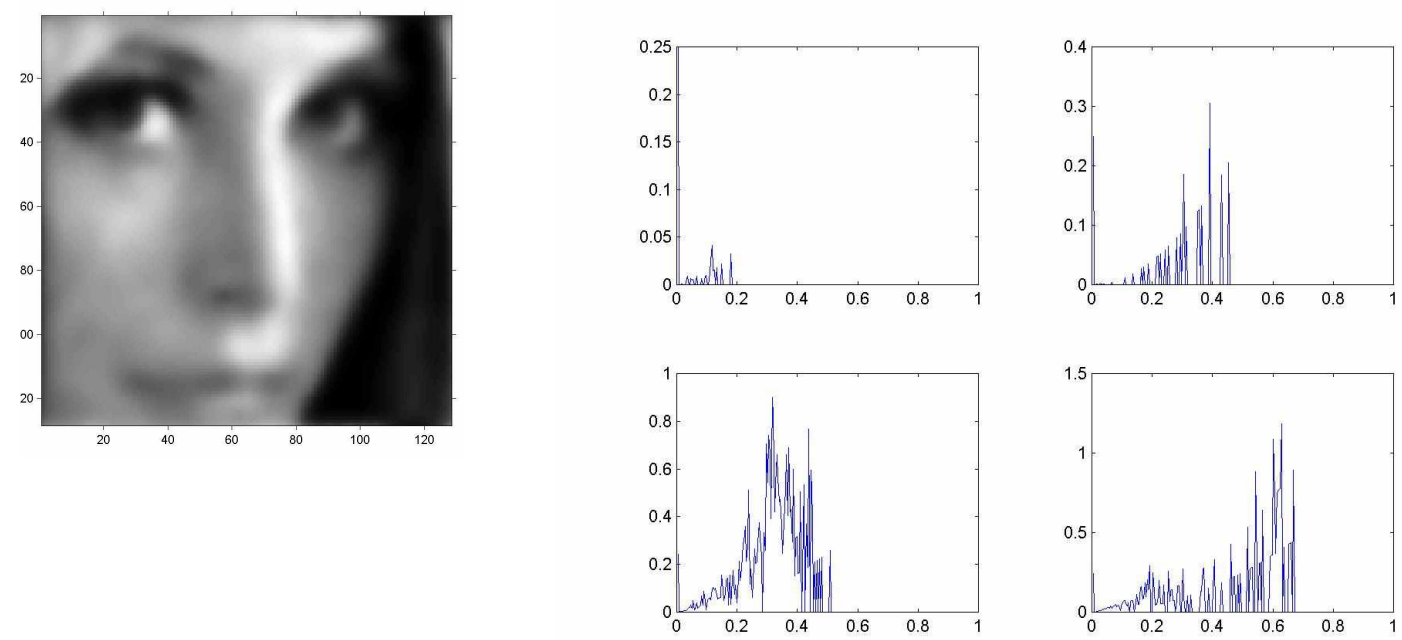

Fig. 7.7 c) "Lenna" restaurada con el algoritmo independiente de la energía del ruido (constante de reconstrucción $=0.35$ ) y sus niveles de energía. PSNR $=+20.35 \mathrm{~dB}$. 

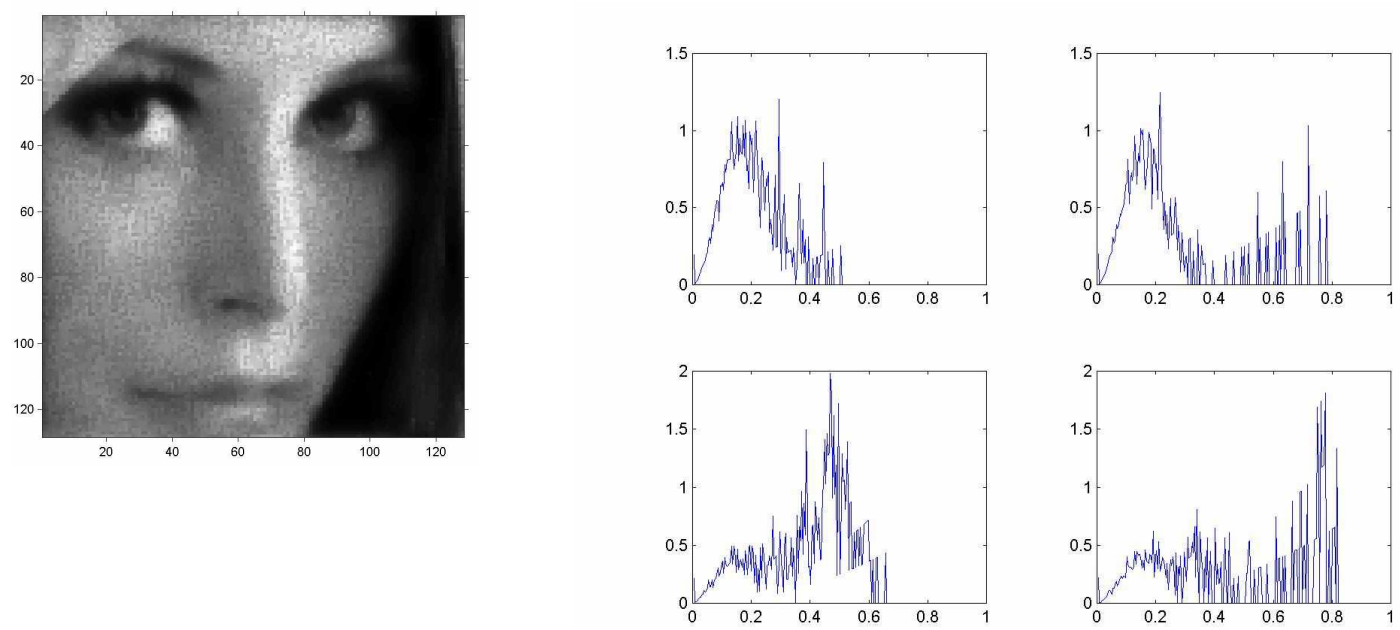

Fig. 7.7 d) "Lenna" restaurada con el algoritmo dependiente de la energía del ruido (constante de reconstrucción $=0.35, \mathrm{U}_{\mathrm{MAX}}=0.7$ ) y sus niveles de energía. $\mathrm{PSNR}=+24.02 \mathrm{~dB}$. 


\section{SEGMENTACIÓN DE LAS REGIONES ECOGÉNICAS}

\subsection{Introducción.}

La cuantificación del grado de calcificación en la válvula aórtica, en el modo B, se basa en la medición de las regiones ecogénicas que representan las zonas calcificadas. Entonces es necesario aislar estas regiones y medir su extensión. El algoritmo de la supresión del ruido se puede utilizar para mejorar la calidad visual de la ecocardiografía en el corte paraesternal de eje corto en diástole, donde se hacen evidentes las regiones calcificadas, y entonces aplicar una técnica de segmentación para aislarlas. La supresión del ruido tiene el papel de reducir los efectos de la interferencia coherente y las regiones ecogénicas (calcificadas) que se puedan aislar poseerán un área más exacta.

\subsection{Segmentación de las regiones ecogénicas.}

Como se señaló en el párrafo 4.1, las zonas calcificadas de la válvula aórtica aparecen como zonas de alta ecogenicidad sobre la ecocardiografía. Estas zonas, que revelan la extensión del calcio y su distribución, son susceptibles de ser medidas como áreas de pixeles mediante un algoritmo de crecimiento de regiones.

El crecimiento de regiones es una técnica de segmentación de imágenes que divide a una imagen en diferentes regiones. Cada región segmentada forma un conjunto de pixeles con una cierta propiedad buscada [16]. La propiedad buscada en este caso es un cierto nivel de gris a partir del cual se pueda segmentar con exactitud las regiones calcificadas. La región de interés se crece a partir del sembrado de una "semilla" (pixel) dentro del área de interés. Esto implica que el sembrado de semillas debe hacerse por el médico sonografista experto en localizar las regiones calcificadas dentro del área del anillo anatómico de la válvula aórtica.

El nivel de gris a partir del cual se puede considerar que un pixel pertenece a una región calcificada de la válvula aórtica es difícil de establecer. Como se puede apreciar en la figura 8.1, d), existen regiones que presentan un nivel de ecogenicidad menor a otras dentro del mismo anillo anatómico que no presentan una media cercana a 1. Este problema se ha solucionado permitiendo una desviación standard de 0.1 alrededor del valor del nivel de gris de la semilla plantada por el médico sonografista. De esta manera, pixeles con un valor diferente a la media actual, pero que se encuentran dentro de la región calcificada apreciada por el sonografista, podrán pertenecer a la región de interés.

Cabe aclarar que el tejido de las valvas aórticas es suave y delgado y, en ausencia de calcificaciones, el tejido tiene una impedancia acústica muy baja. Por lo tanto, es improbable observar regiones ecogénicas o un intenso ruido granular en esta situación. Conviene aplicar la técnica de supresión de ruido del capítulo 7 a las ecocardiografías del 
estudio antes de segmentar las regiones ecogénicas correspondientes a la calcificación porque, de esa manera, el médico sonografista sembraría semillas sobre regiones que representen, con más probabilidad, deposiciones de calcio en lugar de artefactos producidos por la interferencia coherente.

\subsection{Explicación del algoritmo de crecimiento de regiones.}

El algoritmo de crecimiento de regiones utilizado en este trabajo para segmentar las regiones calcificadas de la válvula aórtica es el mismo algoritmo propuesto por Adams y Bischof [17] llamado "crecimiento de regiones por sembrado de semilla" ("seeded region growing", SRG) que normalmente se aplica a imágenes de intensidad de grises y que consiste principalmente en conectar pixeles de valor similar. La explicación adaptada del algoritmo [17] se incluye aquí con el propósito de ayudar a entender la codificación del programa MATLAB del apéndice F.

El algoritmo SRG realiza la segmentación de una imagen con respecto a un conjunto de puntos conocido como semillas. Se comienza con un número de semillas agrupadas en $n$ conjuntos $A_{1}, A_{2}, A_{3}, \ldots, A_{n}$. En ocasiones, algunos conjuntos individuales pueden consistir de un solo punto. Este es el caso del conjunto de semillas sembrado sobre la ecocardiografía. Es la elección de las semillas la que decide entre una característica de interés y una característica irrelevante. Dadas las semillas, el algoritmo SRG busca entonces los componentes conectados de cada región de imagen con la propiedad de un conjunto $A_{i} \mathrm{y}$, sujetas a esta restricción, las regiones se segmentan de la manera más homogénea posible.

Para el caso de imágenes de intensidad en la escala de grises, el proceso de segmentación evoluciona inductivamente a partir de las semillas, es decir, del estado inicial de los conjuntos $A_{1}, A_{2}, A_{3}, \ldots, A_{n .}$ Cada uno de los pasos del algoritmo conlleva a la suma de un pixel a alguno de los conjuntos $A_{i .}$. Considérese el estado de los conjuntos $A_{i}$ después de $m$ pasos. Sea T el conjunto de los pixeles "todavía no incluidos" y que delimitan al menos una de las regiones:

$$
T=\left\{x \notin \bigcup_{i=1}^{n} A_{i} \mid N(x) \cap \bigcup_{i=1}^{n} A_{i} \neq \varnothing\right\}
$$

donde $N(x)$ es el conjunto de los vecinos inmediatos al pixel $x$. En el caso de este trabajo, se utilizó conectividad-8 para el pixel $x$.

Si para $x \in T$ se tiene que $N(x)$ pertenece solamente a un conjunto $A_{i}$, entonces se define un índice $i(x) \in\{1,2, \mathrm{~L}, n\}$ que permita que $N(x) \cap A_{i(x)} \neq \varnothing$ y se define una medida $\delta(x)$ para dimensionar la diferencia entre $x$ y la región adyacente. La definición más simple de $\delta(x)$ es: 


$$
\delta(x)=\mid g(x)-\underset{y \in A_{(x)}}{\operatorname{media}}[g(y)]
$$

donde $g(x)$ es el nivel de gris del pixel $x$. Si $N(x)$ pertenece a dos o más de los conjuntos $A_{i}$, entonces $i(x)$ es un valor de $i$ tal que $N(x)$ pertenece a $A_{i}$ y $\delta(x)$ se minimiza. Bajo esta circunstancia, es recomendable clasificar a $x$ como un pixel limítrofe y añadirlo a un conjunto "B" de "pixeles limítrofe encontrados". Marcar estos pixeles limítrofe es útil para propósitos de visualización. Después se toma una $z \in T$ de tal manera que:

$$
\delta(z)=\min _{x \in T}\{\delta(x)\}
$$

y se añade $z$ a $A_{i}(z)$.

Esto completa el paso $m+1$. El proceso se repite hasta que todos los pixeles hayan sido ubicados. El proceso comienza con un $A_{i}$ único. Las definiciones 8.1 y 8.2 aseguran que la segmentación final produce regiones lo más homogéneas posible, dada la restricción en la conectividad.

La programación original de Adams y Bischof [17], hace uso de una estructura de datos que forma una lista secuencial ordenada (sequentially sorted list, SSL). La estructura SSL es en realidad una lista ligada de objetos, en este caso de coordenadas de pixel, la cual se ordena de acuerdo a un cierto atributo. Por ejemplo, cuando se considera un nuevo pixel, al principio de cada paso del algoritmo SRG, se toma la primer coordenada al principio de la lista. Cuando se añade un pixel a la lista, se le debe colocar de acuerdo al valor del atributo ordenador. En este caso, la lista SSL almacena los datos de $T$ de acuerdo a $\delta$.

La pseudocodificación del algoritmo SRG es la siguiente:

Marcar los puntos semilla de acuerdo a su agrupamiento inicial

Colocar los vecinos de los puntos semilla (el conjunto $T$ inicial) en la lista SSL

Mientras la lista SSL no esté vacía:

Retirar el primer punto y de la lista SSL

Examinar a los vecinos de este punto:

$\underline{S i}$ todos los vecinos de y marcados de antemano (marca diferente a la de pixel limítrofe) tienen la misma marca, entonces

poner a y esta marca

actualizar la media de la región correspondiente

añadir a la SSL todos los vecinos de y que no están en la SSL o que no están marcados de acuerdo a su valor $\delta$

$\underline{\operatorname{sino}}$

marcar a y como pixel limítrofe 
Las regiones calcificadas de la válvula aórtica aparecen como regiones bien homogéneas (fig. 8.1), de manera que se puede realizar una buena estimación del valor medio del nivel de gris de los pixeles que la componen a partir de los ocho vecinos de una semilla formada por un único pixel.

\subsection{Resultados.}

El apéndice $\mathrm{F}$ relaciona el programa MATLAB de segmentación de regiones de acuerdo al algoritmo SRG. La figura 8.1 muestra los resultados de la segmentación sobre algunas de las ecocardiografías de los pacientes del protocolo. 

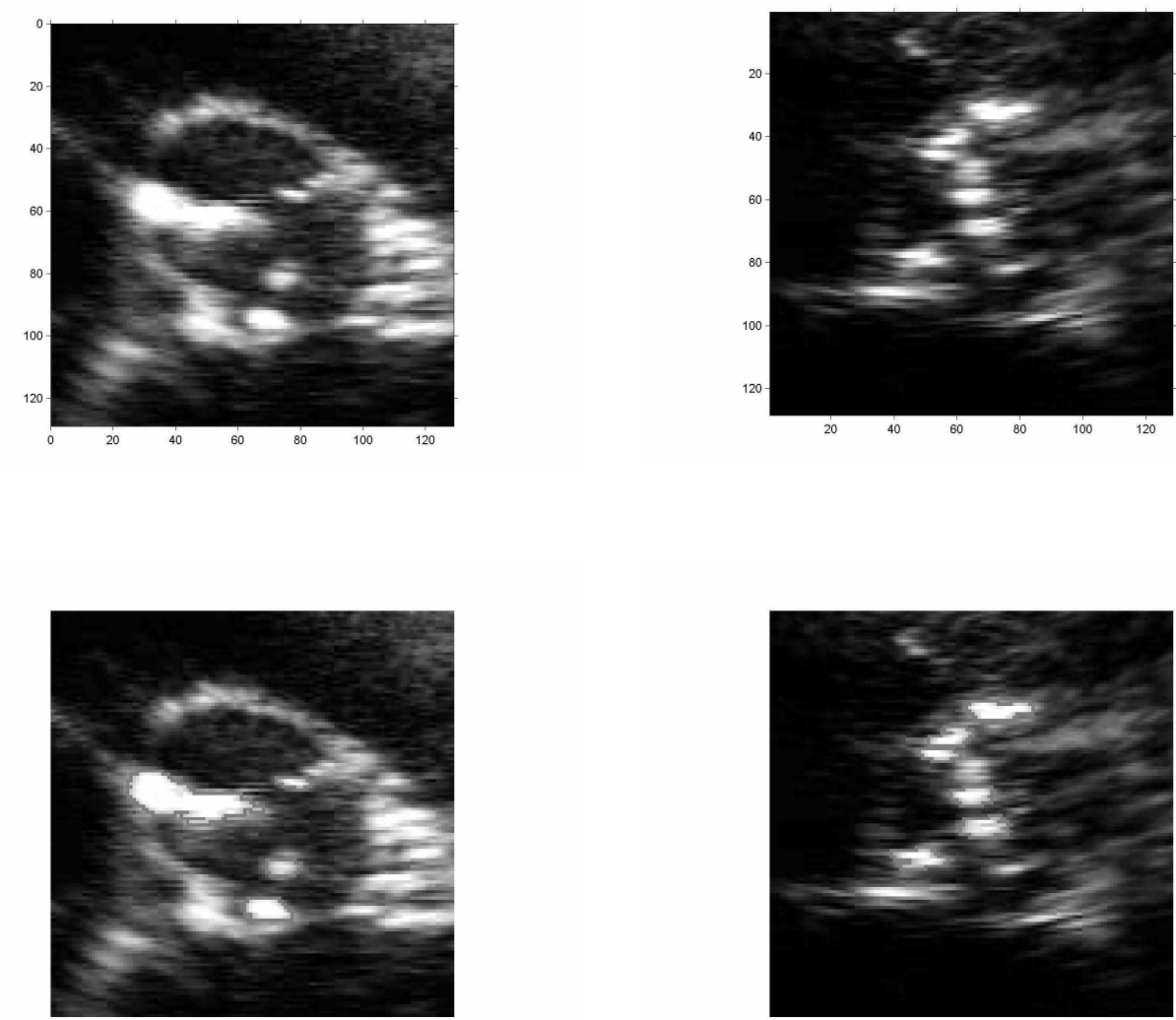

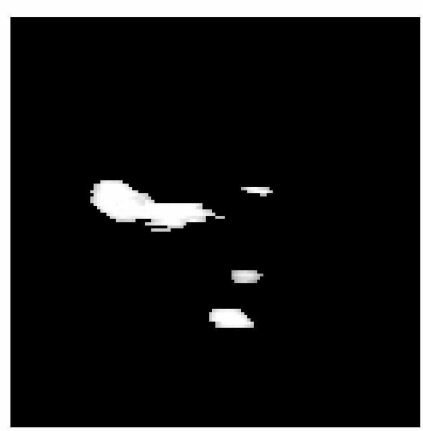

a)

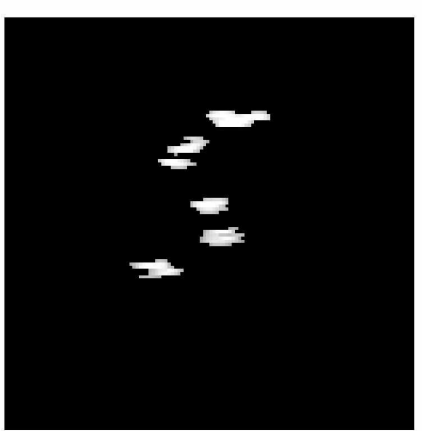

b)

Fig. 8.1, a) y b) Regiones calcificadas de la válvula aórtica dentro de su anillo anatómico. La desviación standard alrededor del nivel de gris de la semilla sembrada es de 0.1 . 

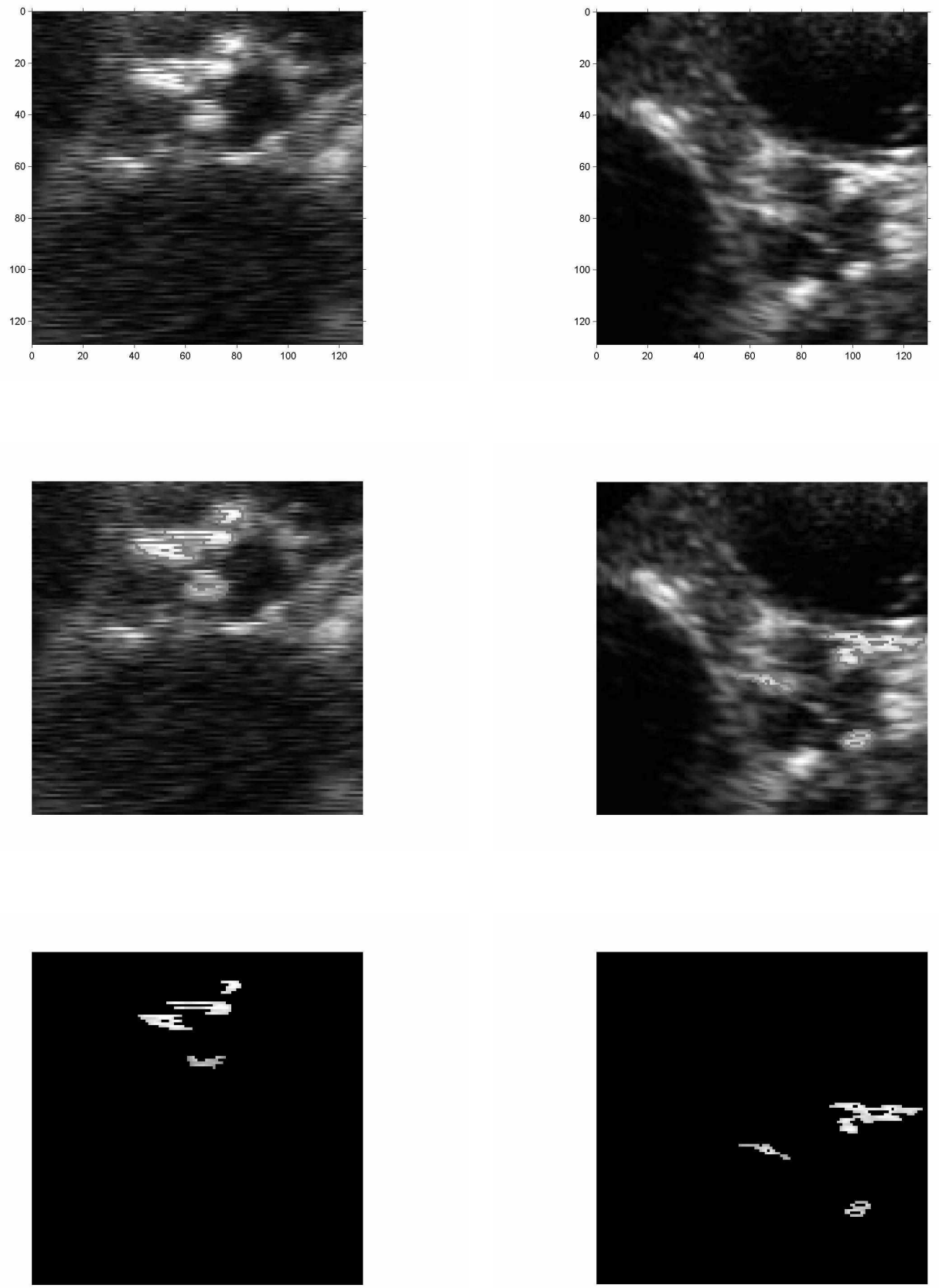

c)

d)

Fig. 8.1 c) y d), cont. Nótese que en d) el área ecogénica invade una parte de las paredes de la aorta. Esta área también está calcificada, aunque no se toma en cuenta para la validación del método. 

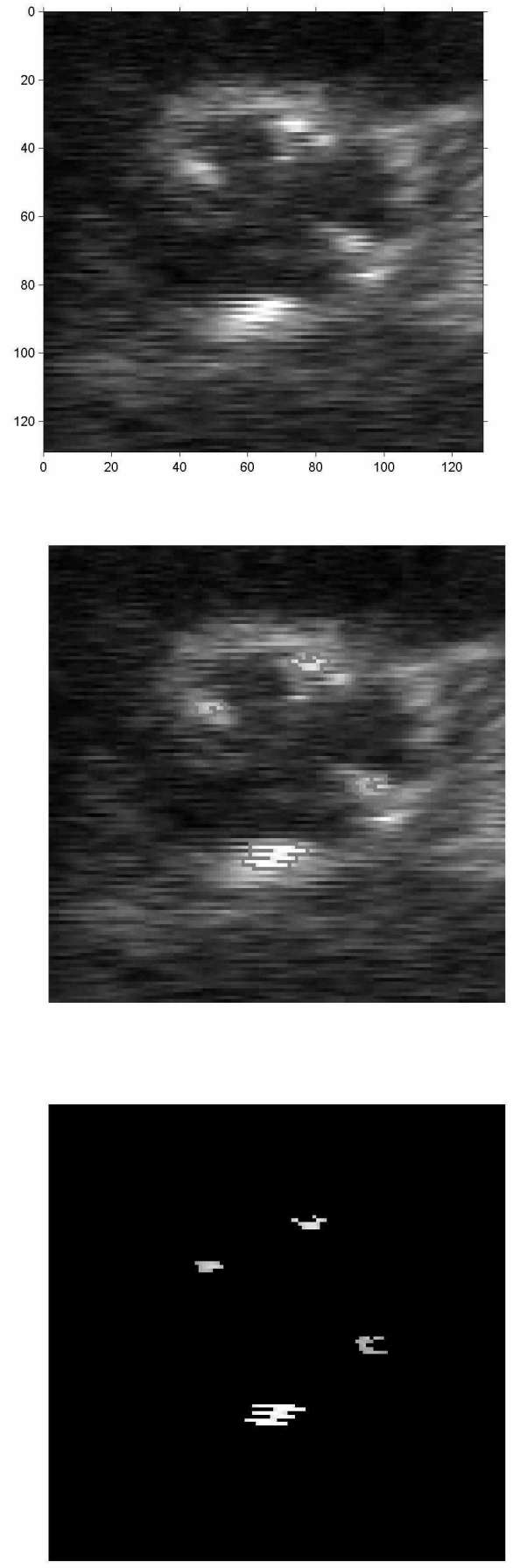

e)

Fig. 8.1 e) cont. Nótese en este ejemplo un área ecogénica en la comisura de la derecha con niveles de gris menores a 1 (imagen de intensidades de gris), pero que corresponde bien a un área calcificada. El algoritmo SGR diseñado posee la habilidad de encontrar este tipo de áreas. 


\subsection{Discusión.}

$1^{\circ}$ Es el médico sonografista quien, ayudado por su experiencia, planta un número de "semillas" igual al número de regiones que él identifica como calcificadas. Por lo tanto, un factor que influye en la medición exacta de las áreas calcificadas, es la elección juiciosa que hace el médico sonografista.

$2^{\circ}$ El médico sonografista debe elegir necesariamente aquellas regiones calcificadas contenidas dentro del anillo anatómico de la válvula aórtica, que son las regiones localizadas sobre las valvas, pues la disminución de la flexibilidad las valvas calcificadas da origen a la estenosis aórtica e interesa, desde un punto de vista clínico, encontrar una relación entre la calcificación y la estenosis.

$3^{\circ}$ Cada vez que se visite un píxel que cumpla la condición $\delta(x)<0.1$ entonces no se añadirá a la región en crecimiento. El valor de la desviación standard de 0.1 se puede interpretar como una tolerancia alrededor del valor medio del nivel de gris de la región actual y el valor de un nuevo pixel visitado no se incluye si está fuera de esta tolerancia. El valor 0.1 se ha elegido por prueba y error. La elección final se hizo al evaluar la extensión final de las áreas consideradas ecogénicas. Estas áreas han sido consideradas por los médicos sonografistas como "buenas aproximaciones" de lo que ellos consideran como regiones calcificadas y coinciden con el criterio, descrito en el párrafo $1^{\circ}$ de la sección 4.1 , para declarar una región ecogénica (calcificada). 


\section{MEDICIÓN DE LAS ÁREAS CALCIFICADAS DENTRO DEL ANILLO ANATÓMICO DE LA VÁLVULA AÓRTICA}

\subsection{El problema de la determinación del área del anillo anatómico de la válvula aórtica.}

El anillo anatómico de la válvula aórtica se aproxima a un círculo cuando se encuentra conservada [1, p. 39], es decir, en sístole en los sujetos sanos. La fig. 9.1 muestra un ejemplo de esta aseveración. Esta imagen muestra a detalle la vista paraesternal de eje corto donde se puede distinguir la forma del anillo anatómico.

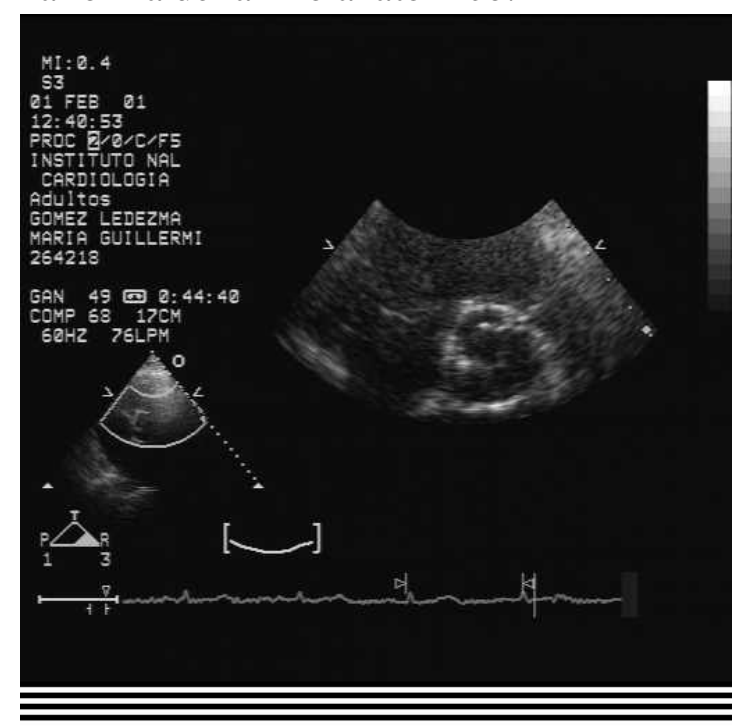

Figura 9.1 Detalle del anillo anatómico de la válvula aórtica en el eje corto.

Como se explicó en la sección 4.2, c), el área del anillo anatómico se aproximaría a la de un círculo y se esperaba que se pudiesen rescatar la mayoría de los bordes de esta estructura en el tercer nivel de descomposición wavelet. Se esperaba que los bordes encontrados, es decir, el conjunto de "arcos" que formarían el anillo anatómico, pudiese determinar suficientemente sus límites. La continuidad del borde de esta estructura se podría asegurar aplicando posteriormente un algoritmo basado en la transformada Hough, por ejemplo. Sin embargo, en esta investigación no se obtuvieron los resultados esperados en relación al círculo y esto se pone en evidencia en la figura 9.2, la cual muestra ejemplos donde no es posible discernir los arcos que forman al anillo anatómico. El área del anillo anatómico se estimaría en la vista paraesternal de eje corto en sístole. 

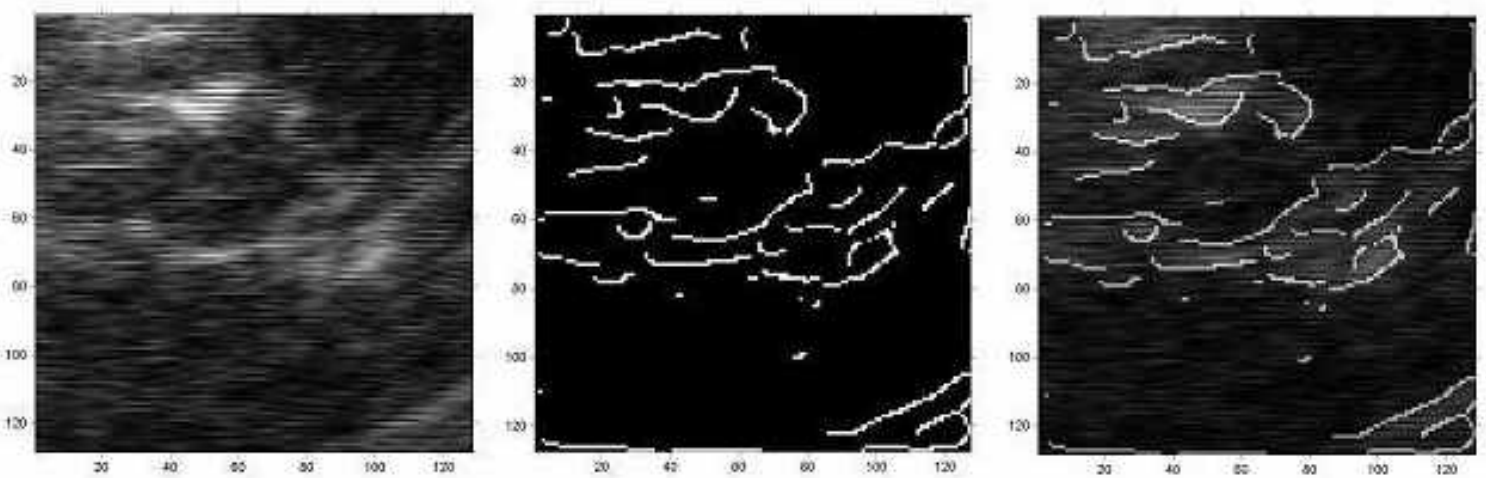

a)
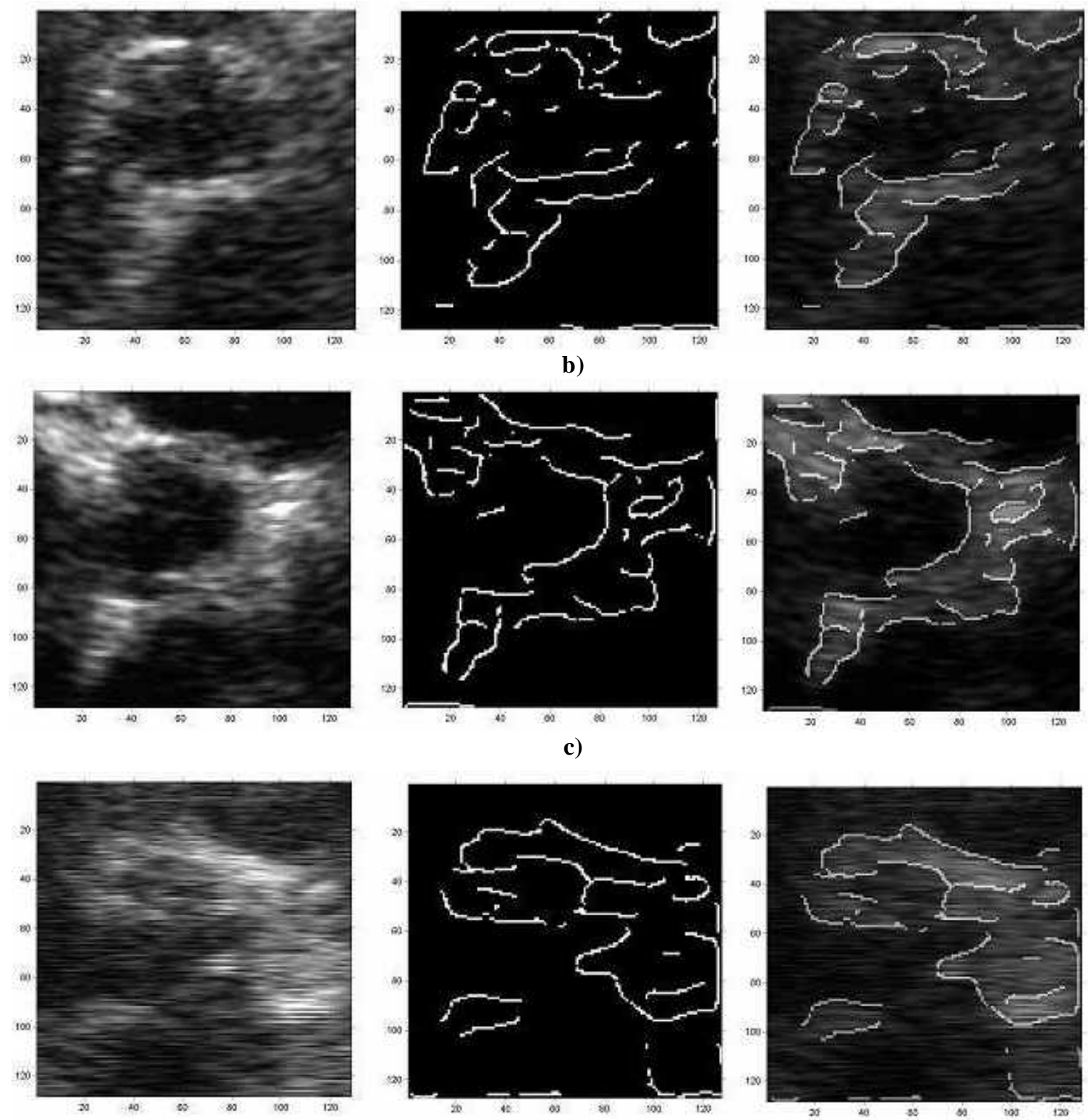

d) 

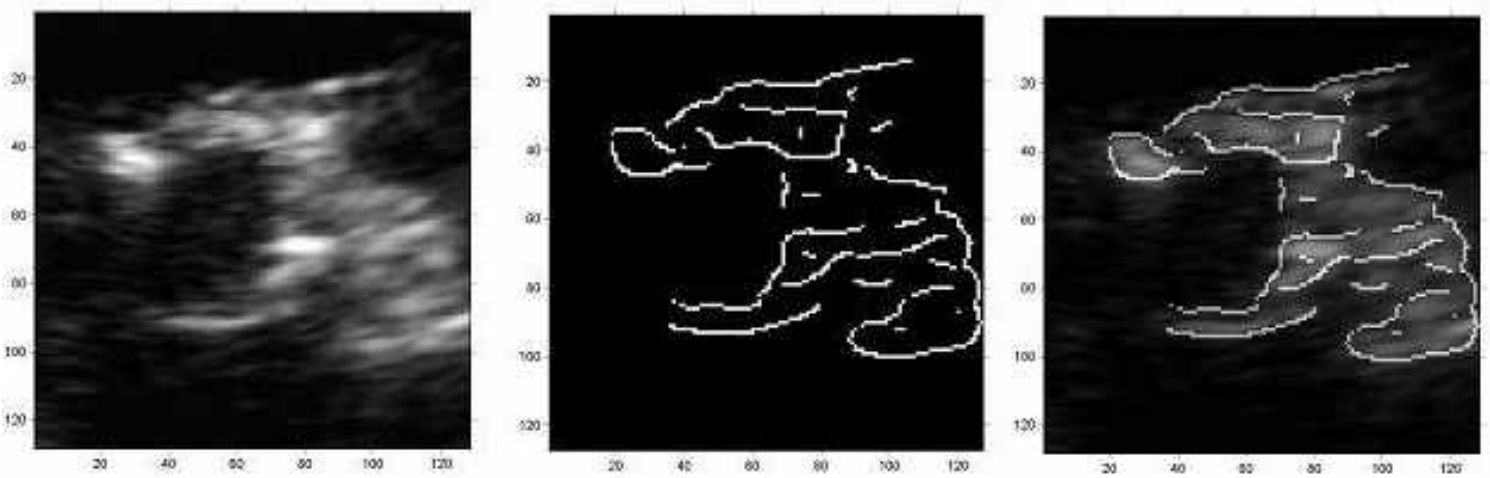

e)

Figura 9.2 Ejemplos de mapa de bordes del anillo anatómico de la válvula aórtica en el eje corto.

En las figuras 9.2 a) y b), se pueden apreciar algunos segmentos de borde pertenecientes a la pared interior del anillo anatómico, pero no se encontraron bordes suficientes con forma de arcos; en las figuras 9.2 c) y e), se encontró aproximadamente la mitad de los bordes del anillo anatómico que interesan, desgraciadamente la otra mitad no aparece; finalmente, la figura 9.2 d) muestra una vista donde el área del anillo anatómico puede confundirse con la de la aurícula izquierda. En casos como este, solamente un médico sonografista experto puede discernir el área verdadera. Son muy pocos los casos donde la forma del anillo anatómico de la válvula aórtica se conserva cuando la calcificación ha avanzado hacia el anillo anatómico (posiblemente 1 caso de cada 10). Como se puede apreciar en la fig. 9.3, la estructura del anillo anatómico se pierde completamente y el mapa de bordes encontrado ni siquiera la define.
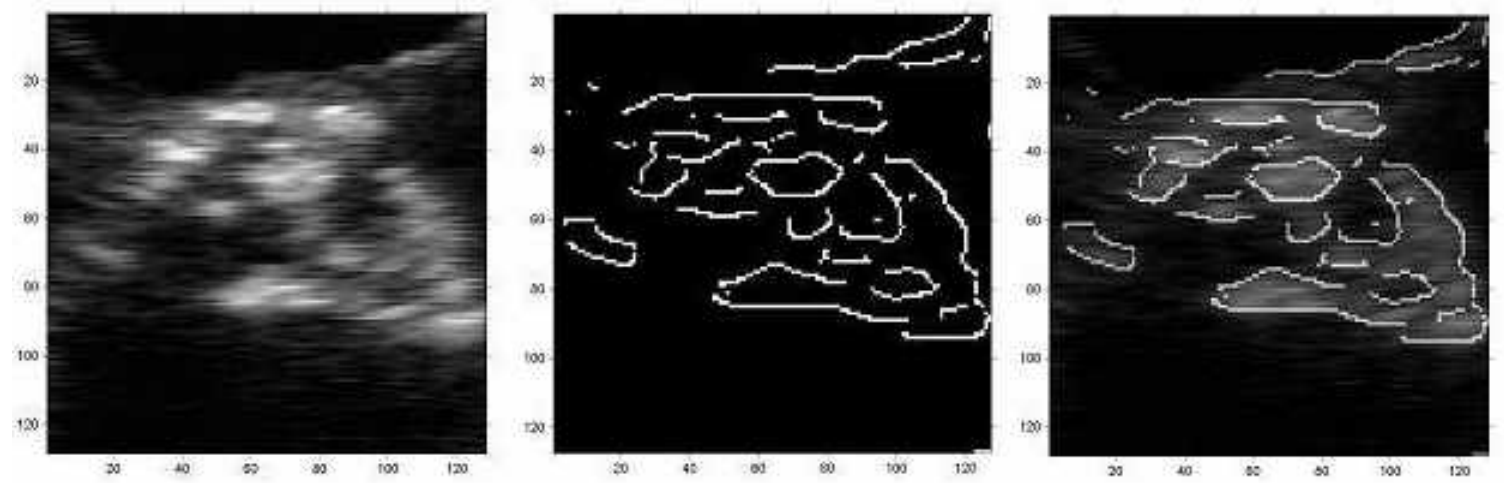

Figura 9.3 Ejemplo de anillo anatómico de la válvula aórtica mal definido.

Existen tres razones por las cuales se presenta esta situación:

$1^{\mathrm{a}}$ El calcio alrededor del anillo aórtico o el calcio sobre los velos próximo a las paredes aórticas o el que ha invadido las comisuras deforma la forma original del anillo anatómico. La fig. 9.3 es un buen ejemplo. 
$2^{\mathrm{a}} \quad$ Pueden existir nódulos de calcio que se sobreponen al borde del anillo anatómico y que el buscador de bordes lo puede presentar como un borde continuo que puede confundir la búsqueda de formas, de acuerdo a lo señalado en el $3^{\mathrm{r}}$ párrafo de la sección 4.1, independientemente del grado de calcificación. La experiencia de campo, durante las estancias en el INC, demostró que, aun para un inspector entrenado, es difícil discernir entre el borde de un nódulo de calcio y el borde del anillo anatómico de la válvula aórtica. Obsérvese, por ejemplo, la figura 9.4.
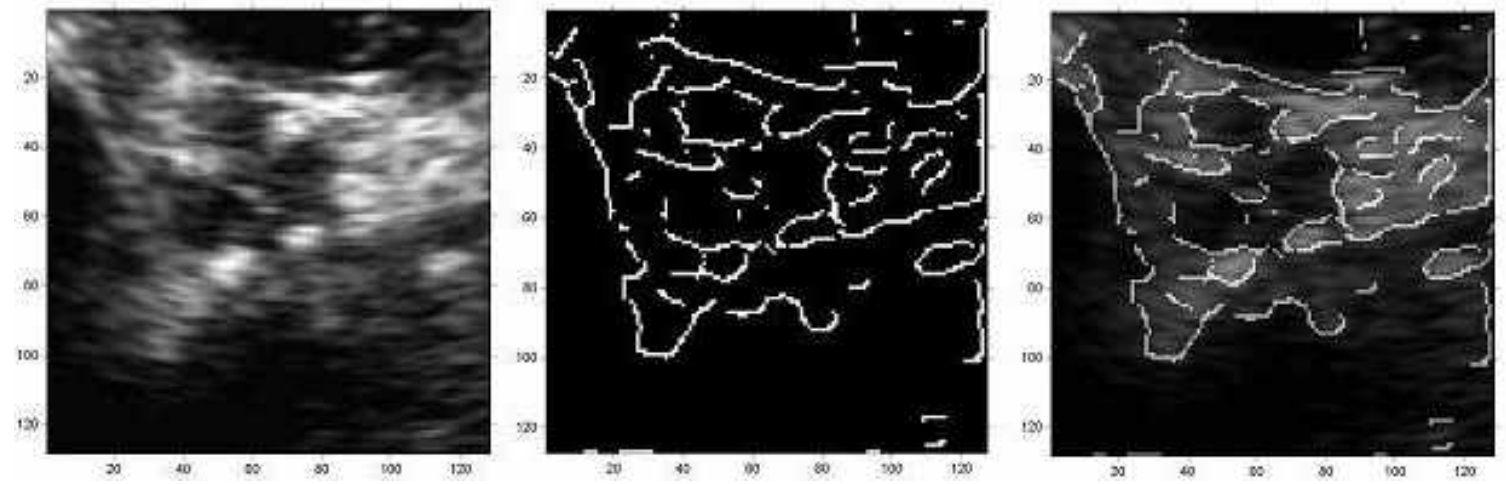

Figura 9.4 Las calcificaciones se confunden con el anillo anatómico de la válvula aórtica.

$3^{\mathrm{a}}$ A los inconvenientes anteriores se añade que, no en pocos casos, la calidad de la ecocardiografía es pobre cuando la "ventana" del paciente es mala. Esto se discutió en el capítulo 4, $\S 4$ 4. Esto dificulta mucho la búsqueda de bordes y limita el estudio sobre una población total de pacientes.

\subsection{Los intentos de reconstrucción del anillo anatómico de la válvula aórtica.}

De la discusión anterior, se desprende que la forma del anillo anatómico de la válvula aórtica, en la mayor parte de los casos, no presente una forma regular (próxima a un círculo) y ésta es una razón fundamental por la cual la reconstrucción no se pudo realizar. Sin embargo, se presenta aquí un caso excepcional de lo que pudo haberse obtenido en las condiciones anticipadas. Este caso se presenta aquí para demostrar la viabilidad parcial de la primer metodología concebida.

En la figura 9.5 se presenta un corte paraesternal de eje corto en diástole de una aorta en la cual los nódulos calcificados se concentran sobre los velos, particularmente alrededor de las uniones de éstos, y no han deformado sensiblemente al anillo anatómico. En este caso, se aprecia una forma elíptica debida probablemente a que el transductor se colocó fuera de la línea perpendicular del eje corto. La ecocardiografía es de una muy buena calidad porque, aun para un inspector humano con poca experiencia, es posible identificar claramente las paredes interna y externa de la aorta. 

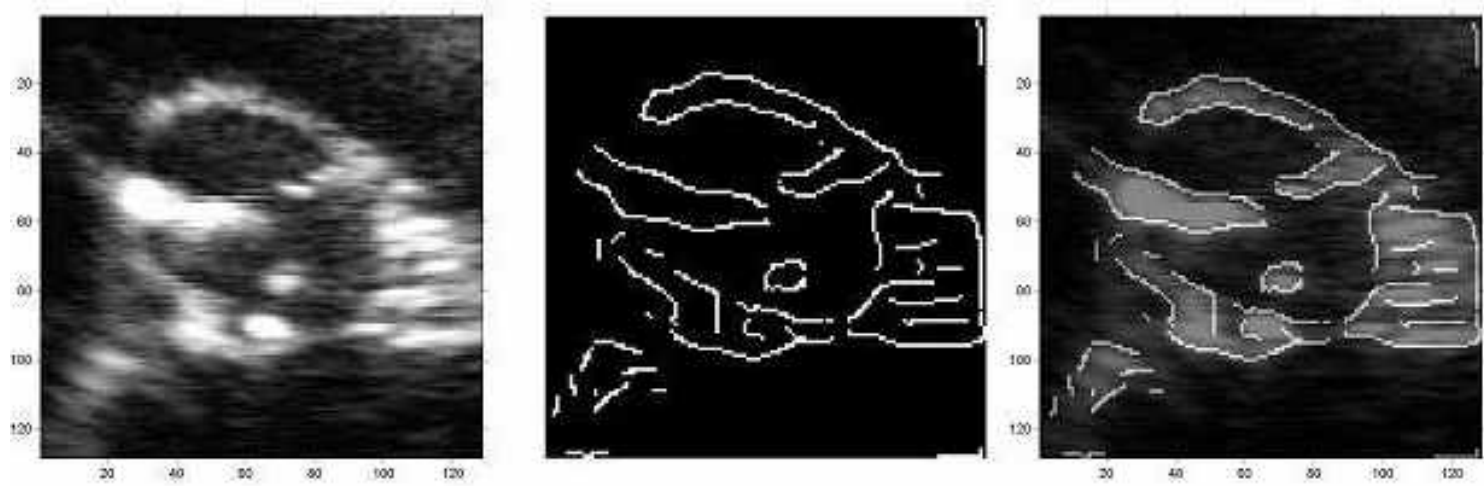

Figura 9.5 Aorta con anillo anatómico bien definido.

En la figura 9.5 se obtiene la estructura de la aorta mediante las técnicas descritas en capítulos anteriores. Nuevamente se nota que la mayor parte de los arcos que forman la elipse del anillo anatómico, una forma regular, queda bien definida por el buscador de bordes. El siguiente paso, de acuerdo a la metodología propuesta en el capítulo 4, consistiría en aislar los arcos de elipse y "encadenarlos" de manera a reconstruir la forma completa del anillo anatómico de la válvula aórtica.

Para saber si la reconstrucción era viable, se aislaron manualmente los arcos del anillo anatómico de la válvula aórtica. Este resultado se muestra en la figura 9.6 a).

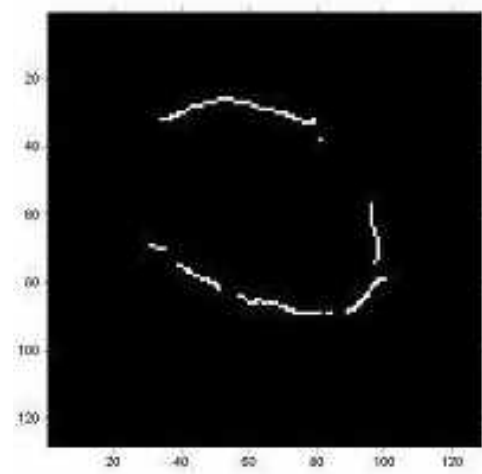

a)

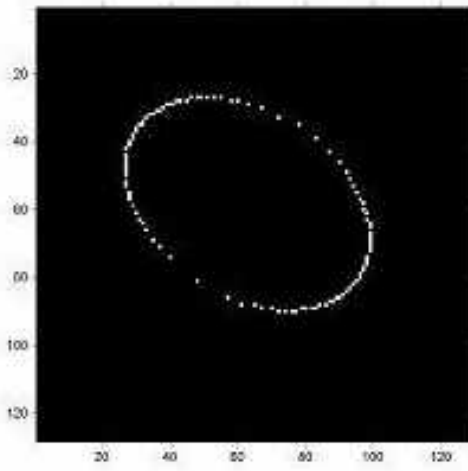

b)

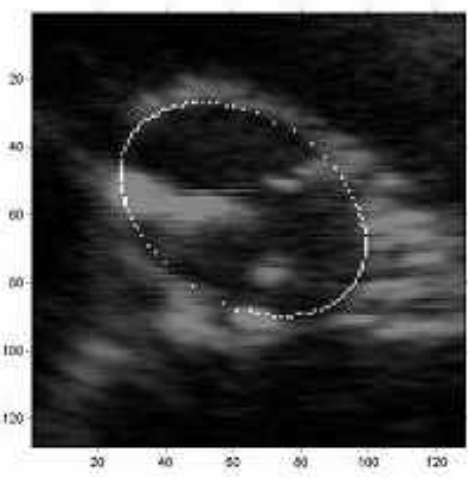

c)

Figura 9.6 Reconstrucción de la forma del anillo anatómico de la válvula aórtica.

Como la forma que se logra percibir corresponde a la de una elipse, se aplicó el algoritmo de ajuste directo de elipses mediante mínimos cuadrados [28] cuyo resultado se muestra en la figura 9.6 b). La fig. 9.6 c) muestra la aproximación entre el borde verdadero del anillo anatómico y la elipse ajustada. Cabe aclarar que la aorta de la fig. 9.6 se encuentra en diástole, pero esta condición no modifica la forma del anillo anatómico y la calcificación solamente se presenta entre la cúspide semilunar posterior y la cúspide semilunar derecha.

A partir de aquí, la integridad de la elipse se podría llevar a cabo mediante algún algoritmo derivado de la transformada Hough. Al respecto, se consultaron las referencias 
[29] y [30]. Sin embargo, como ya se ha adelantado, la reconstrucción de la forma es imposible cuando no se tiene un número suficiente de arcos, como lo demuestran los ejemplos de la figura 9.2. El problema principal de la deformación del anillo anatómico de la válvula aórtica, debida a la aparición de zonas calcificadas en la estructura de la válvula aórtica, no permite la reconstrucción de una forma regular a partir de los bordes encontrados.

\subsection{Diseño de la técnica para la estimación aproximada del área del anillo anatómico de la válvula aórtica.}

Los objetivos generales de este trabajo se vieron comprometidos por los inconvenientes descritos en el párrafo 9.1. Para poder cumplir con los objetivos de trabajo, se decidió estimar el área del anillo anatómico de la válvula aórtica aproximando su forma a la de un círculo, que es la forma original aproximada cuando no existe la calcificación. Se sabía de antemano que la estimación del área sería aproximada, pero se esperaba que el error fuese aceptable en el sentido de poder obtener una conclusión clínica. Este cambio en la metodología obligó a incluir las siguientes operaciones en el protocolo original aplicado a cada paciente:

a) Se incluyó una medición del área del anillo anatómico tal como lo permite el ecógrafo SONOS 5500 de Agilent Technologies (delimitación manual y cálculo automático del área delimitada).

b) Se incluyó una medición del anillo aórtico tal como lo permite el mismo ecógrafo (ubicación de dos marcadores y medición automática de la distancia entre los marcadores).

c) Se procura que la adquisición de la vista paraesternal de eje largo como la de la vista paraesternal de eje corto se realice a un solo valor de profundidad del haz ultrasónico. La profundidad elegida para este trabajo fue de $16 \mathrm{~cm}$, correspondiente a una distancia de 22 pixeles/cm en las imágenes adquiridas.

La medición del área del anillo anatómico de la válvula aórtica realizada con los comandos del ecógrafo serviría para compararla contra la medición del área realizada por el procedimiento que se propone en este trabajo y que se describe más adelante.

La medición del anillo aórtico es necesaria para poder establecer el diámetro del círculo que aproxima al anillo anatómico de la válvula aórtica.

El procedimiento final para trazar el círculo del anillo anatómico y medir su área es del tipo semiautomático y se describe a continuación:

$1^{\circ}$ Se elige una vista paraesternal de eje largo de la aorta en sístole de manera que las valvas no interfieran con la medición del anillo aórtico. 
$2^{\circ}$ Se extrae una imagen con una resolución de $128 \times 128$ pixeles, incluida la sección del anillo aórtico.

$3^{\circ}$ Se aplica la búsqueda poli-escalar de bordes y se conserva el tercer nivel de descomposición donde aparecen los bordes de la estructura de la raíz aórtica.

$4^{\circ}$ Se realiza una búsqueda automática de la distancia del anillo aórtico.

$5^{\circ}$ Se elige una vista paraesternal de eje corto de la aorta en diástole (en esta vista las valvas se cierran y permiten ver las zonas calcificadas).

$6^{\circ}$ Se extrae una imagen de $128 \times 128$ pixeles que contenga únicamente los bordes del anillo anatómico de la válvula aórtica.

$7^{\circ}$ Sobre esta última imagen, se ubica el centro del anillo anatómico de manera manual y con el dato de la distancia se traza el círculo del anillo anatómico.

$8^{\circ}$ El procedimiento final consiste en calcular el área dentro del círculo dibujado alrededor del centro del anillo anatómico. El resultado se puede expresar en pixeles o en $\mathrm{cm}^{2}$ cuando se conoce el número de pixeles por centímetro cuadrado según la profundidad del haz ultrasónico.

\subsubsection{Medición del anillo aórtico.}

A continuación, se ilustra con un ejemplo el procedimiento de la medición aproximada del área aórtica.

1. La figura 9.7 muestra la vista paraesternal de eje largo original a partir de la cual se hará la medición del anillo aórtico. 


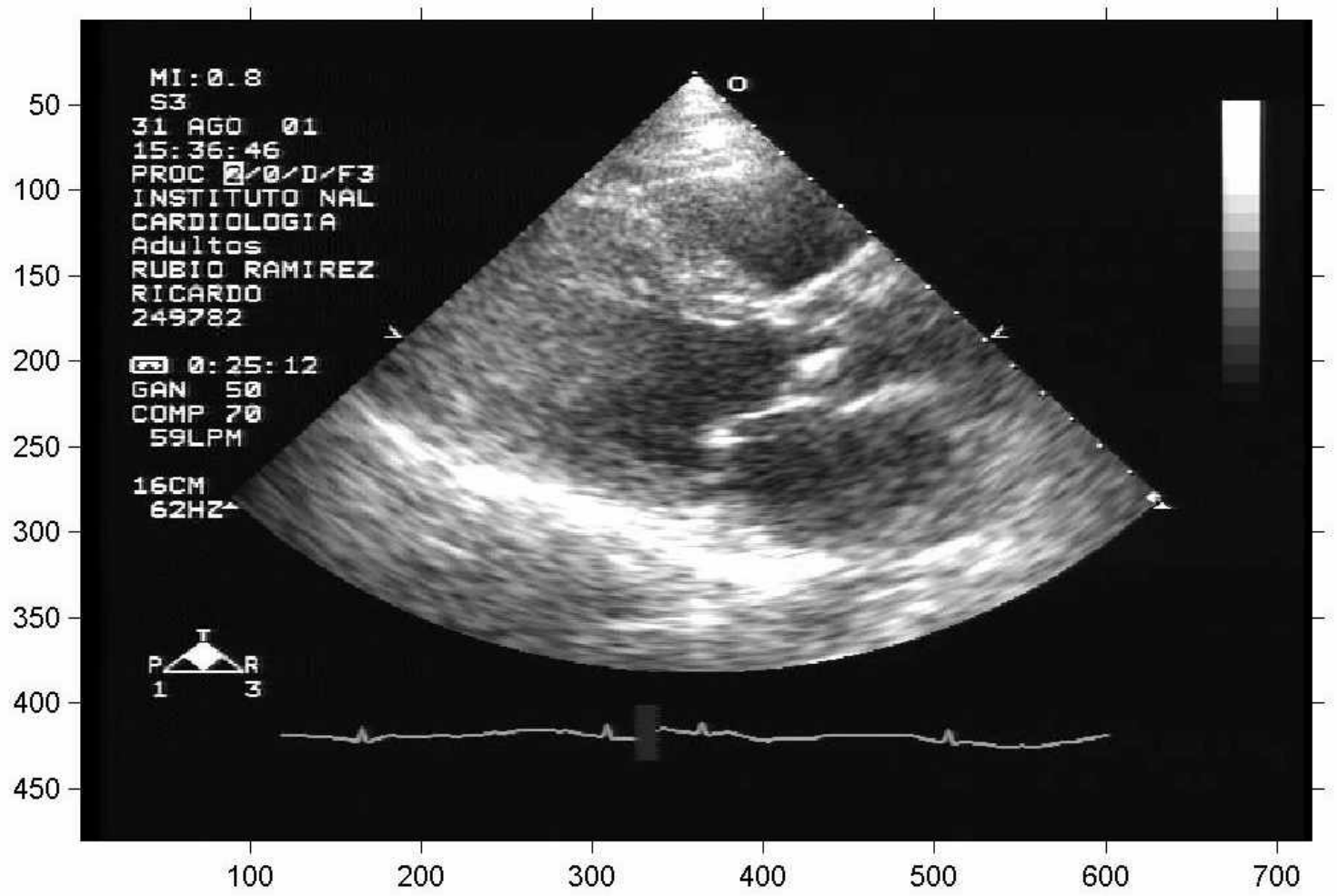

Figura 9.7 Vista paraesternal de eje largo inicial.

2. En la fig. 9.8 se muestra la imagen de $128 \times 128$ pixeles que incluye la sección del anillo aórtico. Esta imagen se extrae de la anterior para reducir el tiempo de procesamiento cuando se aplique la búsqueda de bordes.

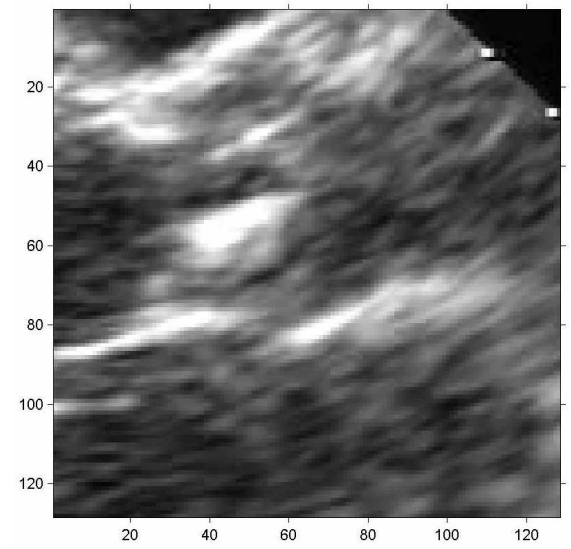

Figura 9.8 Imagen de la válvula aortica. El anillo aórtico está próximo al margen izquierdo del recuadro (imagen de $128 \times 128$ pixeles).

El médico sonografista es quien elige la posición de la raíz aórtica dentro del recuadro de $128 \times 128$ pixeles. La extracción de este detalle de la vista paraesternal se hace con la 
instrucción MATLAB ginput la cual permite de obtener las coordenadas de un pixel en una imagen. Las siguientes instrucciones permiten la extracción del recuadro a partir del pixel localizado por ginput:

$$
\begin{aligned}
& {[x, y]=\text { ginput; } x=\operatorname{round}(x) ; y=\operatorname{round}(y)} \\
& I 2=X(y: y+127, x: x+127)
\end{aligned}
$$

I2 contiene el detalle de la vista paraesternal de eje largo bajo una resolución de $128 \times 128$ pixeles. Es muy importante que la sección del anillo aórtico se encuentre próxima al margen izquierdo de la imagen para permitir la estimación automática de su distancia en una etapa posterior. El médico sonografista debe de tener siempre en cuenta esta posición relativa de la sección del anillo aórtico.

3. La fig. 9.9 muestra el tercer nivel de la búsqueda poli-escalar de bordes donde se logra obtener la forma de la estructura de la raíz aórtica.

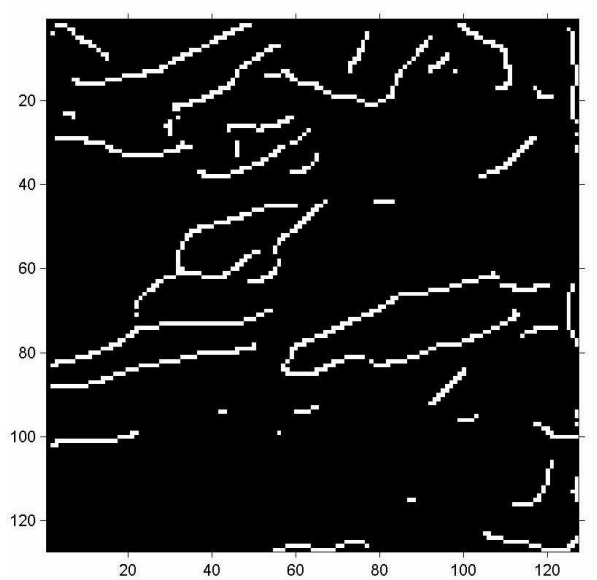

Figura 9.9 La forma de la estructura de la válvula aórtica (bordes en el tercer nivel de descomposición TDW).

A la imagen de la fig. 9.8 se le aplica, invariablemente, la reducción del ruido. Es muy importante que no aparezcan rastros de bordes a lo largo de la sección interna del anillo aórtico porque el algoritmo que estima la distancia de éste lo hace a partir de la localización óptima de los puntos de la pared interna de la aorta que definen la distancia de interés. Recuérdese que esta distancia determina el diámetro del círculo que aproxima la forma del anillo anatómico de la válvula aórtica. En la fig. 9.10 se ha sobrepuesto la ecocardiografía de detalle de la raíz aórtica y el mapa de sus bordes y se ha incluido la línea que define la distancia del anillo aórtico que se trata de medir automáticamente a partir del mapa de bordes. 


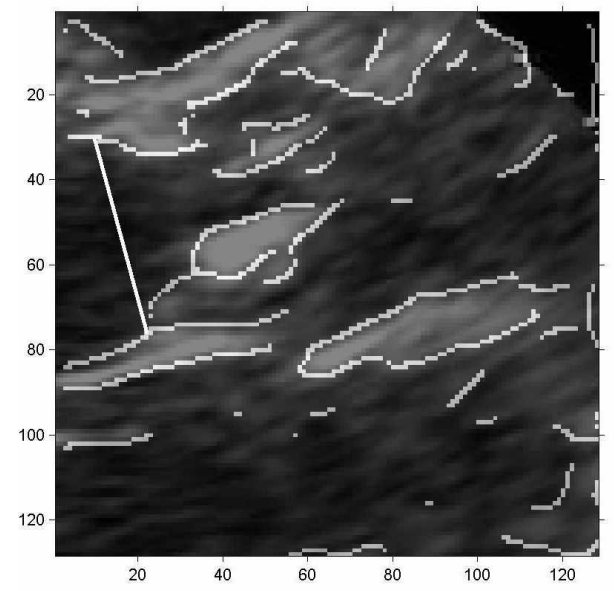

Figura 9.10 Ilustración de la distancia del anillo aórtico.

Si la sección del anillo aórtico está próxima al margen izquierdo de la imagen, se puede encontrar, en un buen número de casos, que esta distancia se encuentra en un sector comprendido dentro de un ángulo máximo de $30^{\circ}$ con respecto a la vertical que coincide justamente con este borde izquierdo. La figura 9.11 ilustra esta observación.

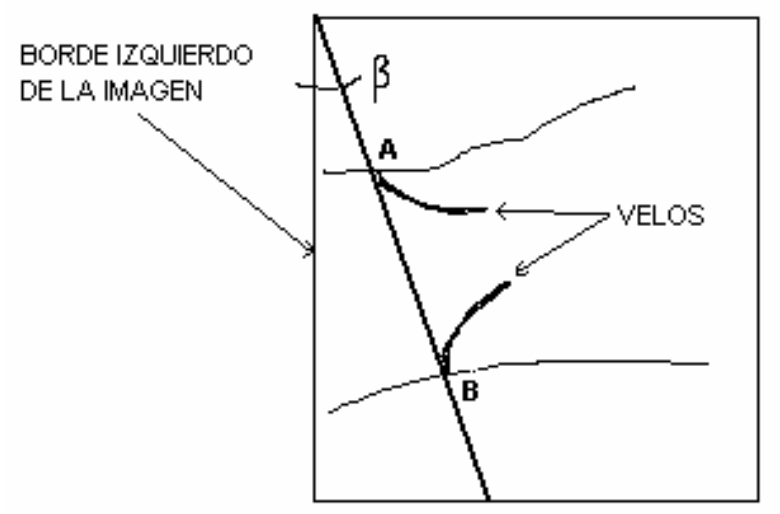

$$
\beta_{\max }=30^{\circ}
$$

A-B DISTANCIA DEL ANILLO AÓRTICO

Figura 9.11 El segmento $\mathrm{AB}$ de la recta que hace el ángulo $\beta$ con respecto a la vertical izquierda del recuadro, define al anillo aórtico.

Bajo las condiciones descritas, se ha diseñado un programa MATLAB que traza líneas rectas que tienen su origen en el renglón 1, columna 1 y que se van distanciando de la vertical hasta un ángulo máximo de $30^{\circ}$. Estas rectas "barren" el sector donde existe probabilidad de encontrar los dos puntos cuya distancia entre sí corresponde a la del anillo aórtico. Para obtener los resultados esperados, es necesario conocer la profundidad de penetración del haz ultrasónico y la cantidad de pixeles por $\mathrm{cm}$. Bajo la técnica de trabajo que se describió en el inciso c) del párrafo 9.3, la búsqueda termina cuando se encuentra la distancia promedio del anillo aórtico establecida en $1.9 \pm 0.2 \mathrm{~cm}$ [1, apéndice A], para la cual corresponde una distancia de $y_{A}-y_{B}$. El apéndice E contiene el programa MATLAB que estima esta distancia. La fig. 9.12 muestra algunos ejemplos de la operación de esta etapa y la tabla 9.1 muestra las mediciones correspondientes sobre los pacientes del protocolo. 


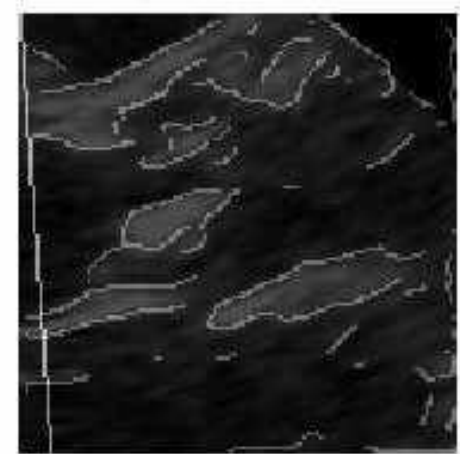

a)

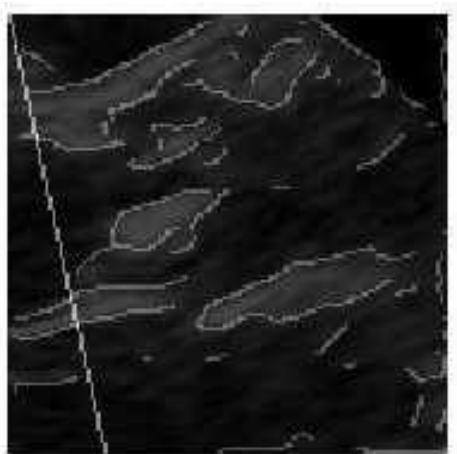

d)

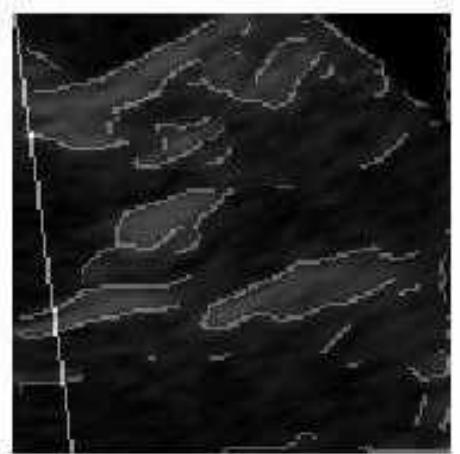

b)

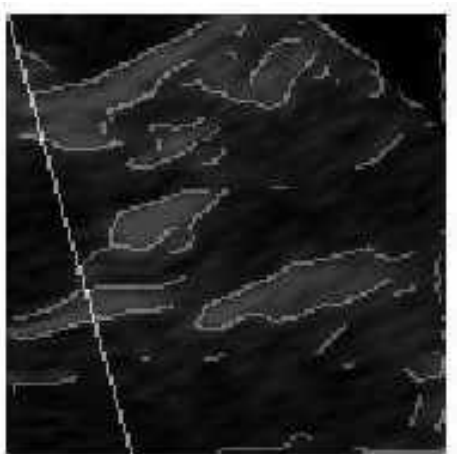

e)

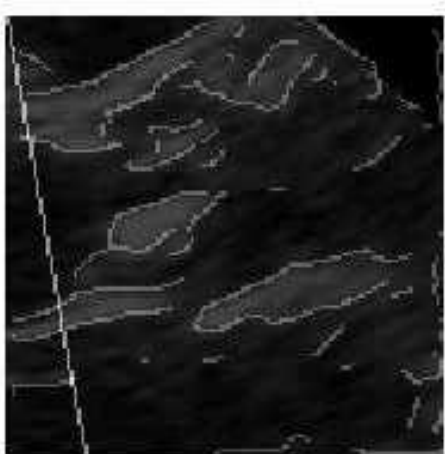

c)

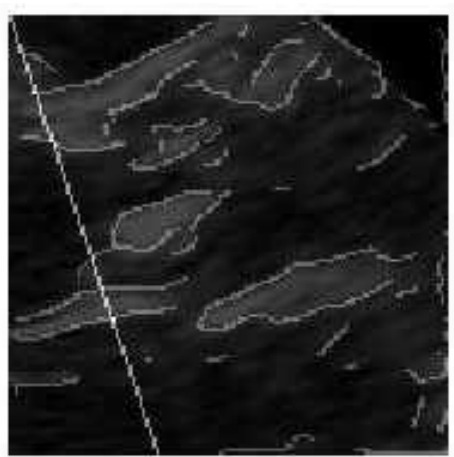

f)

Figure 9.12 Ejemplos de búsqueda del anillo aórtico: a), b) y c) muestran la línea de búsqueda moviéndose dentro del sector de $30^{\circ}$; d) muestra la línea que marca la distancia $\mathrm{AB}$ del anillo aórtico; e) y f) muestran líneas de búsqueda que no sirven pues han rebasado la distancia promedio de $1.9 \mathrm{~cm}$, pero el programa MATLAB las ignora.

\subsubsection{Estimación aproximada del área del anillo anatómico de la válvula aórtica.}

Una vez que se obtiene la distancia del anillo aórtico, este dato se utiliza para trazar el círculo que va a aproximar la forma del anillo anatómico. El procedimiento se ilustra en las diferentes imágenes de la figura 9.13. Una descripción de los pasos ilustrados por esta figura aparece inmediatamente después. 


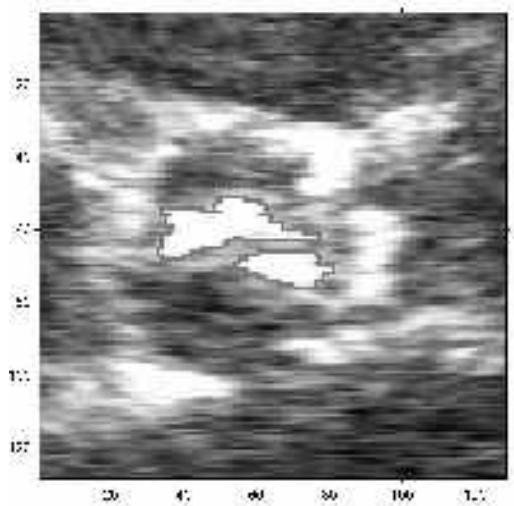

Figura 9.13 Corte paraesternal de eje corto y las áreas calcificadas.

La fig. 9.13 muestra el anillo anatómico de la válvula aórtica tal como lo permite un corte paraesternal de eje corto. La imagen se ha tomado en diástole para permitir la visualización de las áreas calcificadas sobre las valvas. La imagen muestra las áreas calcificadas delimitadas previamente por el algoritmo de crecimiento de regiones. Es sobre esta imagen que el médico sonografista debe colocar el centro del anillo anatómico alrededor del cual se traza el círculo que se aproxima a su área, utilizando la distancia (diámetro) encontrada para el anillo aórtico.

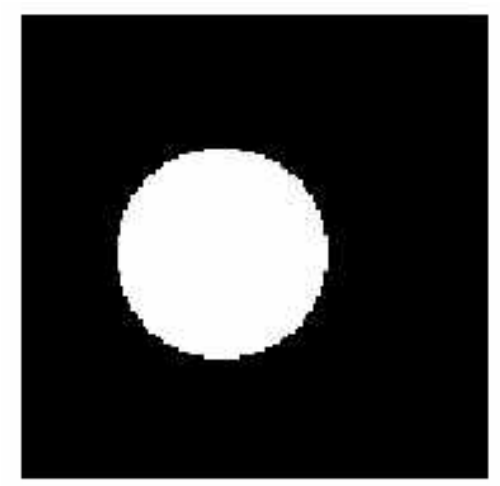

Figura 9.14 Área circular

La fig. 9.14 muestra el área del círculo, en una imagen binaria, como un área blanca. Inicialmente, se traza el perímetro del círculo sobre una imagen de $128 \times 128$ pixeles de fondo negro y una instrucción bwfill rellena de pixeles blancos el área del círculo, aunque es el médico sonografista quien debe marcar con el "mouse" el área que bwfill debe rellenar. El apéndice F explica el desarrollo de la función "traza_círculo" que traza el perímetro circular. 

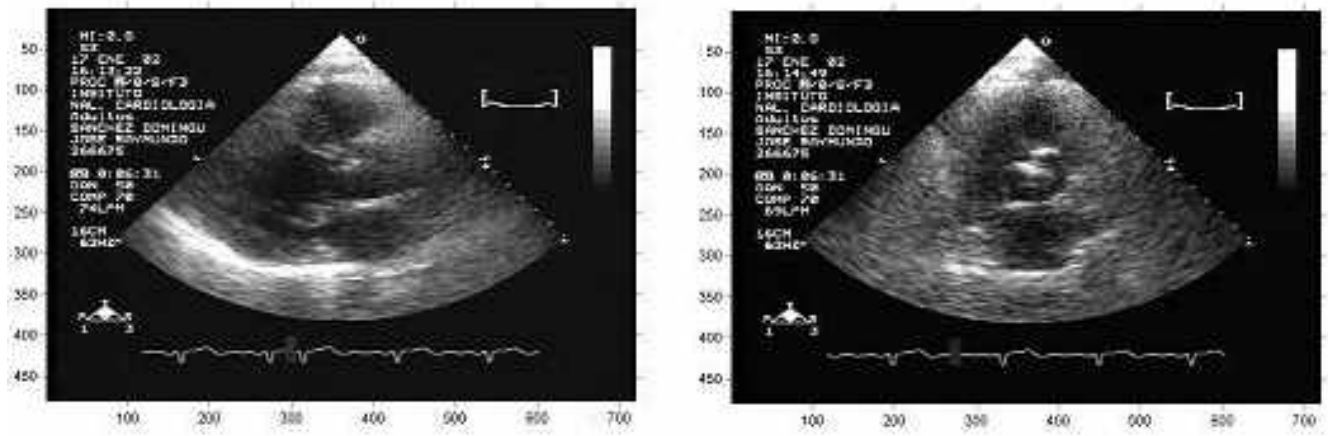

Figura 9.16 a) Ecocardiografías del paciente \#27 del protocolo.
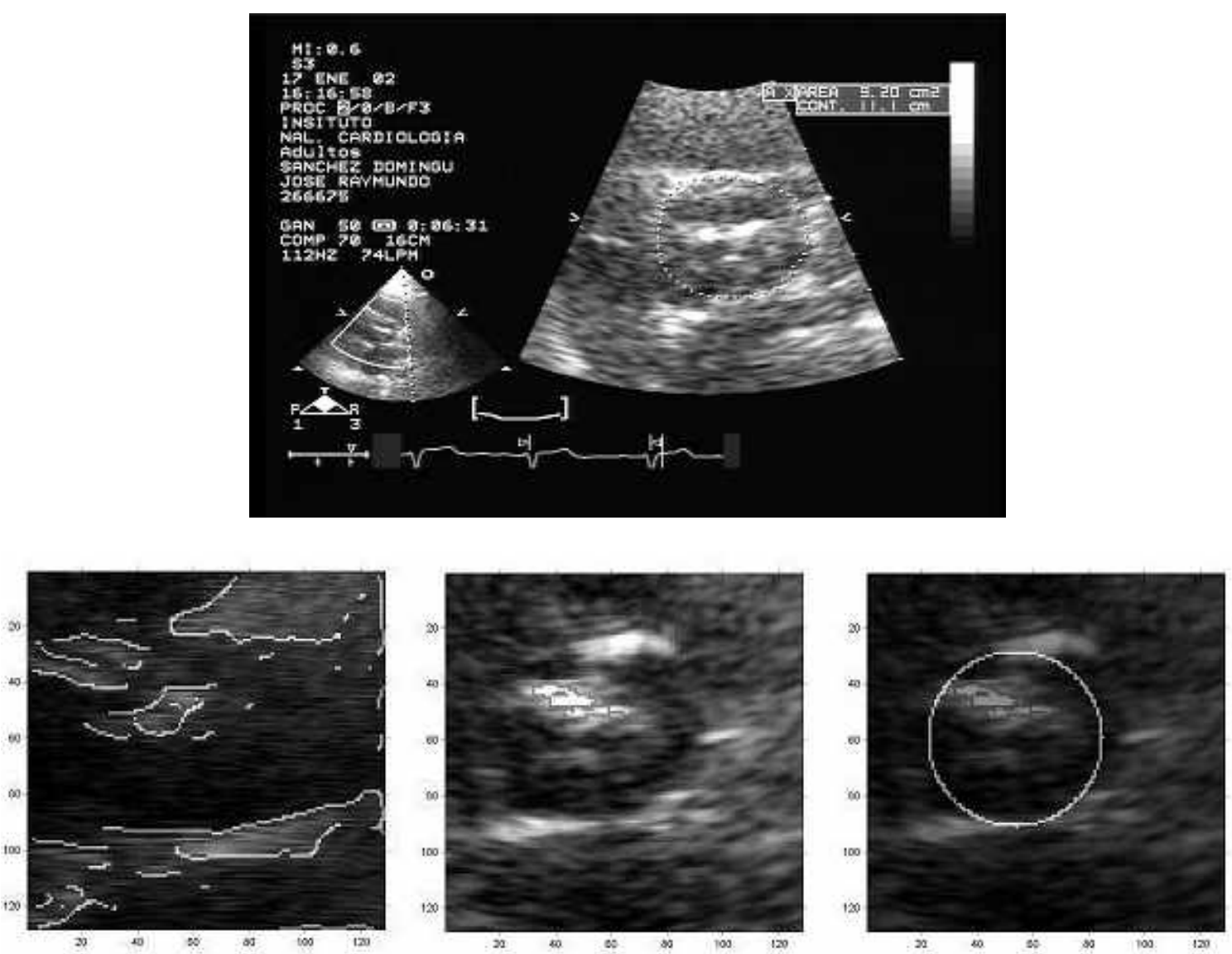

Figura 9.16 b) Imágenes de la cuantificación del calcio del paciente \#27. El círculo se aproxima bien al área del anillo anatómico de la válvula aórtica (área planimétrica $=9.20 \mathrm{~cm}^{2}$, área estimada $=6.47 \mathrm{~cm}^{2}$, error $=$ $29.7 \%)$. 

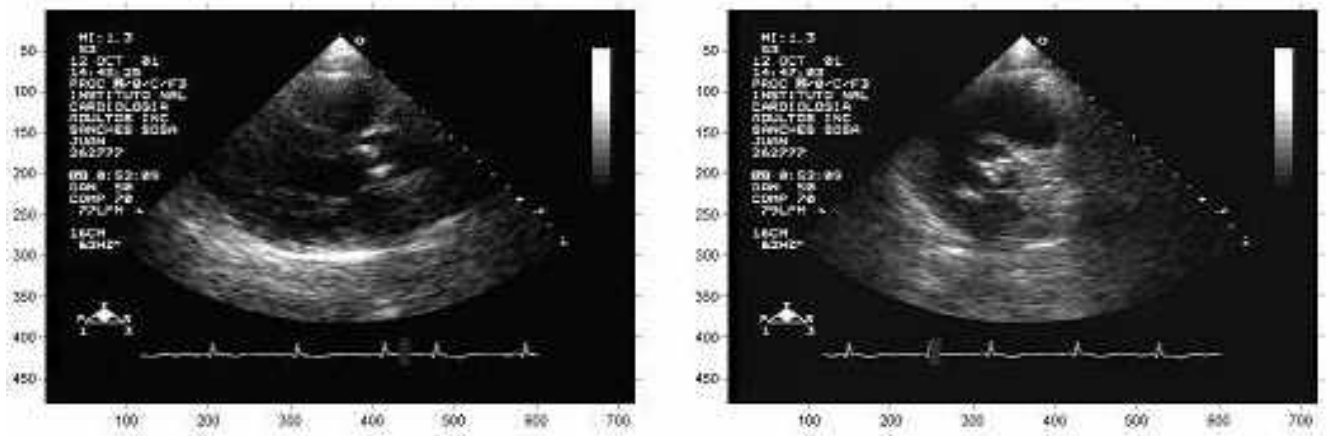

Figura 9.16 c) Ecocardiografías del paciente \#25 del protocolo.
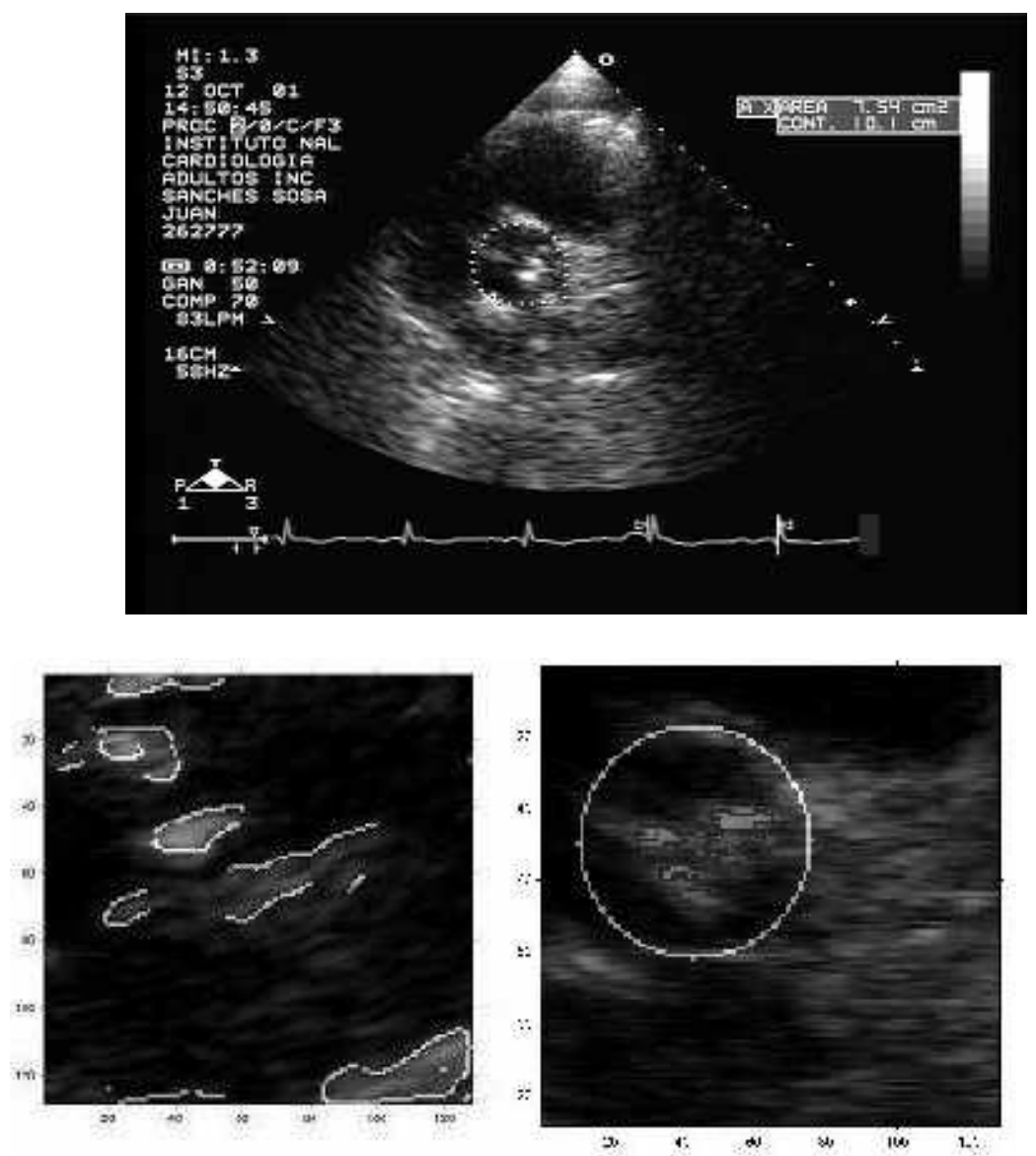

Figura 9.16 d) Imágenes de la cuantificación del calcio del paciente \#25. Existe deformación del lado de la valva coronaria izquierda y el círculo no se aproxima bien al área del anillo anatómico de la válvula aórtica (área planimétrica $=7.54 \mathrm{~cm}^{2}$, área estimada $=7.12 \mathrm{~cm}^{2}$, error $=-5.6 \%$ ). 


\subsection{Resultados.}

La tabla 9.1 muestra la lista completa de pacientes del protocolo, aunque algunos se encuentran fuera de protocolo. La discusión se centra sobre los resultados hallados en los pacientes del último protocolo según lo apuntado en la sección 9.3. La misma tabla muestra cantidades interesantes para la discusión.

\subsection{Discusión.}

Es de notar que cuando no existen limitaciones para la medición del anillo aórtico o una "mala ventana" del paciente, es posible obtener errores entre la medición planimétrica del área del anillo anatómico de la válvula aórtica efectuada con el SONOS 5500 y el área circular de aproximación de menos del 6\%. La fig. 9.17 muestra la comparación entre las áreas medidas en los casos donde las limitaciones fueron mínimas. En estos casos, la cuantificación del calcio que consiste en medir el área del anillo anatómico y diferenciarla del área que ocupan las regiones calcificadas dentro del perímetro del anillo es muy confiable. El error estimado es del $6 \%$.

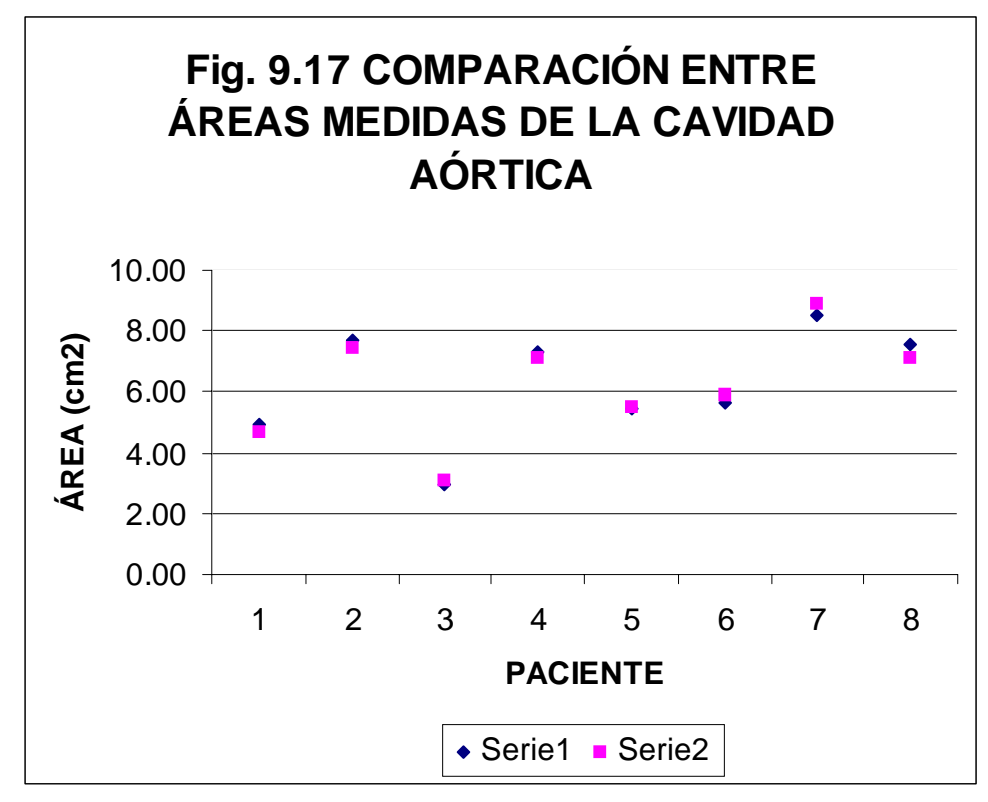

Por otro lado, el Dr. Ángel Romero Cárdenas, subjefe del Departamento de Ecocardiografía del Instituto Nacional de Cardiología "Ignacio Chávez", ha propuesto una medición de las áreas calcificadas de las valvas aórticas a partir de imágenes obtenidas mediante rayos $\mathrm{X}$ de las piezas quirúrgicas de los pacientes del protocolo. Es sabido que el calcio depositado en los tejidos de las valvas aparece como áreas brillantes bien definidas cuando son atravesadas por los rayos X. En estos casos, las áreas calcificadas presentan alta sensibilidad a la radiación y, teóricamente, es posible una cuantificación más precisa del calcio depositado. Los errores son mínimos porque el tejido libre de calcio no refleja los rayos $\mathrm{X}$, no existen capas de tejido intermedios, como en el caso de las ecocardiografías, la 


\begin{tabular}{|c|c|c|c|c|c|c|c|}
\hline $\begin{array}{c}\text { No. } \\
\text { PACIENTE }\end{array}$ & $\begin{array}{c}\text { GRADIENTEE } \\
\text { MEDIO } \\
\text { [mmHg] }\end{array}$ & \begin{tabular}{|c|} 
ÁREA \\
PLANIMÉTRICA \\
[cm2]
\end{tabular} & $\begin{array}{c}\text { ÁREA } \\
\text { CIRCULAR } \\
\text { [pixeles] }\end{array}$ & $\begin{array}{c}\text { ÁREA } \\
\text { APROXIMADA } \\
\text { [cm2] }\end{array}$ & $\begin{array}{c}\text { ERROR } \\
\text { [\%] }\end{array}$ & $\begin{array}{c}\text { CALCIFICACIÓN } \\
{[\%]}\end{array}$ & OBSERVACIONES \\
\hline 1 & 50 & & 2385 & 4,93 & & 2,52 & No se encontró el registro del paciente. \\
\hline 2 & & & 2660 & 6,03 & & 4,53 & Paciente externo. No dejó registro. \\
\hline 3 & 7,84 & 4,26 & & & & & No se nota calcificación en el eje corto \\
\hline 4 & 30 & 4,91 & 2049 & 4,65 & $-5,37$ & 1,11 & $\Delta$ \\
\hline 5 & 108 & 2,92 & 2139 & 4,42 & 51,35 & 11,31 & Anillo aórtico deforme \\
\hline 6 & 2,6 & 8,69 & 3245 & 7,36 & $-15,32$ & 11,94 & \\
\hline 7 & 9 & 2,78 & 2922 & 6,04 & 117,17 & 6,60 & Posible mala calibración de los calipers en el SONOS 5500 \\
\hline 8 & 62 & & & & & & La raíz de la aorta está deformada \\
\hline 9 & 100 & & & & & & Eje corto poco ecogénico. No se pudo cuantificar \\
\hline 10 & 63 & & & & & & Ventana pobre. No se pudo cuantificar. \\
\hline 11 & 21 & 10,60 & 3245 & 6,70 & $-36,75$ & 4,26 & Probable error de medición \\
\hline 12 & 38 & 4,07 & 3040 & 6,28 & 54,32 & 10,27 & Probable error de medición \\
\hline 13 & 27 & 8,77 & & & & & Áreas poco ecogénicas. No se pudo cuantificar. \\
\hline 14 & 45 & 7,72 & 6228 & 7,41 & $-4,07$ & 12,12 & $\nabla$ \\
\hline 15 & 60 & & & & & & Eje corto sin trazas de calcificación. \\
\hline 16 & 42 & 5,16 & 2924 & 9,02 & 74,90 & 7,95 & Baja ecogenicidad. Anillo aórtico muy deforme. \\
\hline 17 & 70 & 2,96 & 2570 & 3,06 & 3,24 & 1,83 & $\Delta$ \\
\hline 18 & 51 & 5,38 & 3245 & 6,70 & 24,62 & 7,65 & Probable error de medición \\
\hline 19 & 90 & 7,28 & 3445 & 7,12 & $-2,23$ & 21,35 & 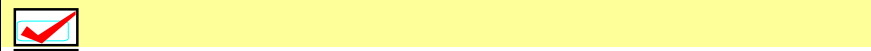 \\
\hline 20 & 46 & 5,48 & 2660 & 5,50 & 0,29 & 14,70 & $\sim$ \\
\hline 21 & 60 & 7,64 & 4322 & 8,93 & 16,88 & 11,68 & Eje largo mal definido \\
\hline 22 & 17,64 & 5,67 & 2852 & 5,89 & 3,93 & 11,85 & 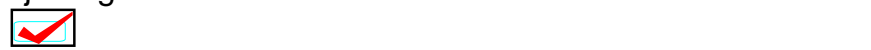 \\
\hline 23 & 41 & 4,46 & 2385 & 4,93 & 10,49 & 19,75 & Anillo aórtico deforme. \\
\hline 24 & $?$ & 8,54 & 4322 & 8,93 & 4,56 & 12,68 & $\nabla$ \\
\hline 25 & 60 & 7,54 & 3445 & 7,12 & $-5,60$ & 8,63 & $\Delta$ \\
\hline 26 & $?$ & & & & & & \\
\hline 27 & 22 & 9,20 & 3131 & 6,47 & $-29,68$ & 3,47 & Probable error de medición \\
\hline
\end{tabular}

Pacientes fuera del primer protocolo.

Mediciones dentro del protocolo.

Profundidad equivocada, pero la corrección se hace en la tabla. 
Tabla 9.1 Cuantificación de la calcificación en la totalidad de los pacientes de la muestra. 
técnica es muy sencilla porque solamente se necesita colocar la pieza quirúrgica al frente de la fuente de radiación y la ayuda de un técnico radiólogo.

Puesto que con esta técnica las áreas calcificadas se observan sin artefactos, este método de la medición de regiones podría constituir un método de validación. Desgraciadamente, existen dos problemas mayores.

$1^{\circ}$ Todo depende de que la pieza quirúrgica se rescate íntegra. Esto no es así en la mayoría de los casos porque el médico cirujano puede tener dificultades en retirar los velos completos debido a la calcificación. Los velos sólo pueden ser retirados como fragmentos y resulta impráctico "armar" los fragmentos para formar los velos. En otras ocasiones, los fragmentos se pierden o el patólogo dispone de la pieza quirúrgica antes de someterla a los rayos X. La figura 9.18 muestra una placa donde se puede apreciar una de las pocas piezas quirúrgicas rescatadas completas.

$2^{\circ} \quad$ Llega a ser evidente que la proyección guardada por el plano de la pieza quirúrgica y la del corte paraesternal de eje corto no coincidirán probablemente nunca. Este es un problema grave al momento de tratar de buscar coincidencias entre las áreas de las dos imágenes.

Por lo tanto, el método propuesto aquí para la cuantificación de la calcificación en la válvula aórtica espera el desarrollo de un método diferente, más exacto, que sirva como método de validación. 

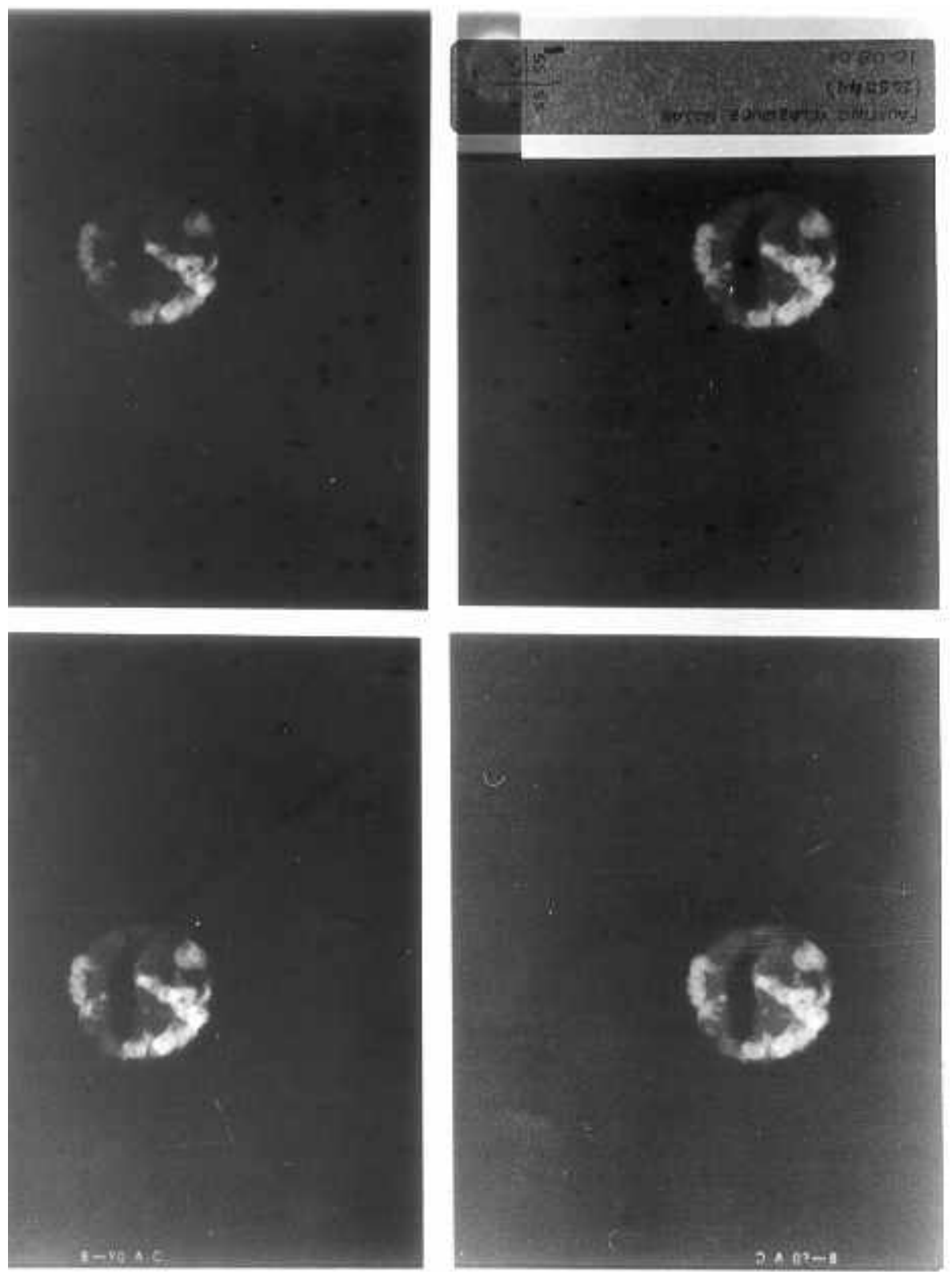

Figura 9.18 Rayos X de las valvas del paciente No. 15.

Es también notable que una radiografía de la pieza quirúrgica puede mostrar evidentes regiones calcificadas mientras que la ecocardiografía de eje corto correspondiente no muestra trazas del calcio. La radiografía de la figura 9.18 es un ejemplo. Esto sólo significa que el médico sonografista sólo puede sospechar de una válvula aórtica calcificada al realizar mediciones del gradiente de presión u observar el patrón Doppler intracavitario. Si el contexto del paciente pone en evidencia la estenosis aórtica, el médico sonografista tendrá que esforzarse en mejorar su técnica de exploración para poder ver las regiones ecogénicas propias de la calcificación. La técnica que permite una buena definición de las regiones calcificadas fue: 
Poder de penetración: $\quad 55 k V_{p}$

Intensidad Rx: $\quad 400 \mathrm{~mA}$

Tiempo de exposición: $\quad 5 \mathrm{~ms}$

Sensibilidad de la película: sensible al verde.

Sólo para fines ilustrativos, la figura 9.19 muestra unos ejemplos ilustrativos de la medición de las regiones calcificadas sobre las placas de rayos $\mathrm{X}$ de dos piezas quirúrgicas rescatadas.
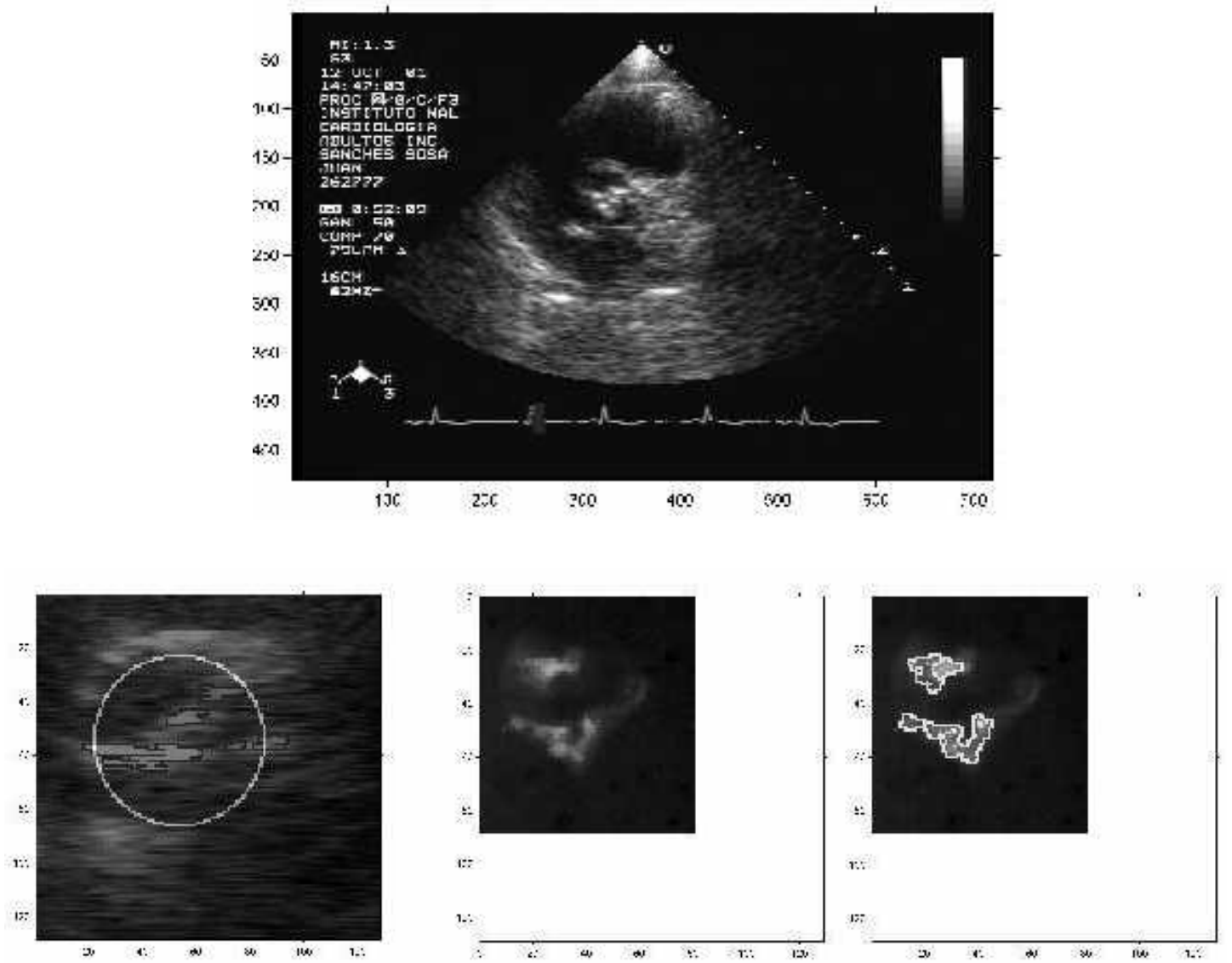

a)

Fig. 9.19 a) Ecocardiografía del eje corto del paciente \#19 y las áreas calcificadas expuestas por los rayos X de su pieza quirúrgica 

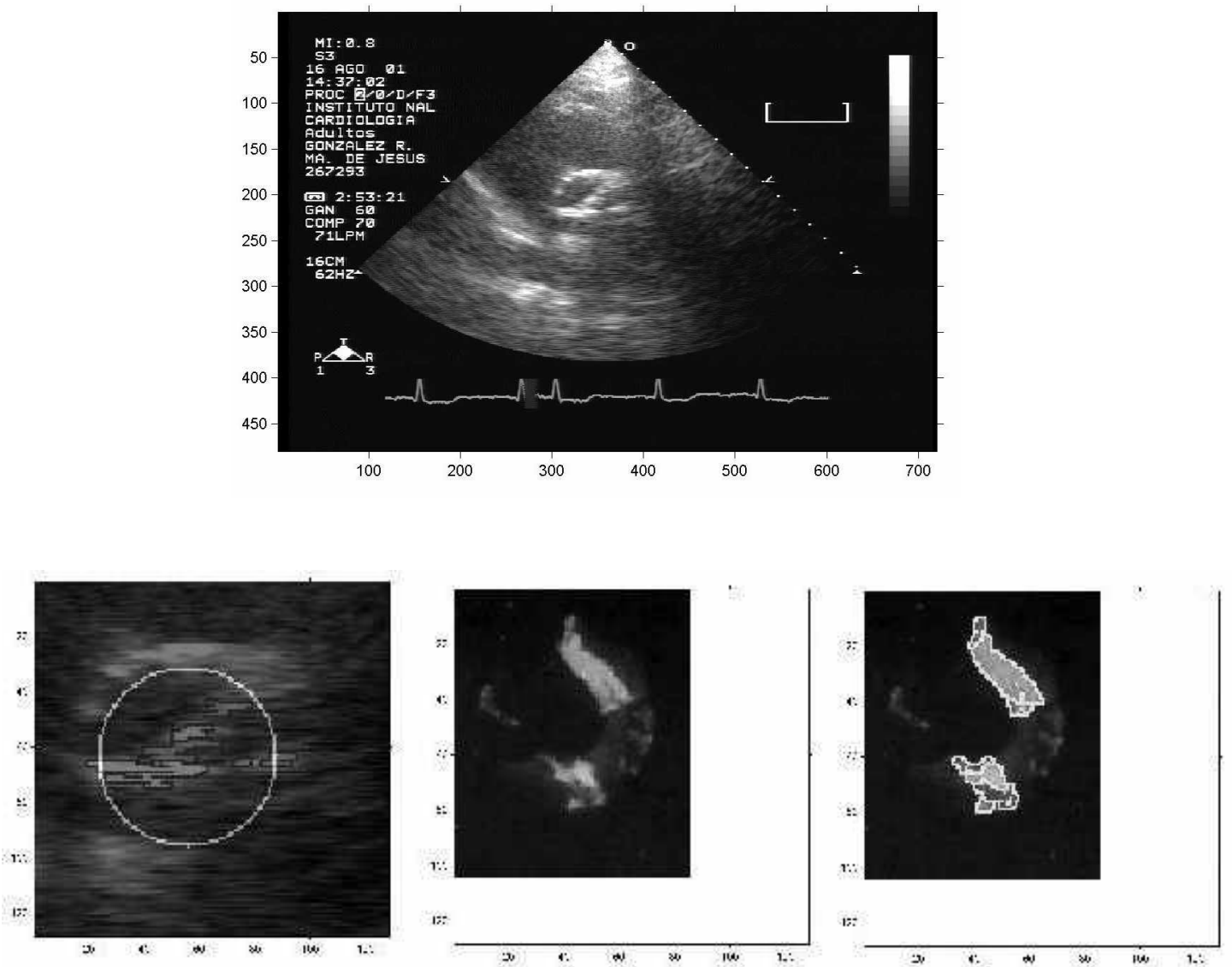

Fig. 9.19 b) ecocardiografía del eje corto del paciente \#25 y las áreas calcificadas por los rayos X de su pieza quirúrgica.

La tabla 9.2 muestra los resultados de la medición de las regiones calcificadas sobre las imágenes de rayos $\mathrm{X}$.

\begin{tabular}{|c|r|r|r||}
\hline $\begin{array}{c}\text { No. } \\
\text { PACIENTE }\end{array}$ & ÁREA Rx & $\begin{array}{c}\text { ÁREA Rx } \\
\text { CALCULADA } \\
\text { [cm2] }\end{array}$ & $\begin{array}{c}\text { ÁREA } \\
\text { MÉTODO } \\
\text { [cm2] }\end{array}$ \\
\hline 19 & 409.63 & 0.7112 & 0.458 \\
25 & 270.13 & 0.469 & 0.489 \\
\hline
\end{tabular}

Tabla 9.2 Las áreas calcificadas de los pacientes del protocolo medidas con el método propuesto y las que aparecen en la radiografía de la pieza quirúrgica.

La discrepancia de las cifras en la tabla 9.2 se debe principalmente a la manera de registrar la imagen ecocardiográfica. Recuérdese que este registro depende de la buena técnica del médico sonografista y la apariencia de las áreas ecogénicas será siempre diferente debido a los movimientos del corazón. Puede suceder también que el médico 
sonografista haya omitido sembrar semillas en áreas que no le resulten, a su juicio, propias de la calcificación y que no aparecen evidentes en la ecocardiografía. Los resultados de la tabla 9.2 son muy limitados porque sólo se obtuvieron 6 placas radiográficas, de las cuales 2 correspondieron a pacientes donde no se pudo hacer la cuantificación debido a la calidad de las ecocardiografías y en las 2 restantes, existe un error muy alto en la medición de las áreas. Las imágenes digitales de las placas de Rayos X se obtuvieron gracias a un "scanner" marca HP, Modelo Scanjet 6100C. Desgraciadamente, el rango dinámico del instrumento no se especifica por el fabricante [34]. 


\section{CONCLUSIONES Y PERSPECTIVAS}

Se diseñó una metodología para la cuantificación del grado de calcificación de la válvula aórtica que utiliza técnicas especializadas de procesamiento digital de imágenes ecocardiográficas para evitar cuantificar subjetivamente la calcificación durante un examen sonográfico de la función del corazón humano.

De acuerdo a los datos contenidos en la tabla 9.1, el grado máximo de calcificación encontrado en esta investigación es de $21.35 \%$, aunque un estudio más extenso podría arrojar porcentajes mayores. Se propone entonces la siguiente escala del grado de calcificación en base al estudio de las imágenes de esta investigación:

\begin{tabular}{|c|c|c|c|c|c|c|}
\hline $\begin{array}{c}\text { GRADO DE } \\
\text { CALCIFICACIÓN }\end{array}$ & 0 & 1 & 2 & 3 & 4 & 5 \\
\hline $\begin{array}{l}\text { PORCENTAJE DE } \\
\text { CALCIFICACIÓN }\end{array}$ & $0 \%$ & $1-5 \%$ & $6-10 \%$ & $11-15 \%$ & $16-20 \%$ & $21-25 \%$ \\
\hline
\end{tabular}

Tabla 10.1 Escala de calcificación de la válvula aórtica de acuerdo al porcentaje de calcificación obtenida por el método propuesto en esta investigación.

Los grados de calcificación pueden aumentar entonces si se encuentran porcentajes de calcificación mayores mediante esta metodología. Sin embargo, no se puede pensar en hablar de grados muy altos (9 ó 10) que correspondan a calcificaciones del 90-100\% porque esta información clínicamente ya no es útil en vista de que el diagnóstico sería evidente.

El método propuesto es limitado porque depende de los siguientes factores:

a) de la adquisición de una ecocardiografía de calidad ("buena ventana del paciente"),

b) de que la forma de la aorta se encuentre conservada,

c) de las habilidades del médico sonografista para localizar los nódulos calcificados y ubicar con buena exactitud el centro de la aorta y

d) de no cometer omisiones en el protocolo de medición.

El método desarrollado en este trabajo es válido sólo en el sentido de detectar y cuantificar las áreas calcificadas de las valvas aórticas. Debido al movimiento del corazón y a la buena técnica de estudio del médico sonografista, la cuantificación de las áreas calcificadas de la aorta obtenida con una imagen única resultaría inexacta. Se puede obtener una cuantificación más exacta al promediar los resultados de varios cortes del eje corto en diástole.

La representación poli-escalar de Mallat y Zhong [21] ha probado ser, en este trabajo, un buen método para separar ruido y características de manera eficaz, simultánea y localmente. La wavelet diádica utilizada en la descomposición wavelet de 
la ecocardiografía localiza apropiadamente las componentes de la señal de pronunciada variación y cuyo alto contenido de energía representan al ruido de moteado.

El ruido de granulado en las ecocardiografías es inherente a ellas y, en la búsqueda de características de tales imágenes, siempre se deberá eliminar o reducir esta clase de ruido. El esquema de supresión de ruido mediante la umbralización suave de Donoho es un método natural cuando se utiliza, como se hizo en este trabajo, una descomposición wavelet de una señal mediante un filtro jerárquico. La wavelet de descomposición se eligió en el sentido de operar con una wavelet con buenas propiedades de localización para poder resolver bien la búsqueda de bordes y se mejoró el criterio para la supresión de ruido propuesto por Donoho al tener en cuenta la energía del ruido en los diferentes niveles de descomposición. La función de escalamiento correspondiente al análisis poliresolución que se investigó y aplicó en este trabajo permite reconstrucciones de la señal con altos valores de la PSNR (PSNR $>+33 \mathrm{~dB}$ ) y la reconstrucción es visualmente aceptable.

El método de cuantificación de la calcificación de la válvula aórtica, propuesto aquí, es conveniente por las siguientes razones:

a) Pertenece a la modalidad no invasiva (examen transtorácico), por lo tanto, no ofrece molestias al paciente y no hay evidencias de daños debidos a la exposición de la onda ultrasónica durante el tiempo de un estudio normal.

b) El registro de las imágenes sólo exige al médico ultrasonografista habilidades similares a las del manejo de los controles de un ecógrafo.

c) El tiempo de procesamiento es pequeño (menor a 4 minutos).

d) La técnica de examen ecocardiográfica es sencilla, no requiere de una preparación especial por parte del paciente y los medios de registro son baratos (cintas magnéticas o discos compactos).

e) Puede utilizarse como herramienta de entrenamiento para desarrollar la capacidad de los médicos sonografistas para detectar nódulos calcificados en la válvula aórtica.

En la clínica, la información sobre la extensión de los nódulos calcificados en los velos de la válvula aórtica no se cuantificarían más de manera subjetiva como se viene haciendo en el INC. Los médicos sonografistas pueden utilizar el software desarrollado aquí para estudiar la extensión y distribución del calcio en cada valva, sea en el caso tricúspide o bicúspide, la incidencia de la calcificación, la evaluación de la función de la válvula aórtica y diagnósticos más precisos o informaciones útiles para el médico cirujano.

La escala del grado de calcificación que se ha propuesto sirve sólo a propósitos de diagnóstico y una estratificación más discreta de sus niveles está a discusión por parte de la comunidad médica. 
Se ha querido incluir aquí, a manera de ejemplo, el resultado clínico de relacionar el grado de calcificación y el gradiente intracavitario al nivel de la válvula aórtica que es una medida de la estenosis aórtica. La figura 10.1 muestra esta relación. 
Fig. 10.1 Relación entre calcificación aórtica y gradiente de presión aórtico

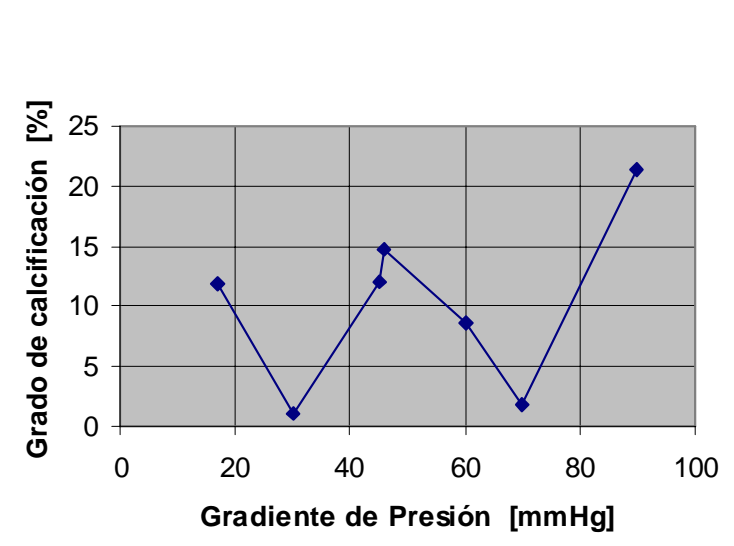

La gráfica corresponde a los pacientes donde el error entre el área del anillo anatómico de la válvula aórtica aproximada por el método y el área planimétrica obtenida con el ecógrafo es menor al 6\%. Es claro que de esta gráfica no se puede concluir que la estenosis aórtica dependa exclusivamente del grado de calcificación como se adelantaba en la sección 2.3 y según la referencia [3a,p.1036]. Los casos donde existen altos grados de calcificación y bajos grados de gradiente aórtico se pueden deber a una deficiente función del corazón. En los casos opuestos podría existir dilatación del ventrículo izquierdo. Cobra importancia el contexto del paciente y, tal como se había explicado en el capítulo 2, el método permite añadir nueva información al estado del paciente.

Informaciones más útiles sólo se pueden encontrar realizando estudios prospectivos o seguimientos clínicos de los pacientes con válvulas aórticas calcificadas. Se piensa que aplicando la técnica de cuantificación sería posible relacionarla directamente con la estenosis aórtica en poblaciones específicas (>60 años). Sería posible encontrar los factores dominantes que produce esta patología en el contexto nacional y, de esta manera, evitar de deducir conclusiones a partir de estudios generados en el extranjero. También es de esperar que un estudio prospectivo revele la manera de estimar el tiempo que transcurrirá antes de que un paciente se someta a una valvuloctomía.

El método propuesto es prometedor y se ha logrado adaptar modelos matemáticos utilizados en el procesamiento digital de señales a criterios clínicos que se han vuelto confiables debido a la experiencia acumulada. Además, las técnicas empleadas son novedosas en la cuantificación del calcio en la válvula aórtica, tal como se hizo aquí. La estimación del área del anillo anatómico de la válvula aórtica, se hizo mediante la aproximación de ésta con la de un círculo. El diámetro de este círculo se calcula en base a la medición automática del anillo aórtico, el cual, en la mayoría de los casos estudiados, se conserva dentro de la tolerancia (Cf. Capítulo 9). Esto evita de trazar un círculo cuyo diámetro o radio dependiera de criterios subjetivos, como el colocar un centro y un punto en algún lugar del perímetro del anillo anatómico en la vista paraesternal de eje corto. Por lo tanto, el grado de calcificación se calcula plenamente sobre criterios objetivos. 
Finalmente, el método para la cuantificación del grado de calcificación de la válvula aórtica, propuesto en esta investigación, establece la existencia de calcio y su extensión y ayuda a mejorar el diagnóstico del médico cardiólogo.

\section{PERSPECTIVAS}

- Los bordes en el tercer nivel de descomposición de la región del corazón donde se confunden las estructuras del ventrículo izquierdo, el ventrículo derecho, la válvula tricúspide y la cúspide no coronaria de la válvula aórtica, en sístole, no se detectan bien en la mayoría de los casos estudiados. Se propone una búsqueda de estos bordes en niveles de descomposición más finos para integrar un mapa de bordes del anillo anatómico de la válvula aórtica más completo y, de esta manera, tener un área más exacta de éste.

- Las deformidades presentadas por el anillo anatómico de la válvula aórtica debidas a la calcificación de la válvula impiden aislar un mapa de bordes regulares (arcos de elipse o de círculo) de este anillo y, por esta misma razón, el encadenamiento de bordes no puede beneficiarse de algoritmos como el de la transformada Hough. La utilización de algún tipo de máscara junto con el uso de filtros de coincidencia podrían hacer posible aislar el contorno del anillo anatómico. El encadenamiento de la forma final, si se cuenta con los suficientes puntos, se puede aproximar mediante polinomios spline. El alcance de esta investigación permitió cumplir con los objetivos planteados mediante un método de aproximación, pero se piensa que es factible encontrar un método más exacto de cuantificación. El análisis poli-escalar orientado a la detección de bordes que se desarrolló y justificó en este trabajo (capítulo 5), se diseñó expresamente para el propósito explicado en la metodología (capítulo 4). Las soluciones a los problemas encontrados posteriormente podrían encontrarse en nuevos periodos de investigación de diferente acotación.

- Detalles de los bordes del anillo anatómico de la válvula aórtica podrían encontrarse en las escalas anteriores y posteriores a la escala 3. La combinación de todos estos bordes podría formar un mapa más completo y dar direcciones más correctas para hacer los encadenamientos. Estos bordes adicionales podrían aislarse como se mencionó en el párrafo anterior.

- Investigar wavelets con mejores propiedades de localización podrían mejorar la integridad de un mapa de bordes y ayudar a separar con mejor resolución los coeficientes wavelet que representan el ruido de granulado. Un buen modelo del ruido en ecocardiografías es un problema abierto.

- El método se puede extender al estudio de la calcificación de la válvula mitral. Puesto que es posible el procesamiento de imágenes de detalle donde sólo aparezcan las estructuras interesantes, se podrían hallar automáticamente los nódulos calcificados en la válvula mitral o la aórtica, es decir, sin la intervención del médico sonografista, una vez que se tenga resuelta el área exacta del anillo anatómico en cuestión. 
- Será tarea de investigadores médicos aplicar este método de cuantificación en el descubrimiento de factores determinantes de alguna cardiopatía que involucre calcificación de estructuras tisulares. 


\section{REFERENCIAS.}

[1] C. M. Otto, A. S. Pearlman, Textbook of Clinical Echocardiography, W. B. Saunders Co. Ed. 1995. ISBN 0-7216-6634-5, pp. 29-41, 209-242, 263-264.

[2] W. L. Henry, A. DeMaria, R. Gramiak, D.L. King, J. A. Kisslo, R. L. Popp, D. J. Sahn, N. B. Schiller, A. Tajik, L. Teichholz, A. E. Weyman, Report of the American Society of Echocardiography Comittee on Nomenclature and Standards in Twodimensional Echocardiography, Circulation, Vol. 62, No. 2, Agosto 1980.

[3] A. E. Weyman, Principles and Practice of Echocardiography, Lippincott Williams and Wilkins, $2^{\text {nd }}$ Ed. 1994, Apéndice A, "Normal Cross-Sectional Echocardiographic Measurements”, pp. 1289-1298.

[3a] Heart Disease, A Textbook of Cardiovascular Medicine, Vol. 2, editado por Eugene Braunwald, W. B. Saunders Co., $5^{\text {th }}$ Ed., 1997, Capítulo 32 "Valvular Heart Disease", pp. 1007-1104.

[4] C. R. Schott, M. N. Kotler, W. R. Parry, B. L. Segal, Mitral Annular Calcification, Arch. Intern. Med., Vol. 137, pp 1143-1150, Sept. 1977.

[5] N. Dashkoff, M. Karacuschansky, P. C. Come, N. J. Fortuin, Echocardiographic Features of Mitral Annulus Calcificacion, American Heart Journal, Vol. 95, No. 5, pp 585-592, Nov. 1977.

[6] W. L. Curati, R. Petitclerc y F. Winsberg, Ultrasonic Features of Mitral Annulus Calcification, Radiology 122:215-217, Enero 1977.

[7] I. A. D'Cruz, H. C. Cohen, R. Prabhu, V. Bisla, G. Glick, Clinical Manifestations of Mitral Annulus Calcification with Emphasis on its Echocardiographic Features, American Heart Journal, Vol. 94, No. 3, pp 367-377.

[8] R. Ross, The Pathogenesis of Atherosclerosis, New England Journal of Medicine, Vol. 314, No. 8, pp 488-500.

[9] B. F. Stewart, D. Siscovick, B. K. Lind, J. M. Gardin, J.S. Gottdiener, V. E. Smith, D. W. Kitzman, C. M. Otto, Clinical Factors Associated with Calcific Aortic Valve Disease, J. Am. Coll. Cardiol. 1997; 29:630-4.

[10] M. Lindroos, M. Kupari, J. Heikkilä, R. Tilvis, Prevalence of Aortic Valve Abnormalities in the Elderly: An Echocardiographic Study of a Random Population Sample, J. Am. Coll. Cardiol. 1993; 21:1220-5.

[11] W. F. Armstrong, Echocardiographic Evaluation of Valvular Heart Disease, Editor's Notebook, ACC July/august 1998, pp 69-73. 
[12] A. N. De Maria, W. Bommer, J. Joye, G. Lee, J. Buuteller, D. T. Mason, Value and Limitations of Cross-sectional Echocardiography of the Aortic Valve in the Diagnosis and Quantification of valvular Aortic Stenosis, Circulation 62, No. 2, 1980, pp 304-312.

[13] H. Feigenbaum, Echocardiography, $5^{\text {th }}$ edition (October 1995) Lea \& Febiger, ISBN: 0812116925.

[14] Alphabetical Control Summary, HP SONOS 5500 Imaging System, Reference Guide Version A.0, Hewlett Packard Co., $1^{\text {st }}$ Ed. June 1997, Publication number M2424-95520.

[15] www.hp.co./go/ultrasound

[16] K. R. Castleman, Digital Image Processing, Prentice Hall, 1996, p. 468.

[17] R. Adams, L. Bischof, Correspondence: Seeded Region Growing, IEEE Trans. on Patt. Anal. and Machine Intell., Vol. 16, No. 6, June 1994, pp 641-647.

[18] S. Mallat, A Wavelet Tour of Signal Processing, Academic Press, $2^{\text {nd }}$ Ed. 1999.

[19] G. Strang, T. Nguyen, Wavelets and Filter Banks, Wellesley-Cambridge Press, 1996.

[20] X. Zong, A. F. Laine, E. A: Geiser, Speckle Reduction and Contrast Enhancement of Echocardiograms via Multiscale Nonlinear Processing, IEEE Trans. on Medical Imaging, Vol. 17, No. 4, Agosto 1998.

[20 bis] Anil K. Jain, Fundamentals of Digital Image Processing, Prentice Hall, 1989.

[21] S. Mallat, S. Zhong, Characterization of Signals from Multiscale Edges, IEEE Trans. on Information Theory, Vol. 38, No. 2, Marzo 1992.

[22] S. Mallat, W. L. Hwang, Singularity Detection and Processing with Wavelets, IEEE Trans. on Information Theory, Vol. 38, No. 2, Marzo 1992.

[23] J. Canny, A Computational Approach to Edge Detection, IEEE Trans. on Patt. Anal. and Machine Intell., Vol. PAMI-8, No. 6, Nov. 1986.

[24] S. Mallat, S. Zhong, Wavelet Maxima Representation, en Wavelets and Applications, Proceedings of the International Conference, Marseille, France, May 1989, Yves Meyer Ed., Masson/Springer-Verlag, 1992.

[25] http://www.cs.bham.ac.uk/research/poplog/popvision/help/canny

[26] D. L. Donoho, De-Noising by Soft-Thresholding, IEEE Trans. on Information Theory, Vol. 41, No. 3, May 1995.

[28] A. Fitzgibbon, M. Pilu, R. B. Fisher, Direct Least Square Fitting of Ellipses, IEEE Trans. on Pattern Anal. and Machine Intell., Vol. 21, No. 5, May 1999. 
[29] R. A McLaughlin, Technical Report-Randomized Houhg Transform: Improved Ellipse Detection with Comparison, Univ. Western Australia, 1996.

[30] A. S. Aguado, M. S. Nixon, A New Hough Transform Mapping for Ellipse Detection, Technical Report, University of Southampton, Department of Electronics and Computer Science, 1995, 1995/6 Research Journal.

[31] W. M Newman, R. F. Sproull, Principles of Interactive Computer Graphics, McGraw-Hill, $2^{\text {nd }}$ Ed., 1981.

[32] http://www.ilovemaths.com/3parametric.htm

[33] J-C. Feauveau, Nonorthogonal multiresolution Analysis Using Wavelets, en wavelets: A tutorial in Theory and Applications, C. K. Chui (Ed.), pp 153-178, Academic Press, 1992.

[34] http://www.hp.com/cgibin/cposupport/printerfriendly.cgi?in=scanners/support doc/bps03600 


\section{GLOSARIO}

Anillo Anatómico de la Válvula Aórtica, o simplemente anillo anatómico, es aquél que está definido como el perímetro que circunscribe el área de la raíz aórtica y la base de implantación de las valvas o velos de la válvula aórtica.

Doppler. La ecocardiografía Doppler está basada en el cambio de frecuencia de la señal reflejada por pequeñas estructuras en movimiento (glóbulos rojos) interceptadas por el haz ultrasónico. Este cambio en la frecuencia se puede utilizar para calcular la velocidad de flujo de la sangre y su dirección.

Ecogénico. Es un término sinónimo de brillantez. Es un término de la jerga médica para caracterizar una imagen ecocardiográfica que "genera gran cantidad de ecos", es decir, que aparece muy brillante en el modo B de un ecógrafo.

Fenestrada. Fenestra es un término en desuso sinónimo de ventana y se ha utilizado aquí para referirse a las transformadas de Fourier acotadas (windowed Fourier transform) y evitar de utilizar el verbo coloquial "transformada de Fourier ventaneada". La relación con el término "ventana" (window) es muy común en la literatura de procesamiento de señales.

“Mala ventana". Es un término empleado por los médicos sonografistas para calificar una imagen sonográfica de poca calidad, es decir, con contornos mal definidos, formas poco claras y gran cantidad de ruido de moteado, aun después de haber mejorado la técnica tomográfica.

Modo B. Es el modo de visualización ecocardiográfico en 2D, también conocido como modo de la brillantez dinámica.

Modo M. Es el modo de visualización ecocardiográfico que grafica la posición de los ecos de un objeto en función del tiempo.

Píxel. Acrónimo de las palabras inglesas picture element que denotan al mínimo elemento de información de una imagen digitalizada.

Segmentación. El término se refiere a cualquier técnica imagenológica que sirve para aislar una porción de una escena con características buscadas.

TDW. Transformada Diádica Wavelet.

TDWD. Transformada Diádica Wavelet Discreta.

TDWD2D. Transformada Diádica Wavelet Discreta 2D.

TDWR. Transformada Diádica Wavelet Rápida. 


\title{
APÉNDICE A.
}

\section{PROTOCOLO DE ESTUDIO.} MATERIAL Y MÉTODO.

\author{
Estudio descriptivo, en el que se realizó una medición del grado de cuantificación \\ de la válvula aórtica.
}

Población en Estudio.

Se incluyeron pacientes adultos, de ambos géneros, que se encontrasen hospitalizados y programados para tratamiento quirúrgico de estenosis aórtica con reemplazo valvular aórtico.

\section{Protocolo.}

A todos los pacientes se les realizó un estudio ecocardiográfico bidimensional y Doppler con un ecógrafo SONOS 5500 de Agilent Technologies, utilizando una sonda S3, con una profundidad de $16 \mathrm{~cm}$, los restantes parámetros fueron ajustados según protocolo establecido (Cf. Capítulo 4). Se utilizaron para realizar las mediciones los ejes paraesternal izquierdo largo, paraesternal izquierdo corto y apical de 4 cámaras. En los ejes paraesternal izquierdo largo y corto les fueron realizadas la medición del anillo aórtico en cm, del área de la válvula aórtica obtenida por planimetría de la misma, así como adquisición de imágenes bidimensionales en diástole y sístole de ambos ejes para cálculo por algoritmos del grado de calcificación. En el eje apical de 4 cámaras y mediante técnica Doppler, se realizó medición del gradiente transvalvular aórtico, para evaluar la severidad de la estenosis.

Se concertó con el Servicio de Anatomía Patológica del Instituto Nacional de Cardiología "Ignacio Chávez", el préstamo de la pieza anatómica para la adquisición de imagen radiológica de la misma, la cual serviría para evaluación del método de cuantificación. Esto, lamentablemente no fue posible en la mayoría de los casos, ya que dado que eran válvulas patológicas, su extracción se realizó en muchos casos en fragmentos no reconstruibles para el propósito del estudio.

Con la imagen radiológica obtenida se realizó un crecimiento de regiones para tratar de comparar las áreas radio-opacas por rayos $\mathrm{X}$ con las áreas ecogénicas obtenidas por Ecocardiografía y con esto tratar de validar el método.

Fueron eliminados del estudio, los pacientes con imágenes ecocardiográficas inadecuadas para la evaluación del grado de cuantificación. 


\section{APÉNDICE B.}

\section{ANATOMÍA DE LA AORTA EN LOS PLANOS TOMOGRÁFICOS DE IMAGEN UTILIZADOS EN ESTE TRABAJO DE INVESTIGACIÓN.}

El Comité en Nomenclatura y Normas de la Sociedad Americana de Ecocardiografía [2] ha especificado aún más la identificación de las imágenes producidas por la ecocardiografía de dos dimensiones cuando hace referencia a la posición del transductor del ecógrafo sobre los lugares del cuerpo a partir de los cuales se obtienen los estudios ecocardiográficos (ver fig. B-1). Específicamente, los planos de imagen utilizados en este trabajo, teniendo en cuenta la orientación y la posición del transductor, son:

ß El plano o vista paraesternal de eje largo debe su nombre a la colocación del transductor sobre la región del cuerpo llamada paraesternal, la cual está limitada en la parte superior por la clavícula izquierda, en la parte media por el esternón y en la parte inferior por la región apical. En general, se asume que se trata del lado izquierdo paraesternal del paciente. El transductor se coloca con la marca indicadora apuntando hacia la cabeza del paciente y a la altura del tercer o cuarto espacio intercostal adyacente al esternón. El paciente debe permanecer en la posición de decúbito lateral izquierda con correcciones entre la posición lateral izquierda empinada y la posición cuasi supina, dependiendo del sujeto.

B El plano o vista paraesternal de eje corto se obtiene sobre la misma región de la vista paraesternal de eje largo. El transductor se coloca con la marca indicadora apuntando hacia el lado izquierdo del paciente y a la altura del cuarto espacio intercostal (rotación de $90^{\circ}$ en el sentido horario a partir de la vista de eje largo). Planos de imagen particulares se obtienen angulando el transductor hacia arriba o hacia abajo. 


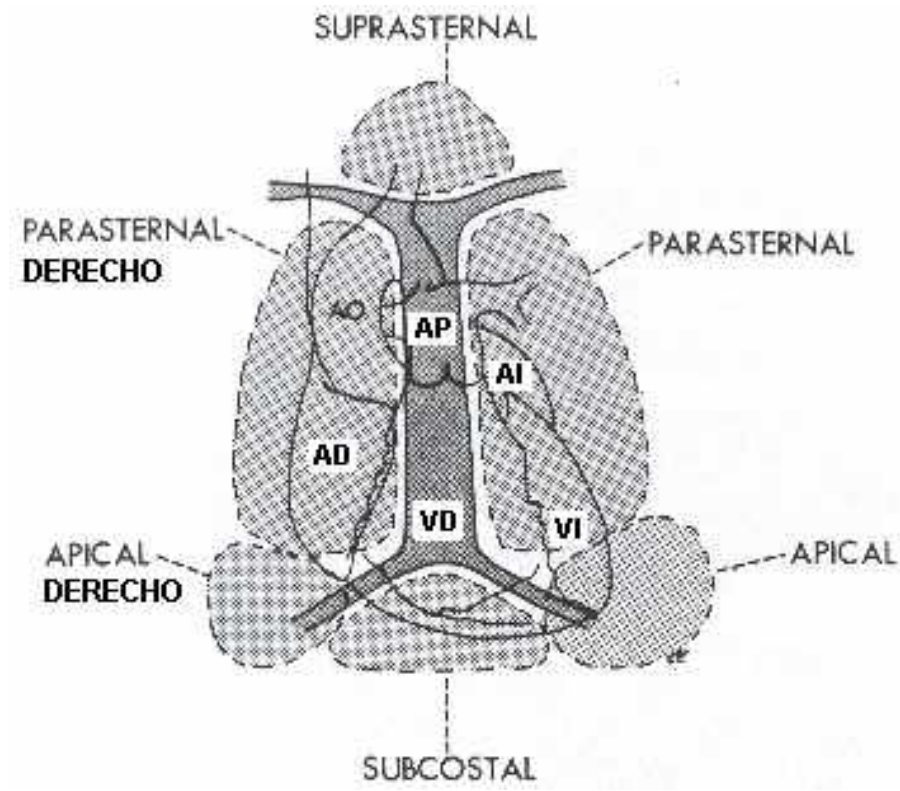

Fig. B-1 Diagrama que indica la nomenclatura para describir las posiciones del cuerpo a partir de las cuales se obtienen los estudios ecocardiográficos. AO: aorta; AP: arteria pulmonar; AI: aurícula izquierda; AD: aurícula derecha; VD: ventrículo derecho; VI: ventrículo izquierdo. Tomado y adaptado de [2].

Puesto que el haz ultrasónico literalmente atraviesa el tórax cuando el transductor se manipula sobre la región paraesternal, estas vistas corresponden al conjunto de vistas conocido como vistas tomográficas transtorácicas o simplemente imágenes transtorácicas. 
La figura B-3 muestra un diagrama con la nomenclatura que describe los lugares del abdomen para obtener los cortes sonográficos de la investigación.

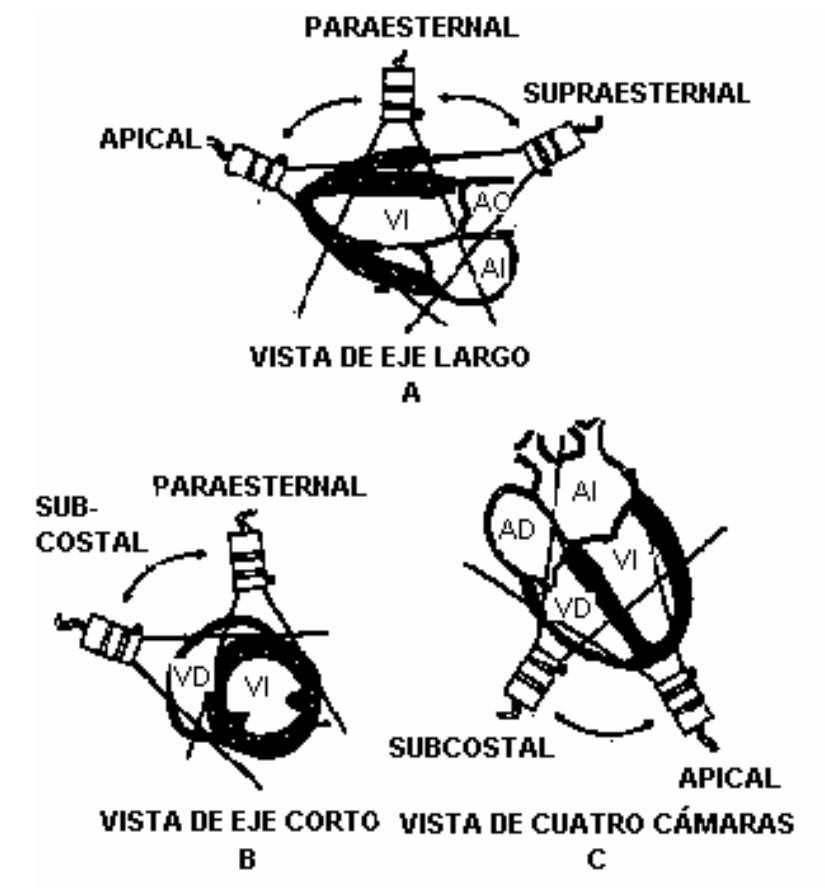

Fig. B-3 Diagrama de las orientaciones del transductor para obtener las vistas de eje largo (A), las vistas de eje corto (B) y las vistas de cuatro cámaras (C) del corazón. Tomado y adaptado de [2].

La figura B-4 muestra los diagramas correspondientes a las vistas que se pueden visualizar en el tubo de rayos catódicos, tanto en el eje largo como en el eje corto, en la posición en que aparecerían sobre la pantalla.

A fin de reconocer los lugares donde aparece el calcio en la válvula aórtica, es necesario que se describa esta estructura tal como aparece en las vistas ecocardiográficas anteriormente mencionadas. 

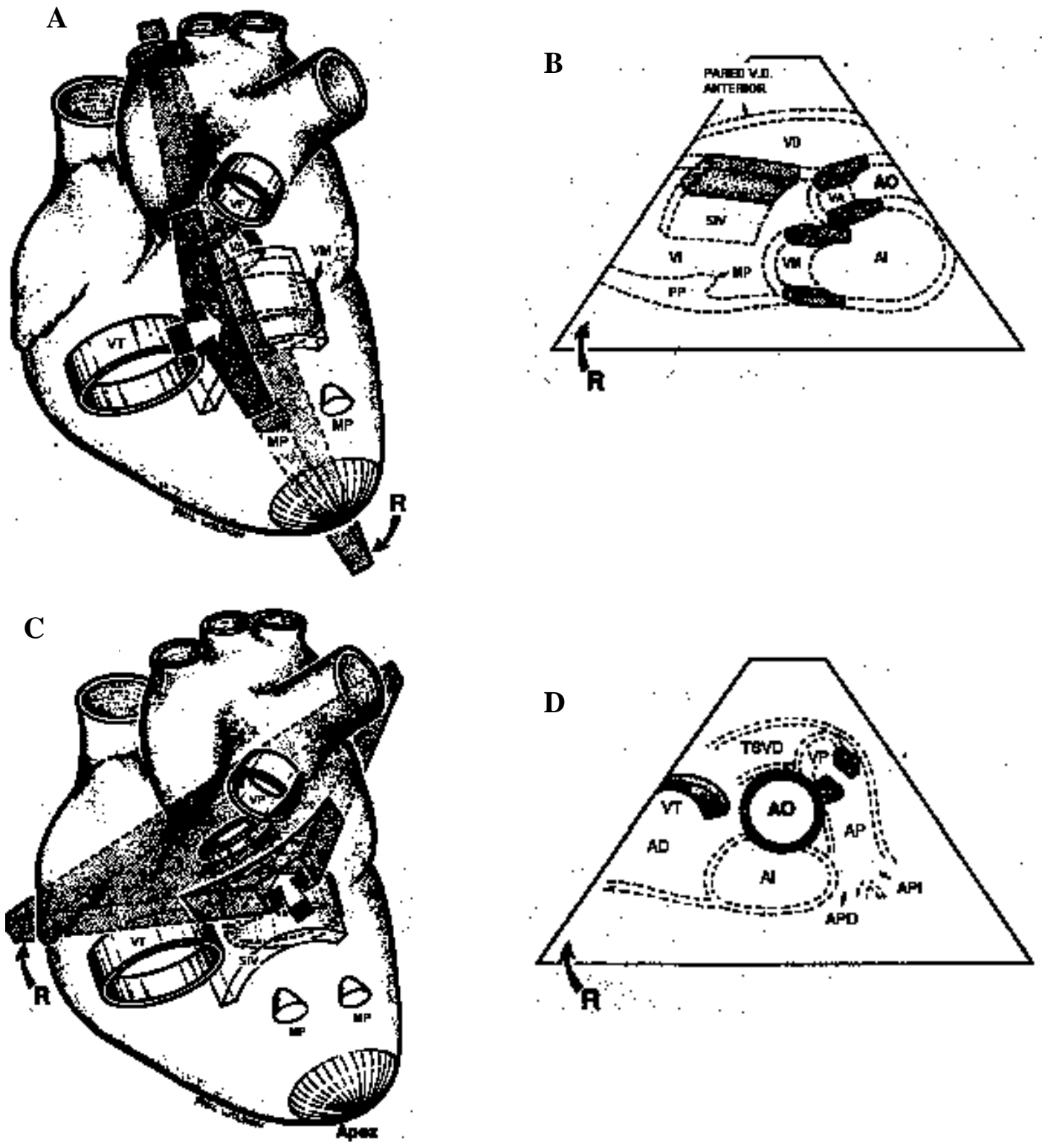

Fig. B-4 A. La orientación espacial del plano de imagen en la vista paraesternal de eje largo y la trayectoria a lo largo de la cual el plano intersecta las principales estructuras ecocardiográficas en esta área. La marca de referencia (R) indica el lado del plano que se ubica en la esquina inferior izquierda de la pantalla del monitor. $\mathrm{VP}=$ válvula pulmonar, VA válvula aórtica, $\mathrm{VM}=$ válvula mitral, $\mathrm{VT}=$ válvula tricúspide, $\mathrm{MP}=$ músculos papilares. B. Las posiciones relativas de las estructuras principales y adyacentes registradas en la vista paraesternal de eje largo tal como aparecen en la pantalla del monitor. La marca de referencia (R) en este diagrama corresponde al punto indicado por su correspondiente en la figura $\mathbf{A}$. $\mathrm{AO}=$ aorta, $\mathrm{VD}=$ ventrículo derecho, $\mathrm{PP}=$ pared posterior del ventrículo izquierdo, $\mathrm{SIV}=$ septum interventricular, $\mathrm{AI}=$ aurícula izquierda, $\mathrm{VA}=$ válvula aórtica, $\mathrm{VM}=$ válvula mitral, $\mathrm{VI}=$ ventrículo izquierdo, $\mathrm{MP}=$ músculo papilar. $\mathbf{C}$. La orientación espacial del plano de imagen en la vista paraesternal de eje corto de la raíz aórtica y la aurícula izquierda. Este plano pasa a través de la valva aórtica (VA) paralelo a su eje corto y pasa oblicuamente a través delmargen inferior de la válvula pulmonar (VP). El punto del sector indicado por la marca de referencia (R) se visualiza en el margen izquierdo inferior de la pantalla del monitor. D. Las estructuras principales y adyacentes que se registran en la vista paraesternal de eje corto. Sus posiciones relativas en la vista final son evidentes. $\mathrm{AD}=$ aurícula derecha, $\mathrm{TSVD}=$ tracto de salida del ventrículo derecho, $\mathrm{AP}=$ arteria pulmonar principal, API = arteria pulmonar izquierda, APD = arteria pulmonar derecha. Tomado y adaptado de [3]. 


\section{La aorta en la vista paraesternal de eje largo}

Un diagrama en diástole de las estructuras que pueden visualizarse en el eje largo paraesternal se muestra en la figura B-5.

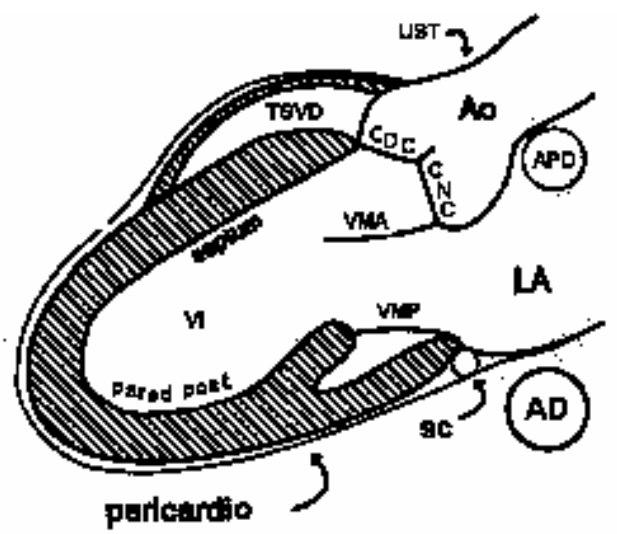

Fig. B-5 Diagrama esquemático de la vista paraesternal de eje largo en diástole que muestra la raíz aórtica (Ao), la unión sinotubular (UST), la cúspide derecha coronaria (CDC) y la cúspide no coronaria (CNC) ambas cerradas, la valva mitral anterior (VMA) y la valva mitral posterior (VMP) ambas abiertas, el septum y la pared posterior del ventrículo izquierdo. El músculo papilar medio se muestra aquí como referencia, pues se requiere una angulación ligera para visualizar esta estructura en la vista de eje largo. El tracto de salida del ventrículo derecho (TSVD) es anterior, mientras que el seno coronario (SC) en el surco atrioventricular y la aorta descendente (AD) se ven en posición posterior. La arteria pulmonar derecha (APD) yace posterior a la aorta ascendente. La posición del pericardio se indica con la línea delgada. Tomado y adaptado de [1].

Nos interesa por supuesto describir la aorta. La raíz de la aorta (Ao), los senos de Valsalva, la unión sinotubular (UST) y aproximadamente de 3 a $4 \mathrm{~cm}$. de la aorta ascendente pueden verse en el eje largo. El límite superior medio correspondiente a las dimensiones de la raíz aórtica en adultos es de $1.6 \mathrm{~cm}$, al nivel del anillo, y de $2.1 \mathrm{~cm}$ al nivel de las puntas de los velos aórticos en sístole [2].

En la vista de eje largo, la valva coronaria derecha de la válvula aórtica es anterior y la valva no coronaria es posterior (la valva coronaria izquierda es lateral al plano de la imagen). En sístole, los delgados velos aórticos abren ampliamente, suponiendo una orientación paralela a las paredes de la aorta. En diástole, los velos están cerrados, con un ángulo pequeño obtuso de cierre entre los dos velos. Los velos aparecen lineales desde la línea de cierre hasta el anillo aórtico debido a la forma hemicilíndrica de los velos cerrados (lineales a lo largo del cilindro, curvos a lo largo de su eje corto). En individuos jóvenes normales, los velos son tan delgados que únicamente es posible ver la porción donde se tocan los velos durante el cierre. La anatomía 3D de la unión de los velos aórticos con la raíz aórtica tiene la forma de una corona con las tres comisuras empalmadas cerca de las cimas de los senos de Valsalva y la porción media de cada velo unida cerca de la base de cada seno (ver fig. B-6). 


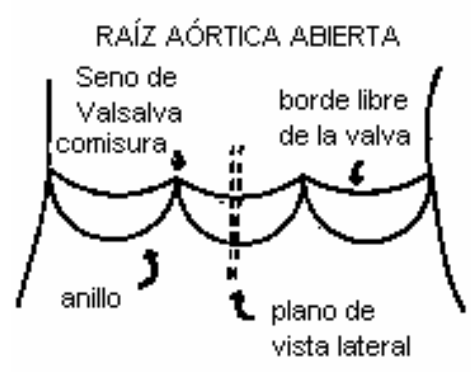

VISTA FRONTAL

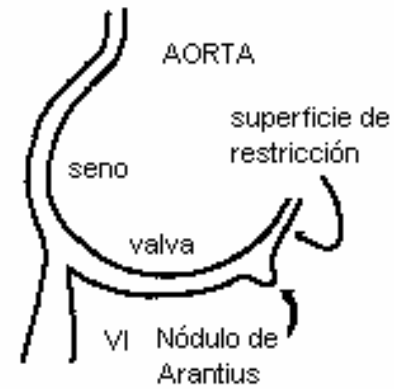

VISTA LATERAL

Fig. B-6 Diagrama esquemático de la anatomía de la válvula aórtica normal mostrada en una vista frontal ( $a$ la izquierda) con la raíz aórtica "abierta" entre dos de las valvas para demostrar en "anillo" en forma de corona. En la vista lateral (a la derecha), las comisuras están cerca de la punta de cada seno de manera que cada unión seno-valva tiene una forma de copa. Tomado y adapatado de [1].

Esta unión se designa a menudo como el "anillo" aórtico, aunque no existen características de tejido distinguibles en esta zona. Nótese que existe una continuidad fibrosa entre la raíz aórtica y el velo anterior mitral. La figura B-7 muestra las ecocardiografías paraesternales en el eje largo donde se aprecia la aorta tanto en sístole como en diástole.

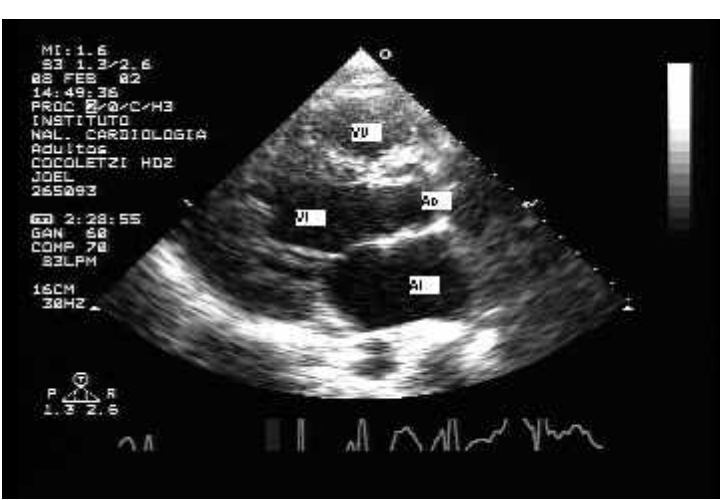

a)

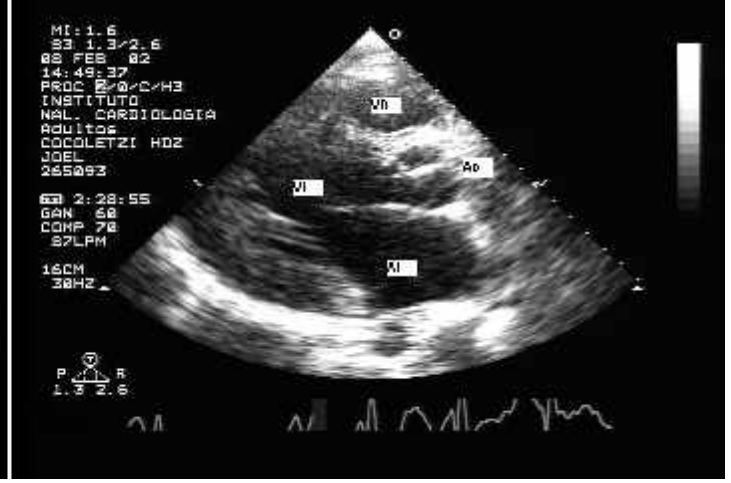

b)

Fig. B-7 a) Ecocardiografía paraesternal de eje largo que muestra la raíz aórtica en sístole; b) ecocardiografía paraesternal de eje largo que muestra la raíz aórtica en diástole.

\section{La aorta en la vista paraesternal de eje corto}

Un diagrama en diástole de las estructuras que pueden visualizarse en el eje corto paraesternal se muestra en la figura B-8. 


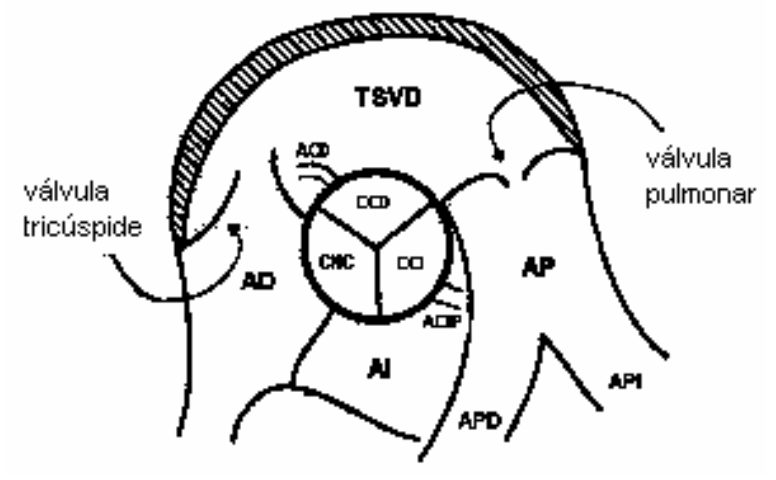

Fig. B-8 Diagrama esquemático de una vista paraesternal de eje corto a nivel de la válvula aórtica que muestra la relación entre las tres cúspides de la válvula aórtica $(\mathrm{CCD}=$ cúspide coronaria derecha, $\mathrm{CNC}=$ cúspide no coronaria, $\mathrm{CCI}=$ cú spide coronaria izquierda) y la aurícula izquierda, la aurícula derecha, el tracto de salida ventricular derecho, la arteria pulmonar principal y sus ramas izquierda y derecha. Se muestran también las posiciones de la arteria coronaria derecha (ACD) la arteria coronaria izquierda principal (ACIP), la válvula pulmonar y la válvula tricúspide.

El eje corto revela en la diástole los tres velos aórticos-derecho, izquierdo y no coronario--. En sístole, los velos aórticos se abren hasta formar un orificio casi circular. En díástole, se puede observar la típica forma de Y de las líneas de coartación de los velos. La identificación del número de velos aórticos se realiza con mayor exactitud en sístole, puesto que una válvula bicúspide puede parecer tricúspide en diástole debido a una sutura o rafé en la posición de una comisura normal. Normalmente, los velos de la válvula aórtica son delgados en la base con un área de engrosamiento sobre el aspecto ventricular a la mitad de la orilla libre de cada valva que sirve para llenar el espacio en el centro de la valva cerrada. La figura B-9 muestra una ecocardiografía de la vista paraesternal de eje corto tanto en sístole como en diástole.

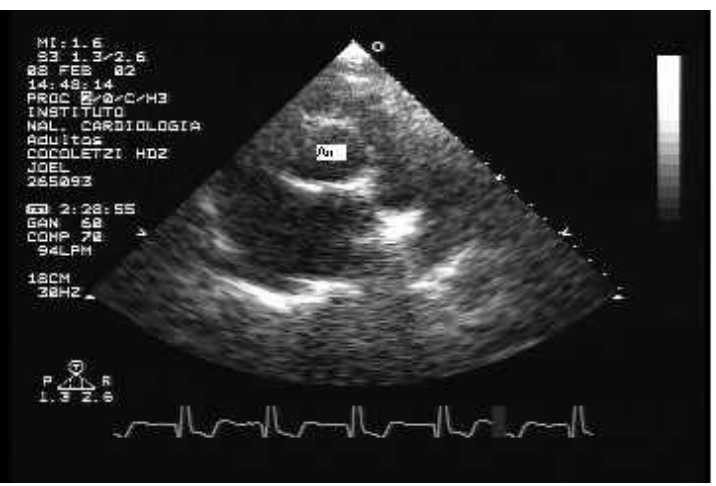

a)

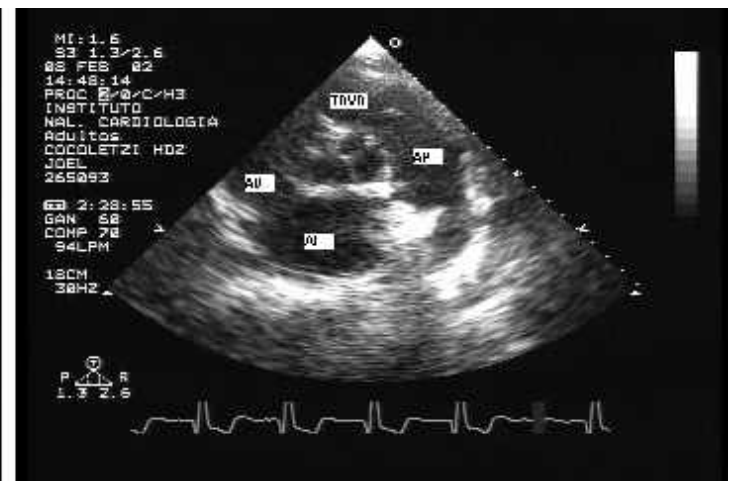

b)

Fig. B-9 a) Ecocardiografía paraesternal de eje corto a nivel de los grandes vasos en sístole. Las valvas de la válvula aórtica están abiertas. b) Mismo corte que en a), pero en diástole. En individuos normales, las valvas apenas son visibles. 


\section{APÉNDICE C.}

\section{AJUSTE DE LOS CONTROLES DEL ECÓGRAFO SONOS 5500 DE AGILENT TECHNOLOGIES.}

El ajuste inicial elegido para la visualización de las ecocardiografías de estudio fue el siguiente:

Ganancia en Modo B (Gain 2D/BMode) = 50. Este control permite de ajustar la potencia acústica de las señales transmitidas por el transductor.

Compresión (Compress) $=$ 70. Este control permite de ajustar el rango dinámico de los ecos de retorno afectando así la escala de grises visualizada en la imagen en Modo B. Existe pues capacidad de recibir señales débiles que suavizan la imagen o producir imágenes de alto contraste donde se eliminan las señales débiles y se reduce el ruido.

TGCs en automático. Los controles deslizables para la compensación de la ganancia temporal (Time Gain Compensation) pueden ajustarse independientemente, pero, como lo especifica la guía de referencia [14], al utilizar un transductor de arreglo lineal, como es el caso, el sistema automáticamente calcula los valores apropiados de los controles TGC. El manual recomienda una posición especial de estos controles cuando se utilizan transductores lineales, la cual se fijó en todas las adquisiciones.

Fusión de Frecuencias (Frecuency Fusion) $=$ 3. Este control permite cambiar la calidad de la imagen que varía entre las características de penetración, textura y resolución. El nivel 3 proporciona la máxima reducción de granulado y mejora la textura del tejido miocárdico. Los rangos de frecuencia alto y bajo de la ultrabanda tienen el mismo peso [15].

Postprocesamiento (Postproc) $=$ C. Este control afecta la suavidad y la brillantez de la escala de imágenes almacenadas en memoria, de acuerdo a la preferencia visual (aplicación de un histograma). Con este control es posible entonces regular la suavidad de la imagen añadiendo o quitando sombras de gris. El control afecta las imágenes en tiempo real y estáticas.

LGCs al mínimo. Existe la posibilidad de ajustar la ganancia lateral de las señales de retorno en el Modo B dentro de un área lateral específica de la imagen. Puesto que el área de interés de la aorta, tanto en el eje corto como en el eje largo, se encuentra aproximadamente al centro de la "ventana", se han adquirido las ecocardiografías con estos controles en sus valores mínimos.

\footnotetext{
${ }^{1}$ Término utilizado por los médicos sonografistas para designar el plano de imagen que se visualiza sobre el TRC.
} 


\section{APÉNDICE D.}

En este apéndice se presenta, en primer lugar, el programa MATLAB correspondiente al cálculo de los coeficientes de los filtros de descomposición y reconstrucción diádica, en segundo lugar, la implementación de la TDWR2D presentada en el Capítulo 6 de este trabajo, de acuerdo al algoritmo "à trous" (se incluyen notas complementarias para comprender la concepción del programa) y en, tercer lugar, el programa para calcular la PSNR entre dos imágenes.

Programa MATLAB para calcular los coeficientes de los filtros $H(\omega), G(\omega), K(\omega) \mathbf{y}$ $L(\omega)$.

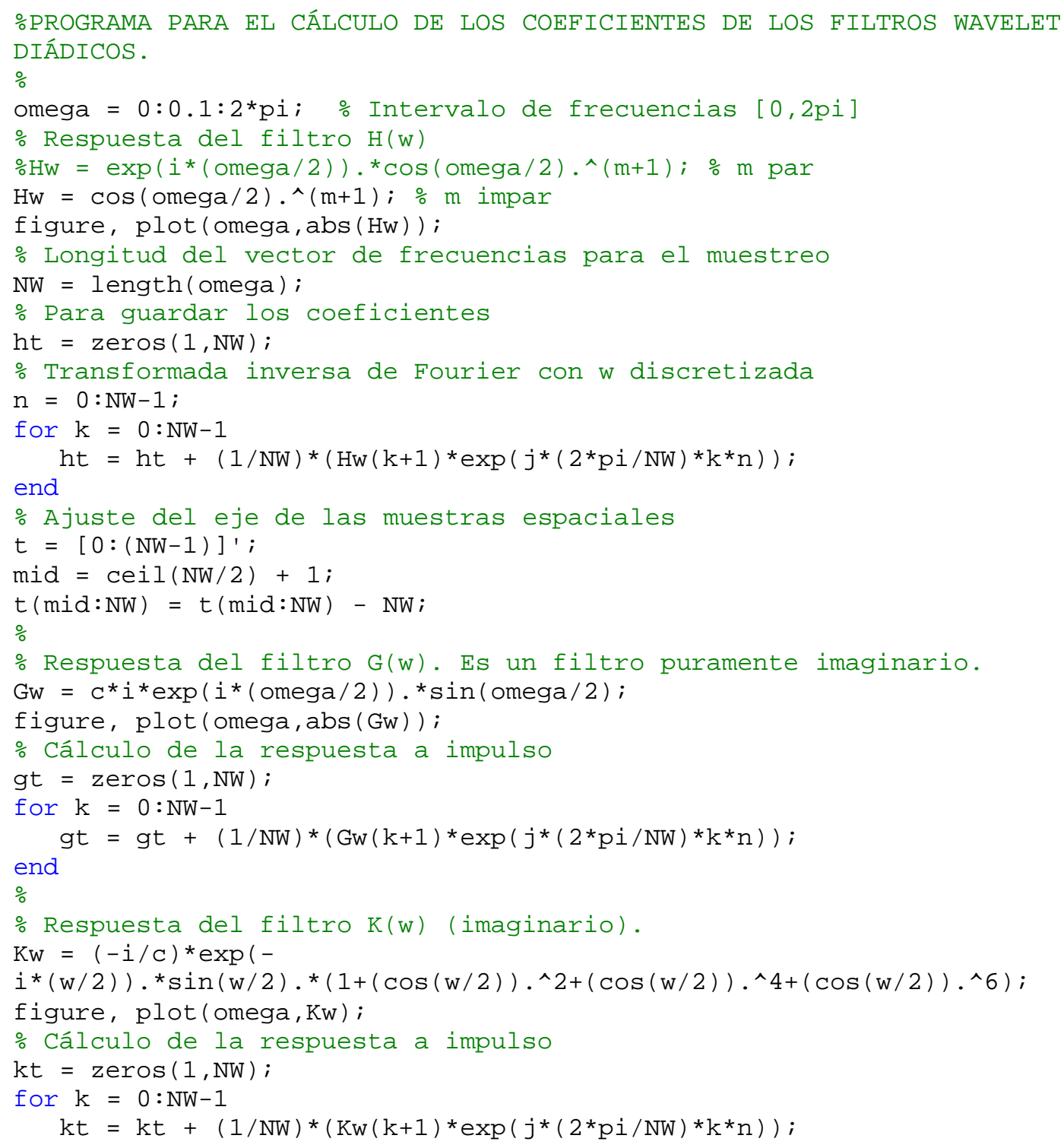




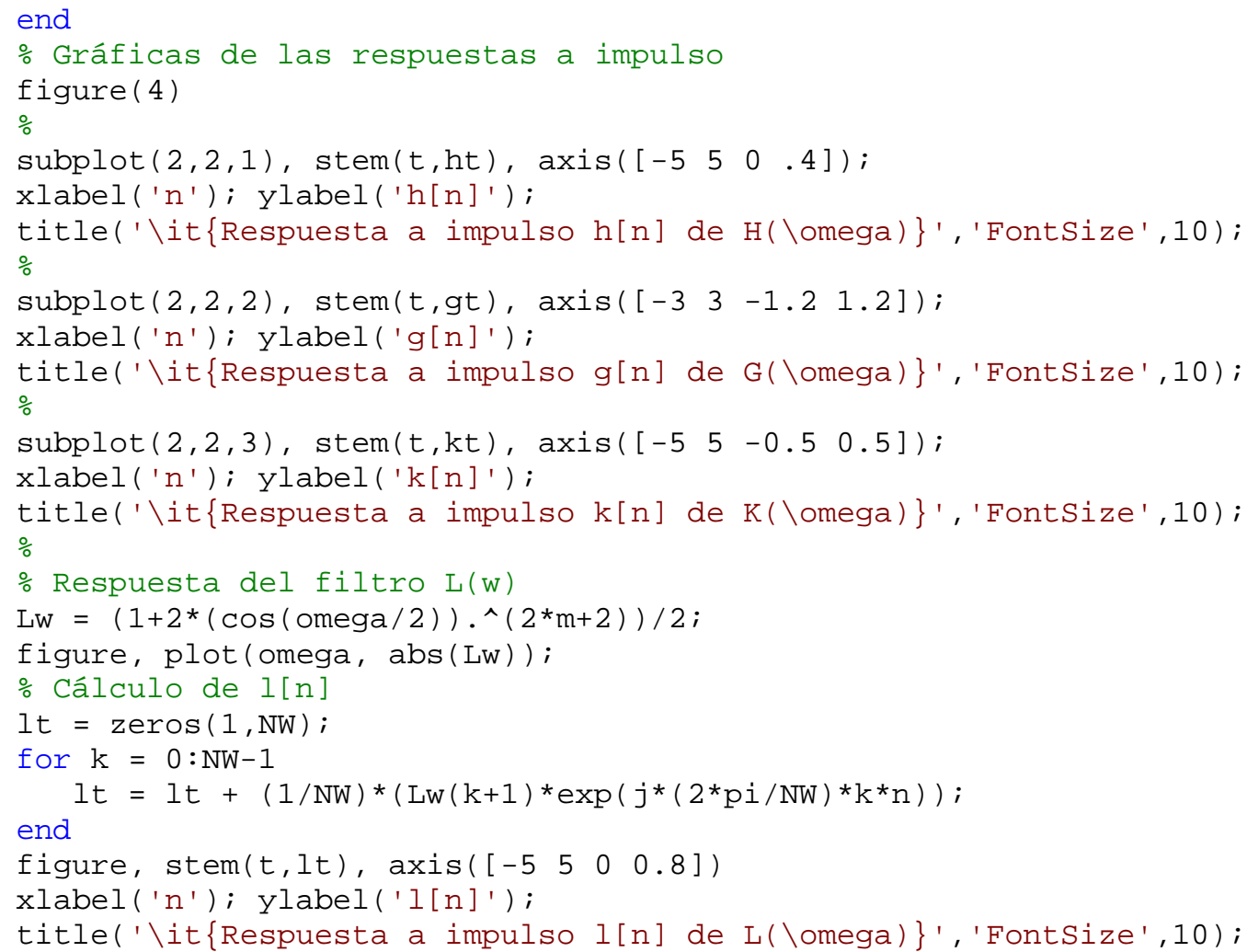

Programa MATLAB de la Transformada Diádica Wavelet Rápida 2D (TDWR2D)

\section{Filtros discretos de descomposición.}

Los filtros discretos de descomposición $G(\omega)$ y $H(\omega)$ son filtros FIR cuyos coeficientes se muestran en la tabla 6.1. Se ha tenido en cuenta el factor $\frac{1}{\sqrt{2}}$ en el producto infinito de la ecuación (6.5). La expresión MATLAB de estos filtros es:

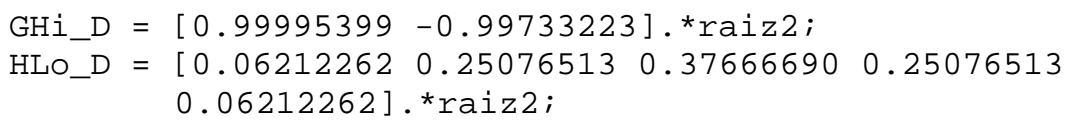

donde raiz2 $=\operatorname{sqrt}(2)$.

\section{Filtros discretos de reconstrucción.}

Los filtros de reconstrucción $K(\omega), L(\omega)$ son filtros FIR cuyos coeficientes se muestran en las tablas 6.1 y 6.2. Para el filtro $K(\omega)$, las expresiones MATLAB también tienen en cuenta el factor $\frac{1}{\sqrt{2}}$ : 


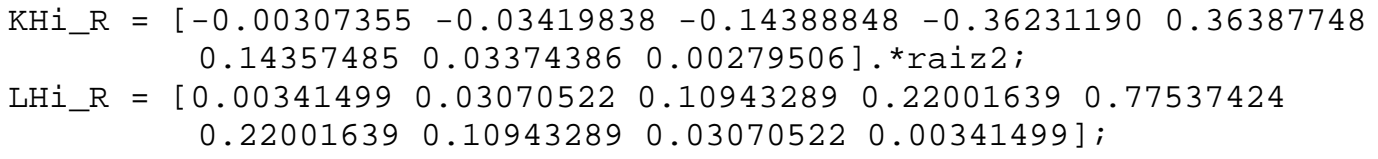

Puesto que el filtro $H(\omega)$ es simétrico alrededor de $0, \bar{h}[n]=h[n]$.

\section{Convolución separada de las columnas y los renglones.}

Mallat et al. [21] demuestran que es posible aplicar los filtros wavelet diádicos 1D para tratar señales 2D, pues las funciones wavelet de descomposición, las funciones de escalamiento y las wavelet de reconstrucción en el dominio 2D poseen la propiedad de separabilidad. Por lo tanto, las convoluciones se realizan separadamente, primero con los renglones (dirección $y$ vertical) de la matriz que representa a la imagen y después con las columnas (dirección $x$ horizontal) de esa matriz. La función MATLAB wconv2d está escrita para realizar la convolución de renglones o de columnas según se le programe. El trabajo mayor de la convolución se deja a la función interna MATLAB conv2.

El filtrado de la señal no se ha obtenido mediante el producto en el dominio de Fourier de la señal de entrada y la función de transferencia del filtro sino, como ya se mencionó, mediante la convolución en el dominio espacial. Esto se debe a la manera en que se han especificado los filtros diádicos. Estos filtros son tipo FIR, pero las tablas 6.1 y 6.2 los presentan con amplitudes en valores negativos del espacio. Por lo tanto, es necesario ajustar mediante corrimientos circulares las columnas y los renglones de la matriz-imagen según se filtre en una u otra dimensión. Esta tarea se encomienda a la rutina corr_izq la cual se repite $2^{p}-1$ veces, de acuerdo al nivel de descomposición o reconstrucción en que se halle la señal.

\section{Periodización de la señal 2D.}

Como se puede notar, antes de iniciar la convolución se realiza un tratamiento de periodización de la señal 2D con la función MATLAB perf. La periodización de las columnas y los renglones de la matriz que representa a la ecocardiografía es necesaria debido a que, si se ve a cada renglón y cada columna de la matriz-imagen como un vector que representa a una señal $1 \mathrm{D}$, la señal comienza y termina abruptamente sin que la convolución circular se complete. Esto provoca un artefacto bien conocido en el procesamiento digital de señales: el fenómeno de Gibbs. La técnica habitual para evitar este artefacto es extender los límites del vector (columna o renglón) un número de muestras igual al número de coeficientes del filtro discreto con el cual se hace la convolución. La expresión matemática del vector periodizado es:

$$
v_{\text {ext }}[n]=\left\{\begin{array}{lrl}
v[n+N+3] & \text { si } & n \in\left[-N_{f},-1\right] \\
v[n] & \text { si } & n \in[0, N] \\
v[n-N-1] & \text { si } n \in\left[N+1, N+N_{f}\right]
\end{array}\right.
$$


Una vez que perf ha periodizado las columnas o los renglones, la matriz imagen convolucionada se vuelve a su tamaño original $(128 \times 128)$ "recortando" el resultado de la convolución. Esta tarea es realizada por la función wcorta.

Por supuesto, recuérdese que conforme se pasa de un nivel a otro de transformación, se deben insertar $2^{p}-1$ ceros entre cada uno de los coeficientes del filtro, en el caso de la descomposición, o suprimir esta cantidad de ceros, en el caso de la reconstrucción.("algorithme à trous"). El ciclo de descomposiciones/reconstrucciones y la extensión de los filtros se controlan con la variable nivel. La periodización y la alineación de la respuesta a impulso con las columnas y los renglones de la señal se requieren tanto en la descomposición como en la reconstrucción. 


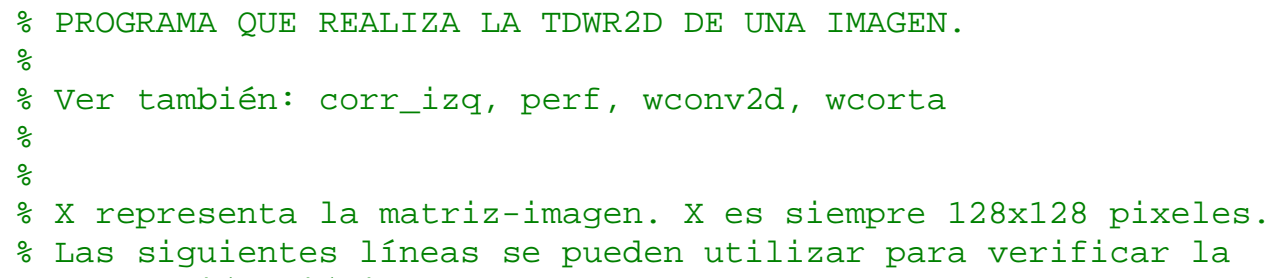




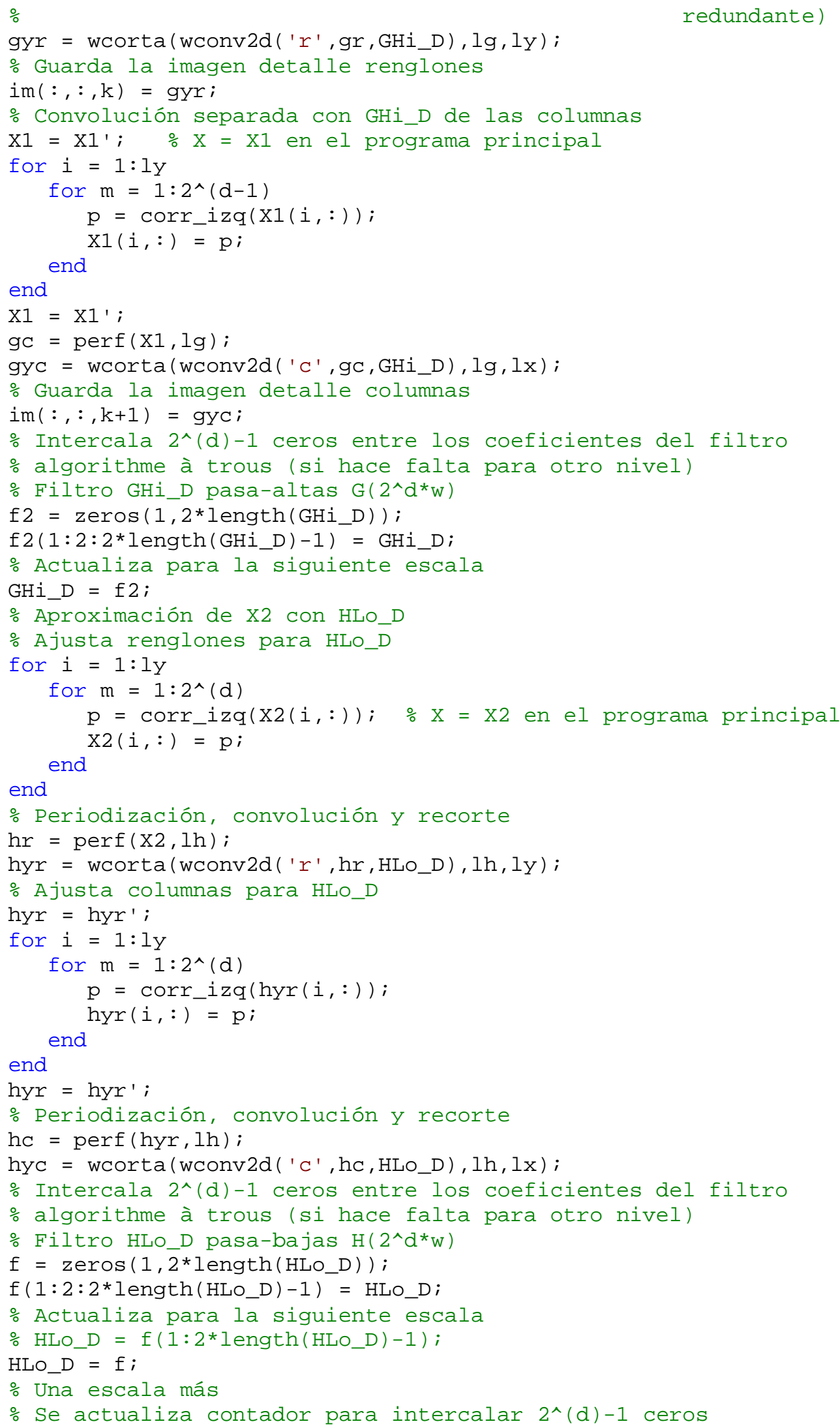




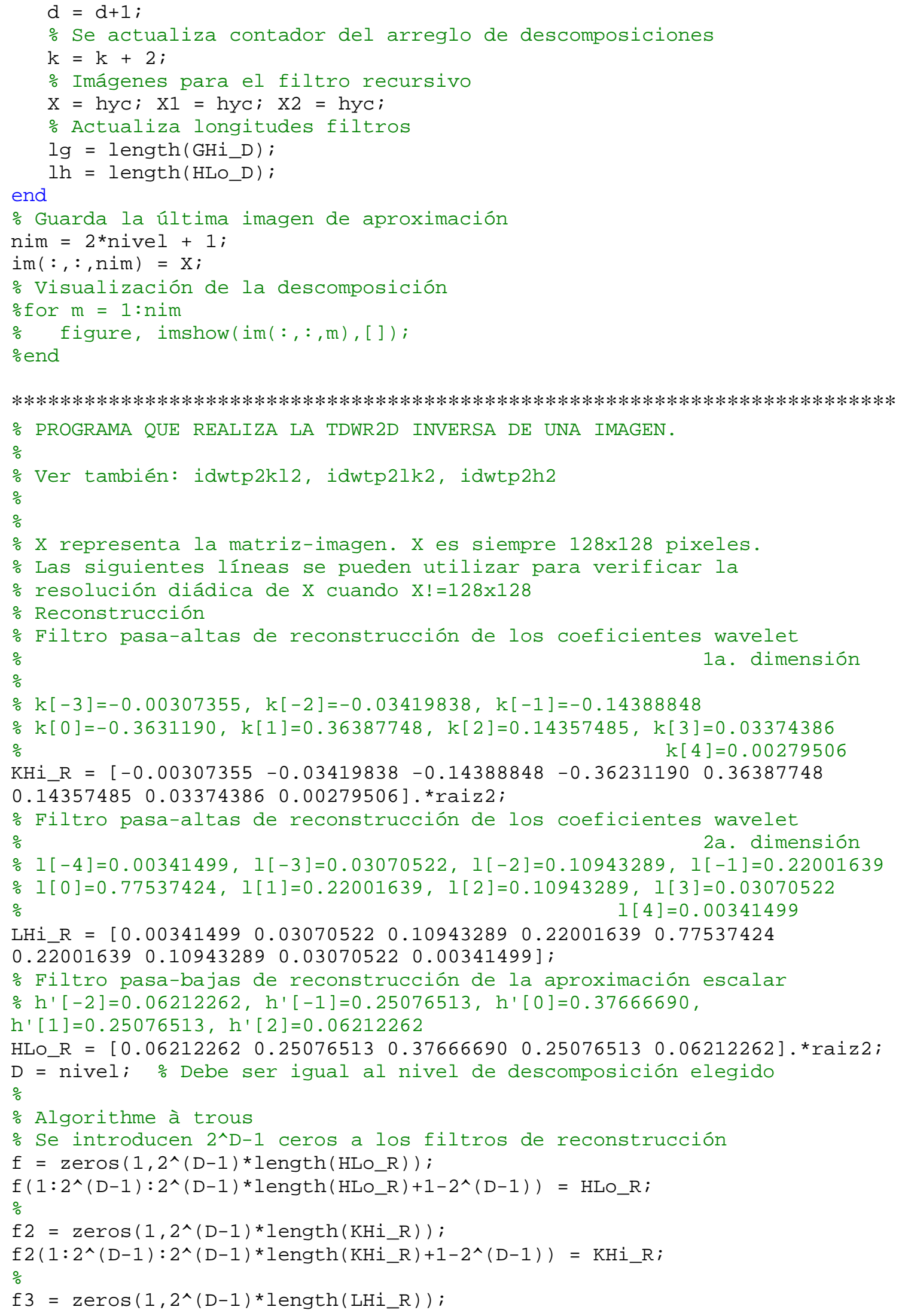




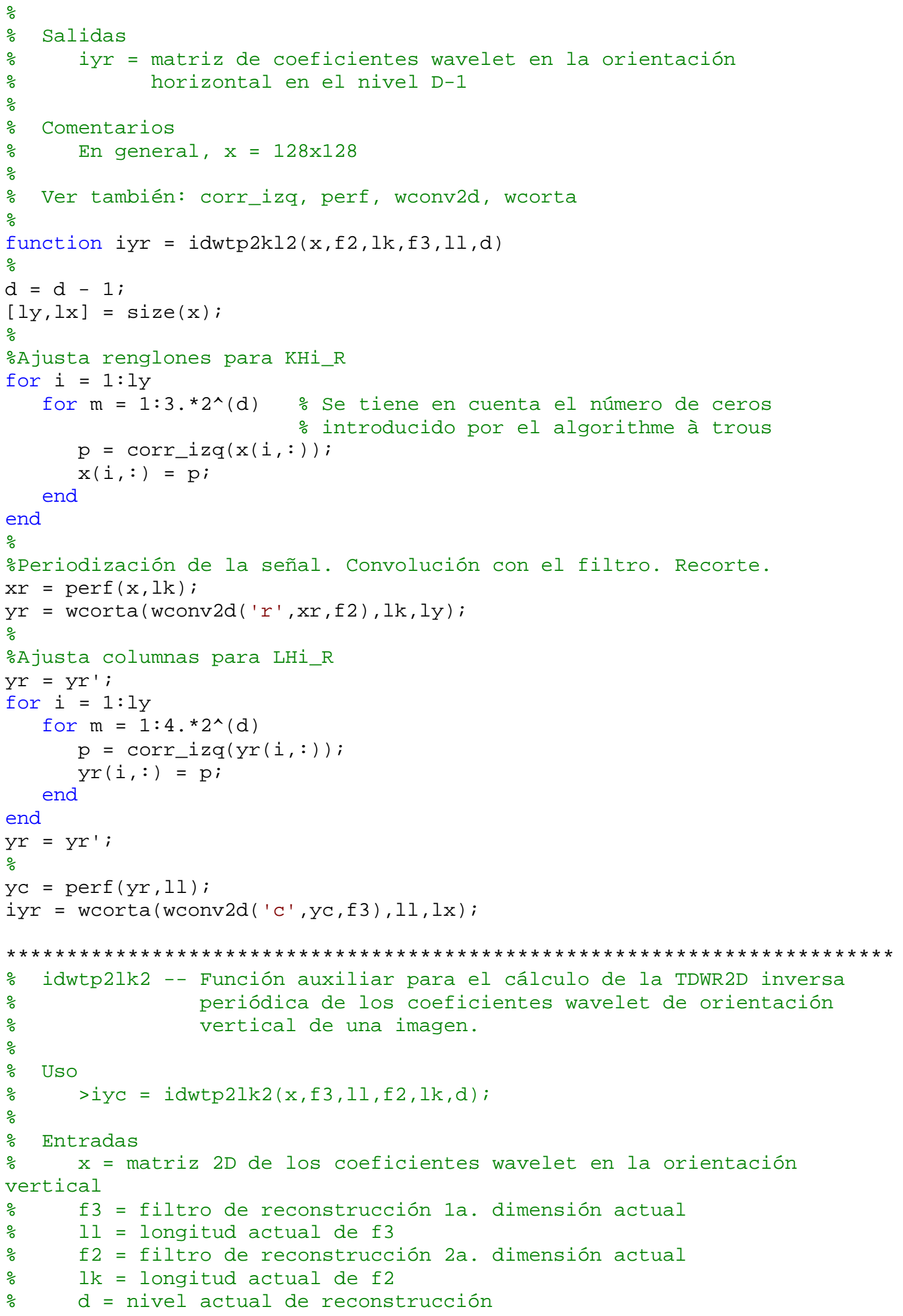




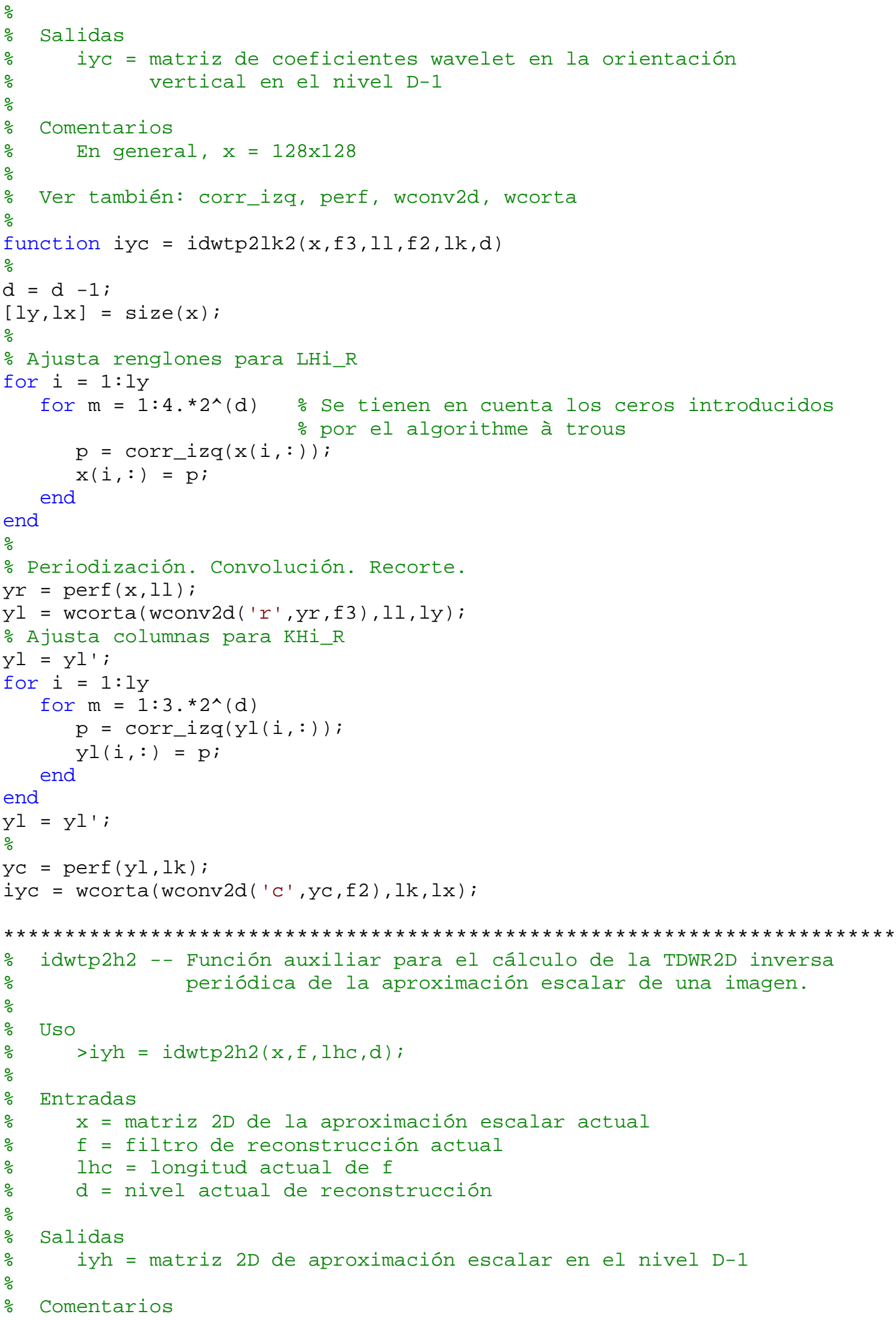




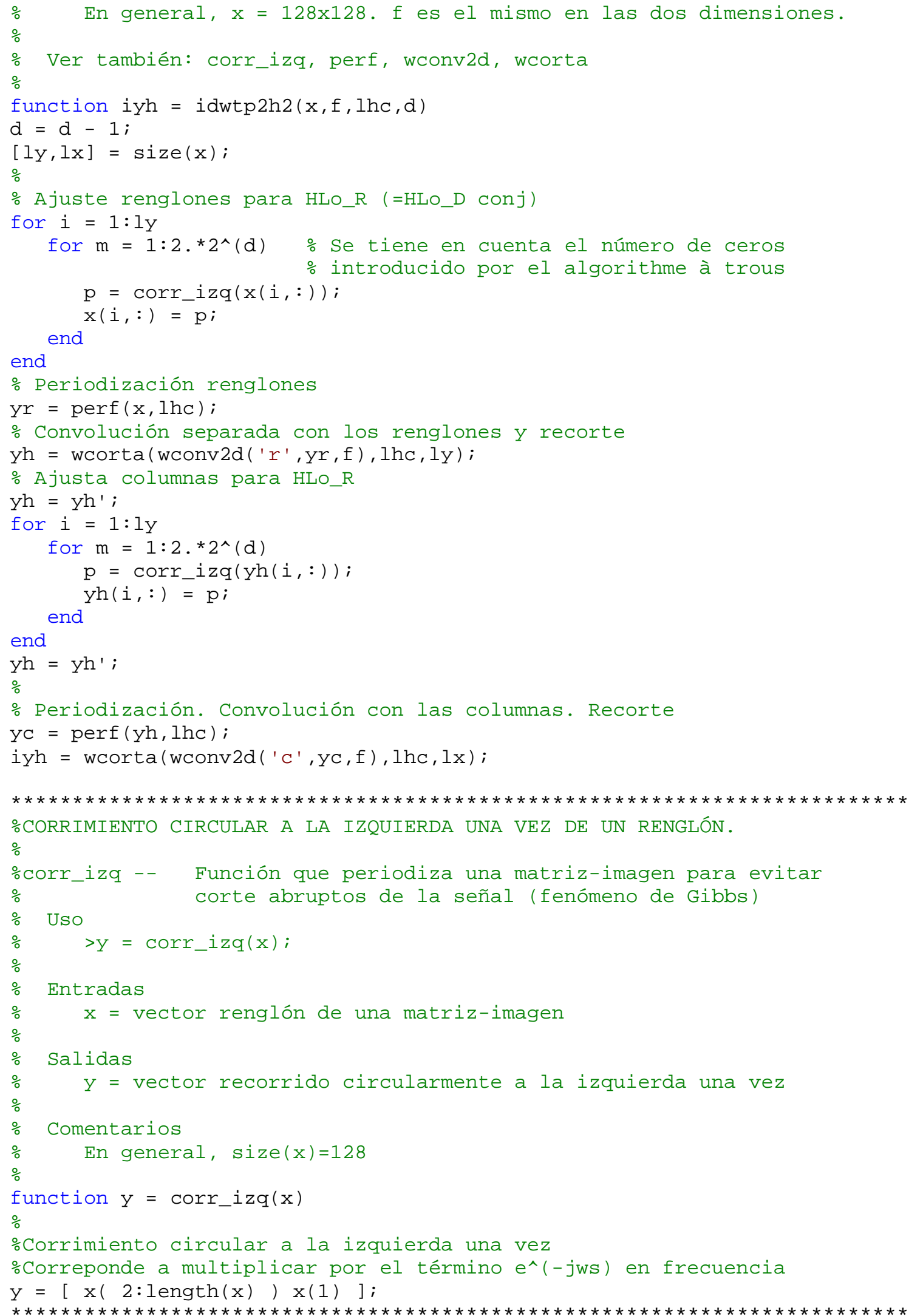




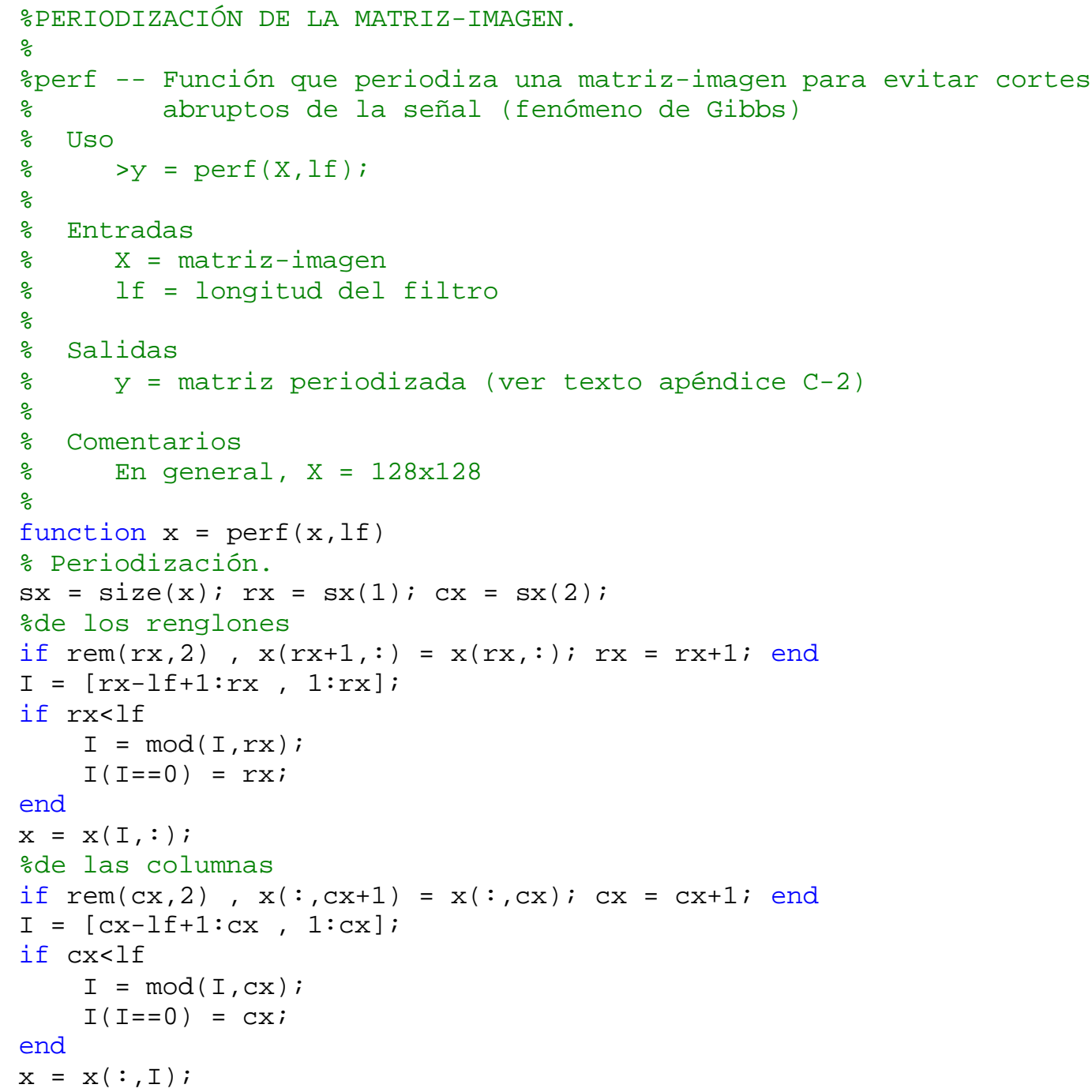




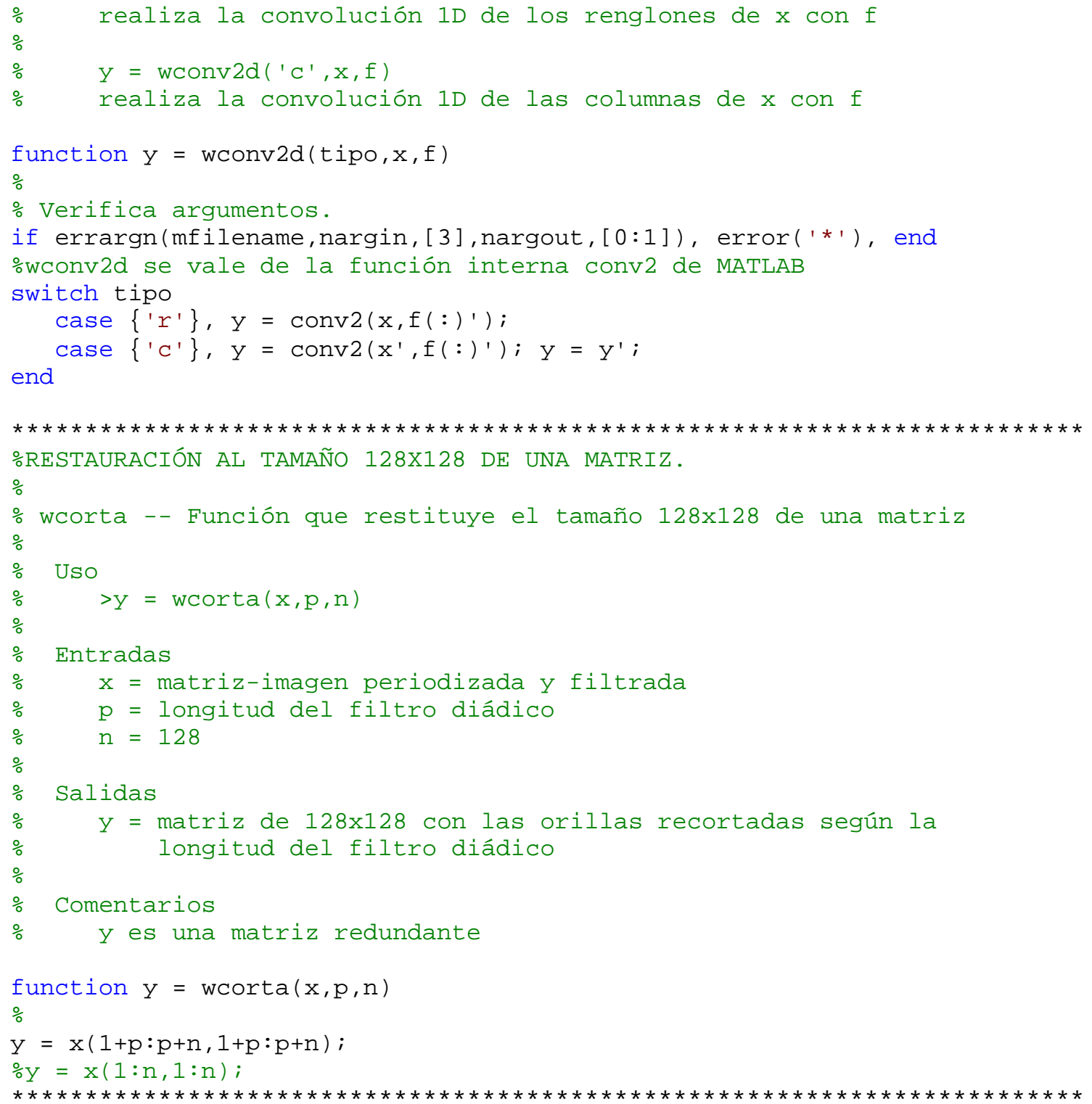

\section{Programa MATLAB para el cálculo de la relación pico señal a ruido (PSNR).}

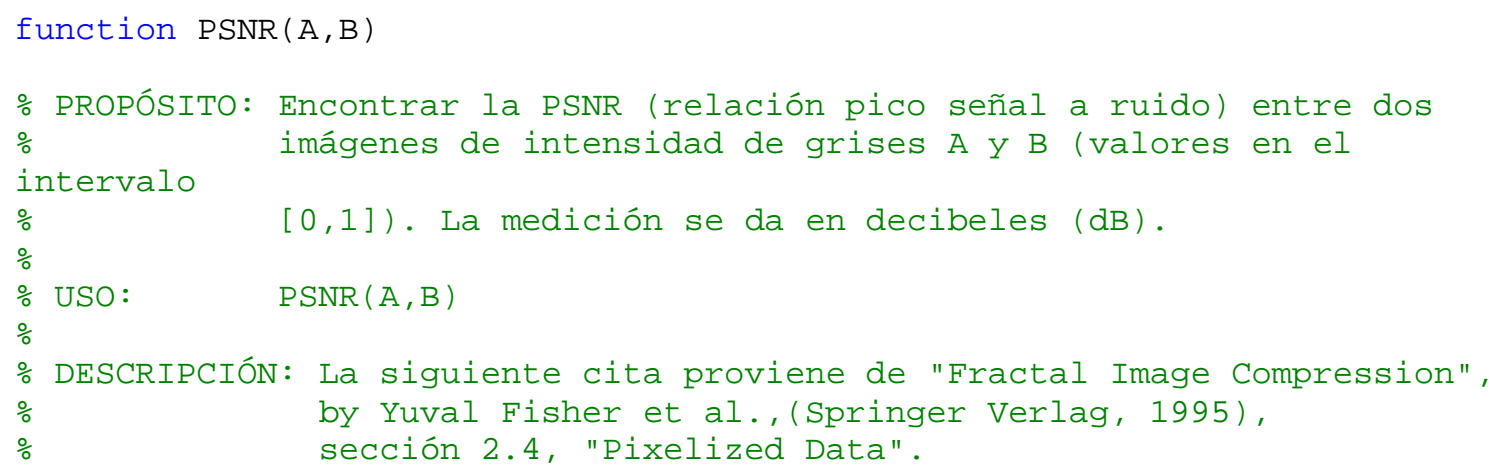




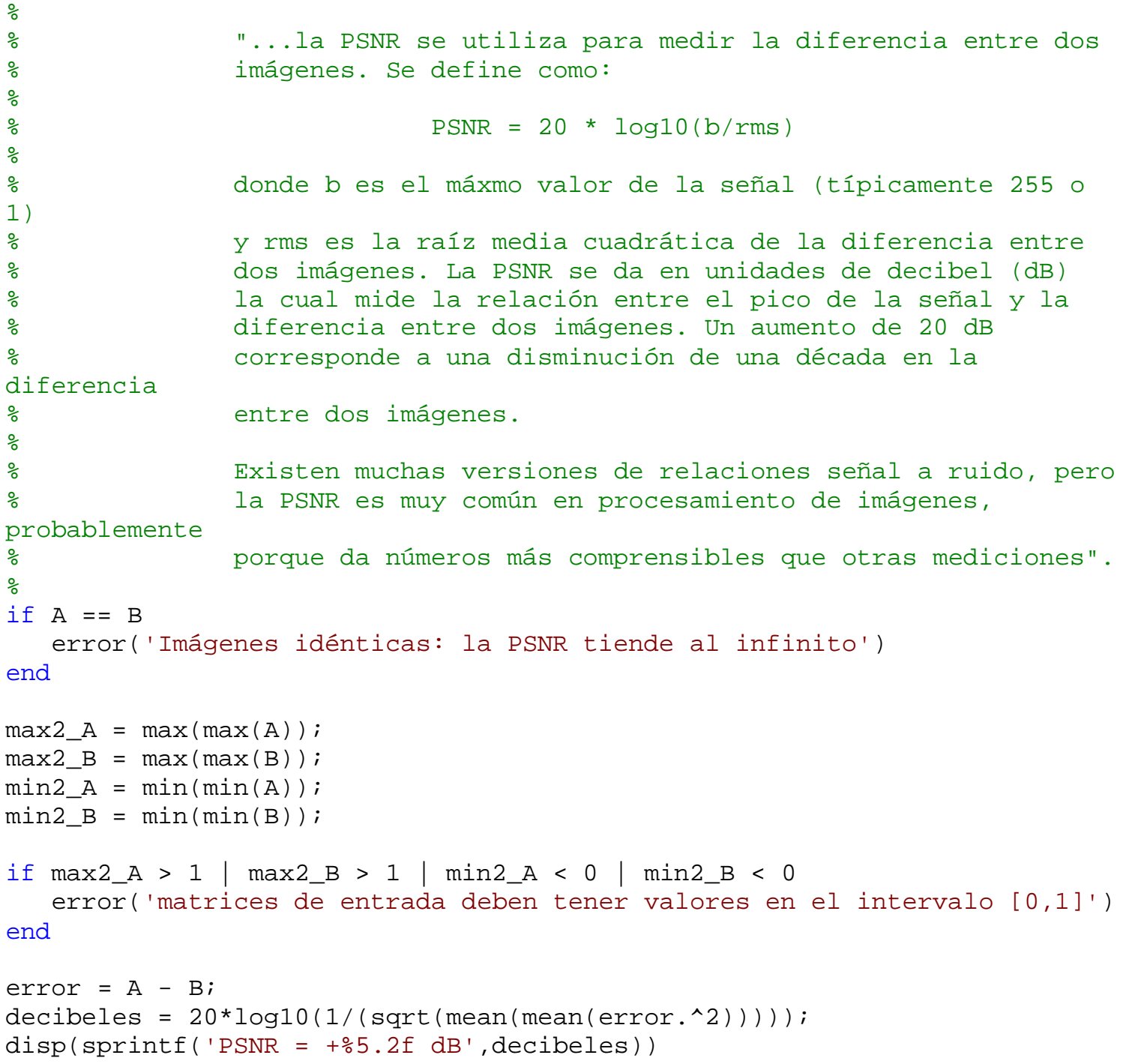




\section{APÉNDICE E.}

\section{Programa MATLAB para la reducción del ruido en ecocardiografías.}

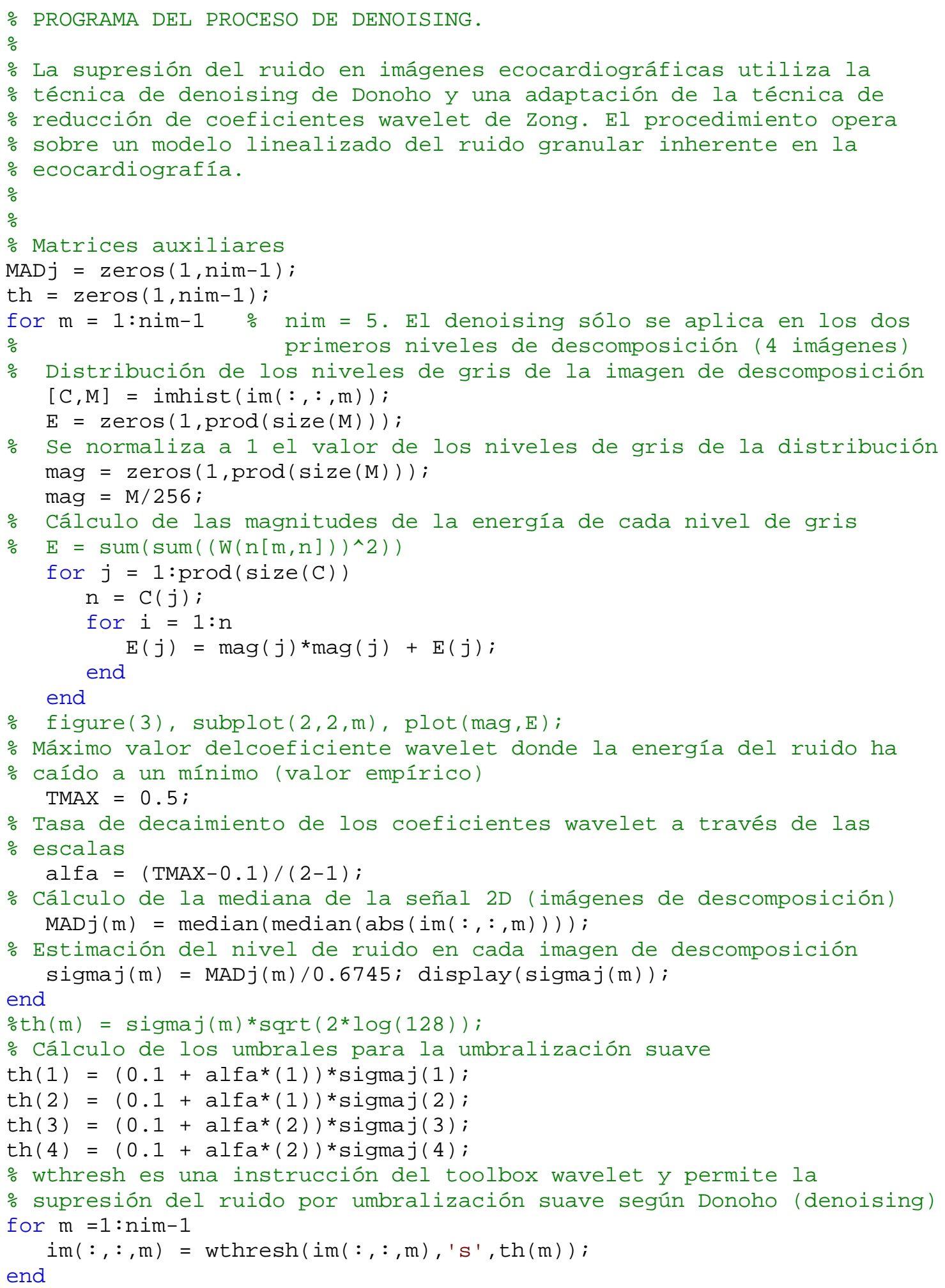




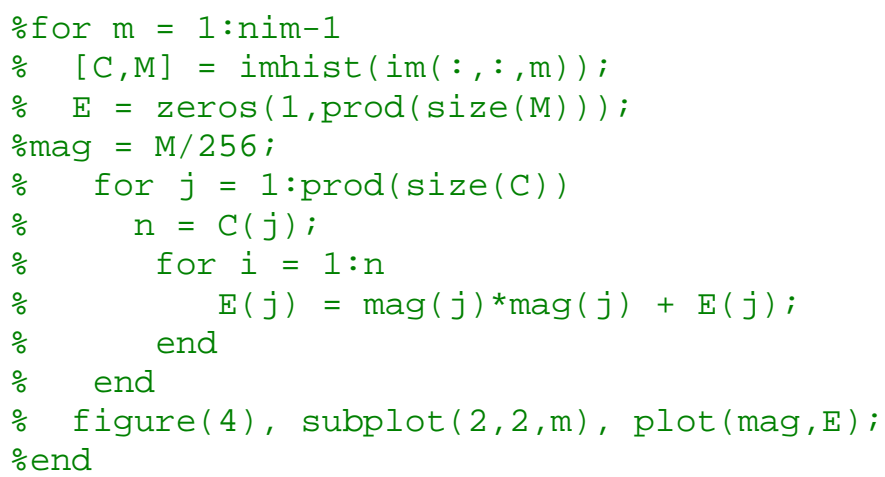




\section{APÉNDICE F.}

\section{Programa MATLAB del crecimiento de regiones.}

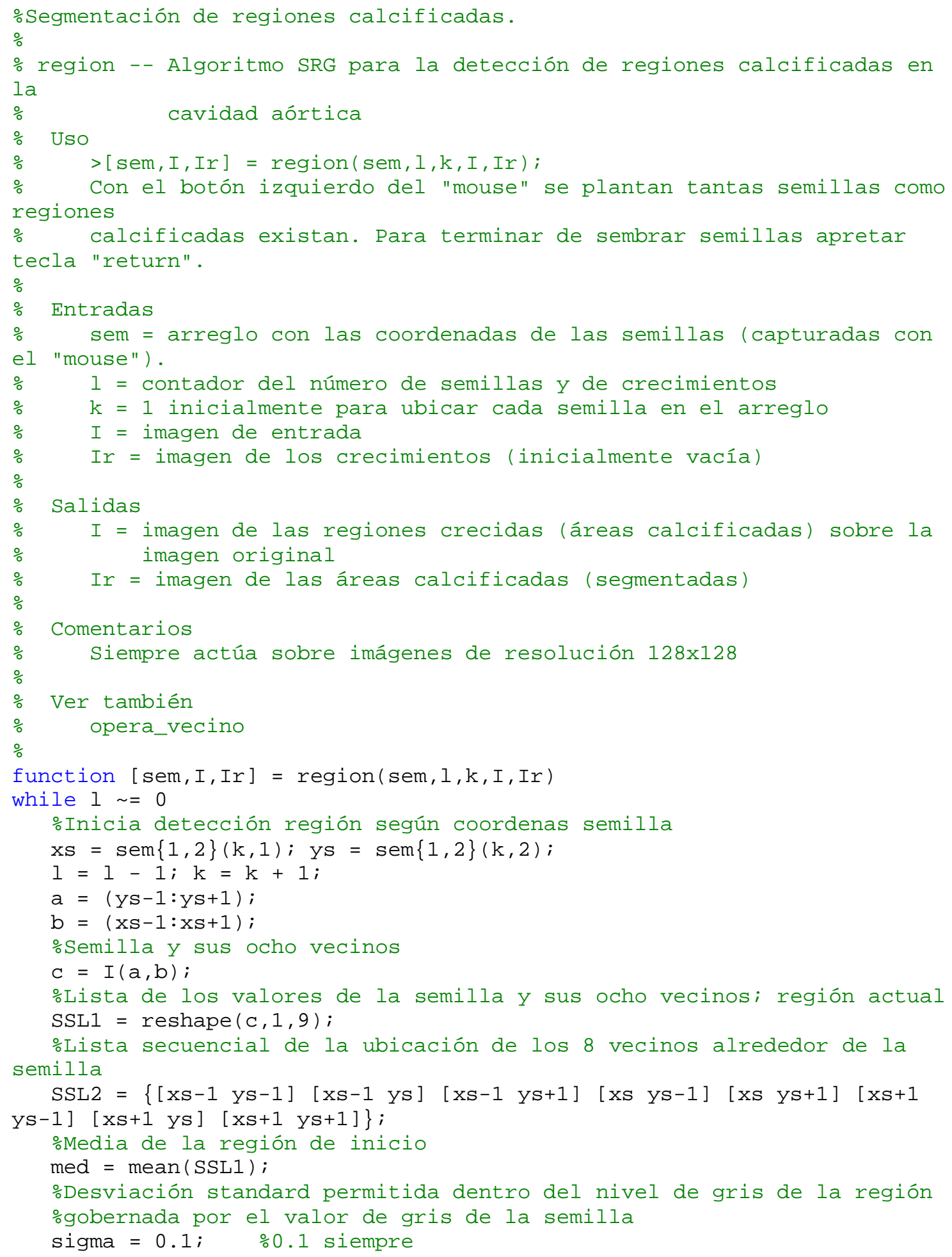



0.3

\%La región segmentada quedará dentro de un cerco de pixeles de valor marca $=0.3$;

\%La semilla es por omisión parte de la región homogénea; se excluye del análisis

$\operatorname{SSL1}(:, 5)=[] ;$

oArreglo auxiliar para verificar si un pixel ya se visitó

Aset $=\left\{\left[\begin{array}{ll}0 & 0\end{array}\right]\right\}$;

$\div$

while isempty (SSL2)

oLa región crece si CADA UNO de los vecinos que circundan a la región homogénea

oactual cumplen con el criterio de homogeneidad (media $=0.1$ )

$\operatorname{pix}=\operatorname{I}(\operatorname{SSL} 2\{1,1\}(1,2), \operatorname{SSL} 2\{1,1\}(1,1))$;

oVerifica si los miembros de la lista actual pertenecen a la región homogénea

delta $=$ abs $($ pix - med);

oVisita a cada uno de los pixeles alrededor del miembro que encabeza la SSL2

if delta < sigma

xizq_sup $=\operatorname{SSL} 2\{1,1\}(1,1)-1$

yizq_sup $=\operatorname{SSL} 2\{1,1\}(1,2)-1$;

pix = I (yizq_sup,xizq_sup);

delta $=$ abs $($ pix - med);

if delta < sigma

oCrece la región. Verifica visitas repetidas a pixeles circundantes.

[SSL2, SSL1, Aset ]

opera_vecino (xizq_sup,yizq_sup, SSL2,SSL1, Aset,pix) ; else

Ir (yizq_sup, xizq_sup) = I (yizq_sup,xizq_sup);

oPixel NO pertenece a la región homogénea; se marca

I (yizq_sup, xizq_sup) = marca;

end;

$\operatorname{xizq}=\operatorname{SSL} 2\{1,1\}(1,1)-1$;

yizq $=\operatorname{SSL} 2\{1,1\}(1,2)$;

pix = I (yizq, xizq);

delta $=$ abs (pix - med);

if delta < sigma

$[$ SSL2, SSL1, Aset ] =

opera_vecino(xizq,yizq, SSL2, SSL1, Aset,pix);

else

$\operatorname{Ir}(y i z q, x i z q)=I(y i z q, x i z q)$;

end;

$I(y i z q, x i z q)=\operatorname{marca}$;

xizq_inf $=\operatorname{SSL} 2\{1,1\}(1,1)-1$

yizq_inf $=\operatorname{SSL} 2\{1,1\}(1,2)+1$;

pix = I (yizq_inf, xizq_inf);

delta $=$ abs $(p i x-$ med) ;

if delta < sigma

[SSL2, SSL1, Aset] =

opera_vecino(xizq_inf,yizq_inf,SSL2,SSL1, Aset,pix);

else

Ir (yizq_inf,xizq_inf) = I (yizq_inf, xizq_inf);

I (yizq_inf,xizq_inf) = marca;

end;

$\operatorname{xsup}=\operatorname{SSL} 2\{1,1\}(1,1)$; 


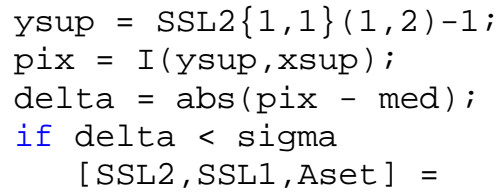




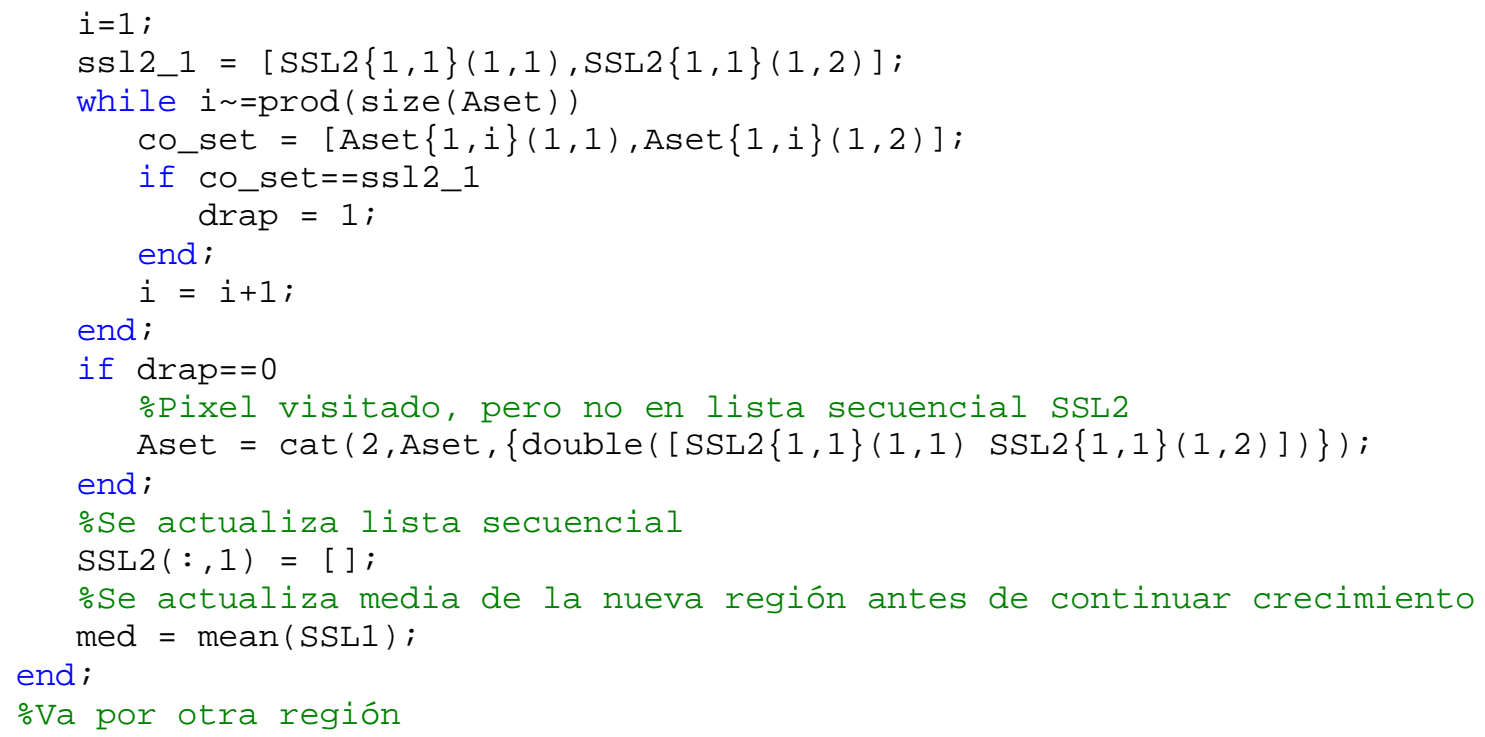




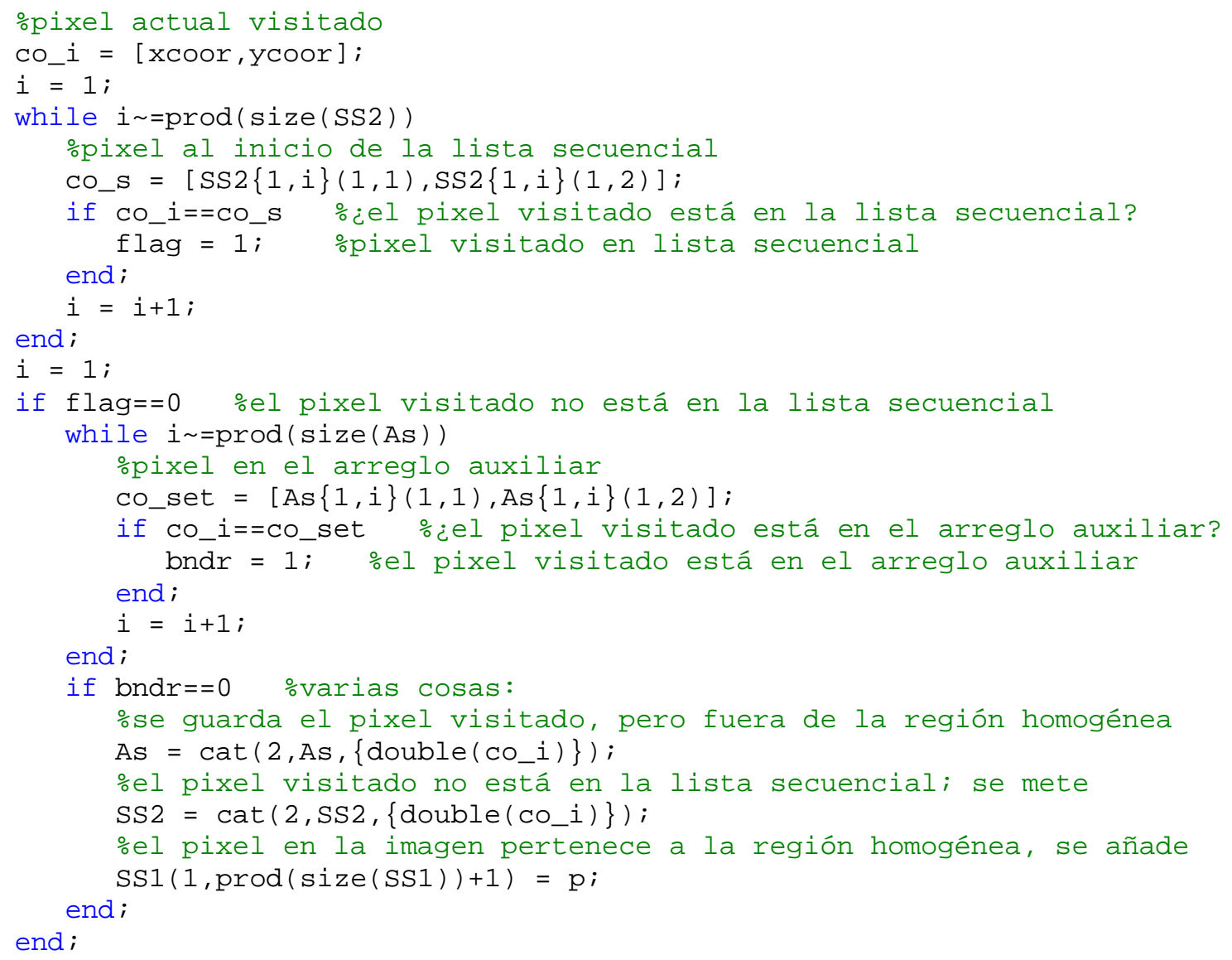




\section{APÉNDICE G.}

\section{Programa MATLAB para la medición de la distancia del anillo aórtico.}

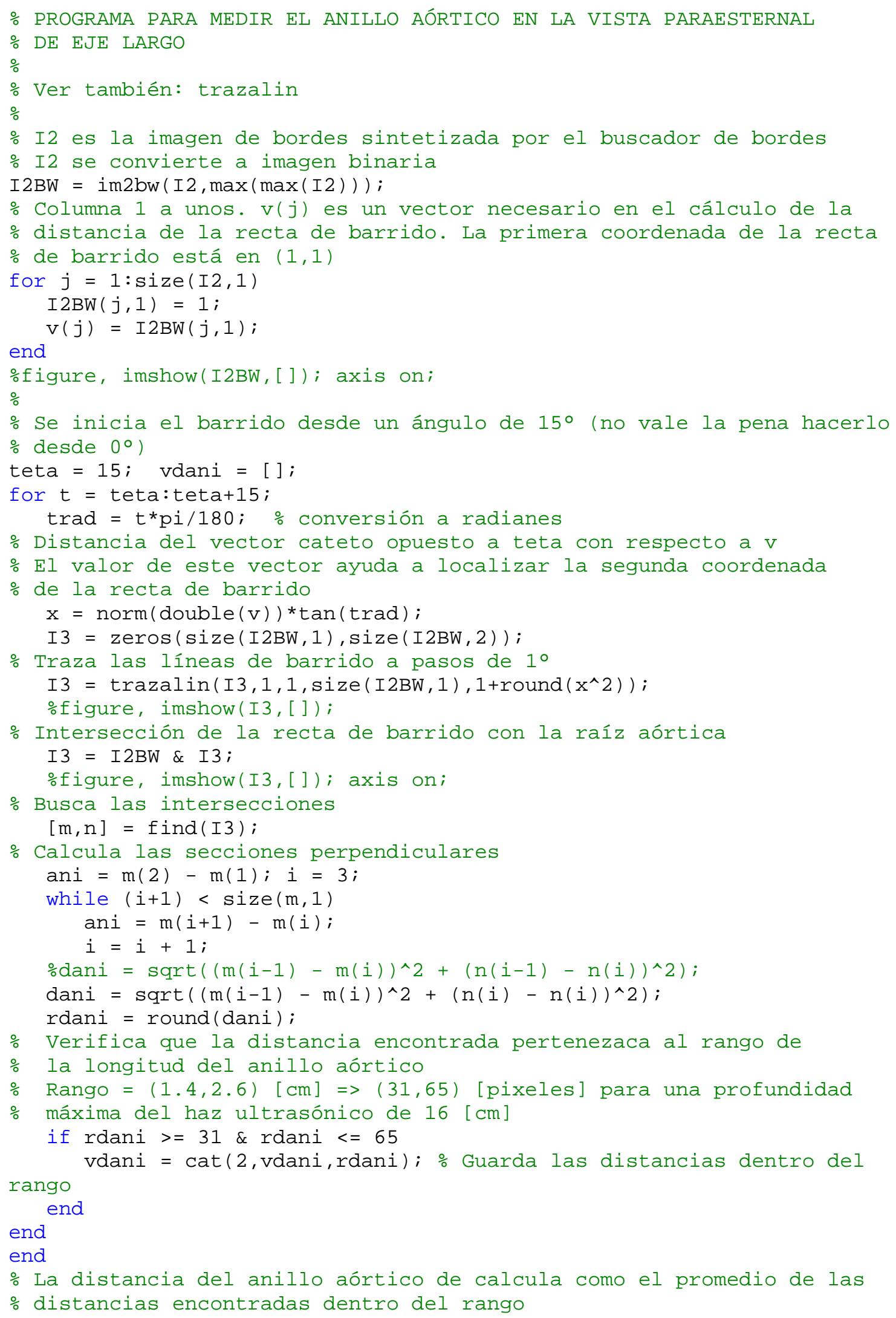




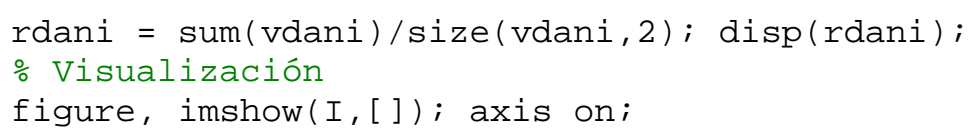




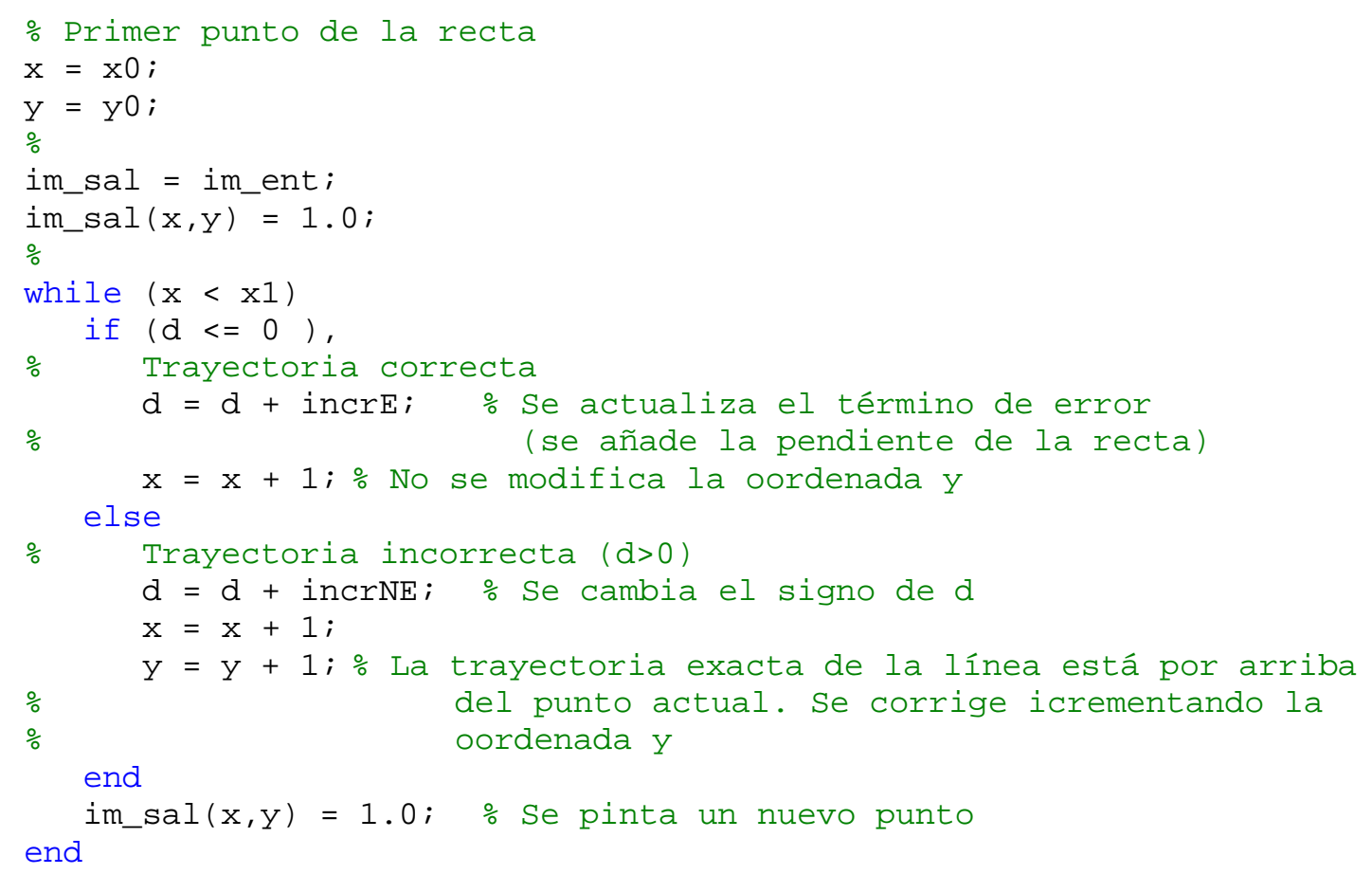




\section{APÉNDICE H.}

\section{Programa MATLAB para trazar el círculo que aproxima el área de la cavidad (incluye la cuantificación del grado de calcificación de la válvula aórtica).}

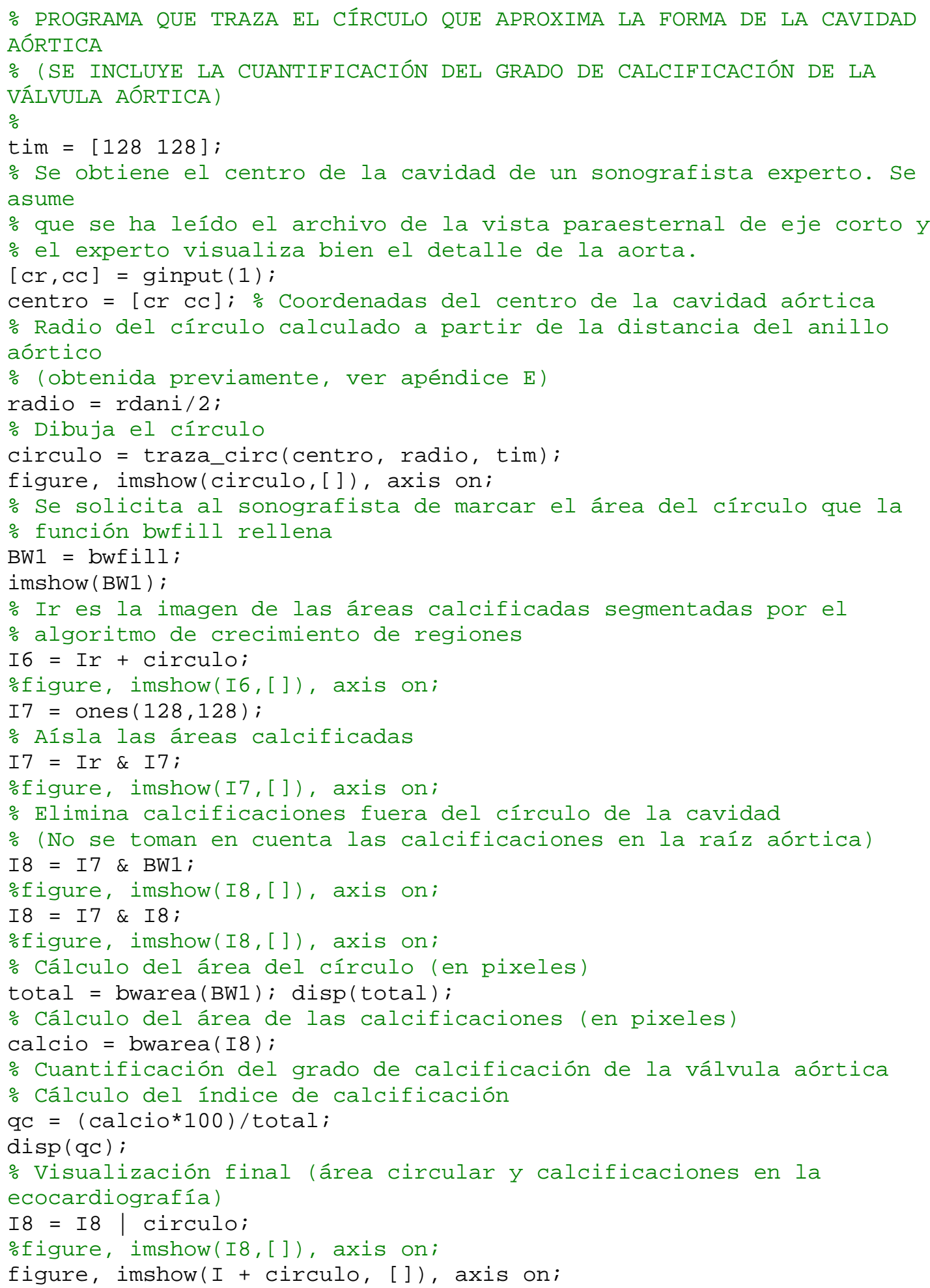




\section{Explicación del programa que traza el círculo.}

Recuérdese [32] que $x=r \cos \theta$ y $y=r \operatorname{sen} \theta$ con $0 \leq \theta \leq 2 \pi$ representan al círculo $x^{2}+y^{2}=r^{2}$, donde $\theta$ parámetro y el punto $P(r \cos \theta, r \operatorname{sen} \theta)$ se llama punto " $\theta$ " del círculo $x^{2}+y^{2}=r^{2}$.

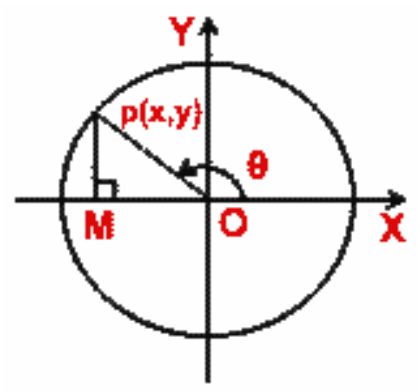

El programa MATLAB que traza el círculo utiliza la forma paramétrica $(x-h)^{2}+(y-k)^{2}=r^{2}$ donde el centro del círculo es el punto $C(h, k)$. De esta manera, cada punto $P$ del círculo se representa como:

$$
\left\{\begin{array}{l}
x=h+r \cos \theta \\
y=k+r \operatorname{sen} \theta
\end{array}\right.
$$

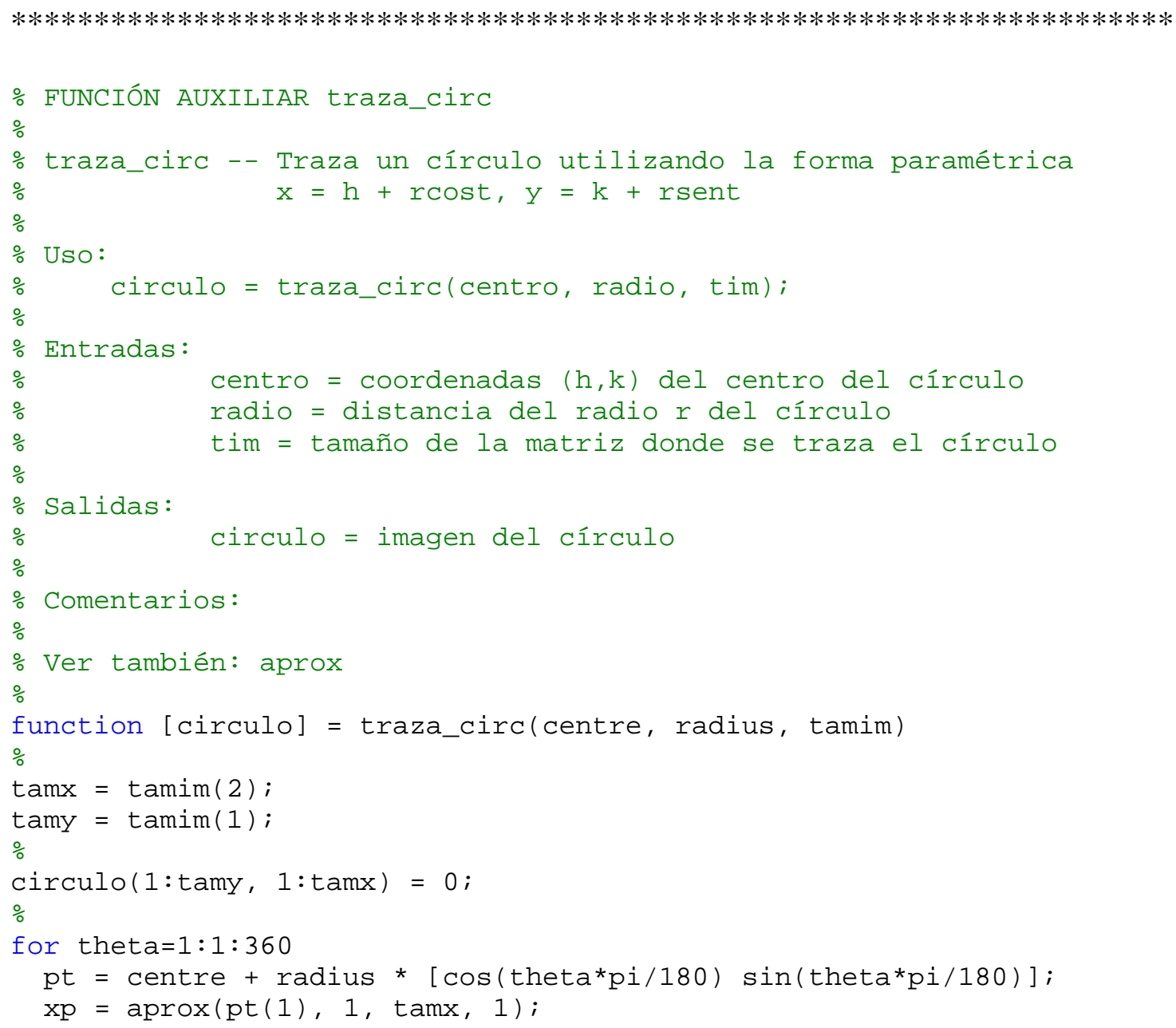




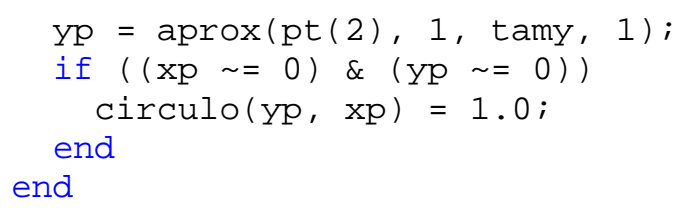

